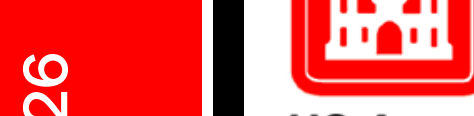

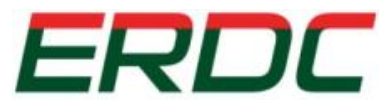

INNOVATIVE SOLUTIONS

for a safer, better world of Engineers $\mathrm{B}_{\circledast}$ Engineer Research and Development Center

\title{
Comparison and Analysis of Energy Performance of Baseline and Enhanced Temporary Army Shelters
}

Axy Pagan-Vazquez, Dahtzen Chu, Megan Kreiger, Som Shrestha, September 2015 Anthony Latino, Charles T. Decker, Debbie J. Lawrence, and Ashok Kumar

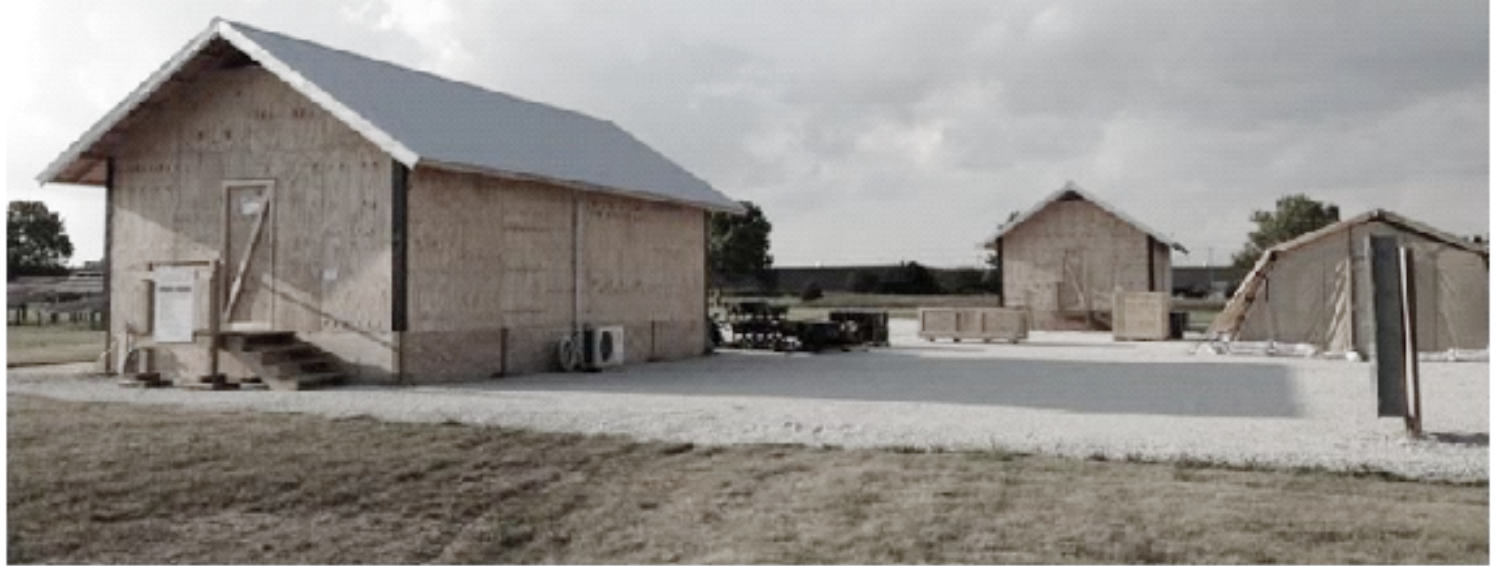


The U.S. Army Engineer Research and Development Center (ERDC) solves the nation's toughest engineering and environmental challenges. ERDC develops innovative solutions in civil and military engineering, geospatial sciences, water resources, and environmental sciences for the Army, the Department of Defense, civilian agencies, and our nation's public good. Find out more at www.erdc.usace.army.mil.

To search for other technical reports published by ERDC, visit the ERDC online library at http://acwc.sdp.sirsi.net/client/default. 


\section{Comparison and Analysis of Energy Performance of Baseline and Enhanced Temporary Army Shelters}

Axy Pagan-Vazquez, Dahtzen Chu, Megan Kreiger, Charles T. Decker, Debbie J. Lawrence, and Ashok Kumar

U.S. Army Engineer Research and Development Center (ERDC)

Construction Engineering Research Laboratory (CERL)

2902 Newmark Dr.

Champaign, IL 61824

Som Shrestha

Oak Ridge National Laboratory (ORNL)

Oak Ridge, TN 37831

Anthony Latino

The PERTAN Group

Final Report

Approved for public release; distribution is unlimited.

Prepared for Headquarters, U.S. Army Corps of Engineers

Washington, DC 20314-1000 


\section{Abstract}

The reduction and efficient use of resources are critically important issues for the U.S. Department of Defense. The Army builds and uses temporary shelters commonly known as "B-huts" at forward operating bases, where energy efficiency is mission critical. B-huts are typically not insulated, lack airtightness, and are inherently energy inefficient. Significant opportunities exist to improve the energy performance of these temporary shelters. This work tested the performance and feasibility of several common technologies and techniques to improve overall energy efficiency, constructability, and sustainability of the B-hut. The performance of one control (baseline) B-hut shelter was compared with the performance of one enhanced B-hut shelter, which used the tested commercially available technologies. The data indicate that improvements made to the Enhanced Shelter reduced its energy consumption to at least one-fourth that of the Control Shelter. 


\section{Contents}

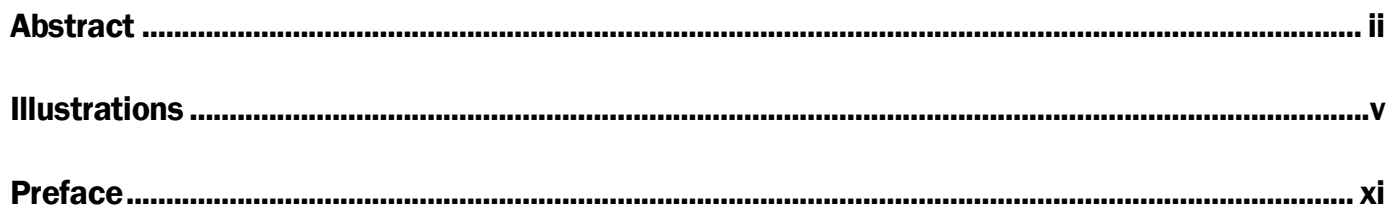

1 Introduction ................................................................................................................................ 1

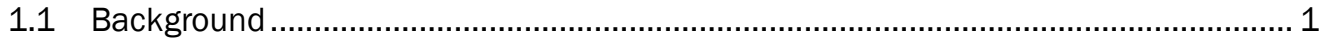

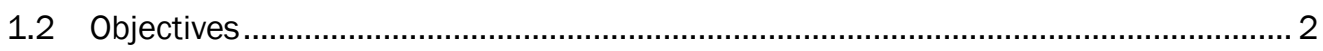

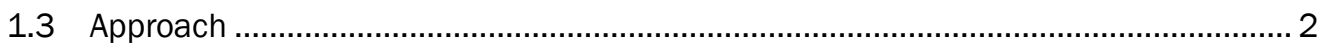

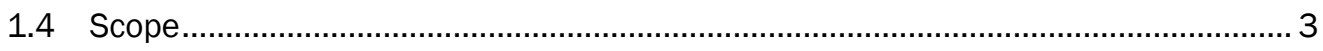

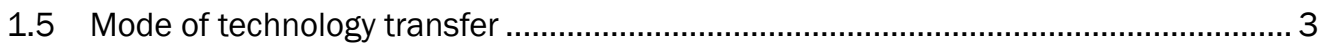

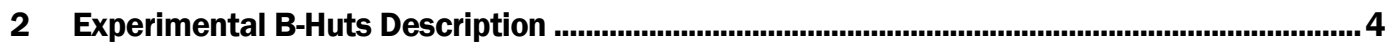

2.1 Control Shelter S2 ................................................................................................... 4

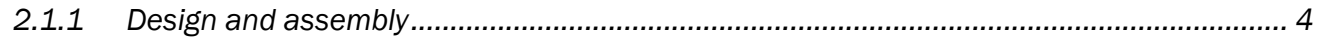

2.1.2 Heating, ventilating and air-conditioning (HVAC) ..................................................... 5

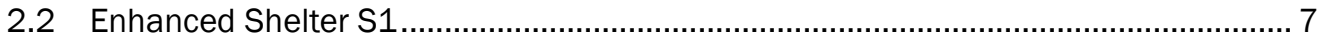

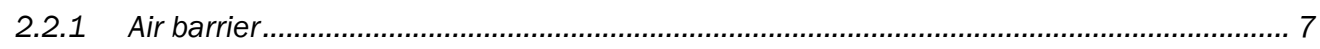

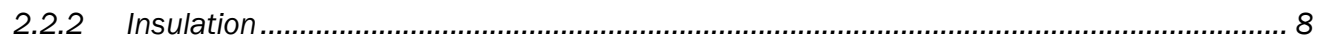

2.3 Air sealing tape evaluation and testing ............................................................. 10

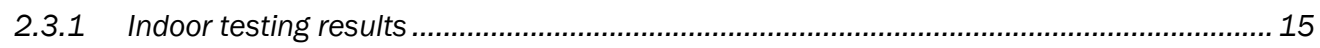

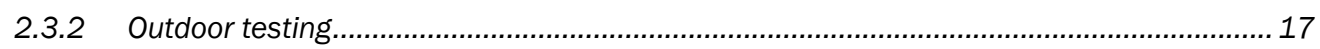

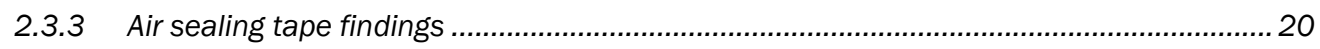

2.4 Air sealing tape effectiveness; blower door testing .............................................20

2.5 Tracer gas test............................................................................................ 21

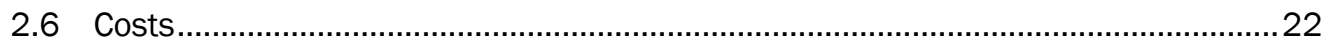

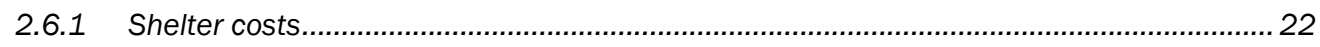

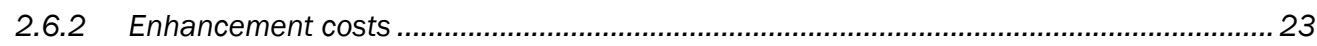

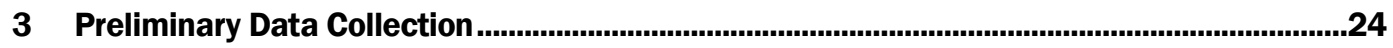

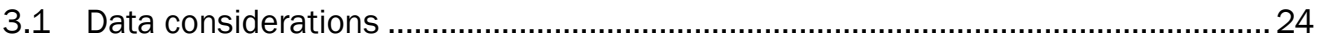

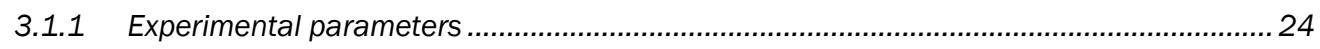

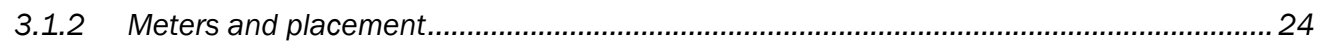

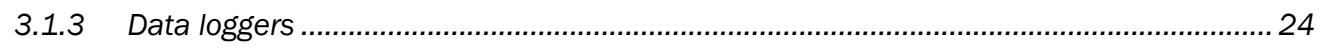

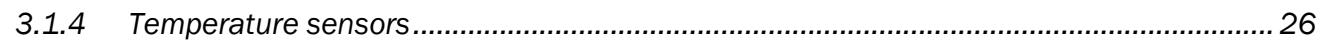

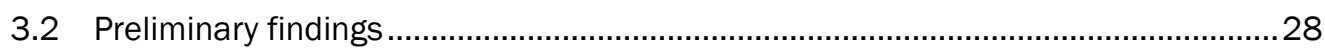

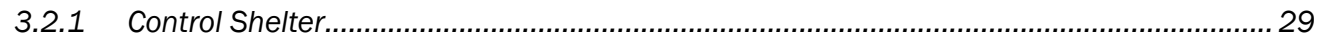

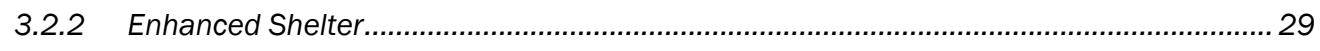

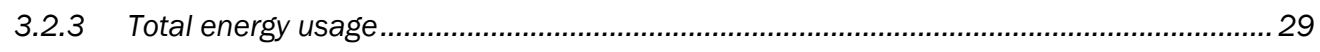

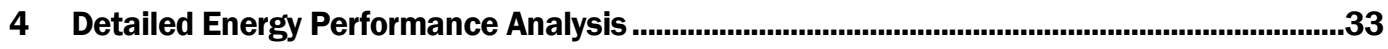

4.1 Analysis of each heating and cooling equipment used to maintain the desired indoor conditions............................................................................... 33

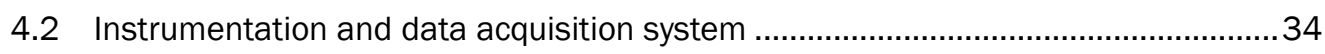


4.3 EnergyPlus modeling ....................................................................................... 37

4.4 Predicted vs. field-measured data and validation of EnergyPlus models ................43

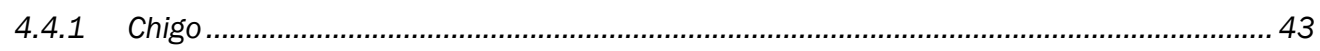

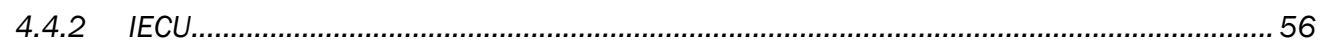

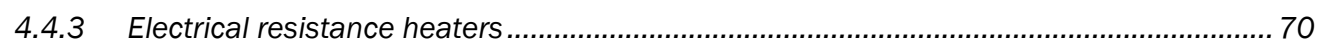

5 Conclusions, Findings, and Recommendations ..................................................................76

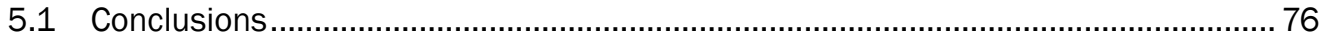

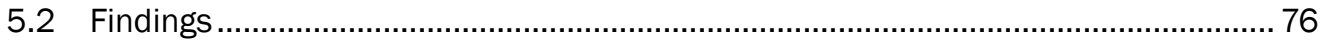

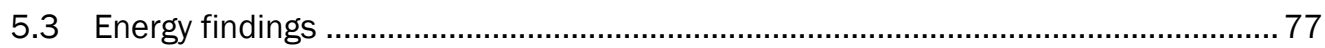

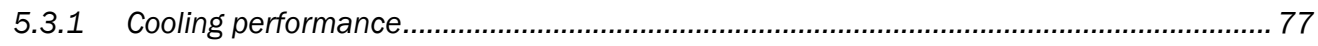

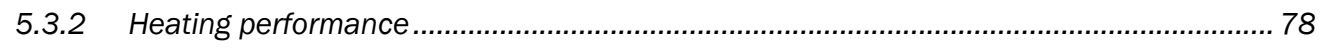

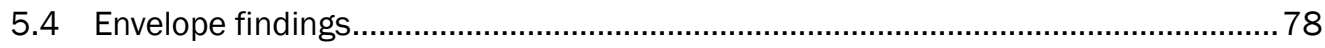

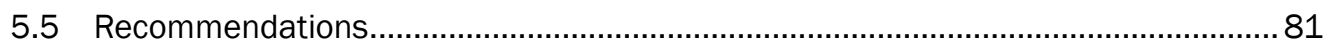

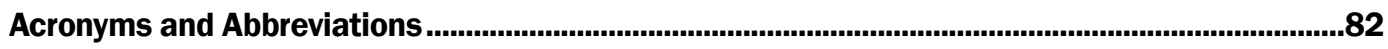

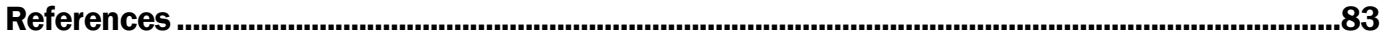

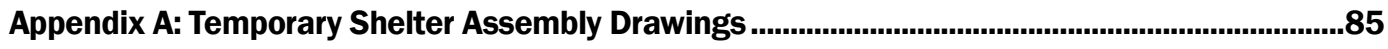

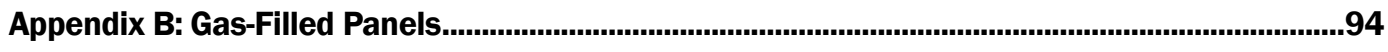

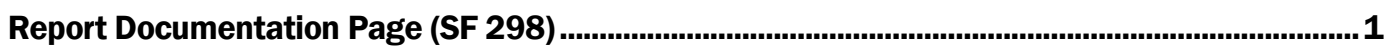




\section{Illustrations}

\section{Figures}

2-1 View of the research site looking to the North, with the Enhanced Shelter in the foreground and the Control Shelter to the rear

2-2 Exterior view of the Enhanced Shelter showing the roof and floor (at the rim joist) felt air barrier

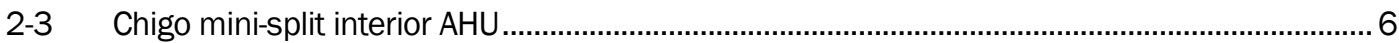

2-4 Chigo mini-split exterior condensing unit................................................................................... 6

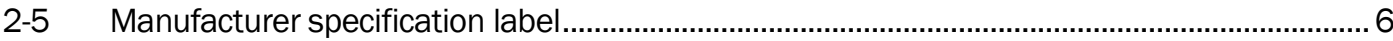

2-6 Interior view of the Enhanced Shelter and the installation of the wall felt air barrier .............. 8

2-7 Interior view of the Enhanced Shelter showing the wall and door insulation

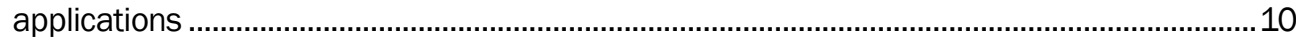

2-8 View of attic insulation and baffles in the Enhanced Shelter ...................................................10

2-9 Enhanced Shelter skirting XPS insulation behind panel ........................................................11

2-10 Enhanced Shelter door with XPS insulation attached .............................................................11

2-11 Unimproved and improved B-hut interiors: The inside of an unimproved B-hut (left) and a B-hut fully taped from the interior with air barrier tape (right)

2-12 Tape layers: Tape layers consist of backing, primer/adhesive, and release liner layers of the tape.

2-13 Pressure Chamber: Three dimensional representation of the pressure chamber holding the plywood sample (left) and actual pressure chamber used for tape leakage tests (right)

2-14 Cross section of pressure chamber ......

2-15 Aged Tape B and C from Set I: Visual degradation in Tape B (top) and C (bottom), samples at 0 hours, 12 hours, 24 hours, 1 week, 2 weeks, and 4 weeks (left to right) in the QUV Accelerated Weathering Tester.....

2-16 Tape F degradation: After 4 weeks of accelerated aging, observed under a National DC5-420th Stereo Microscope with a zoom objective magnification of 1.6x in combination with a $20 x$ eyepiece lens

2-17 Weather Data for Champaign, IL. Weather data for duration of the outdoor testing in the city of Champaign, IL from 30 September 2013 to 28 May 2014 for temperature, wind speed, relative humidity, and precipitation (The Weather Underground, Inc. (2014, June 30). Weather History for Champaign, IL [Online].)

2-18 Outdoor Weathering Samples after 8 Months: Approximately 8 months after application (28 May 2014) on the south wall (top) and west wall (bottom). Tape D in the vertical $W$ location (indicated with the red box), completely peeled off within the first 2 months.

2-19 Tape D after Outdoor Exposure: Tape D after 8 months of outdoor exposure in the horizontal SW (right) locations

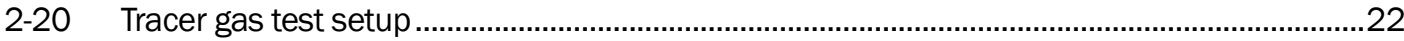

2-21 Tracer gas test sample result 


\section{Figures}

3-1 Placement of the Enhanced Shelter's metering equipment …………...................................25

3-2 Placement of the Control Shelter's metering equipment.........................................................25

3-3 Control Shelter transducer clamp attached to the HVAC power cable .....................................2

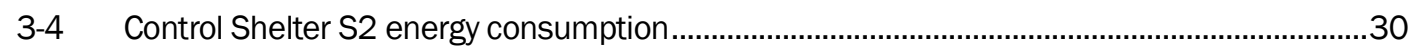

3-5 Enhanced Shelter-S1 energy consumption.........................................................................30

3-6 Energy consumption overview ……………................................................................. 31

4-1 Weather station and data acquisition system with remote access capability ........................35

4-2 Direct normal solar radiation measured at weather station and estimated with the

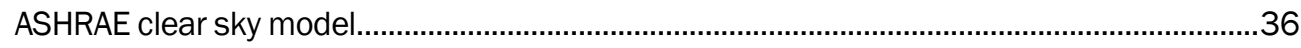

4-3 Measured global horizontal radiation and EnergyPlus calculated incident solar radiation on a horizontal surface .........................................................................................36

4-4 Measured and EnergyPlus calculated solar radiation on east and west roof surfaces...........37

4-5 Renderings of EnergyPlus model of the B-hut ....................................................................38

4-6 Discoloration of the exterior walls (left new, right after 20 months) and wide variation in SR on the same side of the wall (as evidenced by the color difference) ...............................38

4-7 Typical methods used to mount HFTs to measure heat flux through building envelope ........40

4-8 Outdoor air temperature and relative humidity ........................................................................ 44

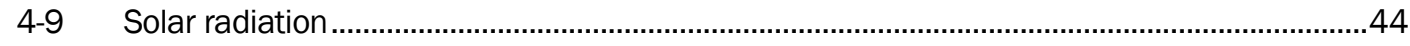

4-10 Conditioned space air temperature …………….................................................................4

4-11 Comparison between measured (solid lines) and EnergyPlus predicted (dotted lines) exterior surface temperature for the baseline B-hut ...................................................................45

4-12 Measured (solid lines) and EnergyPlus predicted (dotted lines) exterior surface temperature for the enhanced B-hut.

4-13 Measured (solid lines) and EnergyPlus predicted (dotted lines) interior surface temperature when TARP SurfaceConvectionAlgorithm:Inside object was used for the baseline B-hut

4-14 Measured (solid lines) and EnergyPlus predicted (dotted lines) interior surface temperature when CeilingDiffuser SurfaceConvectionAlgorithm:Inside object was used for the baseline B-hut.

4-15 Measured (solid lines) and EnergyPlus predicted (dotted lines) interior surface temperature when CeilingDiffuser SurfaceConvectionAlgorithm:Inside object was used for the enhanced B-hut.

4-16 EnergyPlus and COMSOL predicted heat flux at interior surface of the south wall for the baseline B-hut.

4-17 Measured and COMSOL predicted heat flux at the HFT location for the baseline B-hut .......48

4-18 EnergyPlus and COMSOL predicted heat flux at interior surface of the south wall for the enhanced B-hut.

4-19 Measured and COMSOL predicted heat flux at the HFT location for the enhanced Bhut. 


\section{Figures}

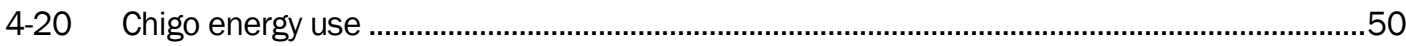

4-21 Outdoor air temperature and relative humidity ......................................................................51

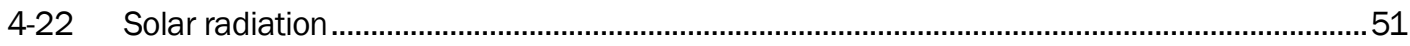

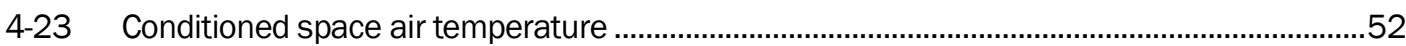

4-24 Measured (solid lines) and EnergyPlus predicted (dotted lines) exterior surface temperature for the baseline B-hut..........................................................................................52

4-25 Comparison between measured (solid lines) and EnergyPlus predicted (dotted lines) exterior surface temperature for the enhanced B-hut.

4-26 Measured (solid lines) and EnergyPlus predicted (dotted lines) interior surface temperature for the baseline B-hut.

4-27 Comparison between the measured (solid lines) and EnergyPlus predicted (dotted lines) interior surface temperature for the enhanced B-hut........................................................53

4-28 EnergyPlus and COMSOL predicted heat flux at interior surface of the south wall of the

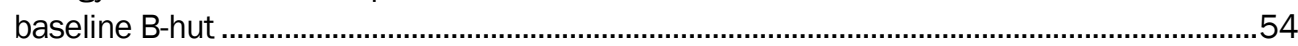

4-29 Measured and COMSOL predicted heat flux at the HFT location of the baseline B-hut.........54

4-30 EnergyPlus and COMSOL predicted heat flux at interior surface of the south wall of the enhanced B-hut.................................................................................................................

4-31 Measured and COMSOL predicted heat flux at the HFT location of the enhanced B-hut......55

4-32 EnergyPlus predicted cooling load and Chigo energy use for the baseline B-hut.....................55

4-33 EnergyPlus predicted cooling load and Chigo energy use for the enhanced B-hut..................56

4-34 Outdoor air temperature and relative humidity ...........................................................................57

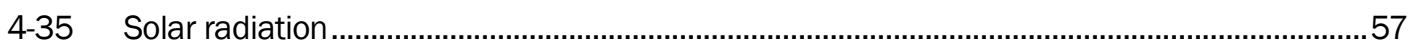

4-36 Conditioned space air temperature ……….....................................................................

4-37 Measured (solid lines) and EnergyPlus predicted (dotted lines) exterior surface temperature for the baseline B-hut......................................................................................58

4-38 Measured (solid lines) and EnergyPlus predicted (dotted lines) exterior surface temperature for the enhanced B-hut

4-39 Measured (solid lines) and EnergyPlus predicted (dotted lines) interior surface temperature for the baseline B-hut.

4-40 Measured (solid lines) and EnergyPlus predicted (dotted lines) interior surface temperature for the enhanced B-hut

4-41 Comparison between the EnergyPlus and COMSOL predicted heat flux at interior surface of the south wall of the baseline B-hut.

4-42 Comparison between the measured and COMSOL predicted heat flux at the HFT location of the baseline B-hut.

4-43 EnergyPlus and COMSOL predicted heat flux at interior surface of the south wall of the enhanced B-hut.

4-44 Measured and COMSOL predicted heat flux at the HFT location of the south wall of the enhanced B-hut. 


\section{Figures}

4-45 IECU serving the B-hut and the flexible ducts used as supply and return ducts .....................62

4-46 Electric heater energy use and the EnergyPlus predicted heating load for the baseline B-hut.......... 63

4-47 Electric heater energy use and the EnergyPlus predicted heating load for the

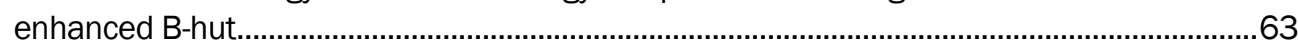

4-48 Outdoor air temperature and relative humidity .......................................................................65

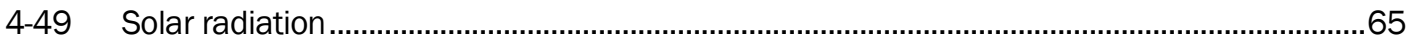

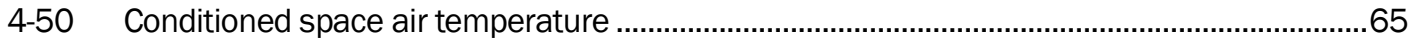

4-51 Measured (solid lines) and EnergyPlus predicted (dotted lines) exterior surface temperature for the baseline B-hut..............................................................................................66

4-52 Measured (solid lines) and EnergyPlus predicted (dotted lines) exterior surface temperature for the enhanced B-hut ........................................................................................66

4-53 Measured (solid lines) and EnergyPlus predicted (dotted lines) interior surface temperature for the baseline B-hut.........................................................................................6

4-54 Measured (solid lines) and EnergyPlus predicted (dotted lines) interior surface temperature for the enhanced B-hut.

4-55 Comparison between the EnergyPlus and COMSOL predicted heat flux at interior surface of the south wall of the baseline B-hut

4-56 Comparison between the measured and COMSOL predicted heat flux at the HFT location of the baseline B-hut

4-57 EnergyPlus and COMSOL predicted heat flux at interior surface of the south wall of the enhanced B-hut

4-58 Measured and COMSOL predicted heat flux at the HFT location of the south wall of the

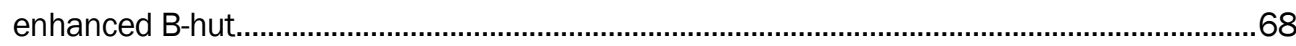

4-59 Conditioned space and outdoor air temperature................................................................69

4-60 Outdoor air temperature and relative humidity .................................................................... 71

4-61 Solar radiation ....................................................................................................................... 71

4-62 Conditioned space air temperature ..................................................................................... 71

4-63 Measured (solid lines) and EnergyPlus predicted (dotted lines) exterior surface temperature for the baseline B-hut.................................................................................................72

4-64 Measured (solid lines) and EnergyPlus predicted (dotted lines) exterior surface temperature for the enhanced B-hut ..........................................................................................

4-65 Measured (solid lines) and EnergyPlus predicted (dotted lines) interior surface temperature for the baseline B-hut..........................................................................................

4-66 Measured (solid lines) and EnergyPlus predicted (dotted lines) interior surface temperature for the enhanced B-hut

4-67 EnergyPlus and COMSOL predicted heat flux at interior surface of the south wall of the

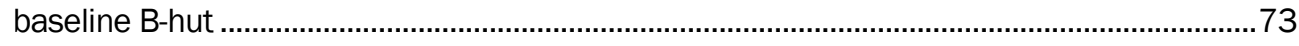

4-68 Measured and COMSOL predicted heat flux at the HFT location of the baseline B-hut..........73

4-69 EnergyPlus and COMSOL predicted heat flux at interior surface of the south wall of the enhanced B-hut 


\section{Figures}

4-70 Measured and COMSOL predicted heat flux at the HFT location of the south wall of the

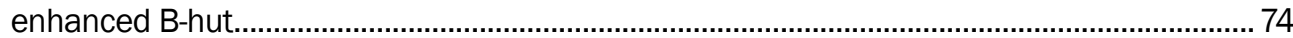

4-71 Electric heater energy use and the EnergyPlus predicted heating load for the baseline

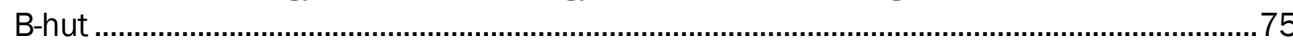

4-72 Electric heater energy use and the EnergyPlus predicted heating load for the enhanced B-hut.................................................................................................................. 75

5-1 Gap in ceiling/wall connection as shown by light entering the space....................................77

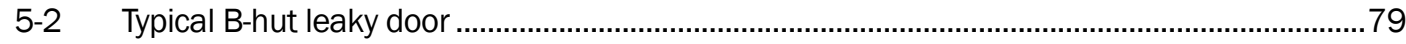

5-3 Entry of enhanced B-hut showing water stains and mold from entry of rainwater .................80

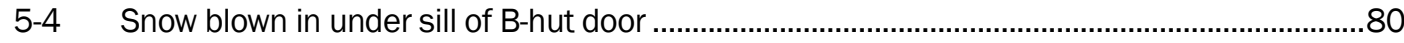

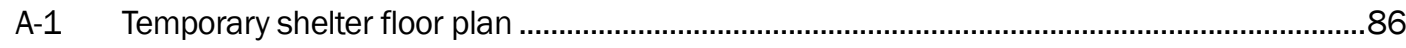

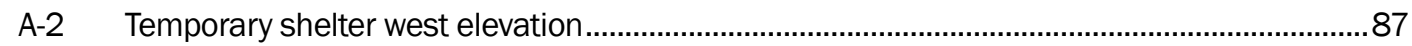

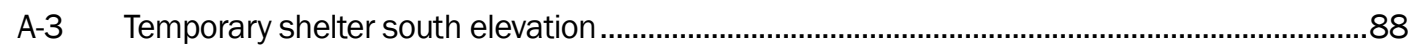

A-4 Temporary shelter north elevation .....................................................................................8

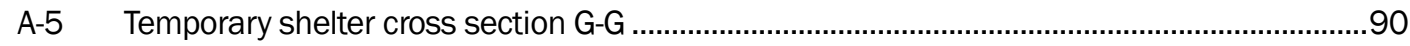

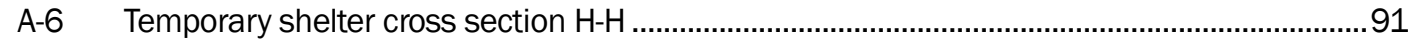

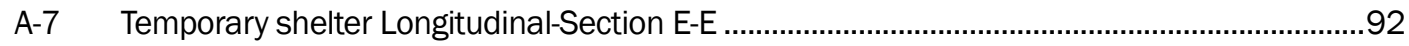

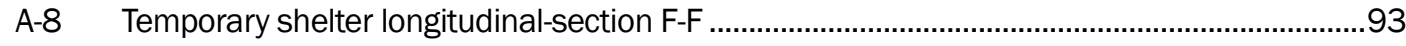

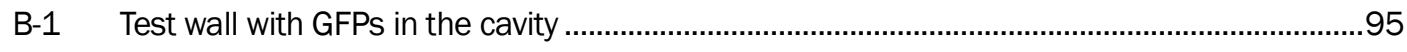

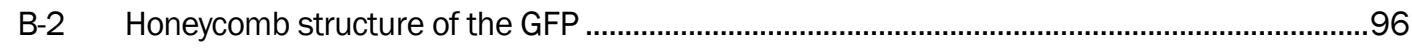

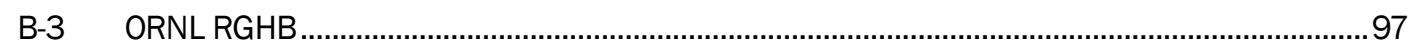

B-4 Schematic of a typical test wall within the hot-box test frame ...............................................97

B-5 R-value as a function of temperature ............................................................................ 103

B-6 Effective thermal resistance of plane air spaces .............................................................. 104

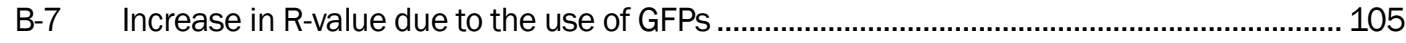

\section{Tables}

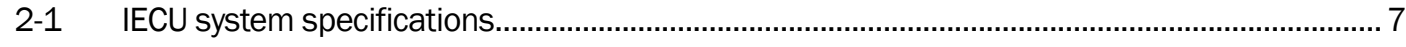

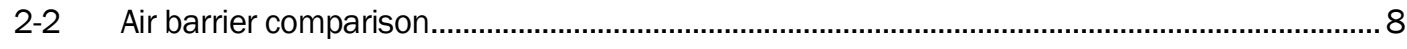

2-3 Envelope enhancements to Shelter S1 and effective assembly values .................................. 9

2-4 Relevant information on tapes: Tapes A-H subjected to outdoor and/or accelerated aging, tape type, and materials used for the backing and adhesive, as well as the associated cost per linear foot...

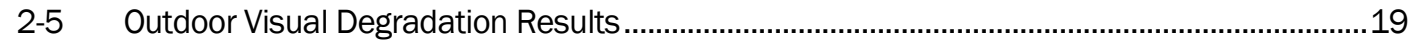

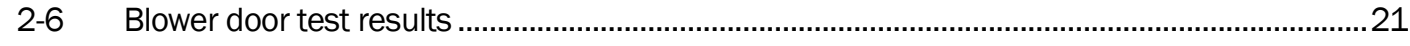

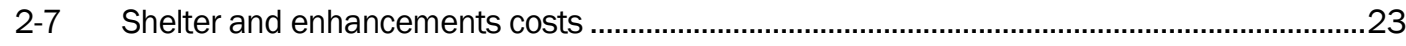




\section{Tables}

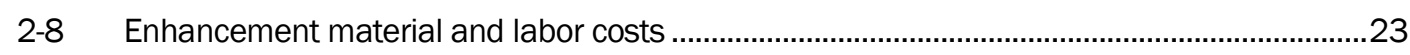

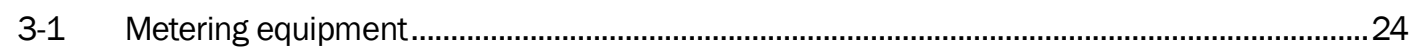

3-2 Enhanced Shelter-S1 data logger configuration ....................................................................26

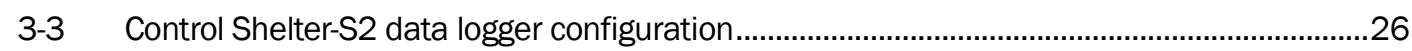

3-4 Overall energy usage of both shelters ................................................................................

3-5 Fuel cost expenses according to contingency fuel supply scenarios for Control and

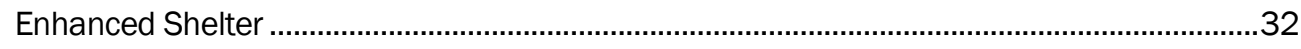

4-1 Periods of data used for validation of EnergyPlus simulation results ......................................34

4-2 Performance monitoring instruments..................................................................................

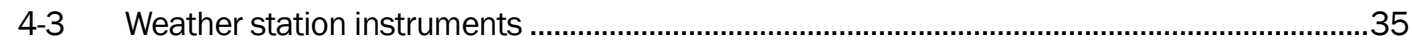

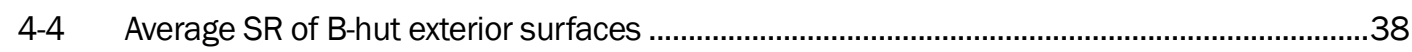

4-5 Effective thermal resistance of 3.5 in. plane space (ASHRAE 2013).....................................39

4-6 EnergyPlus calculated view factors using an area-weighted scheme .....................................42

4-7 Exact view factor used in B-hut models .................................................................................. 42

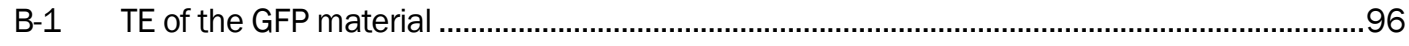

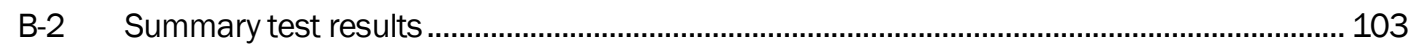




\section{Preface}

This study was conducted for Headquarters, U.S. Army Corps of Engineers (HQUSACE) and the Office of the Assistant Secretary of the Army for Acquisition, Logistics, and Technology, ASA (ALT) under Program Element 622784T45, "Energy Technology Applied to Military Facilities," Project 4451115, "Modeling and Materials for Installations," Task A1180, "Energy Losses in Building Envelopes." Funds were also provided by Office of Assistant Secretary of the Army, Acquisition, Logistics, and Technology (ASAALT) Congressional Interest plus up, and the Department of Defense, Operational Energy Capability Improvement Fund (OECIF) Program titled "Advanced, Energy Efficient Shelter System (AEESS)". The technical monitors were Dr. Ashok Kumar, Program Manager, ERDC-CERL, and Robert M. Saunders, Office of the Assistant Secretary of the Army for Acquisition, Logistics, and Technology (OASAALT).

The work was performed by the Energy Branch (CF-E) with the assistance of the Materials and Structures Branch (CF-M) of the Facilities Division (CF), and supported by the Environmental Processes Branch (CNE) of the Installations Division (CN), U.S. Army Engineer Research and Development Center, Construction Engineering Research Laboratory (ERDC-CERL). Special thanks are owed to Lake Lattimore, J edediah Alvey, and Sam Hunter of ERDC-CERL, and to Phillip Childs and J erry Atchley of Oak Ridge National Laboratory (ORNL) for their technical contributions to this research. Thanks to Dr. Kaushik Biswas, ORNL, for simulation using COMSOL (software package). At the time of publication, AndrewJ . Nelson was Chief, CEERD-CF-E; Michelle J . Hanson was Chief, CEERD-CF; and Kurt Kinnevan, CEERD-CV-T was the Technical Director for Installations. The Deputy Director of ERDC-CERL was Dr. Kirankumar Topudurti and the Director was Dr. Ilker Adiguzel.

LTC J ohn T. Tucker, III was Commander of ERDC, and Dr. J effery P. Holland was the Director. 


\section{Introduction}

\subsection{Background}

The reduction and efficient use of resources are critically important issues for the U.S. Department of Defense (DoD) for a number of reasons. Defense installations are required by law, specifically by the Energy Policy Act of 2005 (EPAct 2005) and the Energy Independence and Security Act of 2007 (EISA 2007), to eliminate fossil fuel use in new and renovated facilities by 2030 and to reduce overall facility energy usage by 30\% by 2015 . Executive Order (EO) 13514 broadly mandates further reductions in waste production and energy consumption, and orders the implementation of the 2030 Net Zero Energy (NZE) building requirement.

These mandates are especially relevant to contingency operating bases (COBs) and forward operating bases (FOBs), where fuel supplies are highly sensitive commodities, and where energy efficiency is mission critical. In these locations, the Army builds and uses temporary shelters, commonly known as "B-huts," that are easily constructed by personnel in the field. Although their primary use is to house military personnel, B-huts can also serve in a variety of other capacities, e.g., as dining, administration, and maintenance facilities. B-huts have an expected lifetime of 3 to 4 years, and are demolished at the end of their service life.

The standard Army design for a Temporary Army Shelter is a 16x32x8-ft (W-L-H, floor to ceiling) basic wood-framed structure with exterior and interior plywood walls, and a metal or plywood covered truss roof, which is placed on 12 to 18-in. high "floating" wood piers set on a gravel base. Bhuts can also be constructed of other materials. Some, for example, have been built with concrete masonry unit (CMU) walls, covered by a metal truss roof, of approximately the same shape and size as the wooden shelters. B-huts are heated and cooled with Army-issued Environmental Control Units (ECUs) or locally procured split air-conditioning units.

Although B-huts are often painted to help protect the assembly's exterior, they are not typically insulated. Because they are not insulated, B-huts lack appropriate airtightness to provide adequate occupant comfort and air quality; they are inherently very energy inefficient and have relatively high heating and cooling requirements. In fact, up to $50 \%$ of the total energy 
demand at contingency bases derives from the operation of ECUs for occupied facilities.

Significant opportunities exist to improve the energy performance of these temporary shelters. Commercially available technologies and common techniques that complement current construction methods may be incorporated into the assembly of temporary shelters to dramatically reduce the fuel requirements at contingency bases and increase occupants' comfort. This work was undertaken to review the performance and feasibility of technologies and techniques that may be incorporated into the existing, inexpensive, B-hut field assembly methods to improve their overall energy efficiency, constructability, and sustainability.

\subsection{Objectives}

The objectives of this work were to quantify the degree to which commercially available technologies and common techniques (i.e., walls insulation, attic radiant barrier, and interior sealing to reduce air leakage) can improve the energy performance of Army Temporary Shelters, and to determine if the return on investment for these enhancements is sufficient to modify the current standard configuration of shelters.

\subsection{Approach}

The objectives of this work were met in the following steps:

1. Engineer Research and Development Center, Construction Engineering Research Laboratory (ERDC-CERL) developed designs for two temporary B-hut shelters (one unimproved Control Shelter and one Enhanced Shelter), detailed in Chapter 2 and Appendix A of this report.

2. These designs were used to construct one Control Shelter and one Enhanced Shelter on the ERDC-CERL Forward Operating Base Laboratory (EFOB-L).

3. Envelope improvements were identified that would augment this project baseline structure to develop an "Enhanced Shelter," and those improvements were made to the Enhanced B-hut.

4. Thermal performance and the energy usage of the two structures were monitored for a predetermined period.

5. The collected energy data and enhancement costs (labor and material) were analyzed to determine energy usage and to calculate and develop a return on investment (ROI) scenario. 
6. Conclusions were drawn and recommendations made regarding potential modifications that could be made to the current standard configuration of temporary B-hut shelters.

\subsection{Scope}

This scope of this work was limited to the application and testing of simple improvements above baseline conditions to the building envelopes of temporary B-hut structures, and to calculating savings (simple payback and Savings to Investment Ratio [SIR]) associated with those improvements. Greater returns and savings are possible above what was achieved in this work by taking more aggressive measures such as increasing insulation within the attic, and further reduction of air infiltration. Appendix B to this report describes one such candidate measure, i.e., the use of gas-filled insulation panels (GFPs).

\subsection{Mode of technology transfer}

Portions of this effort have been disseminated through presentation at a professional society conference and technical publications. On completion of the energy study comparing the performance of the unimproved Control Shelter versus the Enhanced Shelter, the "lessons learned" from this research will be considered for transfer to the Department of Defense through the Army Facilities Component System, a program of record that maintains DoD's contingency construction standard designs and data. 


\section{Experimental B-Huts Description}

Designs for a (unimproved) Control Shelter and the Enhanced Shelter were developed (detailed in Sections 0 and 0 ). The basic structure and layout used for both of these shelters were derived from the Army baseline model. Envelope improvements were identified that would augment this project baseline structure to develop the Enhanced Shelter. These designs were used to erect one Control Shelter and one Enhanced Shelter on the EFOB-L (Figure 2-1).

\subsection{Control Shelter S2}

\subsubsection{Design and assembly}

The Control Shelter was built to reflect the standard (baseline) Army design for a temporary shelter. It was $16 \mathrm{ft}$ wide, $32 \mathrm{ft}$ long, and had an interior height of $8 \mathrm{ft}$. The slope of the corrugated galvanized steel roof was 8:12 and its overall height to the roof peak (including crawl space) was $\sim 15 \mathrm{ft}$. The (windowless) interior was completely enclosed. Doors were located at either gable end. Stairs, with guardrails and a landing, were included to provide access to the shelter. The building interior included typical residential electrical equipment for interior lighting, outlets, and smoke detectors.

Figure 2-1. View of the research site looking to the North, with the Enhanced Shelter in the foreground and the Control Shelter to the rear.

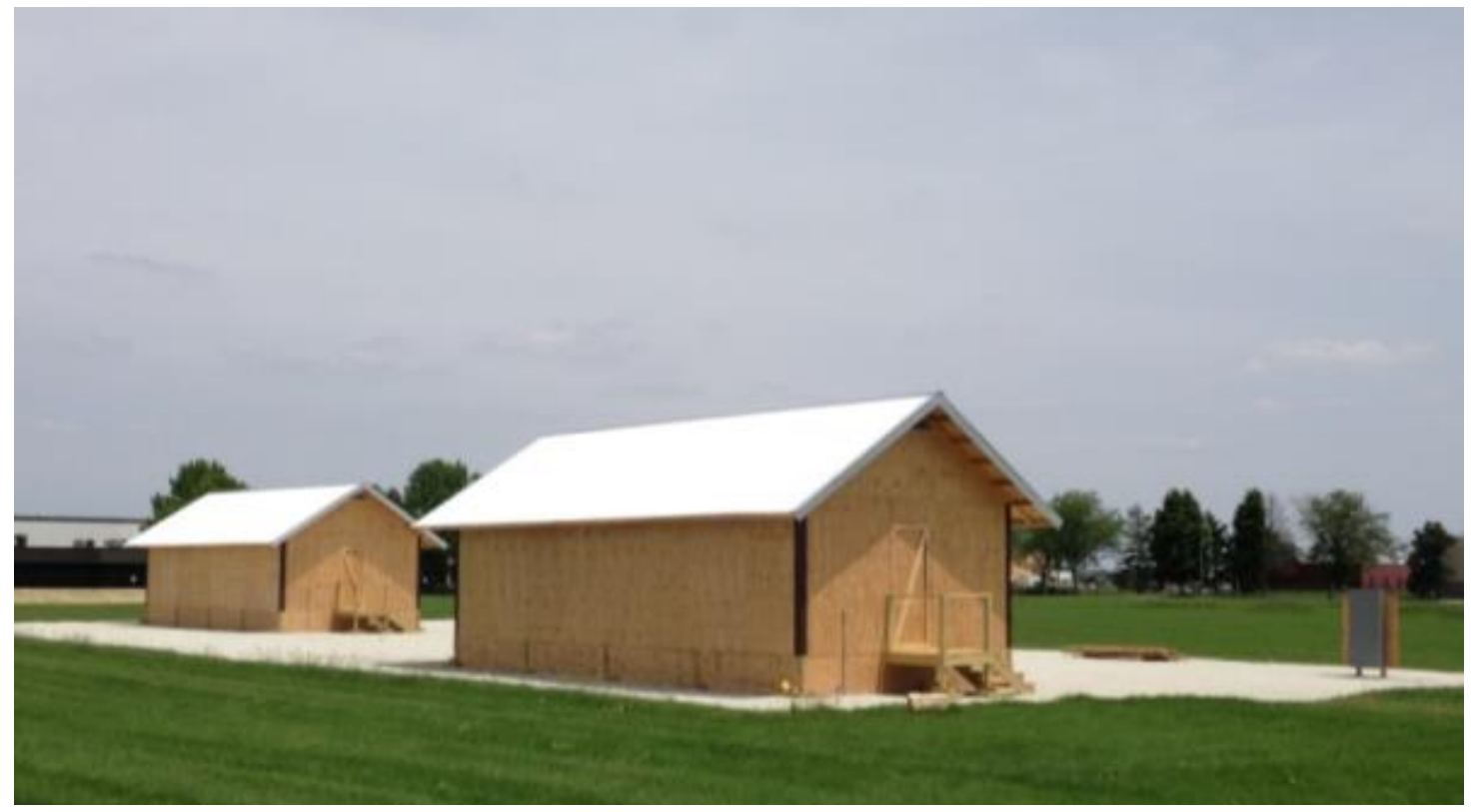


The Control Shelter was constructed with typical 2x4-in. wall framing, 16 in. on center, and an open web roof truss with a standard 4:12 roof pitch. The interior and exterior wall envelopes and the interior ceiling plane were enclosed with $1 / 2$-in. CDX plywood sheathing. The flooring system was assembled with $2 \times 6$-in. floor joists, covered with $3 / 4$-in. plywood flooring. The entire structure was attached to 18- to 24-in. high "floating" wood piers (treated $4 \mathrm{x} 4$-in. posts attached to treated mud plates) set on a gravel base to create a crawl space. The crawl space was enclosed by $1 / 2$-in. plywood skirting panels. The shelter roofing system was composed of \#15 felt attached to $1 / 2$-in. plywood-sheathed roof trusses (Figure 2-2), roofed with 24-gauge corrugated metal roofing panels. The roof extended $2 \mathrm{ft}$ beyond the walls to create a continuous eave around each structure. Appendix A includes the shelter design drawings.

\subsubsection{Heating, ventilating and air-conditioning (HVAC)}

The Control Shelter and Enhanced Shelter were both equipped with Chigo mini-split-unit HVAC systems, ${ }^{*}$ which include an interior air handling unit (AHU) (Figure 2-3) and an exterior condensing unit (Figure 2-4). Chigo mini-split units were selected for this work as they are commonly used in contingency bases in Afghanistan and can be acquired at minimal cost. The HVAC system selected for this application provides 12,000 Btu of cooling in the summer, and 13,200 Btu of heating in the winter. System specifications are listed on the unit's specification label (Figure 2-5). It should be noted that Improved Environmental Control Units (IECU) were subsequently added to both shelters.

In December 2014, DRS Environmental Systems $60 \mathrm{kBtuh}$ IECUs (model NSN 4120-01-543-0741) were installed to meet the conditioning loads of the B-huts. This allowed a side-by-side comparison of the conditioning energy use between the two huts. Table 2-1 lists the IECU specifications (source TM 9-4120-431-14, TO 35E9-9-55, [HQDA 2010]). For heating, three tubular electric resistance heaters, 3kW capacity each are used in the IECUs. Evaporator blower motor and tubular heaters are energized and condenser fan motor and compressor are de-energized when the IECU is set on heating mode. Similarly, the evaporator blower motor, condenser fan motor, and compressor are energized, and tubular heaters are de-energized when the IECU is set on cooling mode.

\footnotetext{
* Manufactured by Guangdong Chigo Air-Conditioning Co., LTD, http://www.chigogroup.com
} 
Figure 2-2. Exterior view of the Enhanced Shelter showing the roof and floor (at the rim joist) felt air barrier.

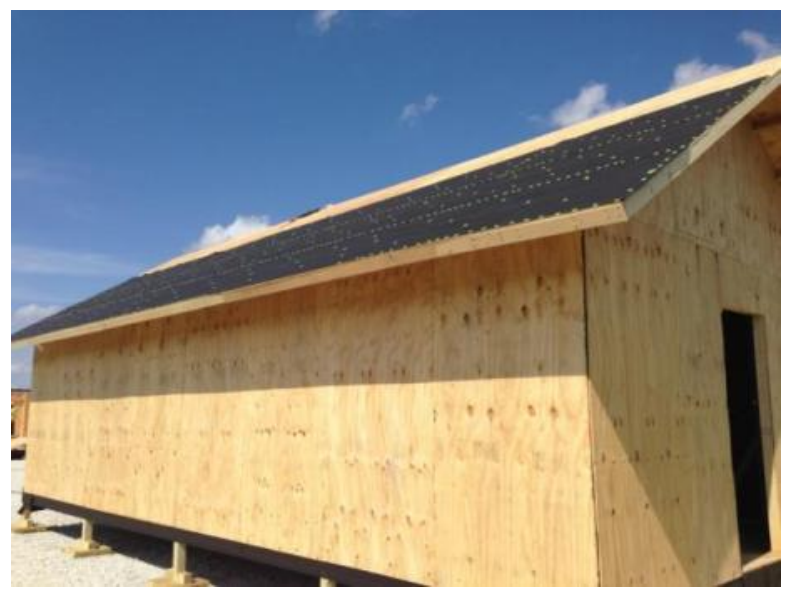

Figure 2-4. Chigo mini-split exterior condensing unit.

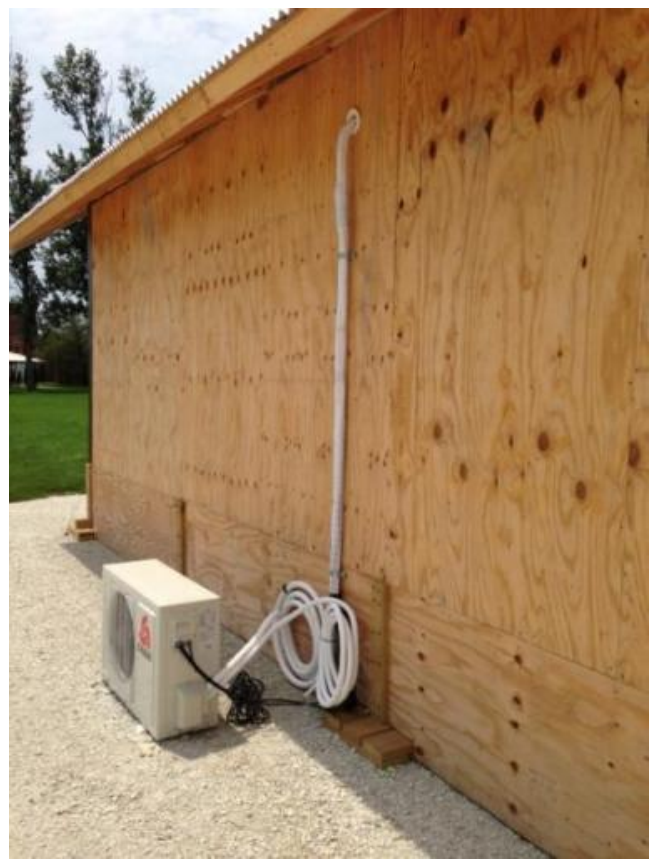

Figure 2-3. Chigo mini-split interior AHU.

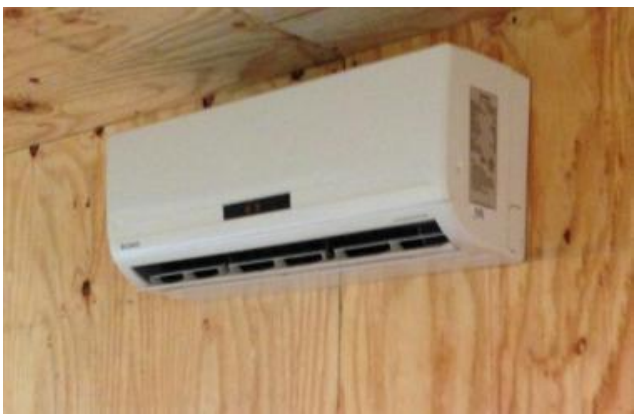

Figure 2-5. Manufacturer specification label.

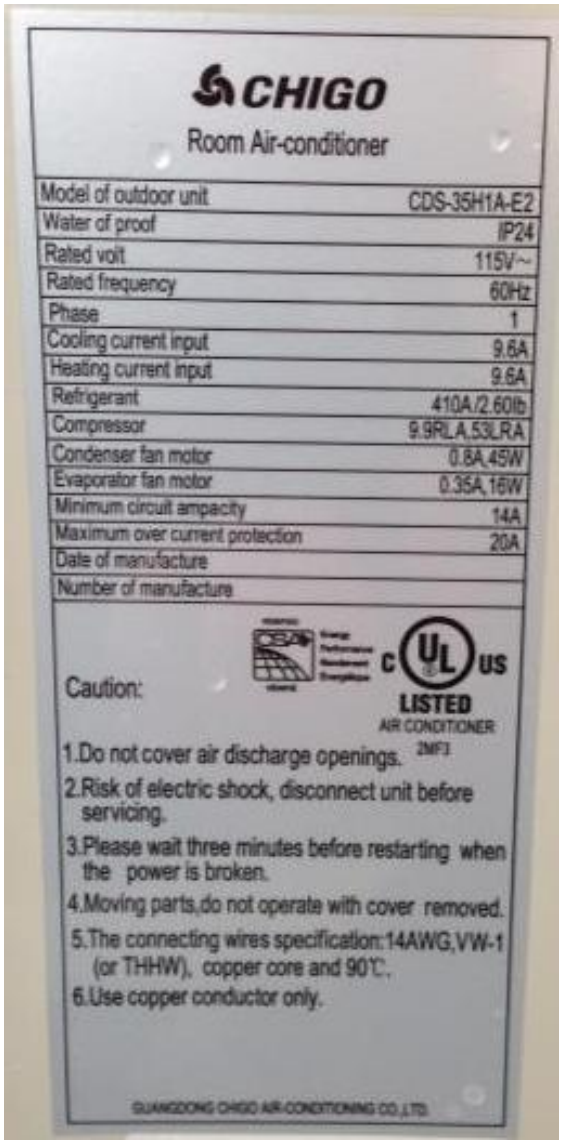


Table 2-1. IECU system specifications.

\begin{tabular}{|c|c|}
\hline PARAMETER & SPECIFICATION \\
\hline Operating Temperatures & $\begin{array}{l}\text { Cooling }=40 \text { to } 125^{\circ} \mathrm{F} \\
\text { Heating }=-50 \text { to } 70^{\circ} \mathrm{F}\end{array}$ \\
\hline Control & Internally or remotely mounted control box \\
\hline $\begin{array}{l}\text { Power Required: } \\
\text { Voltage } \\
\text { Frequency } \\
\text { Phase } \\
\text { Current }\end{array}$ & $\begin{array}{l}197.6 \text { - } 228.8 \text { VAC } \\
50 / 60 \text { Hertz } \\
\text { 3-phase, 5-wire } \\
35.8 \text { amps max. at } 208 \text { VAC }\end{array}$ \\
\hline $\begin{array}{l}\text { Power Consumption } \\
\text { Maximum }\end{array}$ & $11.0 \mathrm{~kW}$ \\
\hline Minimum Power Factor & 0.90 \\
\hline Dimensions (Max.) & $\begin{array}{l}\text { 42-inch }(\mathrm{L}) \times 35 \text {-inch }(\mathrm{W}) \times 46 \text {-inch }(\mathrm{H}) \\
\text { Center-of-Gravity }(\mathrm{CG}) \text { not higher than } 23 \text {-inches from bottom }\end{array}$ \\
\hline Refrigerant & R410A (6.7 lbs (3.04 kg) total charge), non-ozone depleting \\
\hline $\begin{array}{l}\text { Minimum Evaporator Air } \\
\text { Flow }\end{array}$ & 1,700 SCFM \\
\hline Gross Weight & $560 \mathrm{lbs}$. \\
\hline Compressor & $\begin{array}{l}\text { Oil type: Compressor Polyester Oil (CPOE) } \\
\text { Capacity: } 60 \mathrm{oz}\end{array}$ \\
\hline Minimum Cooling Capacity: & $\begin{array}{l}\text { Total: } 60,000 \mathrm{Btu} / \mathrm{hr} \text { (Minimum) } \\
\text { Sensible: } 45,000 \mathrm{Btu} / \mathrm{hr} \text { (Minimum) } \\
\text { Desired Sensible: } 48,000 \mathrm{Btu} / \mathrm{hr} \\
50 \mathrm{~Hz} \text { Total: } 44,000 \mathrm{Btu} / \mathrm{hr} \text { (Minimum) }\end{array}$ \\
\hline Minimum Heating Capacity: & Total: 9.94 kW (33,935 Btu/hr) \\
\hline Minimum Fresh Air Airflow & 280 SCFM \\
\hline Noise Level & $<80 \mathrm{dbA}$ \\
\hline
\end{tabular}

\subsection{Enhanced Shelter S1}

\subsubsection{Air barrier}

The development of the baseline (control) Army shelter into an "Enhanced Shelter" involved several improvements to the envelope system. The first improvement was the installation of a continuous air barrier of \#15 asphalt saturated organic felt around the exterior of the wall stud assembly and floor assembly, and above the roof sheathing. Felt was selected as an air barrier due to its availability, low cost as compared to typical air barriers, and ease of installation in the field. A comparison of air barrier costs per square foot (Table 2-2) revealed that \#15 felt is 48\% less expensive per square foot than the next least expensive comparable material. The wall felt was installed where the exterior side of the stud wall layer meets the interior side of the exterior plywood sheathing. This placement was chosen to provide the optimum performance of the material to enhance the assembly, and to protect the integrity of the material during installation and occupancy. Figure 2-6 shows this configuration. 
Table 2-2. Air barrier comparison.

\begin{tabular}{|c|c|c|c|}
\hline Product & Size & $\begin{array}{l}\text { Cost per unit } \\
(\$)^{*}\end{array}$ & Cost per sq ft (\$) \\
\hline \#15 Asphalt Roofing Felt & $3 \times 144 \mathrm{ft}$ (432 sq ft) & 18.25 & 0.042 \\
\hline \multirow{2}{*}{ DuPont Tyvek House Wrap } & $3 \times 100 \mathrm{ft}(300 \mathrm{sq} \mathrm{ft})$ & 36.49 & $\$ 0.122$ \\
\hline & $9 \times 150 \mathrm{ft}(1350 \mathrm{sq} f t)$ & 158.97 & $\$ 0.118$ \\
\hline \multirow{2}{*}{ Pactiv House Wrap } & $3 \times 100 \mathrm{ft}$ (300 sq ft) & 28.97 & 0.097 \\
\hline & $9 \times 150 \mathrm{ft}(1350 \mathrm{sq} f t)$ & 107.00 & 0.079 \\
\hline
\end{tabular}

Figure 2-6. Interior view of the Enhanced Shelter and the installation of the wall felt air barrier.

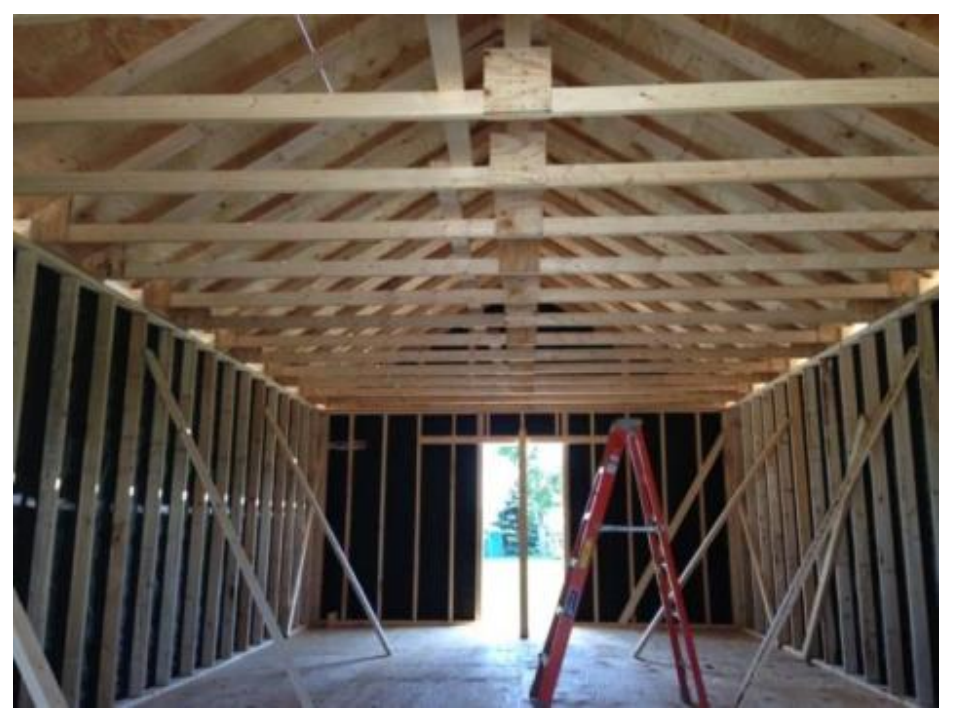

Felt was also installed at the floor plane, across the top of the floor joists and wrapped down the rim joist, and was then covered by $3 / 4$-in. plywood flooring. The roof felt installation followed standard construction conventions, and was installed above of the roof sheathing to prevent water from entering into the interior of the shelter.

\subsubsection{Insulation}

CertainTeed fiberglass batt and Owens Corning Foamular F-150 extruded polystyrene (XPS) insulation were selected to improve the R-value of the shelter envelope assemblies. These insulation materials were selected for their relative availability, low cost, and ease of installation. These are all important factors when considering the implications of shipping this material to contingency bases and using an assembly workforce that may not be familiar with complex installation techniques. Table 2-3 lists the materials, specifications, and assembly location. 
Table 2-3. Envelope enhancements to Shelter S1 and effective assembly values.

\begin{tabular}{|l|c|c|}
\hline \multicolumn{3}{|c|}{ Envelope Enhancements } \\
\hline Location & Thickness (in) & R-Value \\
\hline Attic & 16 & 39 \\
\hline Door & 3 & 15 \\
\hline Floor & 6 & 25 \\
\hline Skirting & 3 & 15 \\
\hline Wall & 3.5 & 13 \\
\hline Felt Air Barrier & negligible & negligible \\
\hline \multicolumn{3}{|c|}{ Effective R \& U-values } \\
\hline Assembly & R-value & U-value \\
\hline Wall & 11.63 & 0.086 \\
\hline Floor & 20.26 & 0.0494 \\
\hline Roof & 30.54 & 0.0327 \\
\hline Source: ASHRAE (2013), Table 1 (p 26.7) and \\
Table 10 (p 26.20). \\
\hline
\end{tabular}

The wall envelope was enhanced with 3.5-in. of Kraft-faced fiberglass batt insulation within the wall cavity (Figure 2-7), which provides an R-value of 13 within the wall. The shelter floor cavity was insulated with 6-in. of Kraft-faced fiberglass batt insulation, which provides an R-value of 25.

The attic above the ceiling plane was insulated with $16 \mathrm{in}$. of unfaced fiberglass batt insulation, which provides an R-value of 39. ADO DuroVent Insulation baffles were also installed in the Enhanced Shelter attic to ventilate the unconditioned attic space and prevent moisture from penetrating into the interior. Figure 2-8 shows the insulation and attic baffles.

To further improve performance, insulation was added to the perimeter of the crawl space at the base of the Enhanced Shelter. Each skirting panel that encloses this space received two layers of $1.5 \mathrm{in}$. of XPS rigid insulation, for a total of 3 in. of insulation (Figure 2-9), which provides an Rvalue of 15. The entrance doors also received two layers of XPS insulation, which provides an R-value of 15 (Figure 2-10). 
Figure 2-7. Interior view of the Enhanced Shelter showing the wall and door insulation applications.

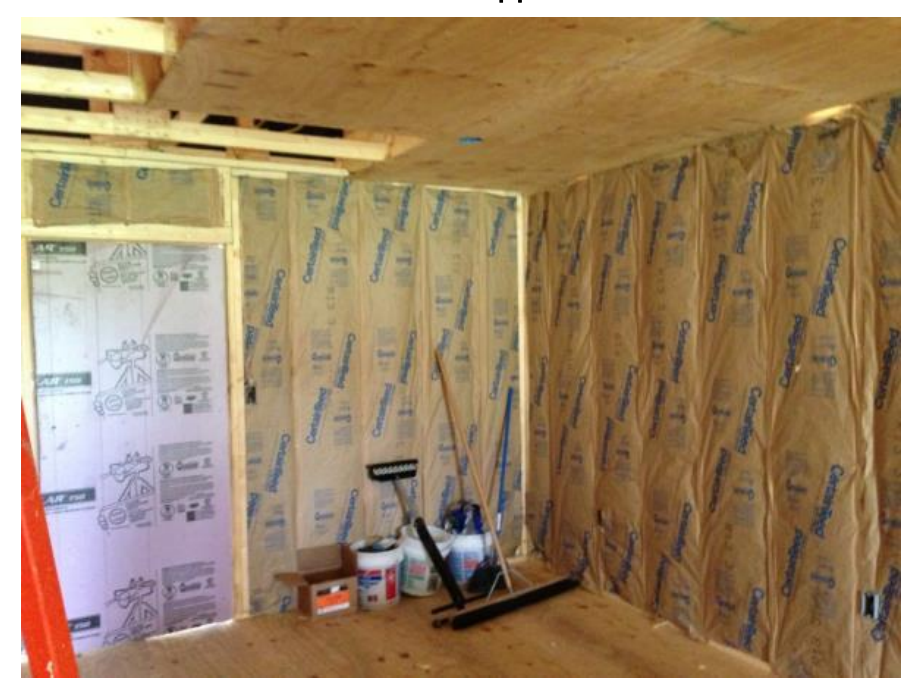

Figure 2-8. View of attic insulation and baffles in the Enhanced Shelter.

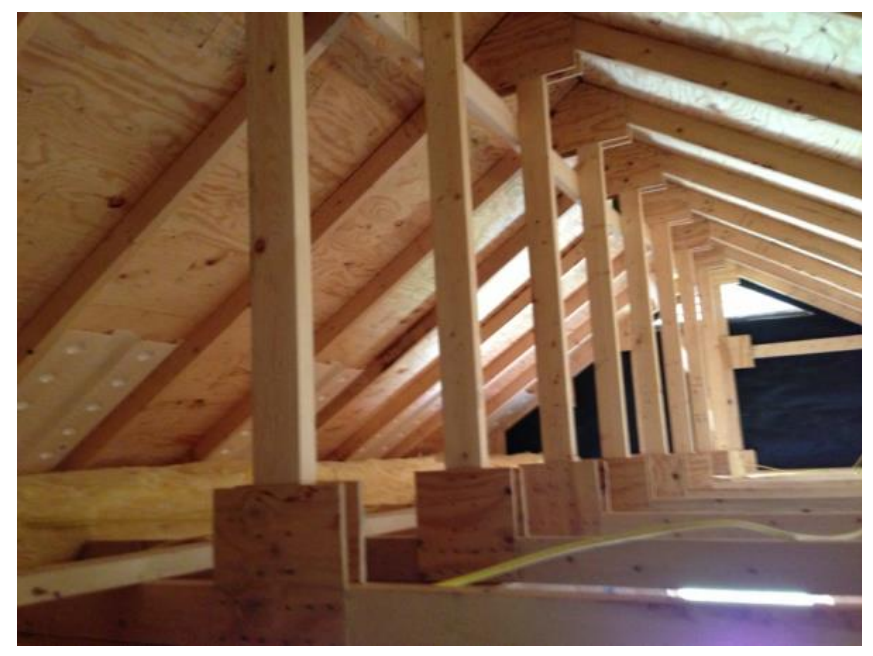

\subsection{Air sealing tape evaluation and testing}

Shortly after the B-huts were completed, the enhanced B-hut was further improved with the application of air sealing tape on the interior. High quality air sealing tape is used in Passive House type construction to make buildings extremely airtight. Improved airtightness can be achieved in the enhanced B-hut by sealing all openings and the seams between the plywood panels on the interior or exterior surfaces with high quality building tape. It is possible to create a continuously tight building envelope using a combination of plywood and air barrier tape because the plywood itself provides an air barrier; only a low airflow can pass through plywood panels. Figure 2-11 shows an example of interior application of air barrier tape in a B-hut. 
Figure 2-9. Enhanced Shelter skirting XPS insulation behind panel.

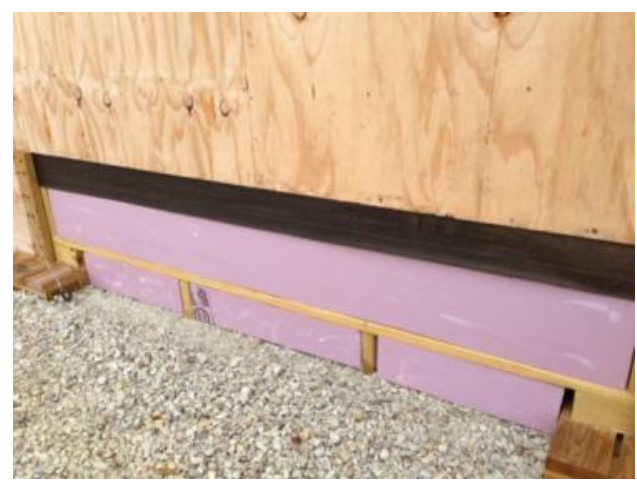

Figure 2-10. Enhanced Shelter door with XPS insulation attached.

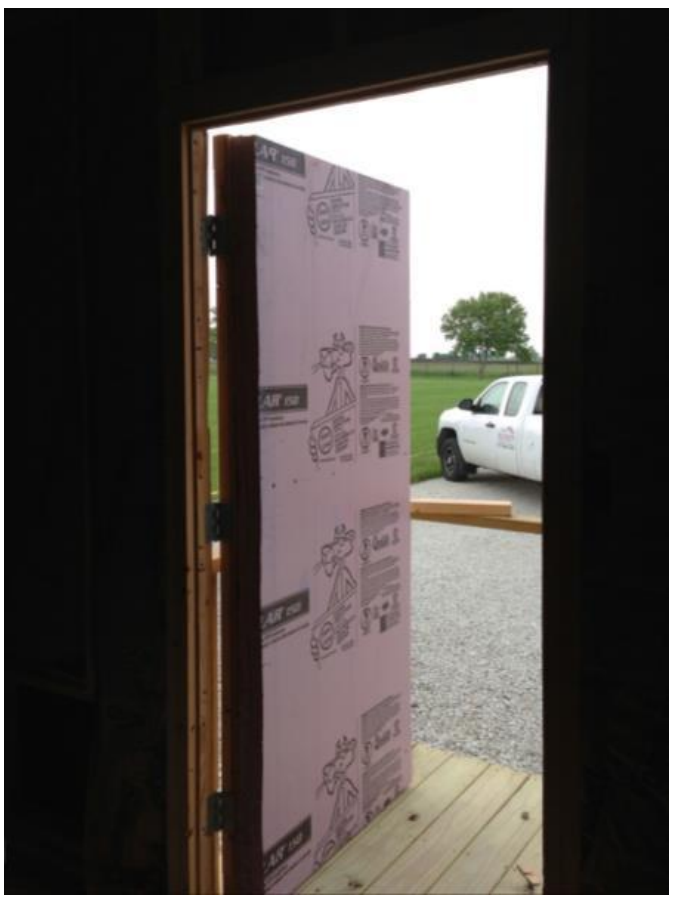

Figure 2-11. Unimproved and improved B-hut interiors: The inside of an unimproved B-hut (left) and a B-hut fully taped from the interior with air barrier tape (right).
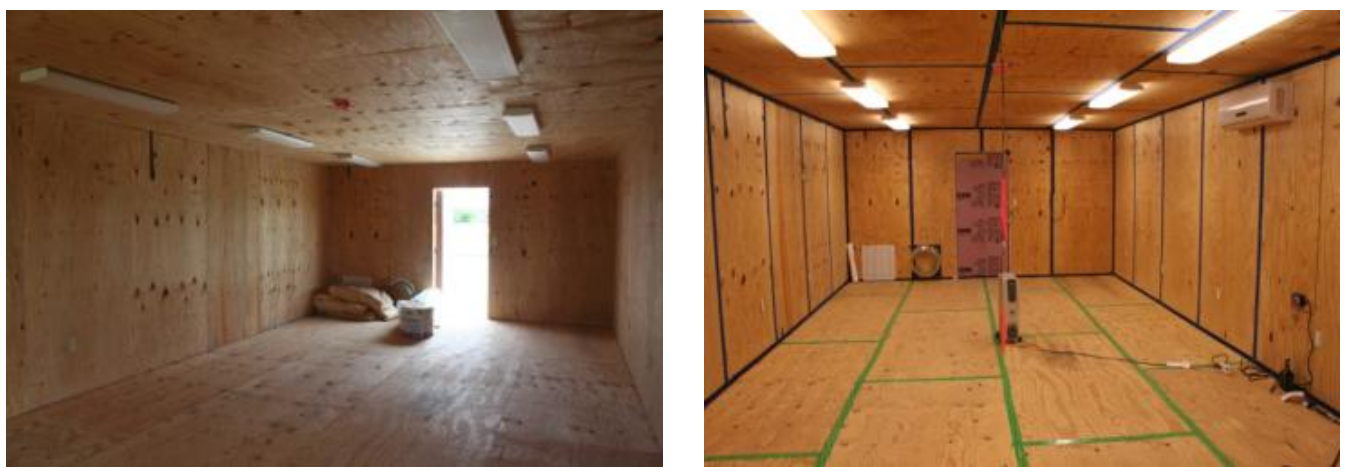

Air barrier tape used to improve building envelope airtightness must address both physical and environmental constraints over the expected 3-4 year service life of a B-hut. These constraints include daily wear-and-tear on the tape surface, the ability of the tape's adhesive to maintain "stickiness" over time after application, and the ability of the tape's backing and adhesive to endure extreme environmental conditions (especially if the tape is applied on exterior surfaces), all while maintaining an airtight seal. Several standards address air sealing tests for air barrier assemblies and degradation testing, but little has been done to test the combination of the two with focus on the performance of the air sealing nature of the tape 
over time. This is partially due to the general structure of common air barriers, where the area of consequence is generally the membrane or house wrap due to the larger area of coverage of this component compared to the small area relying on the tape for sealing.

This study considered the air sealing nature of the tape over time and not the actual air permeance of each material. The goal was to identify commercially available tapes that are most resistant to degradation from environmental conditions on a plywood substrate, that can seal a seam or opening in plywood, and that continue to seal while showing minimal degradation under ultraviolet (UV) exposure, humidity, and high temperature conditions over the expected 3-4 year service life of a B-hut.

This study tested eight exterior air barrier tapes, referred to here as Tapes A through $\mathrm{H}$ (Table 2-4). All eight tapes (Set I), of which three were of European manufacture, underwent initial short-term testing. The tapes are composed of three layers: backing, primer/ adhesive, and liner (Figure 2-12). The tapes were adhered to one substrate for testing - plywood, the surface of interest for the final application on the B-huts. Table 2-4 lists the details of each tape.

Two methods were used to test the tapes under various conditions:

1. Accelerated aging using a "Q-Lab: QUV Accelerated Weathering Tester" (Q-Lab 2011). Results were quantified as leakage measurements taken with a pressurized test chamber (Figures 2-13 and 2-14).

2. Outdoor testing. Results are qualified as visual observation of degradation. 
Table 2-4. Relevant information on tapes: Tapes A-H subjected to outdoor and/or accelerated aging, tape type, and materials used for the backing and adhesive, as well as the associated cost per linear foot.

\begin{tabular}{|c|c|c|c|c|c|}
\hline Name & Testing & Type & Backing & Adhesive & $\$ /$ lin. $\mathrm{ft}$ \\
\hline A & $\begin{array}{l}\text { Outdoor, } \\
\text { Accelerated }\end{array}$ & Sheathing & Polyolefin Film & Butyl Rubber & 0.37 \\
\hline B & Accelerated & Flashing & Cross-laminated HDPE & Rubberized Asphalt & 0.25 \\
\hline $\mathrm{C}$ & Accelerated & Flashing & Polypropylene Film & Rubberized Asphalt & 0.36 \\
\hline $\mathrm{D}$ & $\begin{array}{l}\text { Outdoor, } \\
\text { Accelerated }\end{array}$ & Foil & Aluminum Foil & Acrylic & 0.14 \\
\hline E & $\begin{array}{l}\text { Outdoor, } \\
\text { Accelerated }\end{array}$ & Flashing & Proprietary Film & Acrylic & 0.28 \\
\hline $\mathrm{F}$ & $\begin{array}{l}\text { Outdoor, } \\
\text { Accelerated }\end{array}$ & Sheathing & Polypropylene Fabric & Acrylic & 0.43 \\
\hline G & $\begin{array}{l}\text { Outdoor, } \\
\text { Accelerated }\end{array}$ & Sheathing & $\begin{array}{l}\text { Polypropylene Fabric With } \\
\text { Reinforcement Mesh }\end{array}$ & Acrylic & 0.43 \\
\hline $\mathrm{H}$ & $\begin{array}{l}\text { Outdoor, } \\
\text { Accelerated }\end{array}$ & Sheathing & $\begin{array}{l}\text { Polyolefin Film With } \\
\text { Reinforcement Fabric }\end{array}$ & Acrylic & 0.44 \\
\hline
\end{tabular}


Figure 2-12. Tape layers: Tape layers consist of backing, primer/adhesive, and release liner layers of the tape.

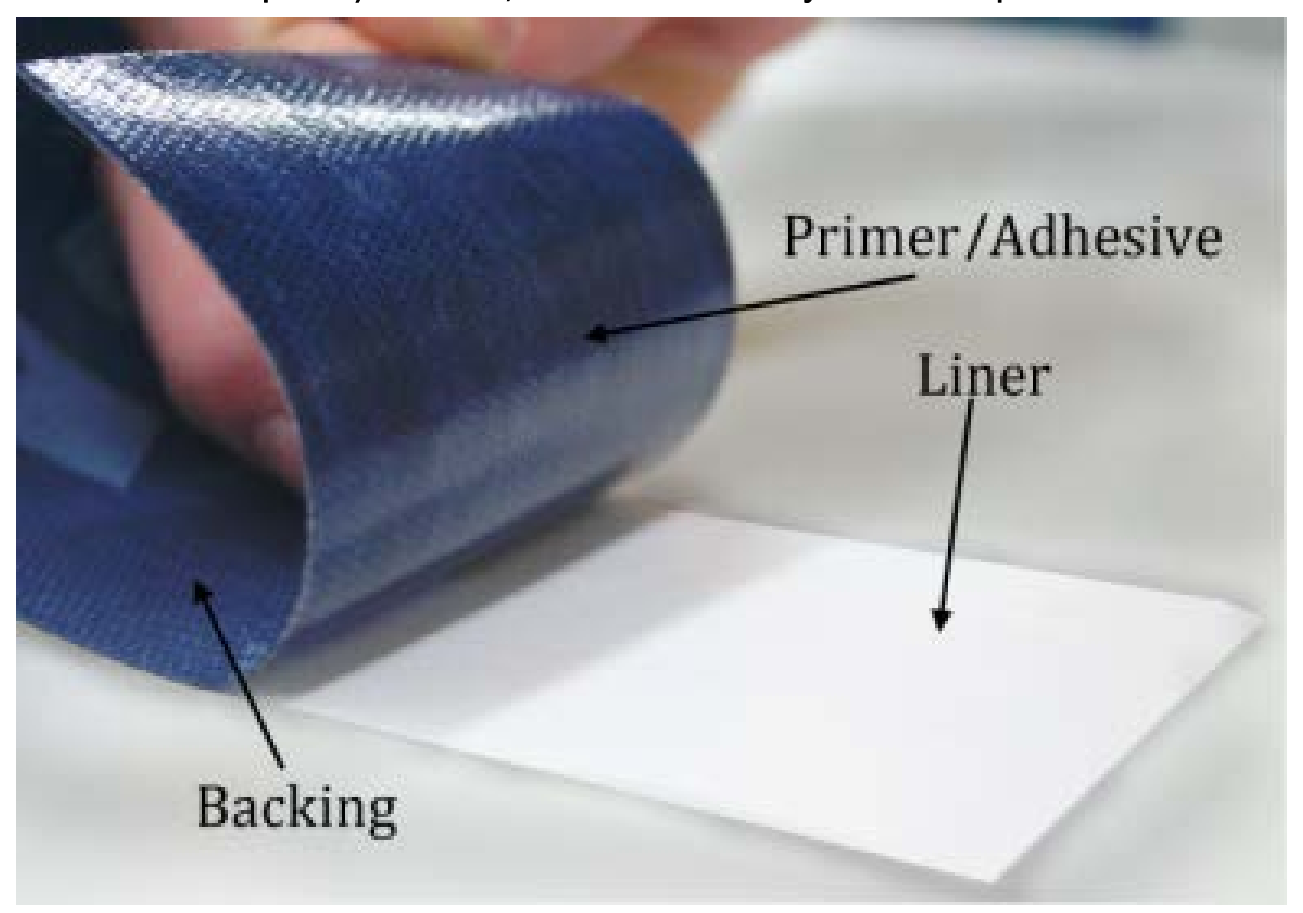

Figure 2-13. Pressure Chamber: Three dimensional representation of the pressure chamber holding the plywood sample (left) and actual pressure chamber used for tape leakage tests (right).
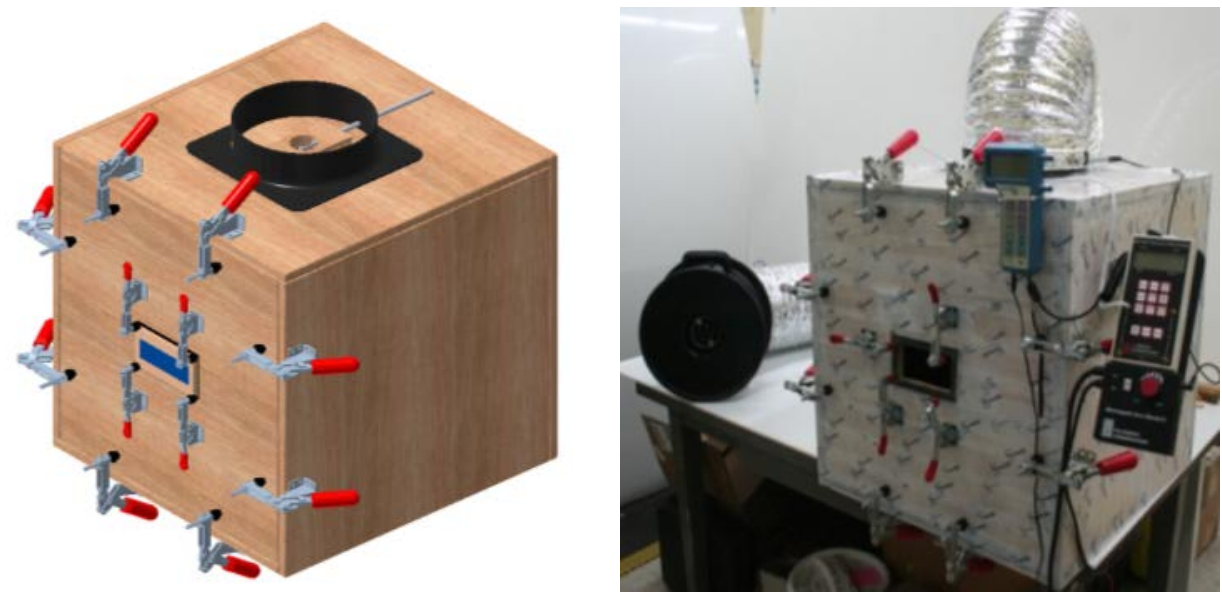
Figure 2-14. Cross section of pressure chamber.

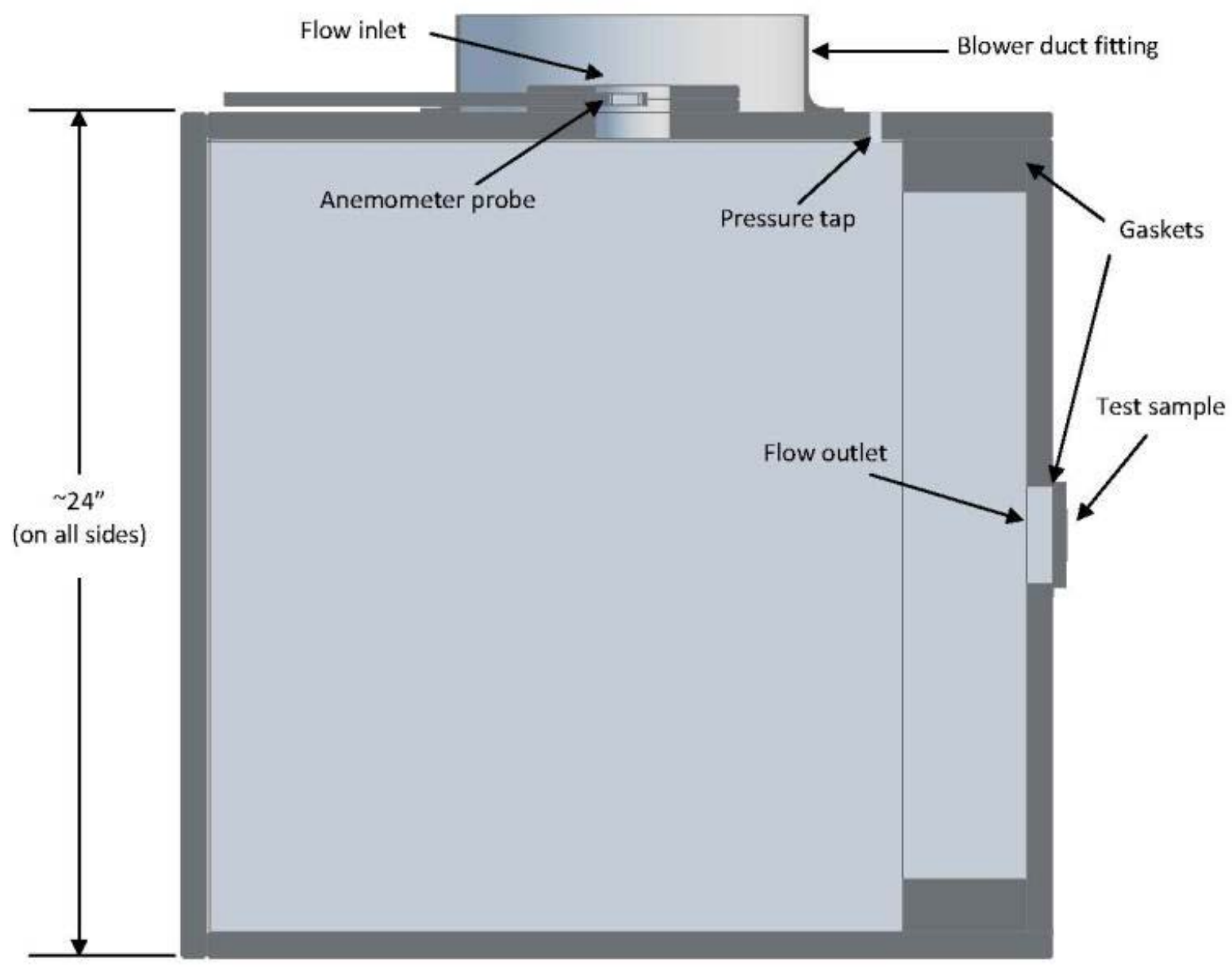

\subsubsection{Indoor testing results}

Tape A showed some warping of the tape backing and some retraction of the backing from the adhesive layer.

Tape B peeled off the substrate within a short amount of time, requiring a staple to be put into the center to ensure the tape would not fall onto the test equipment's UV bulbs and create a fire hazard (Figure 2-15). Of all the samples, this tape had the most significant leakage. Because this tape showed the most dramatic change, it was immediately ruled out as a usable tape for the purposes of this research. Note that this tape's manufacturer does not recommend that this tape undergo long-term exposure to hot conditions due to its rubberized asphalt adhesive. 
Figure 2-15. Aged Tape B and C from Set I: Visual degradation in Tape B (top) and C (bottom), samples at 0 hours, 12 hours, 24 hours, 1 week, 2 weeks, and 4 weeks (left to right) in the QUV Accelerated Weathering Tester.

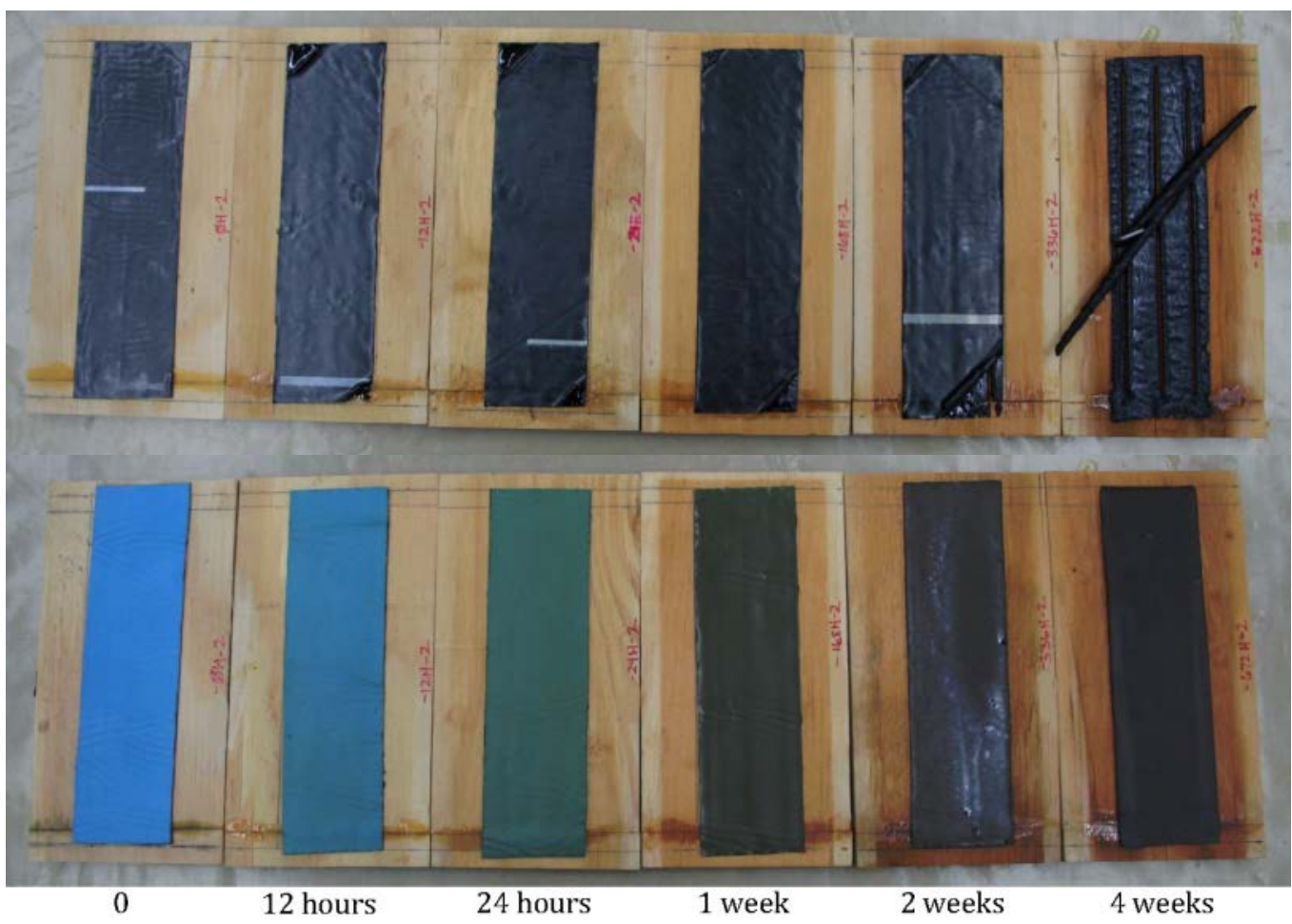

Tape $\mathrm{C}$ became discolored, changing from a bright blue to black (Figure 2-15 bottom). In addition, this tape also showed "fish-mouthing," i.e., lifting of the edges off the substrate. Again, because this tape showed such dramatic changes, it is not recommended for the intended application. Note: the manufacturer of this tape also does not recommend that this tape undergo long-term exposure to hot climates due to its rubberized asphalt adhesive.

Tapes D, E, and G showed minimal degradation in the QUV Accelerated Weathering Tester. Tape $\mathrm{D}$ formed to the grooves of the substrate over time and showed only small wrinkles in the aluminum backing. Tape $\mathrm{E}$ had minor cracking where the substrate was glued using wood glue during substrate preparation. Since wood glue is not typically used in the intended application, this cracking is not expected to be a problem.

Tape F turned black through penetrations in the backing, in areas along the reinforcement mesh (between the adhesive and backing). After examining the sample under an optical microscope (Figure 2-16), it was concluded that the discoloring was an interaction between the adhesive and reinforcement mesh due to the aging process. 
Figure 2-16. Tape F degradation: After 4 weeks of accelerated aging, observed under a National DC5-420th Stereo Microscope with a zoom objective magnification of $1.6 \mathrm{x}$ in combination with a $20 \mathrm{x}$ eyepiece lens.

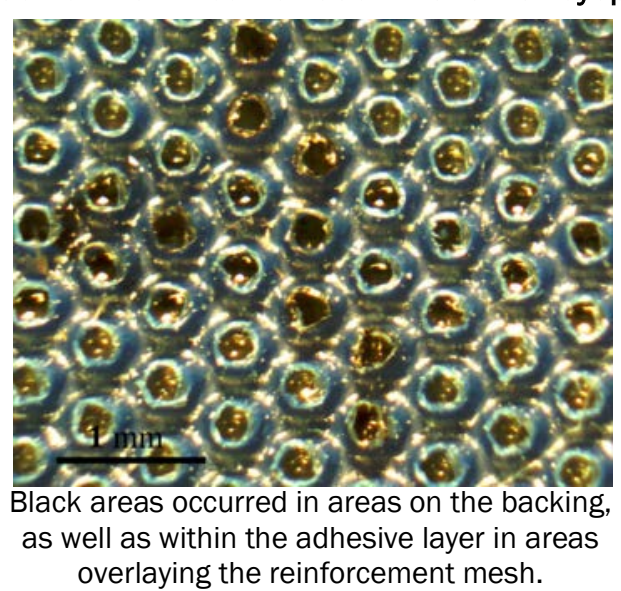

Similar to Tape E, Tape H showed minor cracking where the substrate had been prepared using wood glue. The backing of this tape withdrew from the adhesive in areas along the edge of the tape, leaving the adhesive exposed to the elements.

After Set I testing, it was concluded that the top three performing tapes were Tapes D, E, and G.

\subsubsection{Outdoor testing}

Outdoor exposure testing was also done to identify the tapes to be subjected to long-term (Set II) testing. Outdoor tape samples were applied on 30 September 2013 and were observed periodically until the last observation on 28 May 2014, 8 months after application. The application temperature was approximately $65^{\circ} \mathrm{F}\left(18^{\circ} \mathrm{C}\right)$. Figure $2-17$ shows the recorded weather data in Champaign, IL for the period from 30 September 2013 to 28 May 2014, which indicates the conditions to which the tapes were exposed.

For this study, the term "failed" indicates that the tape has completely or mostly peeled off the area; "minor peeling" indicates that peeling has initiated, but that the majority of the tape is still adhered to the area; and "other" indicates that there has been a change in color, texture, or any other change in a tape. As shown in Figure 2-18 and outlined in Table 2-5, several tapes failed completely. (They peeled off entirely.) Others showed color change, bubbling, or other signs of degradation. 
Figure 2-17. Weather Data for Champaign, IL. Weather data for duration of the outdoor testing in the city of Champaign, IL from 30 September 2013 to 28 May 2014 for temperature, wind speed, relative humidity, and precipitation (The Weather Underground, Inc. (2014, June 30). Weather History for Champaign, IL [Online].)

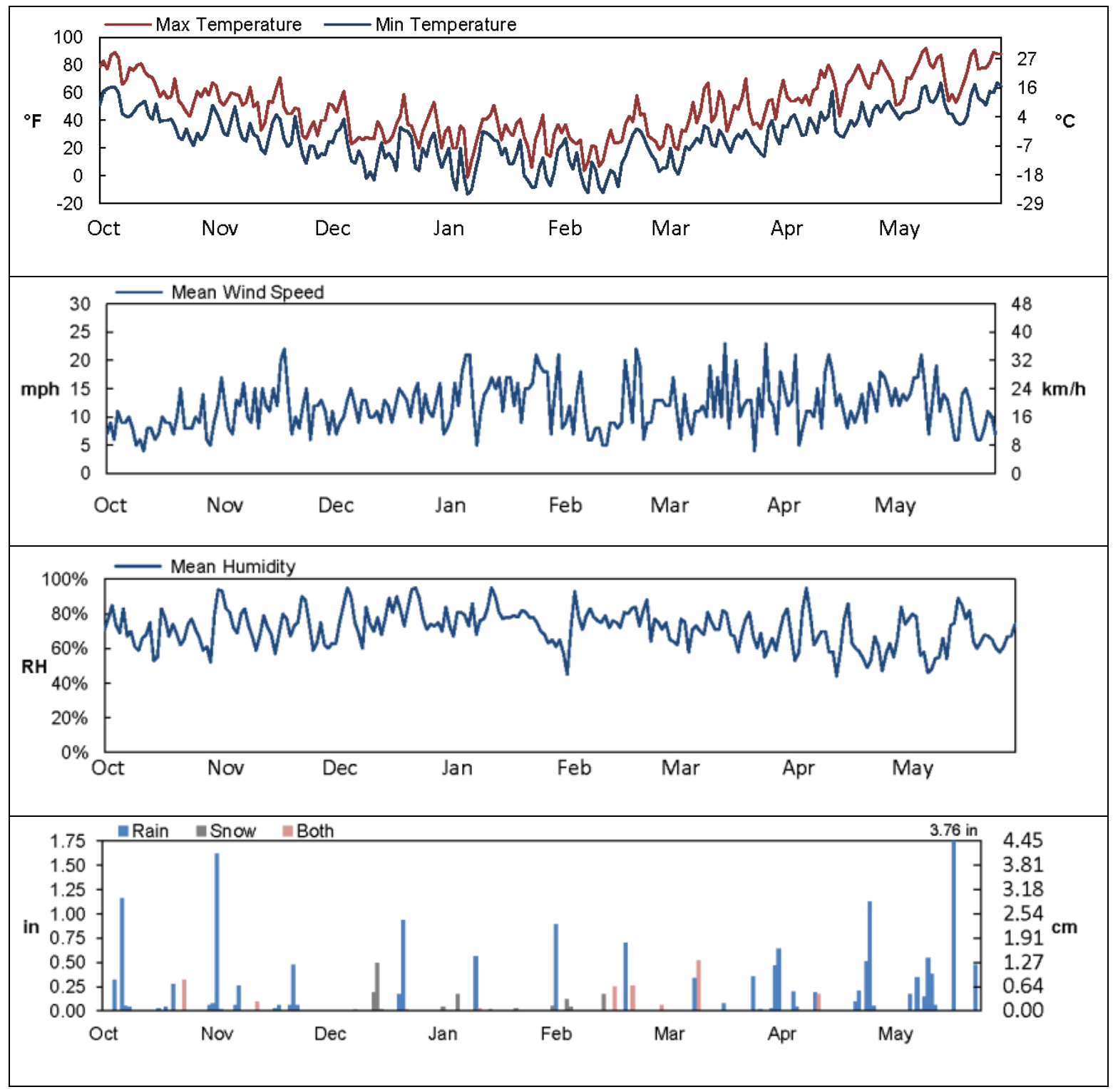


Figure 2-18. Outdoor Weathering Samples after 8 Months: Approximately 8 months after application (28 May 2014) on the south wall (top) and west wall (bottom). Tape D in the vertical $\mathrm{W}$ location (indicated with the red box), completely peeled off within the first 2 months.

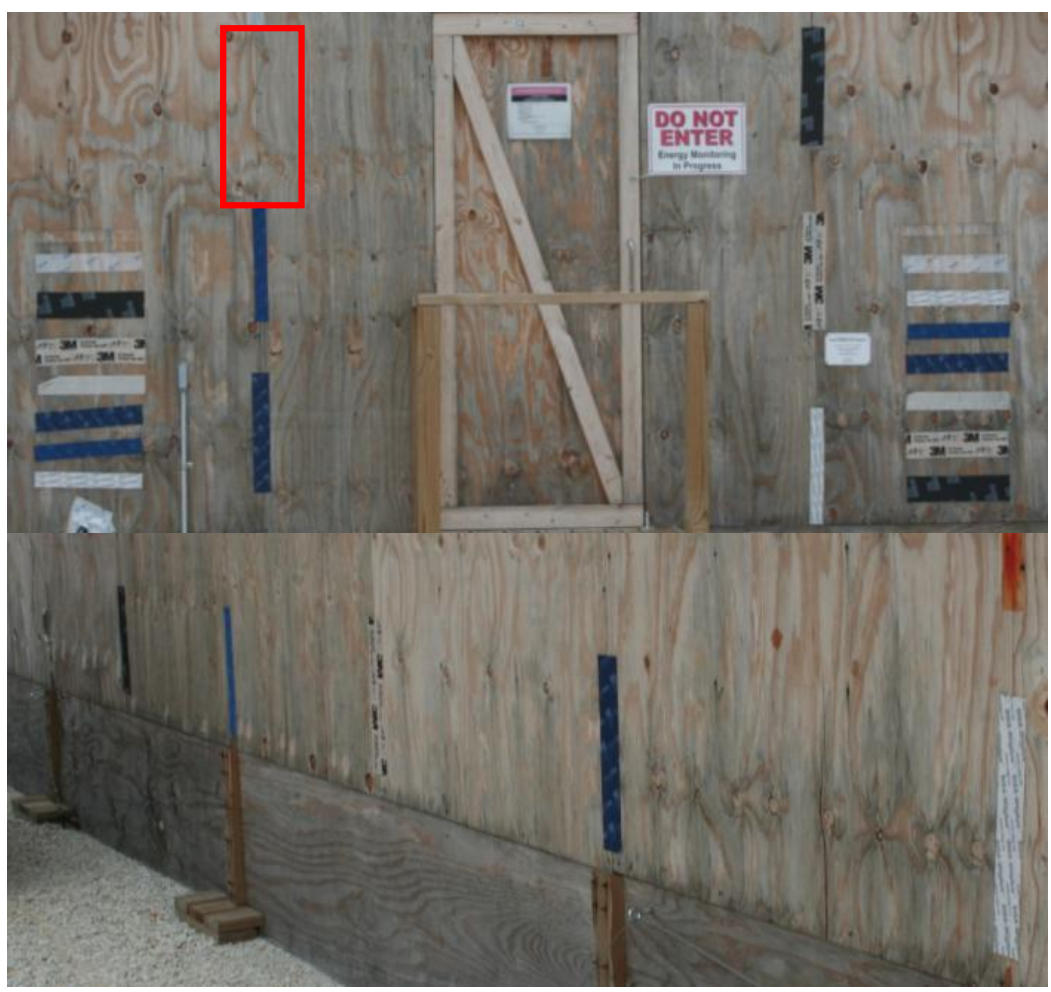

Table 2-5. Outdoor Visual Degradation Results.

\begin{tabular}{|c|c|c|c|c|c|c|c|c|}
\hline \multirow{2}{*}{\multicolumn{2}{|c|}{ Placement }} & \multicolumn{6}{|c|}{ Tape } & \multirow{6}{*}{$\begin{array}{l}X=\text { failed } \\
P=\text { minor peeling } \\
O=\text { other }\end{array}$} \\
\hline & & A & D & $\mathrm{E}$ & $F$ & $\mathbf{G}$ & $\mathrm{H}$ & \\
\hline \multirow[t]{2}{*}{ Vertical } & W & 0 & $x$ & - & 0 & - & 0 & \\
\hline & $S$ & 0 & $x$ & - & - & - & 0 & \\
\hline \multirow[t]{2}{*}{ Horizontal } & SW & - & $P$ & - & - & - & 0 & \\
\hline & SE & - & $P$ & - & - & - & 0 & \\
\hline
\end{tabular}

Similar to the results from Set I testing, the backing of Tapes A and $\mathrm{H}$ retracted from the adhesive layer along the edge of the tape, leaving the adhesive exposed to the elements, and Tape A showed bubbling on the vertical samples. Tape H showed a slight color change in the south vertical sample.

Tape D had peeled from the plywood substrate (Figure 2-19). Two of the four Tape D samples failed completely while other two had begun to peel. The two vertical strips that failed completely had begun peeling within the first month of application, and failed completely within 2 months of application. While this tape was a top performer for Set I, its adhesion performance was largely compromised over time during the outdoor tests. 
Figure 2-19. Tape $D$ after Outdoor Exposure: Tape $D$ after 8 months of outdoor exposure in the horizontal SW (right) locations.

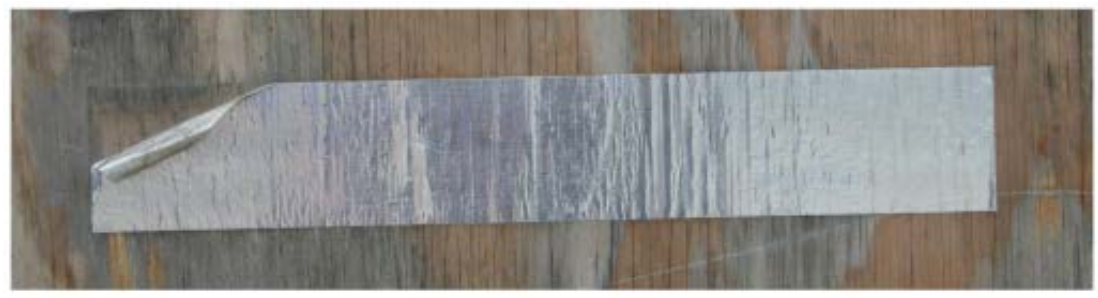

Tapes E and G showed minimal degradation. The Tape F sample on the west wall showed blackened areas that became noticeable in J anuary 2014 ( $\sim 3$ months after application). These results were similar to those of the Tape F sample's Set I testing. The majority of the tapes showed minimal degradation. Tape D, however, performed poorly under outdoor exposure; two Tape D samples completely failed and the remaining Tape D samples peeled. The top performing tapes from the outdoor testing were Tapes $\mathrm{E}$ and G. Because these two tapes were also chosen from Set I, they were selected for further testing in Set II.

\subsubsection{Air sealing tape findings}

Eight exterior air barrier tapes (A-H) were selected for testing to determine the most suitable tape for exterior sealing of plywood seams in B-hut structures. After initial Set I testing, Tapes D, E, and G showed minimal degradation. Of these, the two tapes that showed the least evidence of degradation after outdoor exposure were Tapes $\mathrm{E}$ and $\mathrm{G}$. Since these two tapes showed a strong potential for maintaining an air barrier over the B-huts' expected lifetime, they were chosen for further testing (Set II). After 12 weeks of exposure to UV and condensation cycles, tests showed that neither tape leaked. Both tapes were examined under a Scanning Electron Microscope (SEM). Tape E showed no signs of microscopic degradation while Tape G showed damage to the backing fibers. Results indicate that these tapes would be suitable for application on B-hut structures to improve the building envelopes air barrier.

\subsection{Air sealing tape effectiveness; blower door testing}

Air leakage in buildings can account for 30 to $50 \%$ of conditioned air loss. To improve the airtightness of the enhanced B-hut, all interior seams between the plywood panels and all openings for electrical wiring, outlets, and switches were sealed with tape. Blower door tests were then conducted on each B-hut to measure its airtightness in comparison to its air leakage rate. 
The blower door test creates a pressure differential across the building envelope, and measures the airflow as a function of the pressure difference. A pressure gauge attached to the blower door assembly measures the rate of airflow required to maintain that pressure differential in cubic feet per minute (cfm). In accordance with standard blower door procedures (ASTM E779 [ASTM 2010]), each B-hut was closed-up tightly, then pressurized and depressurized (compared with outside conditions) with the blower door fan. A series of flow and pressure reading were taken over a range of 10 different pressures equally spaced between 40 to 75 Pascals (Pa). The test results clearly show that adequately sealing the enhance B-hut significantly improves its airtightness (Table 2-6).

\subsection{Tracer gas test}

Infiltration is an important contributor to conditioning load. CERL conducted blower door tests to characterize leakage in all huts. ORNL conducted tracer gas tests to measure air change rate during normal operating conditions. Tests conducted using a concentration decay method on the Bhuts in May 2015 measured the air change rate at the conditioned space during normal operating condition when IECUs are used.

After releasing the tracer gas (R-134A) and achieving a well-mixed condition, a LumaSense multipoint sampler was used to sample air from multiple locations. An Innova 1412 photoacoustic field gas monitor was used to measure the concentration of tracer gas in the sample. Figure 2-20 shows the tracer gas test setup and Figure 2-21 shows a sample test result. These tests showed 1.63 air changes per hour (ACH) for the baseline B-hut during the test period on May 27 and 0.39 ACH for the enhanced B-hut during the test period on May 26. The flow coefficient used to model infiltration in EnergyPlus was adjusted to match EnergyPlus predicted ACH with tracer gas test data during the tracer gas test period.

Table 2-6. Blower door test results.

\begin{tabular}{|l|c|c|}
\hline \multirow{2}{*}{ Envelope Improvements } & $\begin{array}{c}\text { Enhanced B-hut } \\
\text { and Sealed, Felt Paper, } \\
\text { and Insulation }\end{array}$ & None \\
\hline Date Tested & 2 September 14 & 8 July 14 \\
\hline Pressurization (cfm/sf) & 0.366 & 1.989 \\
\hline Depressurization (cfm/sf) & 0.098 & 1.828 \\
\hline Combined (cfm/sf) & 0.232 & 1.909 \\
\hline Flow coefficient (cfm/Pan) & 69.94 & 318.12 \\
\hline Pressure exponent & 0.52 & 0.549 \\
\hline
\end{tabular}


Figure 2-20. Tracer gas test setup.

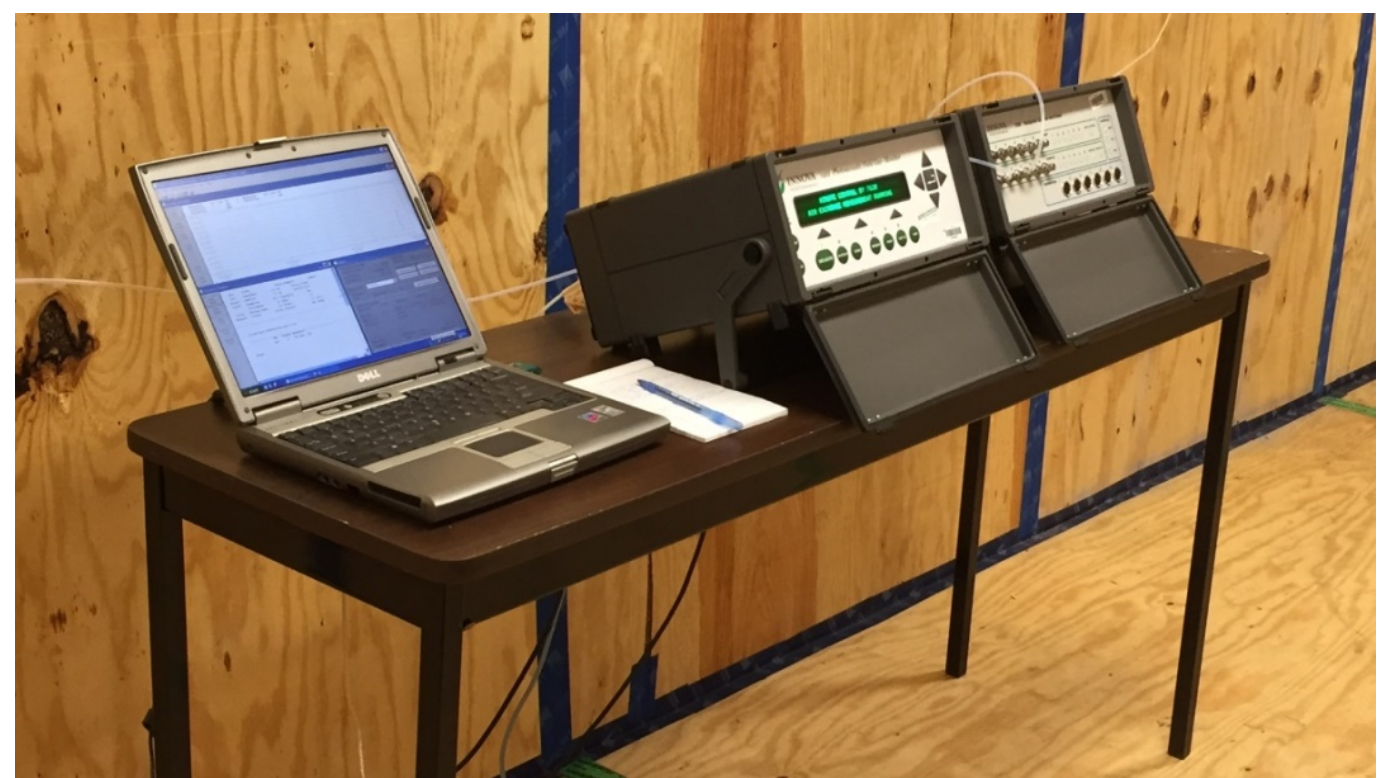

Figure 2-21. Tracer gas test sample result.

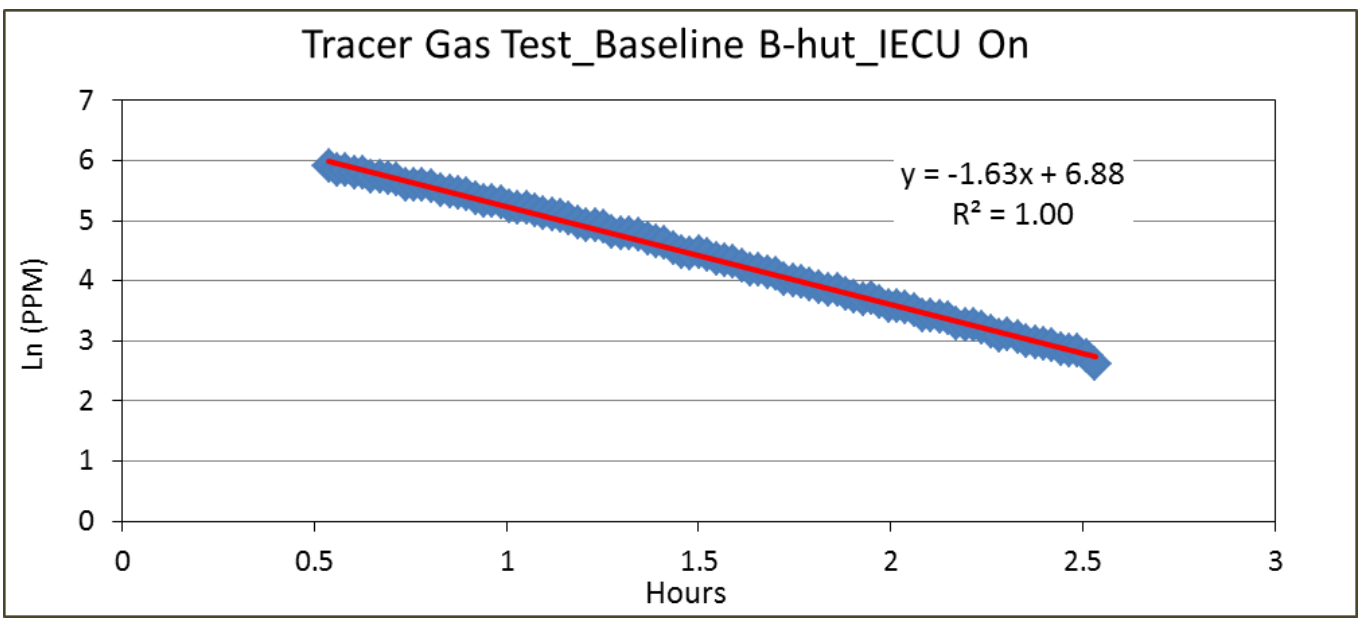

\subsection{Costs}

\subsubsection{Shelter costs}

The assembly cost for the (unimproved) Control Shelter totaled $\$ 21,607.50$ ( $\$ 12,850.00$ for labor and $\$ 8,757.50$ for materials). Costs of improvements done to the Enhanced Shelter enhancements totaled $\$ 4,785.00$ (2,635.00 for labor and 2,150.00 for materials). The cost to build the Enhanced Shelter included the cost of the Control Shelter plus the cost of enhancements, or $\$ 26,392.5$ (Table 2-7). 
Table 2-7. Shelter and enhancements costs.

\begin{tabular}{|l|r|r|r|r|r|}
\hline \multicolumn{1}{|c|}{ Assembly Costs } & Material (\$) & \multicolumn{1}{c|}{ Labor $\mathbf{( \$ )}$} & $\begin{array}{c}\text { Control Shelter } \\
\text { Total }\end{array}$ & $\begin{array}{c}\text { Enhanced Shelter } \\
\text { Totals }\end{array}$ & $\begin{array}{c}\text { Project } \\
\text { Total }\end{array}$ \\
\hline S2 - Control & $8,757.50$ & $12,850.00$ & $\$ 21,607.50$ & & \\
\hline S1 - Enhanced Shelter & $8,757.50$ & $12,850.00$ & & $\$ 21,607.50$ & \\
\hline Enhancements: & $2,150.00$ & $2,635.00$ & & $\$ 4,785.00$ & \\
\hline Grand Totals & $\$ 19,665.00$ & $\$ 28,335.00$ & $\$ 21,607.50$ & $\$ 26,392.50$ & $\$ 48,000.00$ \\
\hline
\end{tabular}

\subsubsection{Enhancement costs}

Costs for the envelope enhancements (materials and labor) to the Enhanced Shelter totaled $\$ 4,785.00$. Table 2-8 lists the individual material and installation costs.

Table 2-8. Enhancement material and labor costs.

\begin{tabular}{|l|l|r|r|r|}
\hline \multicolumn{1}{|c|}{ Enhancement } & \multicolumn{1}{|c|}{ Location } & \multicolumn{1}{c|}{ Material } & \multicolumn{1}{c|}{ Labor } & \multicolumn{1}{c|}{ Cost } \\
\hline Fiberglass batt & Walls & $\$ 250.00$ & $\$ 340.00$ & $\$ 590.00$ \\
\hline & Ceiling & $\$ 980.00$ & $\$ 680.00$ & $\$ 1,660.00$ \\
\cline { 2 - 5 } & Crawlspace & $\$ 400.00$ & $\$ 340.00$ & $\$ 740.00$ \\
\hline Baffles & Attic & $\$ 40.00$ & $\$ 85.00$ & $\$ 125.00$ \\
\hline XPS & Doors \& Skirting & $\$ 360.00$ & $\$ 680.00$ & $\$ 1,040.00$ \\
\hline 15\# Asphalt Felt & Walls \& Floor (roof felt not included) & $\$ 120.00$ & $\$ 510.00$ & $\$ 630.00$ \\
\hline Enhancement Total Cost & $\$ 2,150.00$ & $\$ 2,635.00$ & $\$ 4,785.00$ \\
\hline
\end{tabular}




\section{Preliminary Data Collection}

\subsection{Data considerations}

\subsubsection{Experimental parameters}

The preliminary data collection process involved the measurement and recording of the individual electrical energy consumption of both B-huts for a 1-month period during the cooling season. This commenced immediately after both huts were completed at the end of J uly 2013, before the application of air sealing tape to the interior of the enhanced B-hut. The monitoring period included 24 days when the daytime temperature exceeded $85^{\circ} \mathrm{F}$. The data was collected on a weekly basis, and included the measurement and recording of the interior temperatures of both B-huts and the corresponding exterior temperature during the same minimum 1-month period. The Enhanced Shelter was set to maintain an average interior space temperature of $78^{\circ} \mathrm{F}$.

\subsubsection{Meters and placement}

Real time monitoring was done using OnSet HOBO data loggers and sensors (Table 3-1) located within the Control Structure and the Enhanced Structure. Figures 3-1 and 3-2 show the location of the data collection equipment in the Enhanced and the Control Shelters, respectively. The data collected from these meters were analyzed to determine the implications of the enhancements to a shelter's energy performance. Section 3.2 details this analysis.

\subsubsection{Data loggers}

Each OnSet HOBO U12 Data Logger has four input channels, which allow simultaneous monitoring of up to four sensors. The loggers were located adjacent to each Chigo AHU within the interior of each shelter. Tables 3-2 and 3-3, respectively, list the configurations for each logger channel in the Enhanced and Control Shelters.

Table 3-1. Metering equipment.

\begin{tabular}{|l|c|l|}
\hline Metering Equipment - OnSet Corp. & No. & Location \\
\hline HOBO U12 Data Logger, 4-Channel Indoor External & 2 & Int. S1 \& 2 \\
\hline Split Core Alternating Current (AC) Current Transducer, CTV-A, O-2OA & 2 & Int. S1 \& 2 \\
\hline Tic-HD Water/Soil Temperature Sensor & 3 & Int. \& Ext. S1; Int. S2 \\
\hline
\end{tabular}


Figure 3-1. Placement of the Enhanced Shelter's metering equipment.

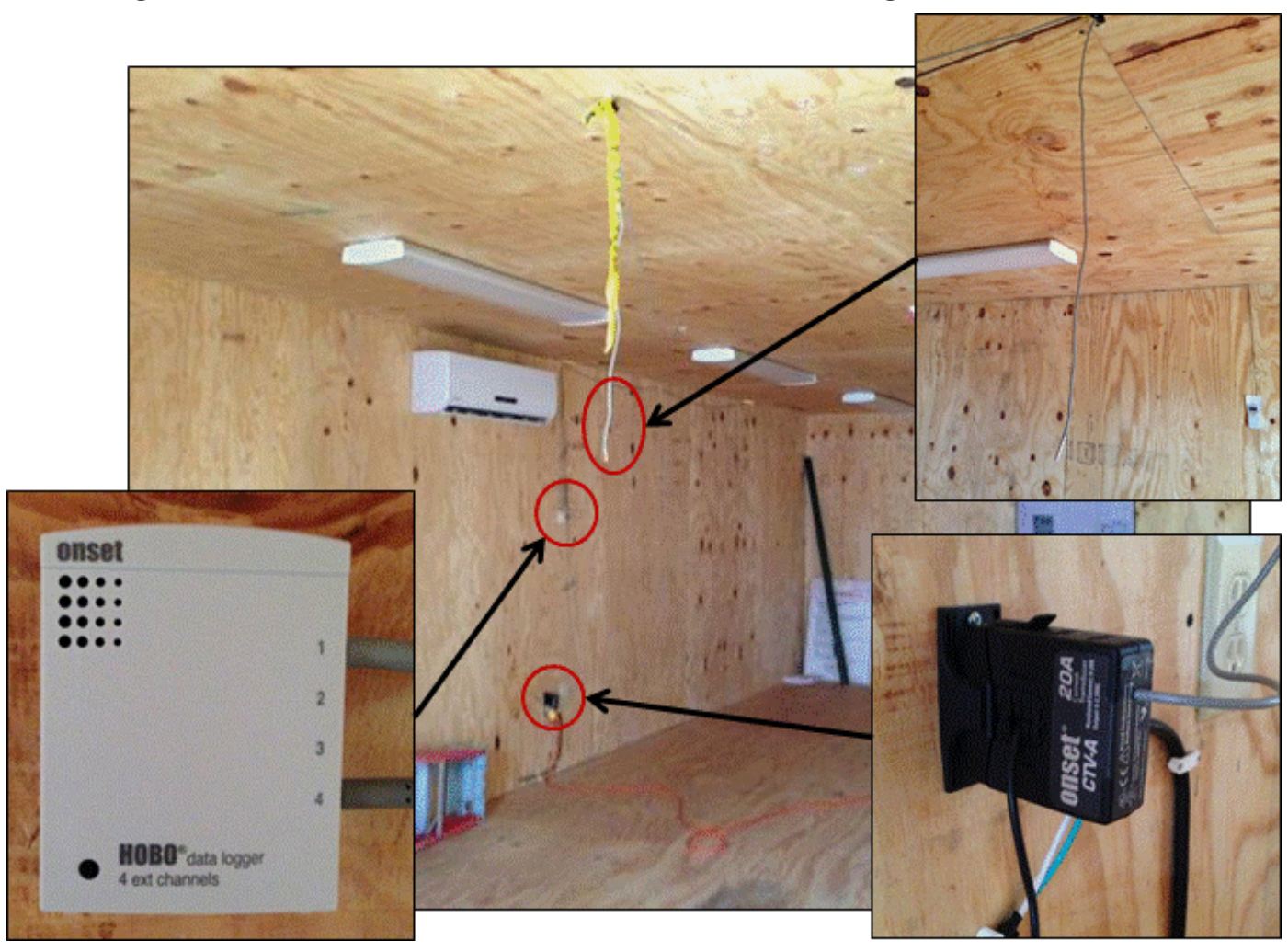

Figure 3-2. Placement of the Control Shelter's metering equipment.

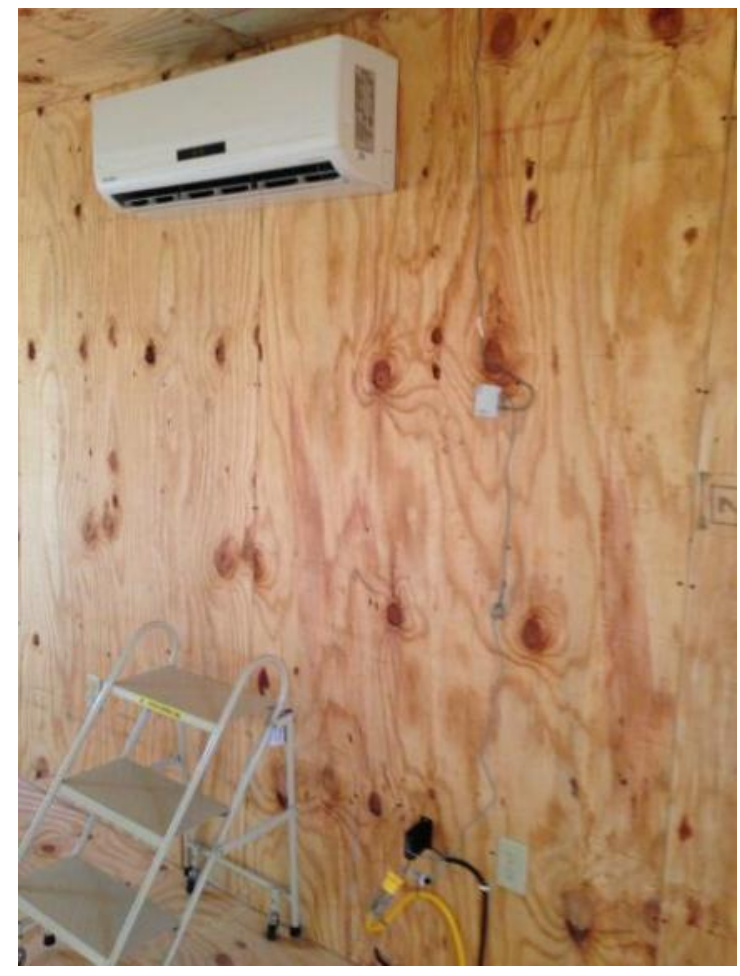


Table 3-2. Enhanced Shelter-S1 data logger configuration.

\begin{tabular}{|c|l|}
\hline Channel & Sensor \\
\hline 1 & CTV-A Split Core AC Current Transducer \\
\hline 2 & NONE \\
\hline 3 & Exterior TMCx-HD Temperature Sensor \\
\hline 4 & Interior TMCX-HD Temperature Sensor \\
\hline
\end{tabular}

Table 3-3. Control Shelter-S2 data logger configuration.

\begin{tabular}{|c|l|}
\hline Channel & Sensor \\
\hline 1 & CTV-A Split Core AC Current Transducer \\
\hline 2 & NONE \\
\hline 3 & NONE \\
\hline 4 & Interior TMCx-HD Temperature Sensor \\
\hline
\end{tabular}

\subsubsection{Temperature sensors}

\subsubsection{Interior}

The interior temperature sensors were placed to the north of each shelter, centered $8 \mathrm{ft}$ from the north gable end and $8 \mathrm{ft}$ from both east and west walls. The sensors were located $6 \mathrm{ft}$ above the floor, to match the location of the HVAC thermostat.

\subsubsection{Exterior}

Only one exterior temperature sensor was required, placed on the east side of the Enhanced Shelter, $4 \mathrm{in}$. below the eave line to protect it from the elements, and to prevent false readings due to overexposure to the sun or influences from air flow exiting the attic space. The sensor was located on the east side of the shelter to minimize the effects of sunlight on temperature readings since sunlight is less intense on the east side of the building in the morning than it is on the west side in the afternoon. The sensor cable from the data logger was run through the attic space and out to the exterior for ease of installation.

\subsubsection{Energy sensor}

The CTA-V Current Transducer clamp was attached to the negative wire of the power cord of each HVAC unit within the interior space of the shelters (Figure 3-3). The transducer clamp can only be installed to one wire lead as it measures the flow of electrical energy in one direction, in this case out to the condensing unit. 
Figure 3-3. Control Shelter transducer clamp attached to the HVAC power cable.

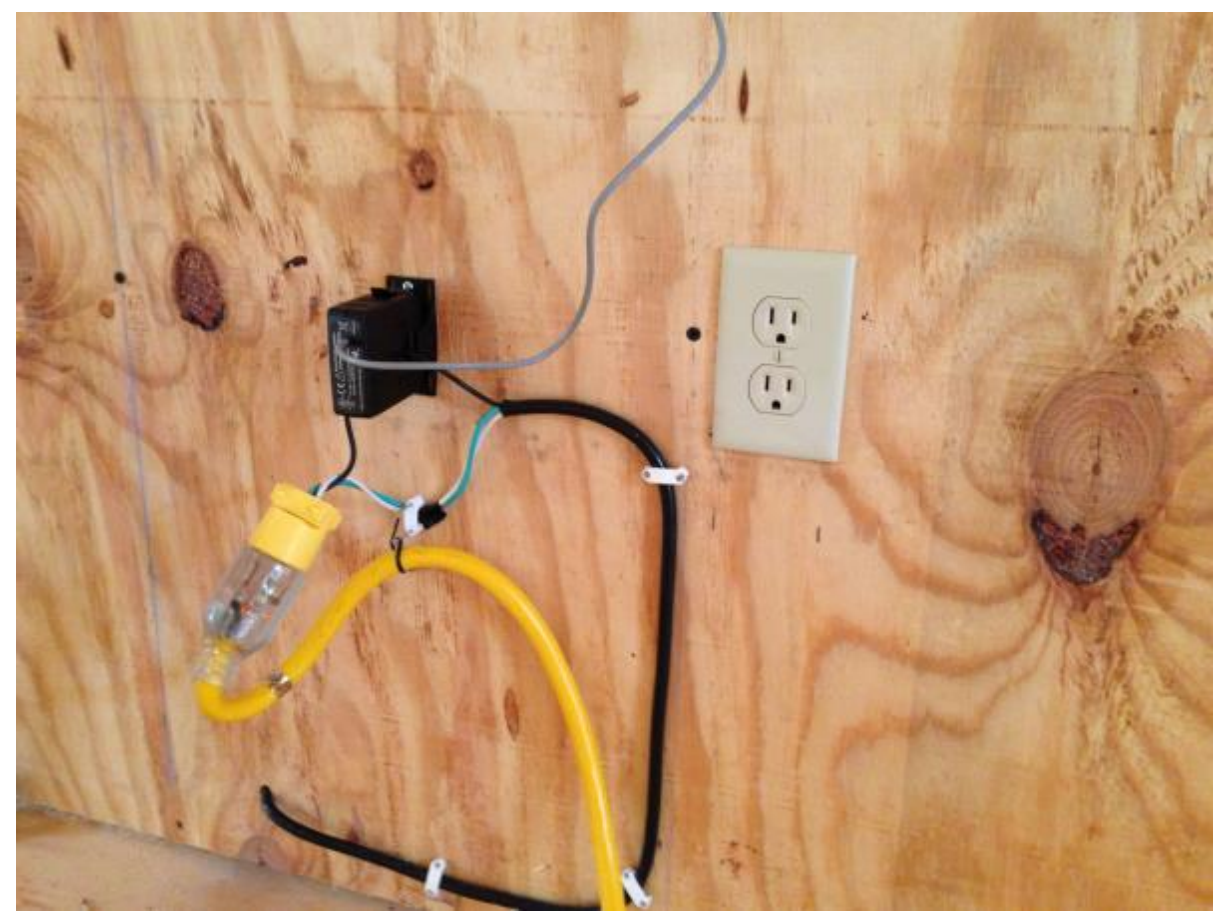

\subsubsection{Data collection and measurements}

In both shelters, data loggers, sensors, and schedules were matched in terms of placement and data collection. The only difference was that the exterior temperature sensor was attached to the Enhanced Shelter's data logger. (Exterior temperatures were assumed to be the same for both structures.)

Raw data were downloaded from each logger once a week on Monday afternoons between 1500 and 1600 hours. Each logger was subsequently relaunched each Monday once the data were collected. Research parameters required weekly data collection. The weekly download was also necessitated by the fact that each logger is only equipped with $64 \mathrm{~kb}$ of storage, which reaches data storage capacity within approximately 10 days.

\subsubsection{Sensor meter filters}

The data were collected through the following filters:

- Electricity. Maximum amperes were measured and logged at 1-minute intervals

- Temperature. Maximum and average temperatures were measured and logged at 30-minute intervals for both interior and exterior temperatures. 


\subsection{Preliminary findings}

This analysis used energy and temperature data from the period of $04 \mathrm{Au}-$ gust to 03 September 2013 (Table 3-4). The 31-day period was selected to better reflect a full month's performance. The average recorded daily temperature was $89.5^{\circ} \mathrm{F}$. During the recording period, temperatures rose above $85^{\circ} \mathrm{F}$ on 24 days. The highest outdoor temperature reached during the data collection period was $101.8^{\circ} \mathrm{F}$.

Table 3-4. Overall energy usage of both shelters.

\begin{tabular}{|c|c|c|c|c|c|}
\hline \multirow[b]{2}{*}{ Date } & \multicolumn{2}{|c|}{ Daily Shelter Energy Consumption (kWh) } & \multirow{2}{*}{$\begin{array}{c}\text { Exterior Temp } \\
\left({ }^{\circ} \mathrm{F}\right)\end{array}$} & \multicolumn{2}{|c|}{ Interior Temp $\left({ }^{\circ} \mathrm{F}\right)$} \\
\hline & Enhanced & Control & & Enhanced & Control \\
\hline 4-Aug & 0.20 & 1.36 & 86.21 & 77.29 & 79.39 \\
\hline 5-Aug & 0.20 & 0.33 & 85.40 & 75.85 & 78.95 \\
\hline 6-Aug & 0.33 & 2.29 & 87.80 & 79.79 & 79.39 \\
\hline 7-Aug & 0.42 & 1.18 & 88.17 & 79.88 & 79.66 \\
\hline 8-Aug & 0.20 & 0.32 & 79.74 & 78.21 & 79.44 \\
\hline 9-Aug & 0.20 & 1.76 & 86.57 & 77.90 & 79.22 \\
\hline 10-Aug & 0.29 & 3.10 & 90.52 & 79.83 & 79.26 \\
\hline 11-Aug & 0.25 & 3.18 & 89.69 & 79.79 & 79.35 \\
\hline 12-Aug & 0.56 & 2.92 & 93.05 & 79.88 & 79.44 \\
\hline 13-Aug & 0.20 & 0.33 & 81.51 & 77.90 & 76.20 \\
\hline 14-Aug & 0.20 & 0.32 & 79.96 & 70.59 & 75.77 \\
\hline 15-Aug & 0.20 & 0.32 & 78.95 & 71.92 & 78.12 \\
\hline 16-Aug & 0.20 & 0.51 & 83.51 & 74.94 & 79.35 \\
\hline 17-Aug & 0.20 & 1.27 & 82.89 & 76.46 & 79.48 \\
\hline 18-Aug & 0.20 & 2.78 & 87.76 & 79.48 & 79.30 \\
\hline 19-Aug & 0.94 & 5.02 & 93.38 & 79.88 & 79.44 \\
\hline 20-Aug & 1.20 & 5.64 & 95.33 & 79.83 & 79.44 \\
\hline 21-Aug & 1.62 & 6.14 & 95.66 & 79.88 & 79.66 \\
\hline 22-Aug & 0.35 & 1.76 & 90.24 & 79.70 & 79.30 \\
\hline 23-Aug & 0.57 & 3.25 & 86.53 & 79.88 & 79.44 \\
\hline 24-Aug & 0.87 & 4.50 & 91.45 & 79.61 & 79.35 \\
\hline 25-Aug & 1.30 & 5.79 & 95.09 & 79.83 & 79.57 \\
\hline 26-Aug & 2.50 & 8.39 & 98.43 & 79.88 & 80.32 \\
\hline 27-Aug & 2.89 & 9.04 & 97.40 & 80.36 & 80.05 \\
\hline 28-Aug & 3.00 & 10.18 & 98.33 & 80.54 & 84.18 \\
\hline 29-Aug & 0.84 & 3.24 & 88.44 & 79.88 & 79.57 \\
\hline 30-Aug & 3.15 & 11.04 & 101.36 & 79.83 & 81.51 \\
\hline 31-Aug & 2.41 & 8.10 & 101.81 & 80.05 & 82.71 \\
\hline 1-Sep & 0.39 & 2.07 & 87.07 & 79.88 & 79.48 \\
\hline 2-Sep & 0.21 & 2.21 & 90.33 & 79.04 & 79.30 \\
\hline 3-Sep & 0.20 & 1.04 & 83.02 & 75.85 & 79.30 \\
\hline
\end{tabular}




\subsubsection{Control Shelter}

The Control Shelter used a total of $109.4 \mathrm{kWh}$ for the 31-day study period. Its peak usage of $11.4 \mathrm{kWh}$ occurred on 30 August when the exterior temperature reached $101.4^{\circ} \mathrm{F}$. Figure 3-4 shows the Control Shelter's energy performance and the average daily outdoor temperature.

\subsubsection{Enhanced Shelter}

The Enhanced Shelter used a total of $26.3 \mathrm{kWh}$ for the 31-day study period. Its peak usage of $3.15 \mathrm{kWh}$ was on 30 August when the exterior temperature reached $101.4{ }^{\circ} \mathrm{F}$. Figure 3-5 shows the Enhanced Shelter's energy performance and the average daily outdoor temperature.

\subsubsection{Total energy usage}

The combined energy usage for both shelters during this cooling period totaled $135.7 \mathrm{kWh}$. The Enhanced Shelter's total electrical energy use was $26.3 \mathrm{kWh}$. The Control Shelter's total electrical energy use was $109.4 \mathrm{kWh}$. Building enhancements reduced energy consumption by $83.1 \mathrm{kWh}$. Figure 3-6 plainly shows the recorded exterior temperatures and the daily energy consumption of the two shelters.

Assuming the Illinois average retail price for electricity $(\$ 0.0913 \mathrm{kWh})$ (EIA 2014) was used to calculate the electrical utility purchase cost, the Control Shelter HVAC unit's $109.4 \mathrm{kWh}$ total energy consumption would cost \$9.99. Similarly, the Enhanced Shelter HVAC unit, which used a total of $26.3 \mathrm{kWh}$, would cost $\$ 2.40$. By comparison, the building enhancements reduced energy consumption in the Enhanced Shelter by $83.1 \mathrm{kWh}$ at a savings of $\$ 7.59$ for this 31-day period.

If annual cooling season consumption is extrapolated from this monthly consumption, the Control Shelter would consume $437.6 \mathrm{kWh}$ annually, at a cost of $\$ 39.96$, while the Enhanced Shelter would consume $105.2 \mathrm{kWh}$, at a cost of only $\$ 9.60$. 
Figure 3-4. Control Shelter S2 energy consumption.

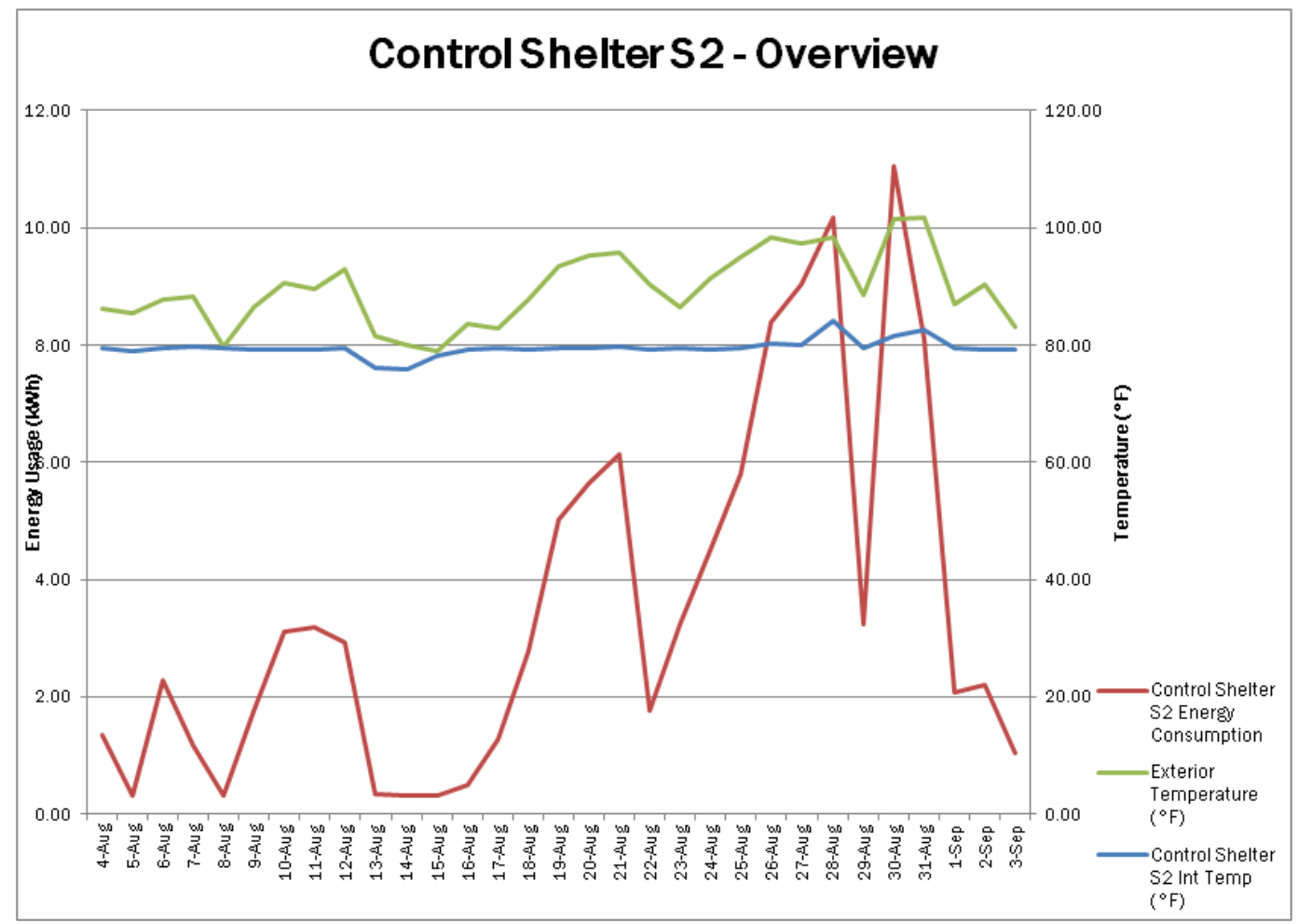

Figure 3-5. Enhanced Shelter-S1 energy consumption.

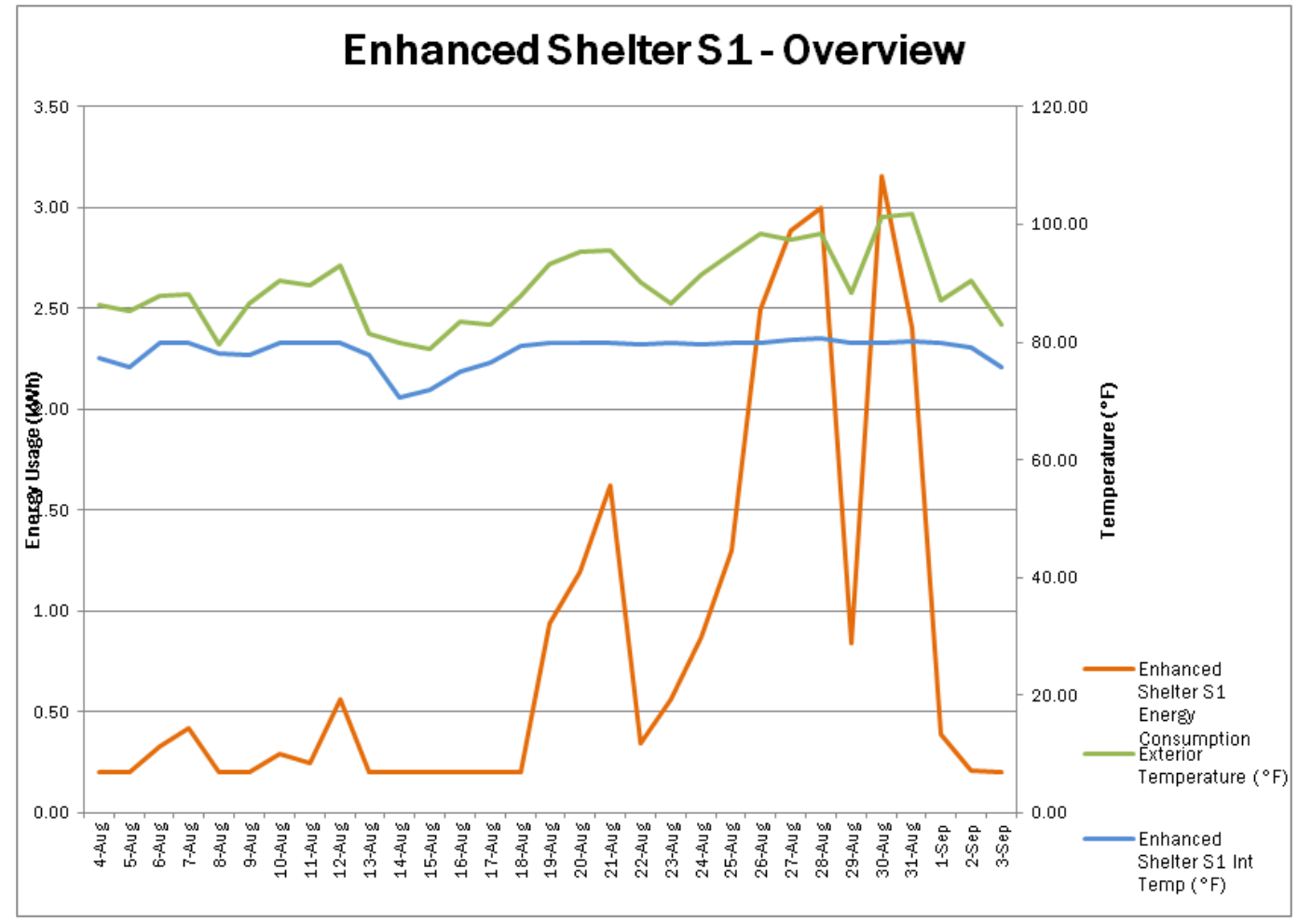


Figure 3-6. Energy consumption overview.

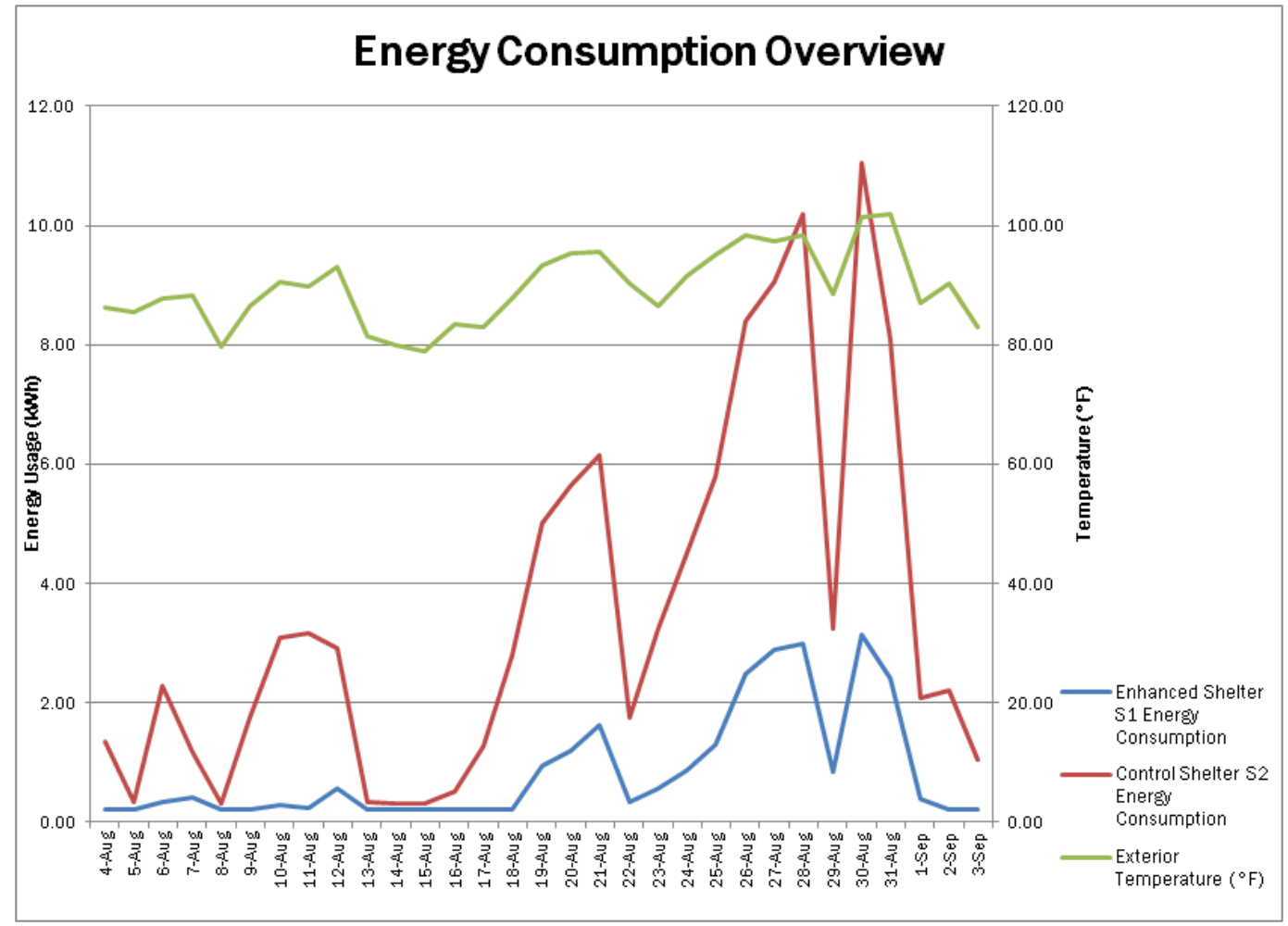

However, more realistic field conditions generally fall into one of three following energy supply scenarios. As described in the Report of the Defense Science Board on More Capable Warfighting through Reduced Fuel Burden (Truly and Alm 2001), the overall energy cost expenses are dependent of the geospatial fuel delivery location. For transportation logistics, a conservative estimate for the cost of fuel for vehicles used to travel short distances is about \$10.00 per gallon. The cost of fuel for overland truck transport can be up to $\$ 10$ per gallon and as much as $\$ 400$ per gallon if the fuel must be delivered by air. These fuel cost scenarios drastically change the overall monthly energy cost expenses picture. For moderate fuel supply transportation distances ( $\$ 10.00$ per gallon) for a typical Control Shelter HVAC unit, a monthly fuel cost could potentially be:

$$
\begin{gathered}
\text { Cost }(\$ / \text { month })=109.4 \mathrm{kWh}\left|\frac{\$ 10.00}{\mathrm{gal}}\right|\left(\left|128,488 \frac{\text { Btu }}{\mathrm{gal} \text { diesel }}\right|\left|2.93 \times 10^{-4} \frac{\mathrm{kWh}}{\text { Btu }}\right|(0.35 \text { eff })\right)^{-1} \\
\operatorname{Cost~} \$ / \text { month })=109.4 \mathrm{kWh}\left|\frac{\$ 10.00}{\mathrm{gal}}\right|\left(\left|37.6470 \frac{\mathrm{kWh}}{\mathrm{gal}}\right|(0.35 \text { eff })\right)^{-1} \\
\operatorname{Cost~}(\$ / \text { month })=109.4 \mathrm{kWh}\left|\frac{\$ 10.00}{\mathrm{gal}}\right|\left(\left|13.18 \frac{\mathrm{kWh}}{\mathrm{gal}}\right|\right)^{-1}
\end{gathered}
$$




$$
\begin{gathered}
\text { Cost }(\$ / \text { month })=109.4 k W h\left|\frac{\$ 10.00}{g a l}\right|\left|0.07589 \frac{g a l}{k W h}\right| \\
\text { Cost }=\$ 83.03 / \text { month }
\end{gathered}
$$

Assuming:

diesel energy volumetric density $=128,488 \mathrm{Btu}$ diesel $\mathrm{gal}$ a typical electric generator fuel to electricity efficiency 0f $35 \%$ the Btu to $\mathrm{kWh}$ conversion factor is $2.93 \times 10^{-4} \mathrm{kWh} / \mathrm{Btu}$.

Table 3-5 lists the estimated fuel costs for the different fuel supply scenarios.

Table 3-5. Fuel cost expenses according to contingency fuel supply scenarios for Control and

\begin{tabular}{|c|c|c|c|c|}
\hline Contingency Fuel Supply Scenario & $\begin{array}{l}\text { Fuel Cost } \\
\text { (\$/gallon) }\end{array}$ & $\begin{array}{l}\text { Estimated } \\
\text { Fuel Cost } \\
\text { (\$/month) }\end{array}$ & $\begin{array}{l}\text { Annual Fuel } \\
\text { Cost }(\$ / y r)\end{array}$ & $\begin{array}{c}\text { Yearly } \\
\text { Savings } \\
(\$ / y r)\end{array}$ \\
\hline Control Shelter, Moderate Distance & \multirow[t]{2}{*}{$\$ 10$} & $\$ 83$ & $\$ 332$ & \multirow[t]{2}{*}{$\$ 252$} \\
\hline Enhanced Shelter, Moderate Distance & & $\$ 19$ & $\$ 79$ & \\
\hline Control Shelter, Overland Long Distance & \multirow[t]{2}{*}{$\$ 45$} & $\$ 373$ & $\$ 1,494$ & \multirow[t]{2}{*}{$\$ 1,134$} \\
\hline Enhanced Shelter, Overland Long Distance & & $\$ 89$ & $\$ 359$ & \\
\hline Control Shelter, Air Long Distance & \multirow[t]{2}{*}{$\$ 400$} & $\$ 3,320$ & $\$ 13,281$ & \multirow[t]{2}{*}{$\$ 10,088$} \\
\hline Enhanced Shelter, Air Long Distance & & $\$ 798$ & $\$ 3,192$ & \\
\hline
\end{tabular}
Enhanced Shelter.

It cannot be overemphasized that these energy consumption costs are subject to: (1) climate region zone, and (2) additional shelter use (plug loads, etc.) by the soldier. Additional sources of energy consumption and extreme climate locations can expose the shelter to even higher energy expenses.

Note that these calculation of costs and energy savings of individual shelters in isolation do not factor in other pertinent issues that must be considered:

- reduction in fuel consumption where the avoided transportation and reduction in generation requirements are critical at contingency bases

- potential carbon taxes

- reduction in greenhouse gas emissions and lower carbon footprint

- increasing useful life of HVAC units

- occupant comfort

- the potential use of other enhancement materials that may provide a better investment return

- the cost of lives lost hauling fuel, i.e., in fuel resupply convoys. 


\section{Detailed Energy Performance Analysis}

As part of this project, ORNL is documenting the energy performance of the enhanced B-hut and the baseline B-hut by monitoring and analyzing energy use in EFOB-L's two co-located B-huts. The huts are monitored unoccupied, with no internal load. ORNL completed its instrumentation of the B-huts and installation of the onsite weather station in September 2013 and the performance data have been collected since then.

Detailed EnergyPlus (U.S. Department of Energy [DOE] EnergyPlus Energy Simulation Software) models of these huts are being developed and calibrated and simulation results are being validated against the fieldmeasured data. Validated models will be used to estimate performance of these huts at other operating conditions, internal load, occupancy schedule, and locations. Savings achieved through envelope upgrade techniques, such as the use of insulation on walls, attic, and floor, and reduced infiltration by sealing joints, can be quantified through the EnergyPlus simulation. ORNL is assisting ERDC-CERL in evaluating the performance of the enhanced B-hut for potential widespread implementation of the improved design features in the DoD. Complete results will be reported in a future ORNL report to be submitted to ERDC-CERL in September 2015.

\subsection{Analysis of each heating and cooling equipment used to maintain the desired indoor conditions}

Various HVAC systems were tested in these huts to evaluate their performance. Initially Chigo mini-split units were used, but those units could not maintain desired indoor conditions during the winter of 2013-2014. Therefore, electrical resistance heaters were used during that time period. Chigo units were again used in the 2014 summer. The HVAC system was then switched to IECUs in winter 2014 to be able to compare the performance of B-hut with the improved system with the performance of a co-located SIP-hut on the EFOB-L site. Specifications of the HVAC systems were described earlier in Chapter 2.

Until permanent power lines were connected in December 2014, power supply to the test site was provided either through temporary extension lines connected to a nearby electrical shack or through electric generators. Power supply was interrupted frequently during that time, intermittent breaks in data collection. Moreover, each time the power supply was interrupted, the solar tracker had to be reset. Therefore, specific time periods 
(listed in Table 4-1) were selected for calibration of EnergyPlus models and for validation of simulation results against measured data for each HVAC equipment when the power supply was uninterrupted, HVAC equipment were running on both huts, and the solar tracker was functioning properly.

\subsection{Instrumentation and data acquisition system}

ORNL instrumented and installed a data acquisition system in each of the test huts. The huts are equipped with sensors to measure temperature at interior and exterior surfaces; heat flux through each side of the walls, ceiling, and floor; energy use to maintain desired indoor conditions; plug loads; and temperature and relative humidity in the conditioned space, crawlspace, and attic. Three temperature sensors were installed at heights of 2,4 , and $6 \mathrm{ft}$. at the center of the conditioned space on each hut to measure indoor air temperature. Similarly, three temperature sensors were used to measure attic air temperature.

An onsite station is collecting all weather parameters required to create an EnergyPlus weather file to run simulations and to validate models. Table 4-2 lists the performance monitoring instruments and Table 4-3 lists the weather station instruments. An instrument to measure the direct beam solar radiation is mounted on Eppley's automatic SMT solar tracker. A Shade Disk Kit (SDK) is mounted on the SMT tracker to measure diffuse solar radiation using a Black \&White pyranometer. Each sensor reading is scanned every 30 seconds and average values are recorded at 5-minute intervals using a Campbell Scientific micrologger CR3000 (Campbell Scientific 2015) along with multiplexers. Two data files were maintained: one with 5-minute data and a second one with hourly data. Remote access of the data for periodic monitoring and archival is performed through a telephone modem. Each heat flux transducer (HFT) was calibrated at ORNL using a LaserComp Fox-605 heat flux meter (LaserComp 2015). Figure 4-1 shows the data acquisition system (DAQ) and the weather station.

Table 4-1. Periods of data used for validation of EnergyPlus simulation results.

\begin{tabular}{|c|c|c|c|}
\hline Equipment & Operation Mode & Start Date & End Date \\
\hline Chigo & Heating & 29 October 2013 & 31 October 2013 \\
\hline Electric & Heating & 16 April 2014 & 20 April 2014 \\
\hline Chigo & Cooling & 25 August 2014 & 31 August 2014 \\
\hline IECU & Heating & 16 February 2015 & 22 February 2015 \\
\hline IECU & Cooling & 1 June 2015 & 7 June 2015 \\
\hline
\end{tabular}


Table 4-2. Performance monitoring instruments.

\begin{tabular}{|l|l|l|}
\hline \multicolumn{1}{|c|}{$\begin{array}{c}\text { Sensor manufacturer and } \\
\text { model }\end{array}$} & \multicolumn{1}{|c|}{ Parameter measured } & \multicolumn{1}{c|}{ Sensor location } \\
\hline Fenwall 192-103LET-A01 & Temperature & $\begin{array}{l}\text { Exterior and interior surfaces of the } \\
\text { envelope, conditioned space, attic, and } \\
\text { crawlspace }\end{array}$ \\
\hline Honeywell HIH-4000-003 & Relative humidity & Conditioned space, attic, and crawlspace \\
\hline Concept Engineering F-002-4 & Heat flux through envelopes & Walls, roofs, ceiling and floor \\
\hline $\begin{array}{l}\text { Continental Control Systems } \\
\text { WattNode WNB-3Y-208-P }\end{array}$ & Energy use & $\begin{array}{l}\text { Switchgear supplying power to the huts and } \\
\text { IECUs }\end{array}$ \\
\hline
\end{tabular}

Table 4-3. Weather station instruments.

\begin{tabular}{|l|l|}
\hline \multicolumn{5}{|c|}{ Sensor manufacturer and model } & \multicolumn{1}{c|}{ Parameter measured } \\
\hline \multirow{4}{*}{ Vaisala Weather Transmitter WXT520 } & Outdoor air temperature \\
\cline { 2 - 2 } & Outdoor air relative humidity \\
\cline { 2 - 2 } & Wind speed \\
\cline { 2 - 2 } & Wind direction \\
\cline { 2 - 2 } & Rainfall \\
\cline { 2 - 2 } & Barometric pressure \\
\hline Eppley Normal Incidence Pyrheliometer sNIP & Direct beam solar radiation \\
\hline Eppley Black \& White Pyranometer 8-48 & Diffuse solar radiation \\
\hline Eppley Standard Precision Pyranometer SPP & Global horizontal solar radiation \\
\hline Eppley Precision Infrared Radiometer PIR & Infrared radiation from sky \\
\hline Campbell Scientific Li-200 & Solar radiation on B-hut 1 roof surfaces \\
\hline
\end{tabular}

Figure 4-1. Weather station and data acquisition system with remote access capability.
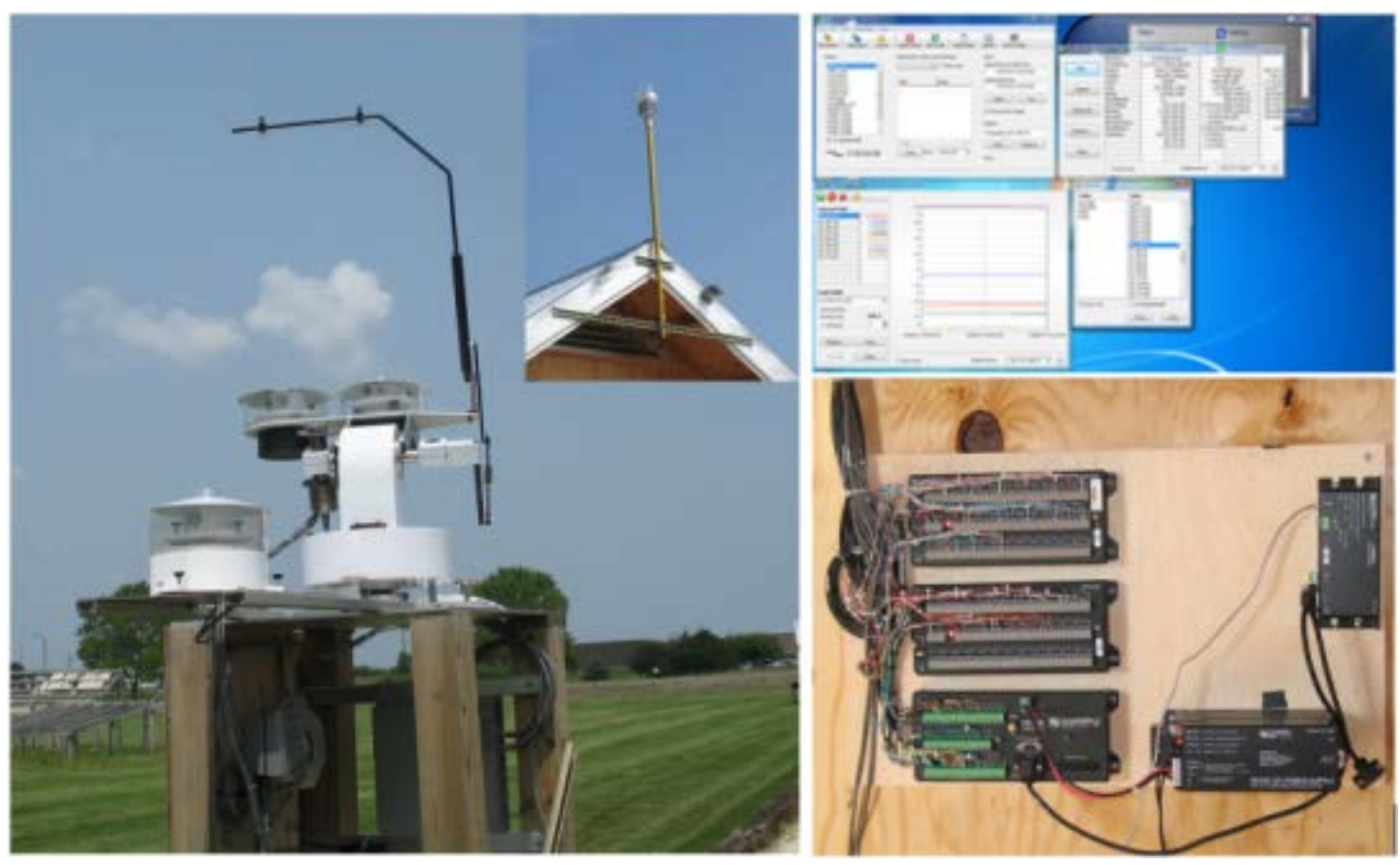
To ensure that the measured solar data were accurate, the direct beam solar radiation measured by the pyrheliometer was compared against the American Society of Heating, Refrigerating, and Air-Conditioning Engineers (ASHRAE) clear sky model (ASHRAE 2013) that is used to predict direct beam solar radiation on a clear sky day. For comparison, Figure 4-2 shows the measured direct beam solar radiation against the predicted values from the ASHRAE clear sky model during a clear sky day. EnergyPlus uses the direct beam and diffuse solar radiation from a weather file along with the location and time to calculate the surface outside face incident solar radiation. Figure 4-3 shows measured global horizontal radiation against surface outside face incident solar radiation on a horizontal surface predicted by EnergyPlus for 16-22 February 15. For comparison, Figure 4-4 similarly lists measured solar radiation on east and west roof surfaces against EnergyPlus calculated values for 16-22 February 15. These comparisons ensure the accuracy of the solar data collected from the onsite weather station.

Figure 4-2. Direct normal solar radiation measured at weather station and estimated with the ASHRAE clear sky model.

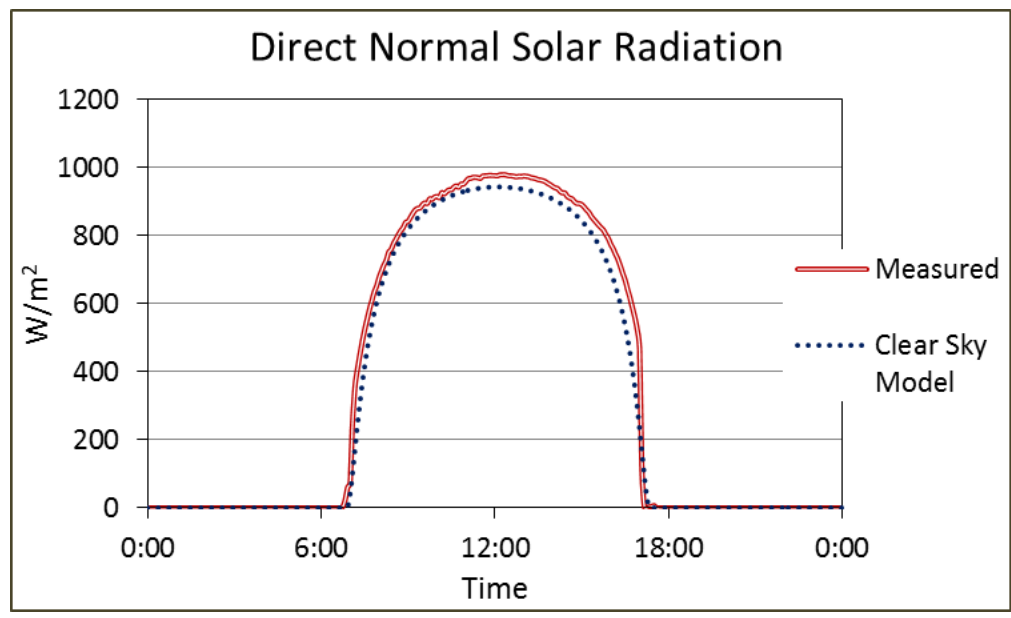

Figure 4-3. Measured global horizontal radiation and EnergyPlus calculated incident solar radiation on a horizontal surface.

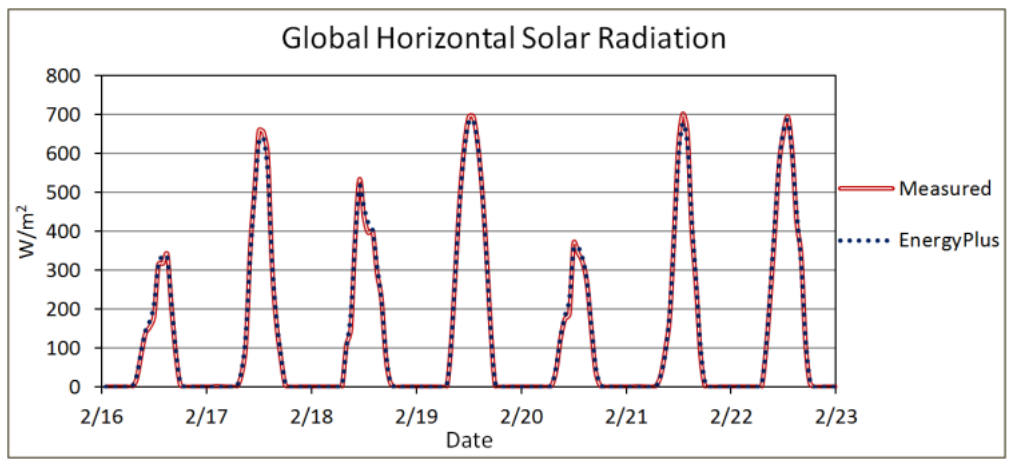


Figure 4-4. Measured and EnergyPlus calculated solar radiation on east and west roof surfaces.

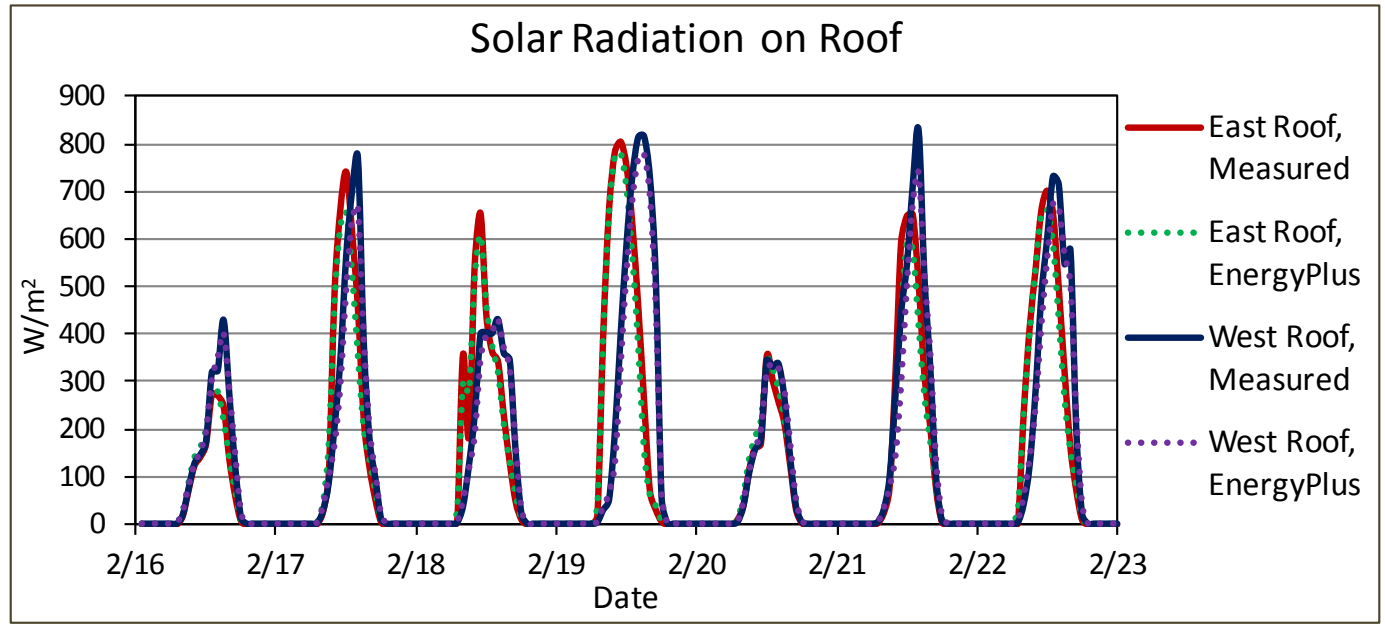

\subsection{EnergyPlus modeling}

It is essential to use accurate material properties to build a good energy simulation model. Thermal and physical properties such as thermal conductivity, specific heat, thickness, density, solar reflectance (SR), and thermal emittance (TE) of building materials were either measured on site, determined by conducting laboratory tests at ORNL, gathered from the ASHRAE Handbook, or obtained from manufacturers' data sheets. Each type of envelope system was then assigned one or more layers of materials based on the actual construction, and each surface was assigned its respective construction, outside boundary condition, and relative geometry. Building geometry was set up using architectural drawings while important parameters such as the exact location of the HFTs, and shading surfaces were verified with field measurements. Figure 4-5 shows renderings of an EnergyPlus model of the B-hut. Each B-hut model has three zones: a conditioned space, an unconditioned attic and an unconditioned crawlspace. Unpainted exterior plywood surfaces that are exposed to weather conditions became discolored over time, which changed its SR values. To evaluate the change, SR of exterior surfaces were measured three times at 10-month intervals, using a Devices and Services Solar Spectrum Reflectometer (DS 2014). Multiple measurements were taken at each side of the walls as SR values widely vary even on the same side of the hut (Figure 4-6). Table 4-4 lists the average values, which indicate a decrease in SR between 26 September 2013 and 2 May 2015 range from 14 to $50 \%$. 
Figure 4-5. Renderings of EnergyPlus model of the B-hut.

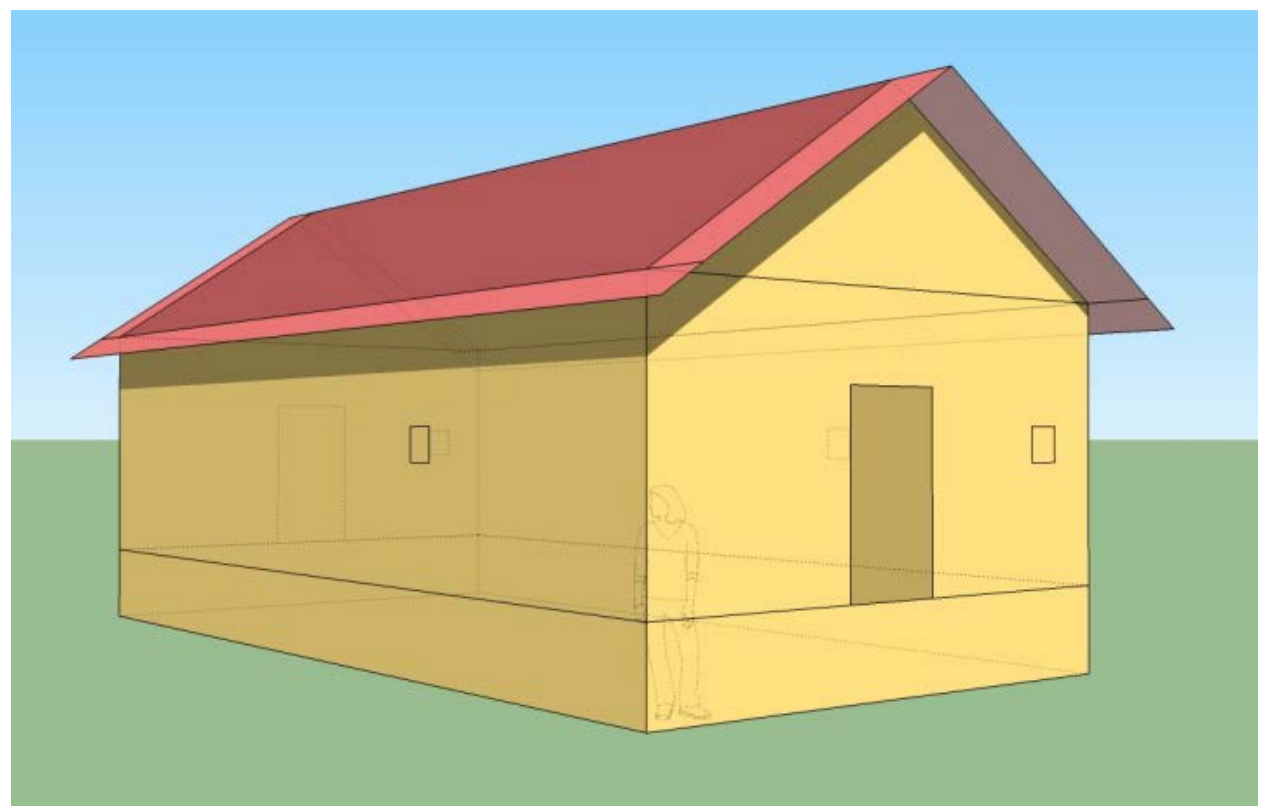

Figure 4-6. Discoloration of the exterior walls (left new, right after 20 months) and wide variation in SR on the same side of the wall (as evidenced by the color difference).
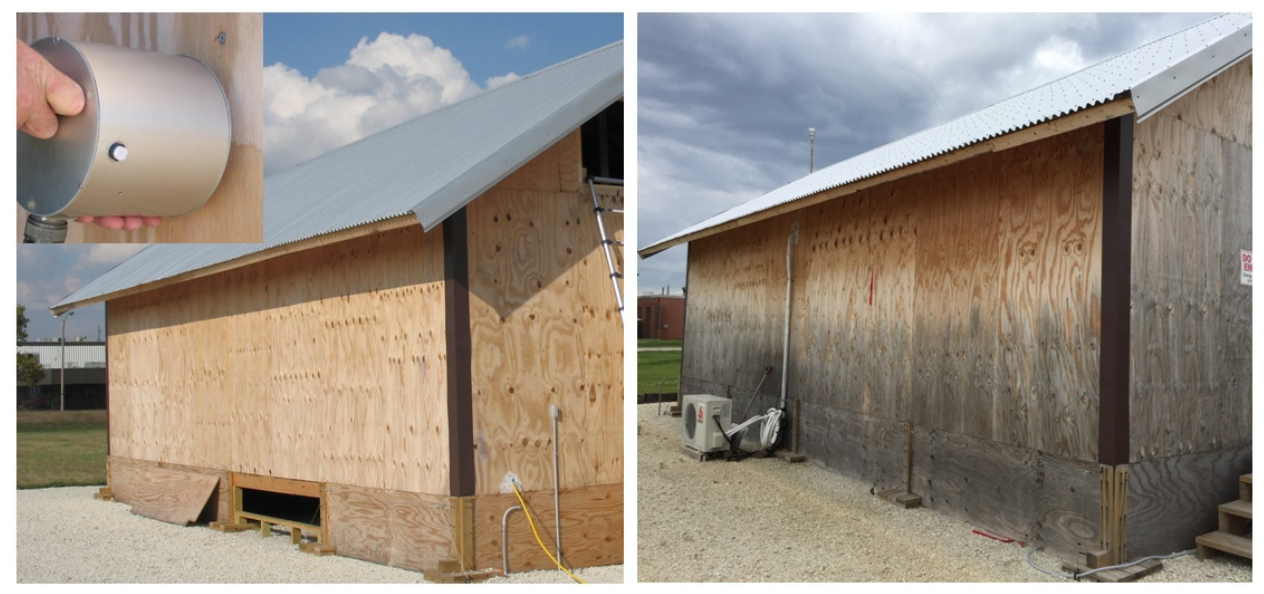

Table 4-4. Average SR of B-hut exterior surfaces.

\begin{tabular}{|c|c|c|c|c|}
\hline \multicolumn{2}{|c|}{$\begin{array}{l}\text { Measurement Date } \\
\text { and Location }\end{array}$} & \multirow{2}{*}{$\begin{array}{c}26 \text { September } \\
2013\end{array}$} & \multirow{2}{*}{$\begin{array}{c}31 \text { July } 2014 \\
0.377 \\
\end{array}$} & \multirow{2}{*}{$\frac{27 \text { May } 2015}{0.309}$} \\
\hline \multirow{4}{*}{ 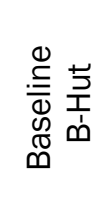 } & South & & & \\
\hline & East & 0.593 & 0.589 & 0.509 \\
\hline & North & 0.593 & 0.65 & 0.432 \\
\hline & west & 0.592 & 0.416 & 0.47 \\
\hline \multirow{4}{*}{ 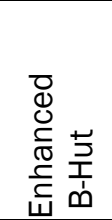 } & South & 0.592 & 0.326 & 0.298 \\
\hline & East & 0.594 & 0.549 & 0.483 \\
\hline & North & 0.593 & 0.594 & 0.457 \\
\hline & west & 0.592 & 0.385 & 0.371 \\
\hline
\end{tabular}


Maximum degradation in SR was observed on the south wall, followed by the west and east walls. This indicates that the change in SR is directly proportional to the amount of incident solar radiation on the surface. The change in SR over time was reflected in EnergyPlus model validations using appropriate SR values from Table 4-4 for the dates listed in Table 4-1. Using the Energy Management System (EMS) option in EnergyPlus, SR will be modeled as a function of the day of the year for annual energy simulations.

Effective thermal resistance of the air cavity in the walls of the baseline Bhut is a function of the cavity thickness, TE of the surfaces facing toward the cavity, mean temperature, and the temperature difference between surfaces across the cavity. Table 4-5 lists the relevant data from Section 26 of ASHRAE Handbook of Fundamentals 2013 (ASHRAE 2013), in which the effective R-value of $3.5 \mathrm{in}$. vertical plain air spaces with horizontal heat flow (similar to the configuration in the baseline B-hut) is quantified as a function of mean temperature and temperature difference for effective emittance of 0.82. Fonts in blue color show the effective thermal resistance at a $10^{\circ} \mathrm{F}$ temperature difference that is used in the model.

The Conduction Finite Difference (ConFD) heat balance algorithm was used in EnergyPlus to model the variable effective thermal resistance of the air cavity. ConFD allows modeling of thermal conductivity of a material as a function of mean temperature, but there is no direct way in EnergyPlus to model thermal conductivity or R-value as a function of the temperature difference between surfaces across the cavity, which may cause some difference between simulation predicted and actual heat flow through walls. Conduction transfer function (CTF) heat balance algorithm was used for all other constructions that do not have materials with variable thermal properties.

Table 4-5. Effective thermal resistance of 3.5 in. plane space (ASHRAE 2013).

\begin{tabular}{|c|c|c|}
\hline \multicolumn{2}{|c|}{ Air Space } & $\begin{array}{c}\text { Effective Thermal Resistance, } \\
\text { hean } \text {.t }^{2}{ }^{\circ} \mathrm{F} / \text { Btu }\end{array}$ \\
\hline 90 & ${\text { Temperature Difference, }{ }^{\circ} \mathrm{F}}^{\circ}$ & 0.85 \\
\hline 50 & 10 & 0.91 \\
\hline 50 & 30 & 1.01 \\
\hline 0 & 10 & 1.14 \\
\hline 0 & 20 & 1.23 \\
\hline-50 & 10 & 1.37 \\
\hline-50 & 20 & 1.50 \\
\hline
\end{tabular}


Figure 4-7. Typical methods used to mount HFTs to measure heat flux through building envelope.

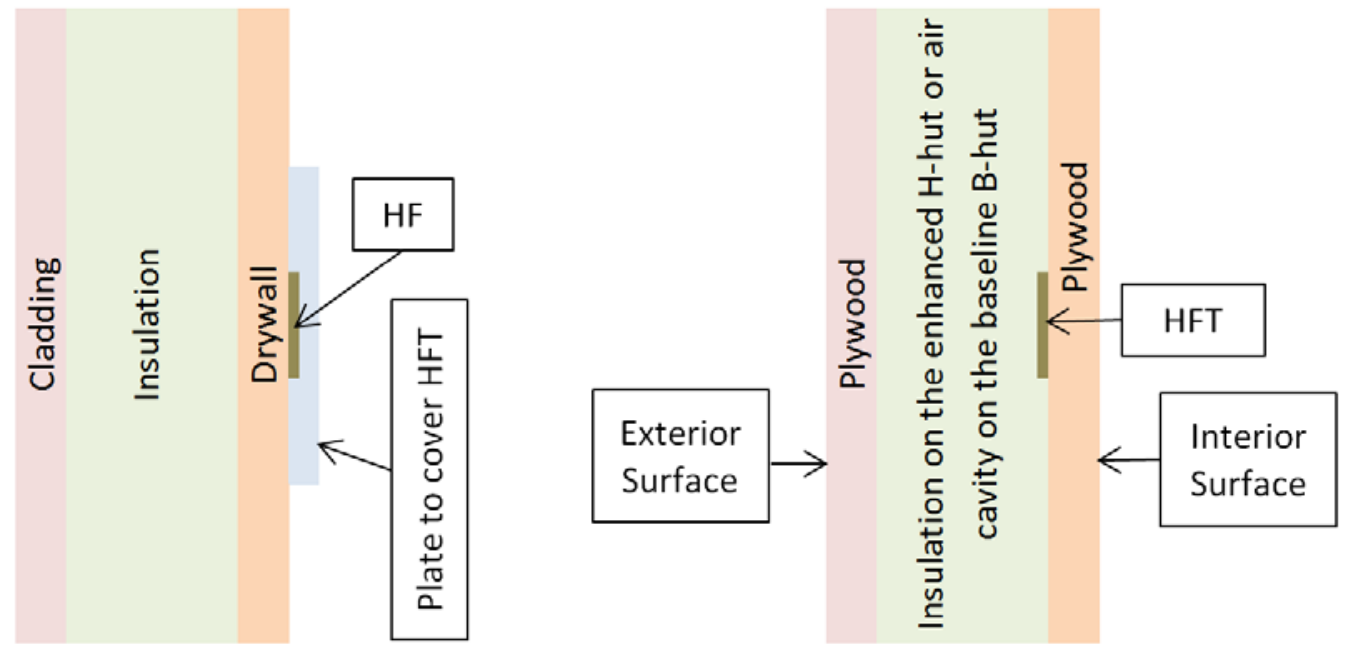

The commonly used method to validate simulation predicted heat flux through an opaque building envelope is to compare simulation results against field-measured heat flux. HFTs (thermopile mounted across a thin material with known thermal conductivity) are used to measure heat flux through the wall. Typically, HFTs are either attached on the interior surface of the wall and then covered with a grooved plate to fit the heat flux sensor (Figure 4-7, left) or attached on interior drywall (or plywood) surface facing toward the insulation (Figure 4-7, right).

When an HFT is mounted on an interior surface exposed to the indoor environment, it is essential to cover the heat flux sensor to avoid the surface temperature disruption problem. At the baseline B-hut walls, HFTs are attached on interior plywood surfaces facing toward the air cavity. At the enhanced B-hut walls, HFTs are attached on interior plywood surfaces facing toward the insulation (Figure 4-7, right). In both cases HFTs are installed halfway between studs to measure the heat flux through the wall section with minimal effect from the studs. HFTs are also installed on the floor and on the ceiling. The exact location of each HFT and wall configuration was used in the EnergyPlus model.

The current version of EnergyPlus can calculate and output heat flux at an exterior surface (facing the outdoor weather) or an interior surface (facing the conditioned space) of a wall, but not at the interface between layers where HFTs are installed. Therefore, there is no way to directly compare simulation predicted heat flux with measured heat flux. It would be possible to directly compare simulation predicted heat flux against measured 
data if the simulation program could calculate heat flux at the interface between materials layers where heat flux is measured. A request submitted to DOE to add capability to report node-to-node heat flux in EnergyPlus has been accepted. It is expected that the new feature will be added by August 2015 and will be used for the final ORNL B-hut report to ERDCCERL, which will be submitted in September 2015.

As a temporary solution, simulations were performed using COMSOL (finite element analysis, solver and simulation software) in combination with field-measured surface temperature and materials properties. EnergyPlus calculated heat flux at interior surfaces is compared with COMSOL calculated heat flux at interior surfaces. Measured heat flux was then compared with COMSOL calculated heat flux at the plane where HFTs were located.

EnergyPlus assumes one-dimensional heat transfer. It is desirable to develop a thermally equivalent wall description (ASHRAE 1145-TRP) in the EnergyPlus model to account for the thermal bridging effect caused by framing when performing whole-building energy analysis. However, the thermally equivalent wall cannot be used to compare EnergyPlus simulation results against the heat flux measured by HFTs. This is because the equivalent wall predicts average heat flux for the whole wall, whereas the HFTs installed in the huts measure the heat flux through a small section of the wall, which is practically unaffected by the studs.

Among the various modes of heat transfer, radiation is the predominant mode of heat transfer in typical building attics, particularly during summer months. Accurate calculation of view factor (that determines the proportion of the radiative heat transfer which leaves surface $A$ and strikes surface B) between the surfaces facing the attic is therefore essential to calculate radiation heat exchange. EnergyPlus has two options for specifying the thermal radiation exchange view factors between surfaces in a zone: the approximate option and the user input option. The first option produces approximate results and uses an area-weighted scheme to calculate "view factors" between surfaces within a thermal zone. Table 4-6 lists the EnergyPlus calculated view factors using an area-weighted scheme and Table 4-7 lists the exact view factors calculated using attic simulation program AtticSim developed at ORNL. The "exact view factor" between the surfaces facing the attic was used in B-hut models using the ZoneProperty:UserViewFactors:bySurfaceName object in EnergyPlus. 
Table 4-6. EnergyPlus calculated view factors using an area-weighted scheme.

\begin{tabular}{|l|c|c|c|c|c|}
\hline \multicolumn{1}{|c|}{$\mathrm{F}(\mathrm{I}, \mathrm{J})$} & $\mathrm{J}=$ Floor & $\mathrm{J}=$ East Roof & $\mathrm{J}=$ West Roof & $\mathrm{J}=$ North Gable & $\mathrm{J}=$ South Gable \\
\hline I = Floor & 0.0000 & 0.4469 & 0.4469 & 0.0528 & 0.0528 \\
\hline I = East Roof & 0.7437 & 0.0000 & 0.2087 & 0.0240 & 0.0240 \\
\hline I = West Roof & 0.7437 & 0.2087 & 0.0000 & 0.0240 & 0.0240 \\
\hline I = North Gable & 0.6339 & 0.1734 & 0.1734 & 0.0000 & 0.0196 \\
\hline I = South Gable & 0.6339 & 0.1734 & 0.1734 & 0.0196 & 0.0000 \\
\hline
\end{tabular}

Table 4-7. Exact view factor used in B-hut models.

\begin{tabular}{|l|l|l|l|l|l|}
\hline \multicolumn{1}{|c|}{$\mathrm{F}(\mathrm{I}, \mathrm{J})$} & $\mathrm{J}=$ Floor & $\mathrm{J}=$ East Roof & $\mathrm{J}=$ West Roof & $\begin{array}{c}\mathrm{J}=\text { North } \\
\text { Gable }\end{array}$ & $\begin{array}{c}\mathrm{J}=\text { South } \\
\text { Gable }\end{array}$ \\
\hline I = Floor & 0.0000 & 0.4652 & 0.4652 & 0.0348 & 0.0348 \\
\hline I = East Roof & 0.7741 & 0.0000 & 0.1470 & 0.0395 & 0.0395 \\
\hline I = West Roof & 0.7741 & 0.1470 & 0.0000 & 0.0395 & 0.0395 \\
\hline I = North Gable & 0.4181 & 0.2846 & 0.2846 & 0.0000 & 0.0127 \\
\hline I = South Gable & 0.4181 & 0.2846 & 0.2846 & 0.0127 & 0.0000 \\
\hline
\end{tabular}

Infiltration is an important contributor to conditioning load. ERDC-CERL conducted blower door tests to characterize leakage in all huts. Table 4-6 lists the blower door tests' summary results. ORNL conducted tracer gas tests to measure air change rate during normal operating conditions when HVAC units are on. The next section discusses the use of tracer gas test data to adjust coefficients used to simulate air leakage in EnergyPlus.

Infiltration was modeled using the ZoneInfiltration:FlowCoefficient object in EnergyPlus, which is based on the AIM-2 model by Walker and Wilson (1998) and is appropriate for smaller, residential-type buildings. This method calculates infiltration as a function of difference between zone air temperature and the outdoor air temperature, wind speed, flow coefficient, stack coefficient, pressure exponent, wind coefficient, and shelter factor. Flow coefficient and pressure exponent are determined from blower door test data. Stack coefficient ( 0.054 for a one story house with no flue), wind coefficient ( 0.128 for a one story house with crawlspace and no flue), and shelter factor ( 0.9 for a typical shelter with no flue) are obtained from the "Enhanced Model Stack Coefficient" listed in the ASHRAE Handbook of Fundamentals (ASHRAE 2013).

Exact latitude and longitude of the building location are essential inputs for the solar tracker to track the sun and for EnergyPlus to calculate incident solar radiation on exterior surfaces and shading. The values obtained from latlong.net for the EFOB-L site are latitude 40.15 degrees, Longitude -88.27 degrees, and elevation $700 \mathrm{ft}$. 


\subsection{Predicted vs. field-measured data and validation of EnergyPlus models}

It is essential to validate building energy models by comparing simulation results against field-measured data to ensure that the models are representative of the actual buildings and that the simulation results are meaningful. Heat flow through the building envelope and air leakage are the two major sources of HVAC load at the B-huts. Therefore, validation of Ener-

gyPlus simulation results are focused mainly on those two parameters and the HVAC energy use. Validation examples of the baseline and enhanced B-hut models for the periods described in the Table 4-1 are discussed below. EnergyPlus weather files (EPW) were created using weather data collected by the onsite weather station and used for the validation study.

\subsubsection{Chigo}

\subsubsection{Chigo in heating mode}

Chigo mini-split units were tested first, as they are commonly used in contingency bases. Data collected from 29 to 31 October 2013 are used to compare EnergyPlus predicted heating load against Chigo energy use. All discussion in this section references this test period. Figure 4-8 shows outdoor air temperature and relative humidity. Figure 4-9 shows direct beam and diffuse solar radiation during that period. The data in these figures indicate that these were completely cloudy days with high humidity. Outdoor air temperature was between 36.4 and $65.5^{\circ} \mathrm{F}$, with an average value of $54.5^{\circ} \mathrm{F}$. For comparison, Figure $4-10$ shows the conditioned space air temperature at the two huts, which shows average temperature in the baseline B-hut was $65.4^{\circ} \mathrm{F}$ and that the temperature in the enhanced B-hut was $68.5^{\circ} \mathrm{F}$, which is $3.1^{\circ} \mathrm{F}$ higher than the baseline B-hut temperature. For comparison, Figures 4-11 and 4-12 show measured (solid lines) and EnergyPlus predicted (dotted lines) exterior wall surface temperature for the baseline B-hut and the enhanced B-hut, respectively. As these were completely cloudy days, temperature at all sides of the exterior walls were almost the same and EnergyPlus predicted surface temperature match with the measured temperature. 
Figure 4-8. Outdoor air temperature and relative humidity

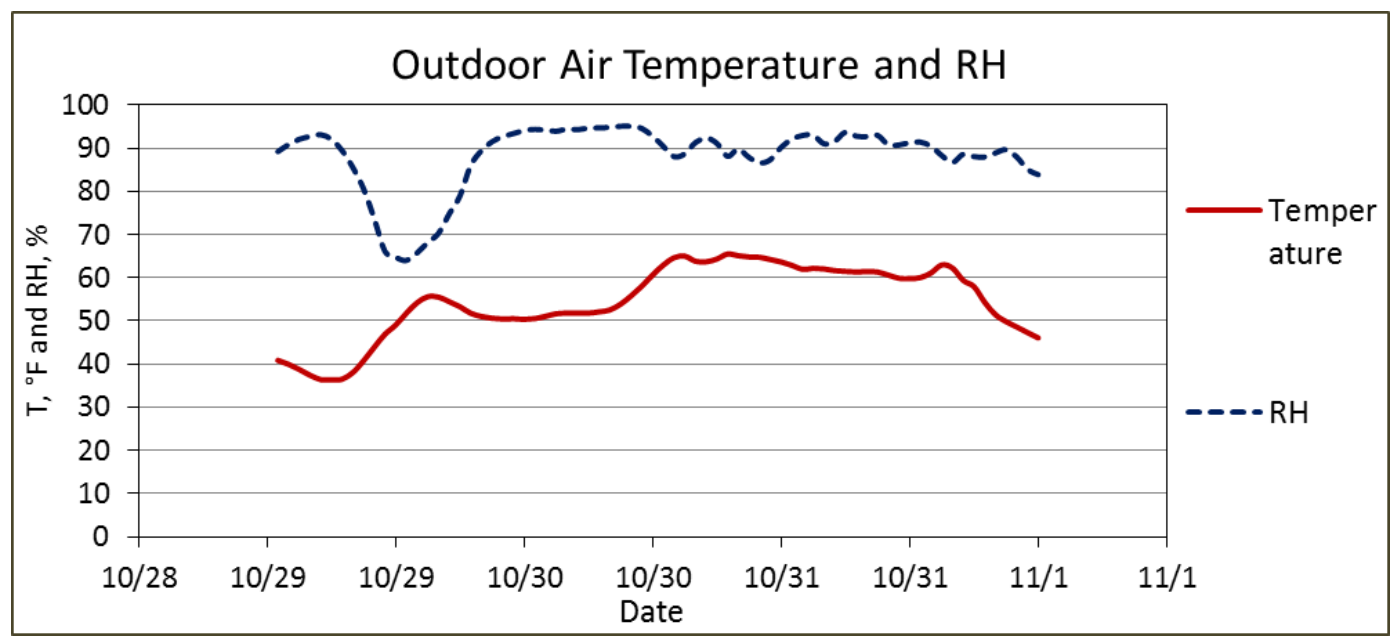

Figure 4-9. Solar radiation.

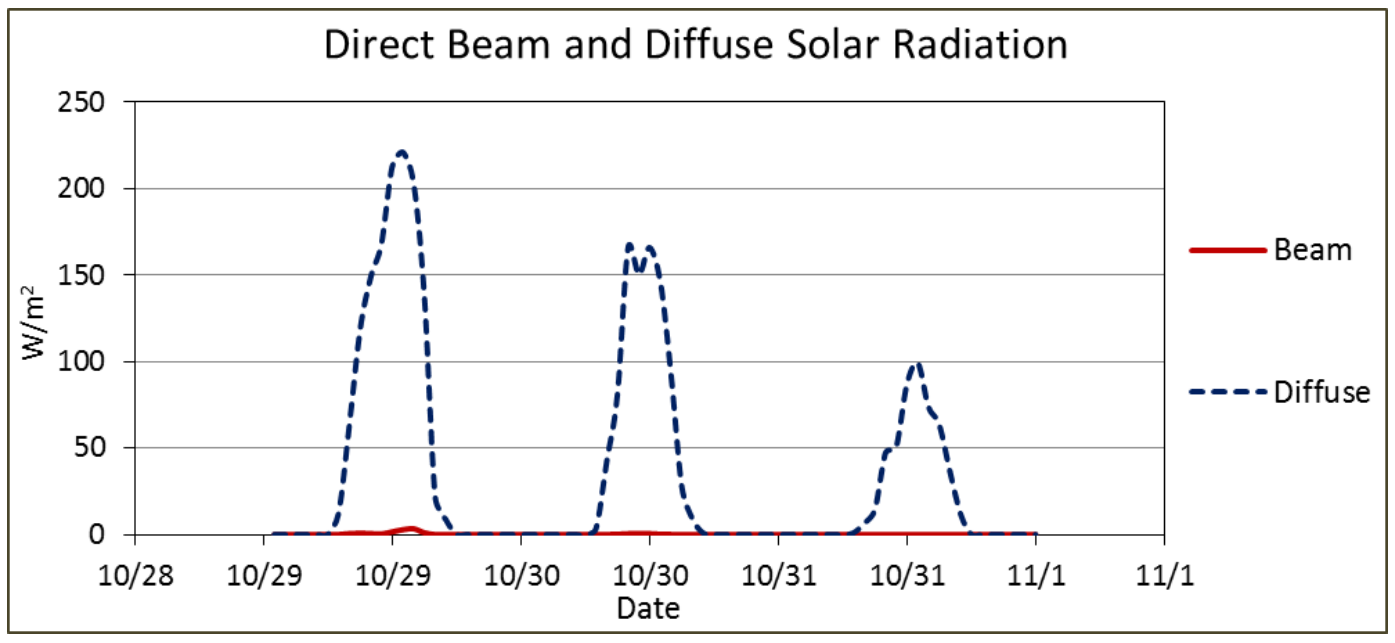

Figure 4-10. Conditioned space air temperature

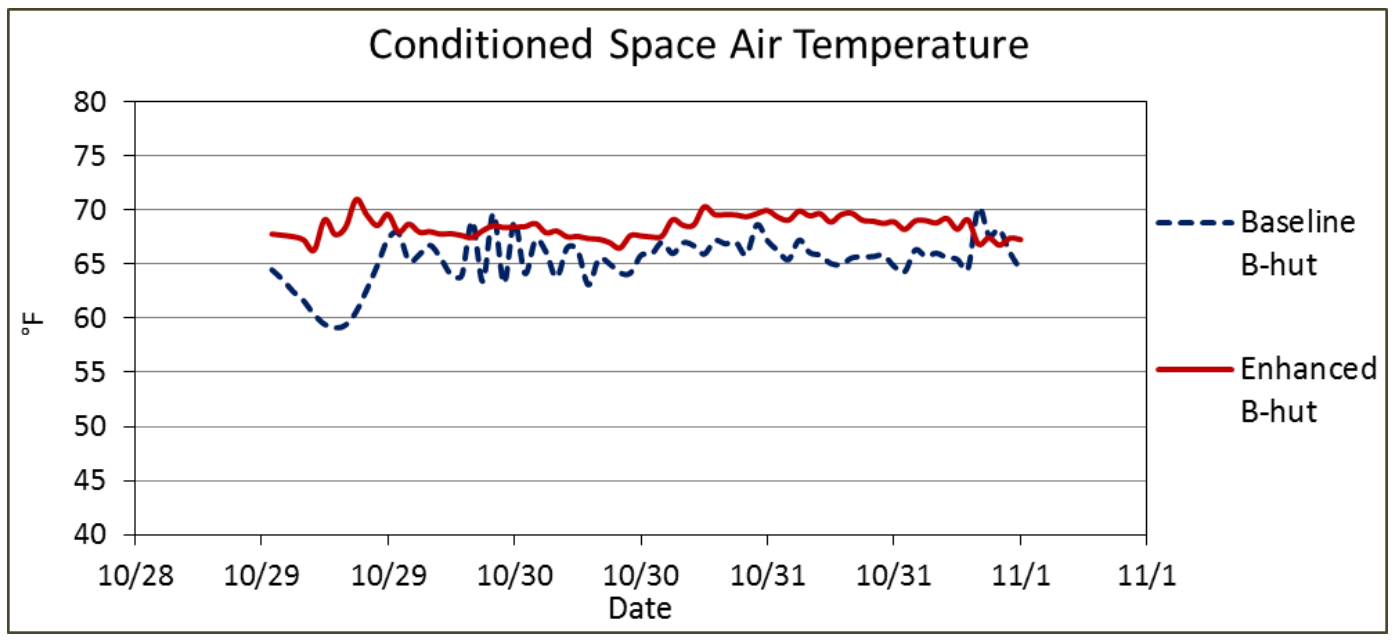


Figure 4-11. Comparison between measured (solid lines) and EnergyPlus predicted (dotted lines) exterior surface temperature for the baseline B-hut

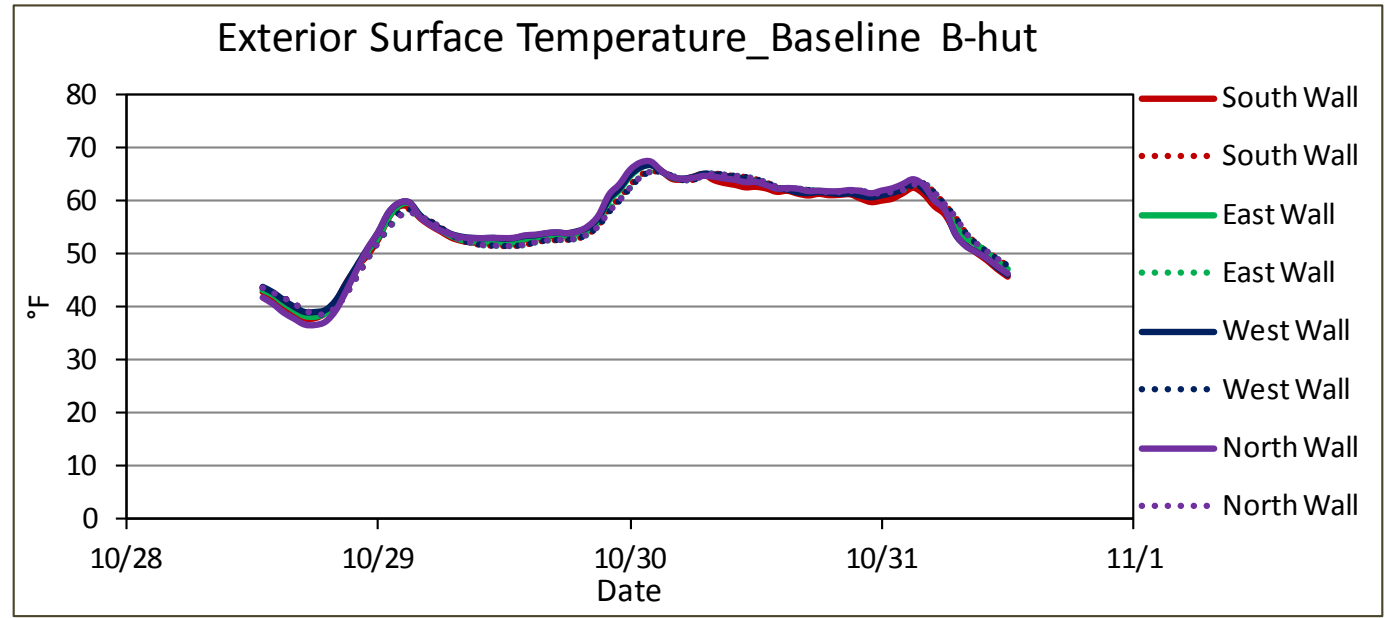

Figure 4-12. Measured (solid lines) and EnergyPlus predicted (dotted lines) exterior surface temperature for the enhanced B-hut

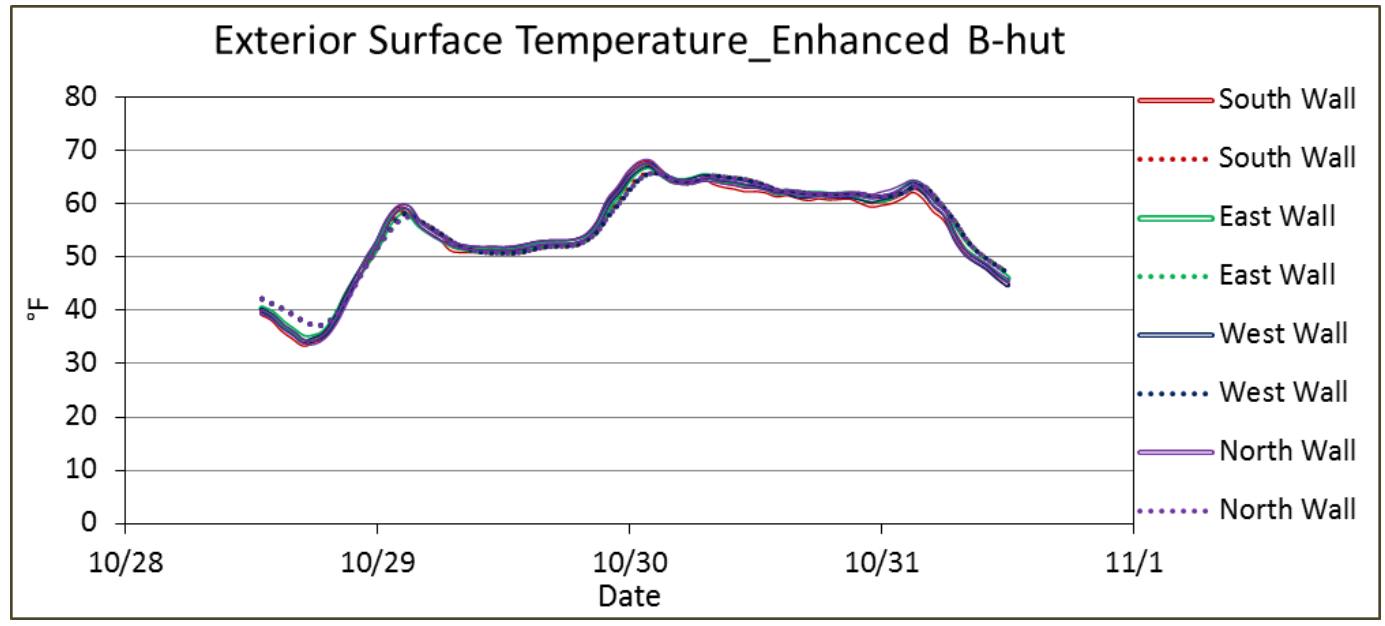

The SurfaceConvectionAlgorithm:Inside object is used in EnergyPlus to control the choice of models used for surface convection at the inside face of all the heat transfer surfaces in the model. The key choices are: Simple, TARP, ${ }^{*}$ CeilingDiffuser, and AdaptiveConvectionAlgorithm. The Simple model applies constant heat transfer coefficients depending on the surface orientation. The TARP model correlates the heat transfer coefficient to the temperature difference for various orientations based on flat plate experiments. The CeilingDiffuser model is a mixed and forced convection model for ceiling diffuser configurations. The AdaptiveConvectionAlgorithm

* Thermal Analysis Research Program 
model is a dynamic algorithm that organizes a large number of different convection models and automatically selects the one that best applies.

Initially the TARP, which is EnergyPlus default object to model inside surface convection coefficients, was used. For comparison, Figure 4-13 shows measured (solid lines) and EnergyPlus predicted (dotted lines) interior surface temperature when the TARP SurfaceConvectionAlgorithm:Inside object was used for the baseline B-hut. As can be seen from the figure, The EnergyPlus predicted interior surface temperature is much lower than the measured values, and the fluctuation in the surface temperature due to the fluctuation in indoor air temperature is not well tracked (see Figure 4-10). Clearly, the convection coefficient calculated by EnergyPlus is lower than the actual values.

Next, all other SurfaceConvectionAlgorithm:Inside objects available in EnergyPlus were tried. The CeilingDiffuser object, which showed itself to be the best of the SurfaceConvectionAlgorithm:Inside objects, gave minimum error between measured and EnergyPlus predicted interior surface temperature for this test. This object was used for all the models discussed hereafter. For comparison, Figures 4-14 and 4-15 show measured (solid lines) and EnergyPlus predicted (dotted lines) interior surface temperature when the CeilingDiffuser SurfaceConvectionAlgorithm:Inside object was used for the baseline and enhanced B-huts, respectively.

Figure 4-13. Measured (solid lines) and EnergyPlus predicted (dotted lines) interior surface temperature when TARP SurfaceConvectionAlgorithm:Inside object was used for the baseline B-hut

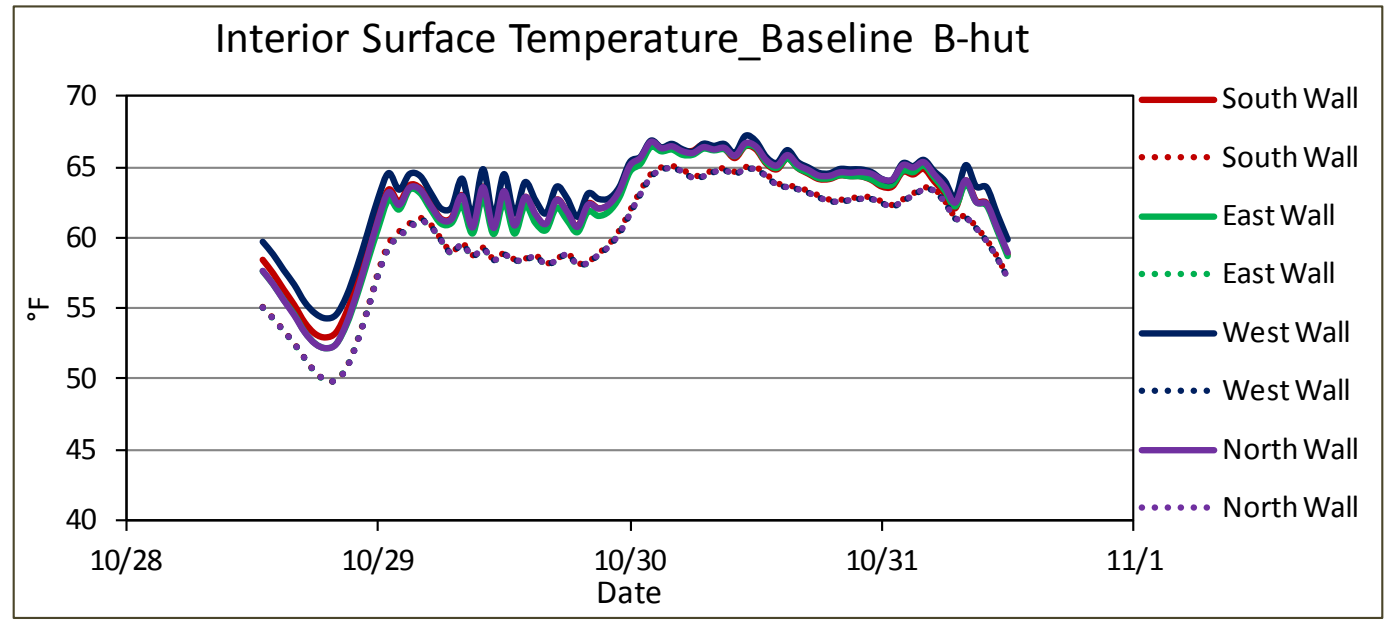


Figure 4-14. Measured (solid lines) and EnergyPlus predicted (dotted lines) interior surface temperature when CeilingDiffuser SurfaceConvectionAlgorithm:Inside object was used for the baseline B-hut

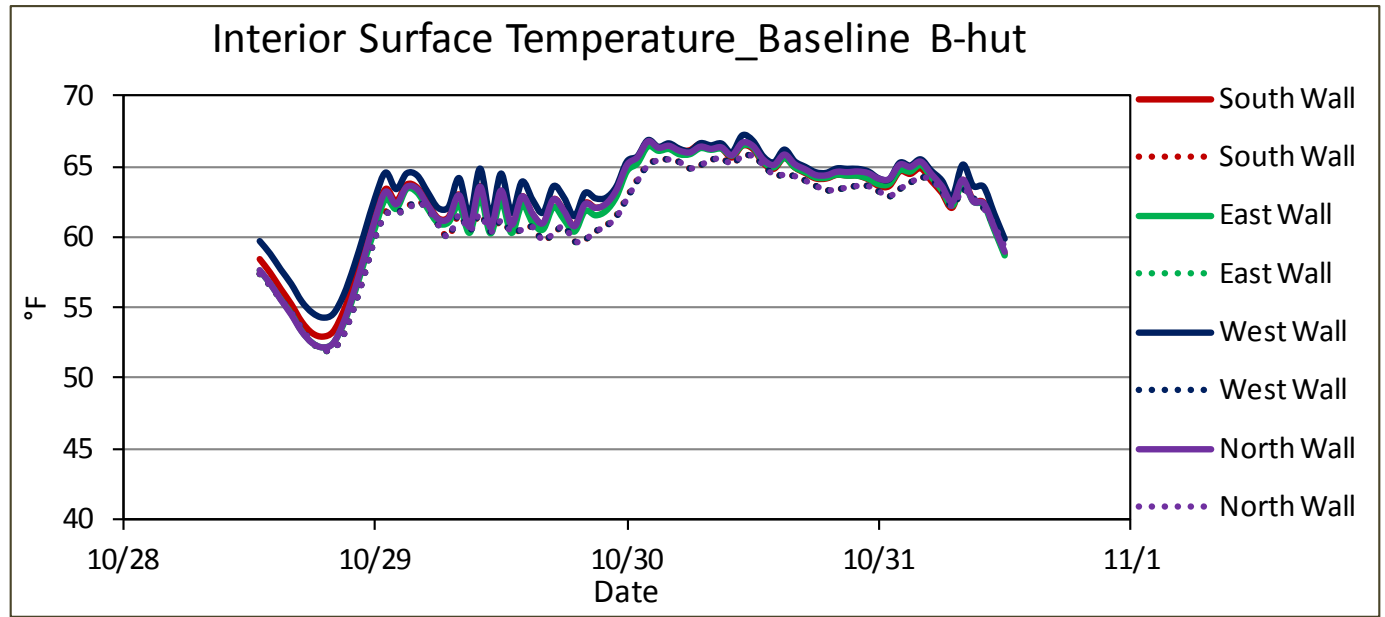

Figure 4-15. Measured (solid lines) and EnergyPlus predicted (dotted lines) interior surface temperature when CeilingDiffuser SurfaceConvectionAlgorithm:Inside object was used for the enhanced B-hut

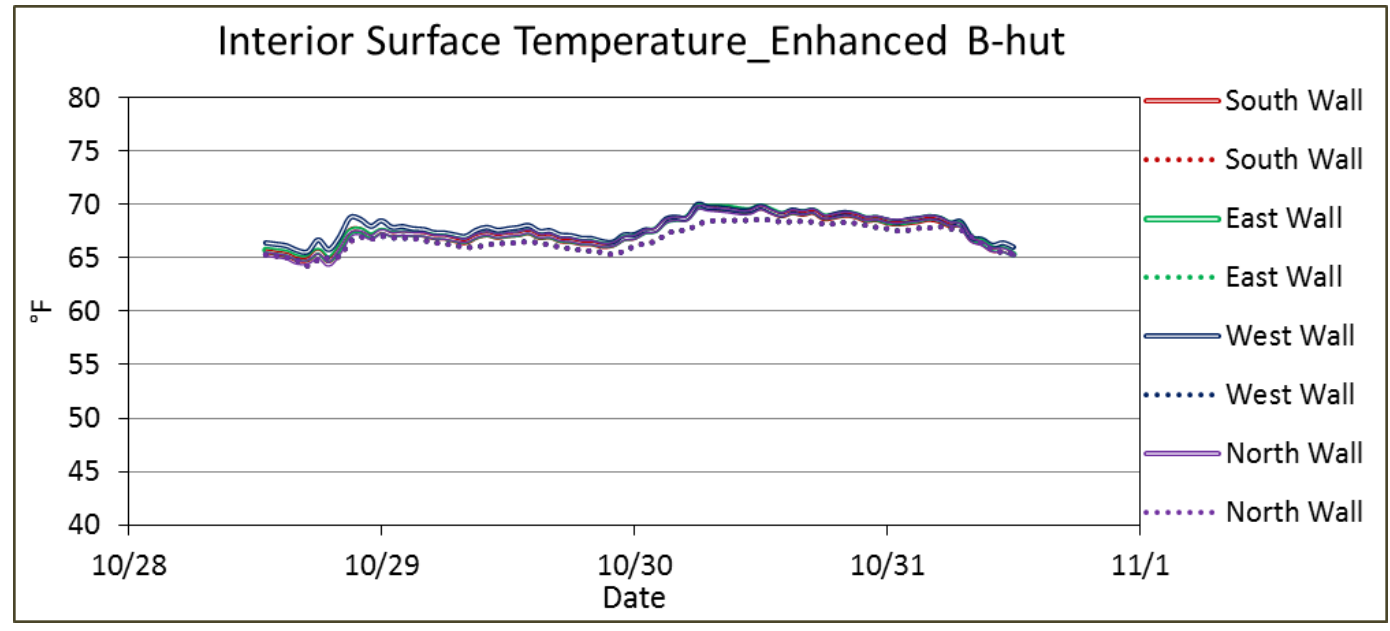

As discussed earlier, the current version of EnergyPlus can output heat flux only at an exterior surface or at an interior surface of a wall, but not at the interface between layers where HFTs are installed. For meaningful comparison, simulations were done using COMSOL in combination with field-measured surface temperature and materials properties. EnergyPlus calculated heat flux at interior surfaces was compared with COMSOL calculated heat flux at interior surfaces. Measured heat flux was then compared with COMSOL calculated heat flux at the plane where HFTs were located. Figures 4-16 and 4-17 show the results for the south wall of the baseline B-hut. 
Figure 4-16. EnergyPlus and COMSOL predicted heat flux at interior surface of the south wall for the baseline B-hut.

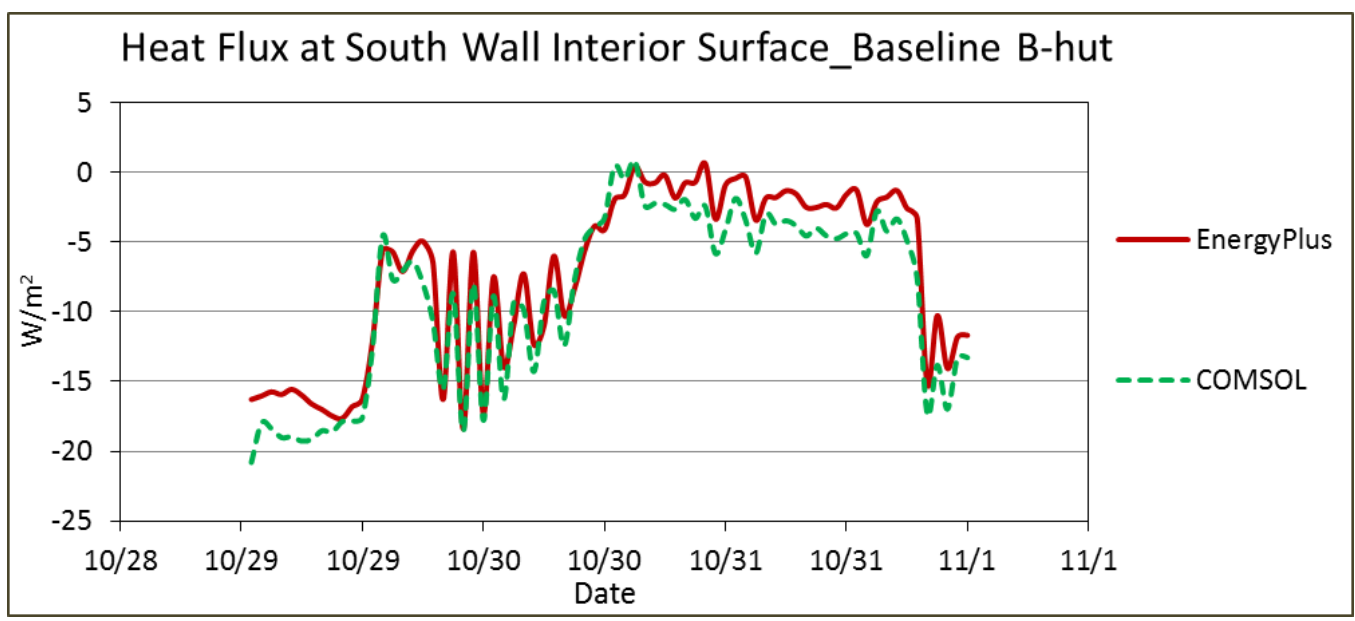

Figure 4-17. Measured and COMSOL predicted heat flux at the HFT location for the baseline B-hut.

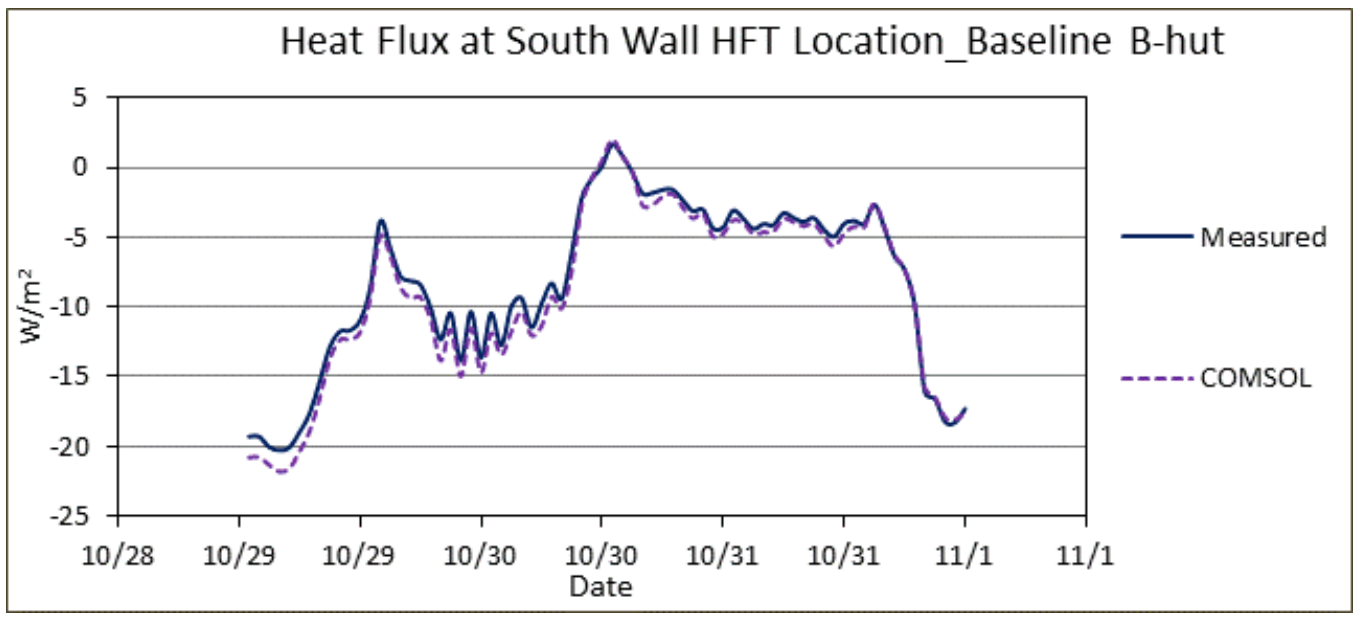

Figures 4-18 and 4-19 show the results for the south wall of the enhanced B-hut, respectively. Due to the computational intensity, these analyses were performed only for the south walls. The negative numbers indicate that the heat flow is toward the exterior surface (heat loss from the conditioned space). When compared to the measured values, the COMSOL calculated average heat loss at the HFT location was $7 \%$ higher for the baseline B-hut and 10\% higher for the enhanced B-hut, which should be considered a good match considering the constraints in effectively modeling the air cavity R-value, and the variation in SR. 
Figure 4-18. EnergyPlus and COMSOL predicted heat flux at interior surface of the south wall for the enhanced B-hut

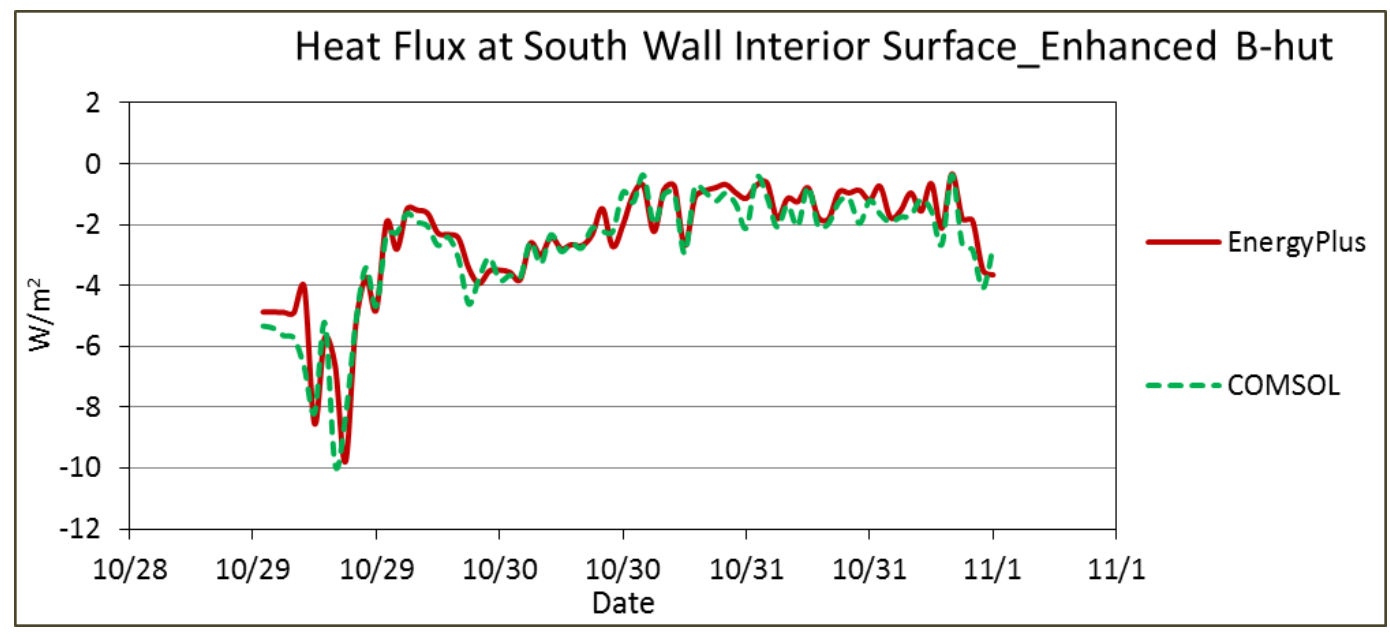

Figure 4-19. Measured and COMSOL predicted heat flux at the HFT location for the enhanced B-hut

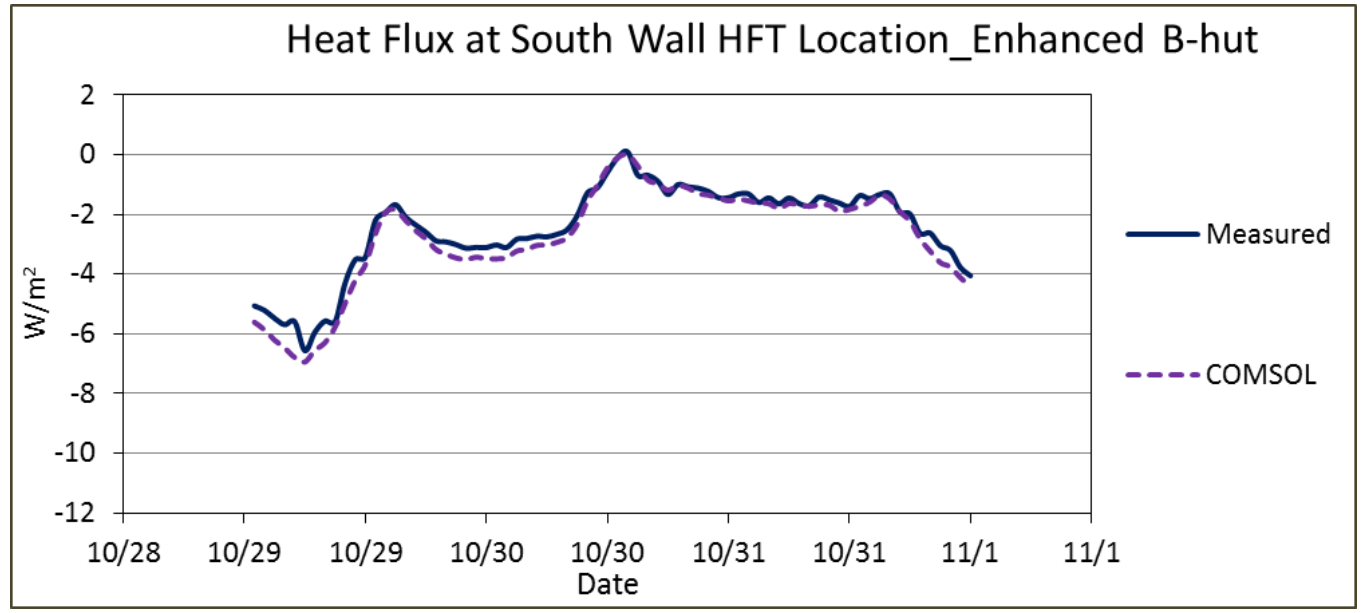

Infiltration was modeled using the blower door test result from J uly 2013, which yielded an average $\mathrm{ACH}$ of 1.02 for the baseline B-hut and an average $\mathrm{ACH}$ of 0.33 for the enhanced B-hut. The hourly average rate of heating energy use for the period was 554 and 180W for the baseline and enhanced Bhuts, respectively (Figure 4-20). Performance curves for the Chigo unit were not available to model the mini-split unit in EnergyPlus that would predict Chigo energy use from EnergyPlus predicted heating load. 
Figure 4-20. Chigo energy use

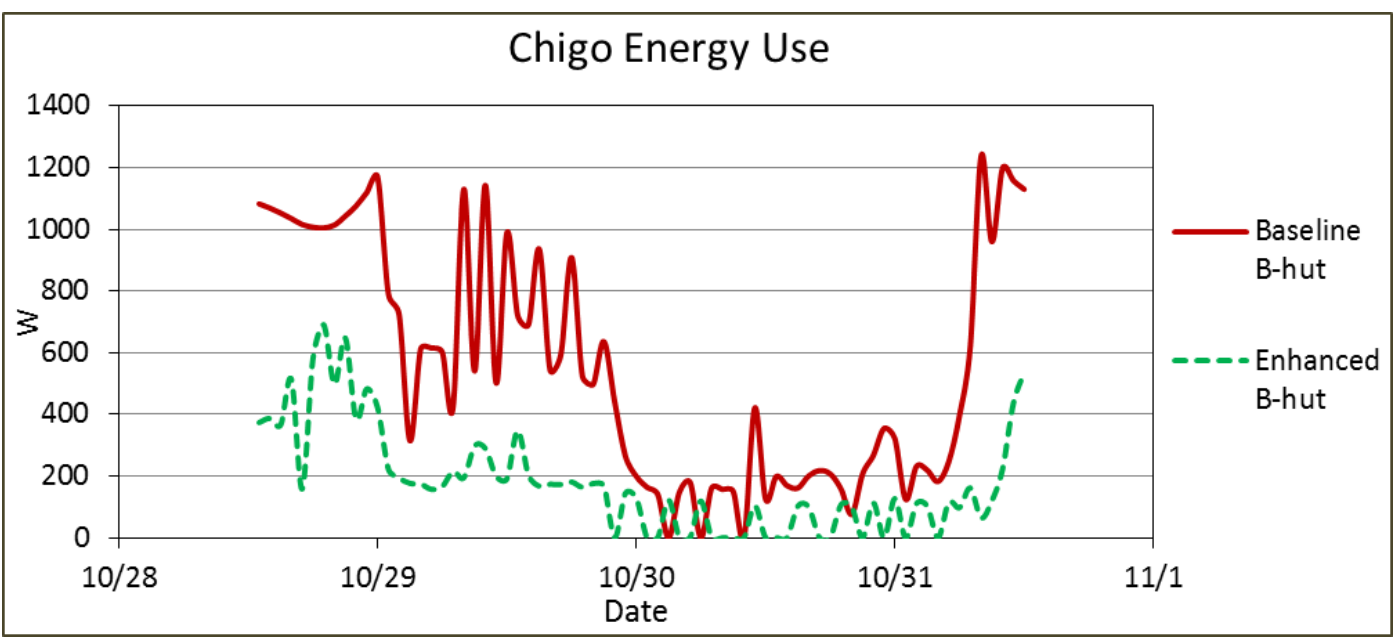

Therefore, the HVACTemplate:Zone:IdealLoadsAirSystem model in EnergyPlus and measured indoor air temperature were used to predict hourly heating load. EnergyPlus predicted heating load for the period was 1696 and 446W for the baseline B-hut and enhanced B-huts, respectively. As mentioned earlier, the average conditioned space air temperature was 65.4 and $68.5^{\circ} \mathrm{F}$ for the baseline B-hut and enhanced B-huts, respectively. To calculate normalized energy use if both huts were maintained at $70^{\circ} \mathrm{F}$, an EnergyPlus simulation was run using the fixed indoor air temperature. This simulation showed the heating load as 2581 and 497W for the baseline and enhanced B-huts, respectively. Therefore, if HVAC units on both huts had the same efficiency, the enhanced B-hut would need only one-fifth of the heating energy needed for the baseline B-hut.

Of the 2581W heating load for the baseline B-hut, 85\% of the load was due to the heat loss through envelope and $15 \%$ was due to the air leakage. Similarly, of the $496 \mathrm{~W}$ heating load for the enhanced B-hut, 76\% of the load was due to the heat loss through envelope and $24 \%$ was due to the air leakage.

\subsubsection{Chigo in cooling mode}

Chigo units were again used in cooling mode during the summer of 2014. Data collected from 25 to 31 August 2014 were used to compare EnergyPlus predicted cooling load against energy use by the Chigo mini-split units. All the analyses in this section reference the data for that period. Figure 4-21 shows the outdoor air temperature and relative humidity. Figure 4-22 shows the direct beam and diffuse solar radiation. 
Figure 4-21. Outdoor air temperature and relative humidity.

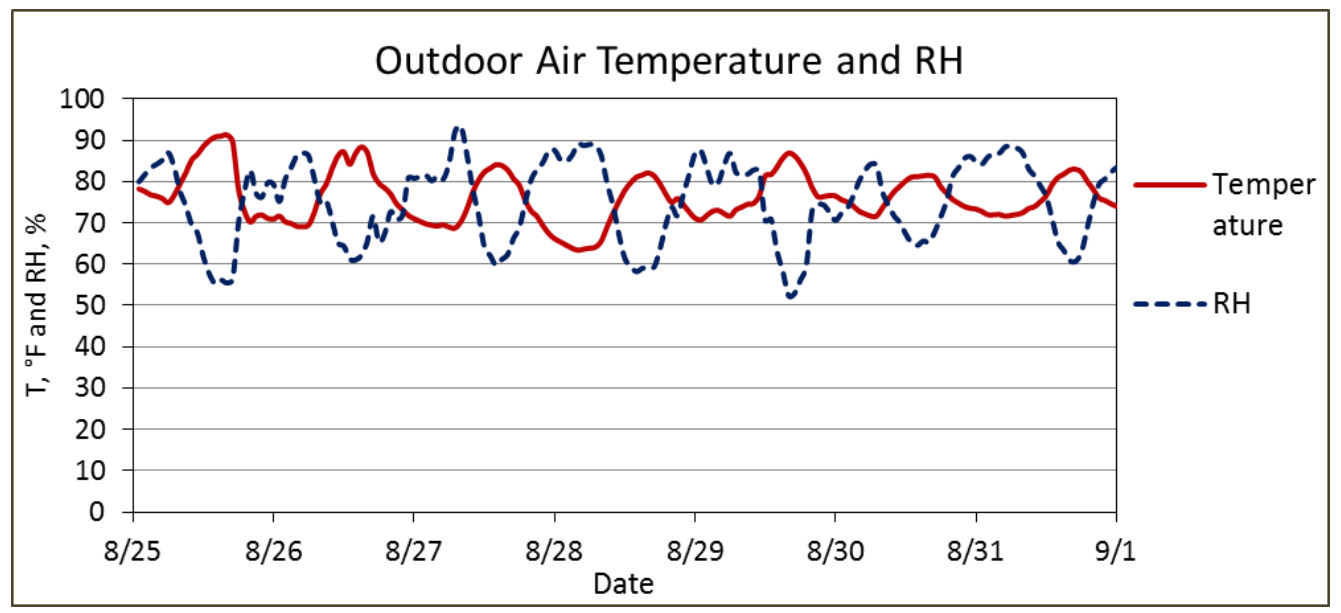

Figure 4-22. Solar radiation.

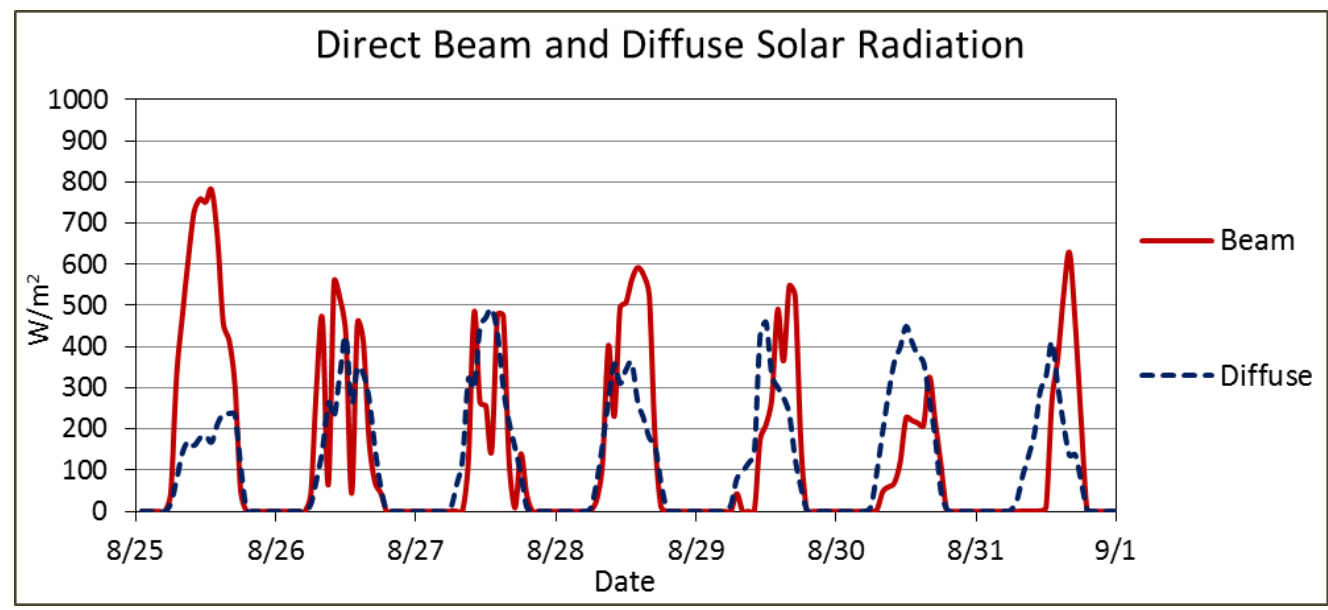

The data in these figures indicate that these were partly sunny days. Outdoor air temperature varied between 63.4 and $91.3^{\circ} \mathrm{F}$, with an average value of $76.3^{\circ} \mathrm{F}$. For comparison, Figure $4-23$ shows conditioned space air temperatures at the two huts, which shows mostly steady temperatures except for some instances in the baseline B-hut. The average temperature was $74.7^{\circ} \mathrm{F}$ in the baseline B-hut and $75.1^{\circ} \mathrm{F}$ in the enhanced B-hut, $0.4^{\circ} \mathrm{F}$ higher than the baseline B-hut temperature. For comparison, Figures 4-24 and 4-25 show measured (solid lines) and EnergyPlus predicted (dotted lines) exterior surface temperatures for the two huts. EnergyPlus predicted surface temperatures matched temperature measurements well except during sunny afternoon hours when EnergyPlus predicted surface temperatures were up to $10^{\circ} \mathrm{F}$ lower than temperature measurements. For comparison, Figures 4-26 and 4-27 show measured (solid lines) and EnergyPlus predicted (dotted lines) interior surface temperatures for the two B-huts. 
Figure 4-23. Conditioned space air temperature.

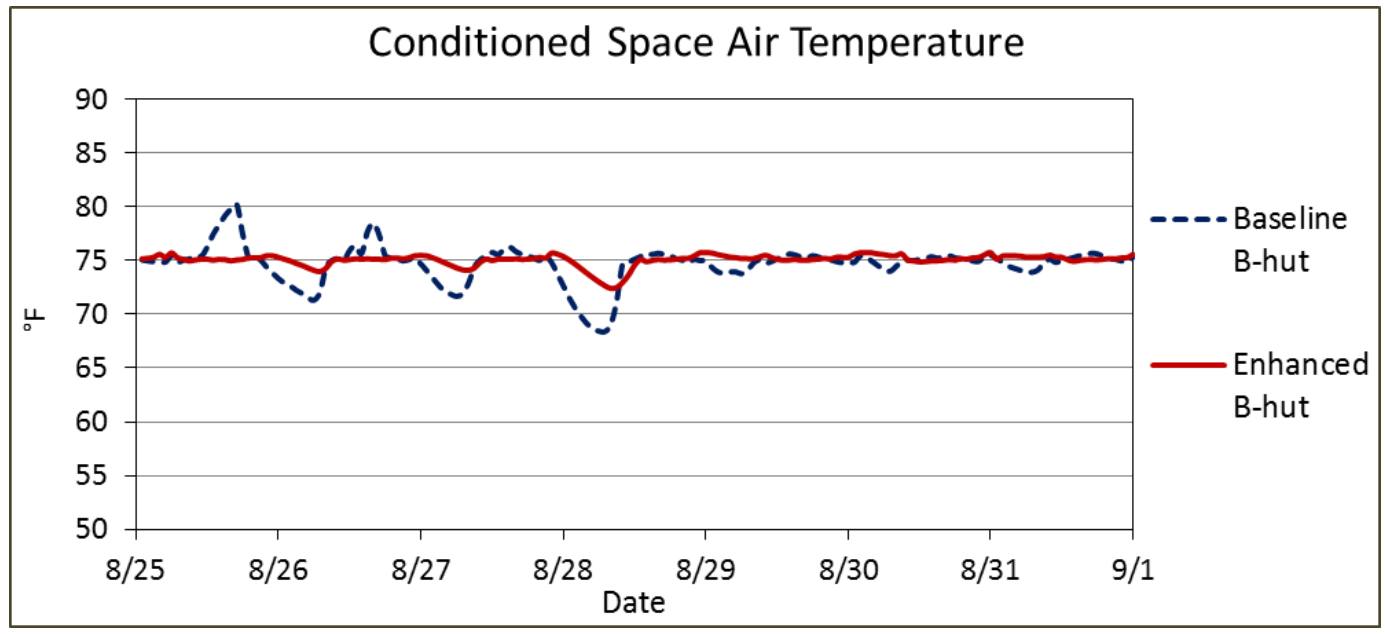

Figure 4-24. Measured (solid lines) and EnergyPlus predicted (dotted lines) exterior surface temperature for the baseline B-hut

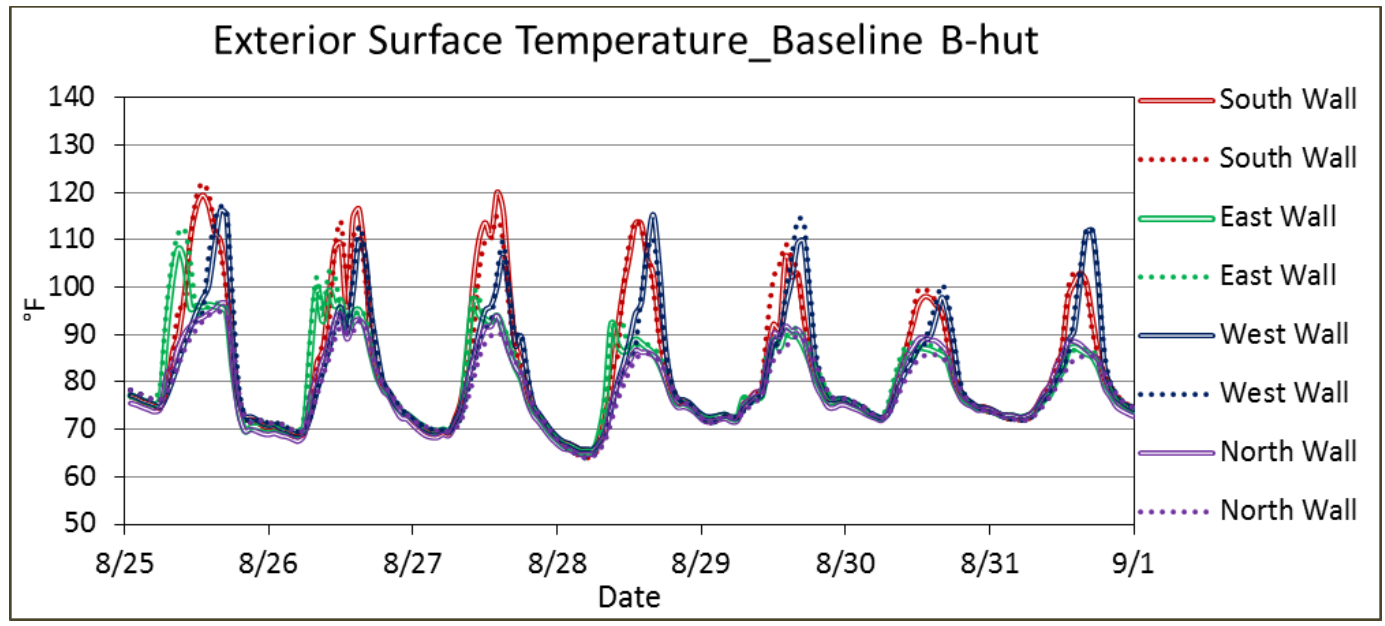

Figure 4-25. Comparison between measured (solid lines) and EnergyPlus predicted (dotted lines) exterior surface temperature for the enhanced B-hut

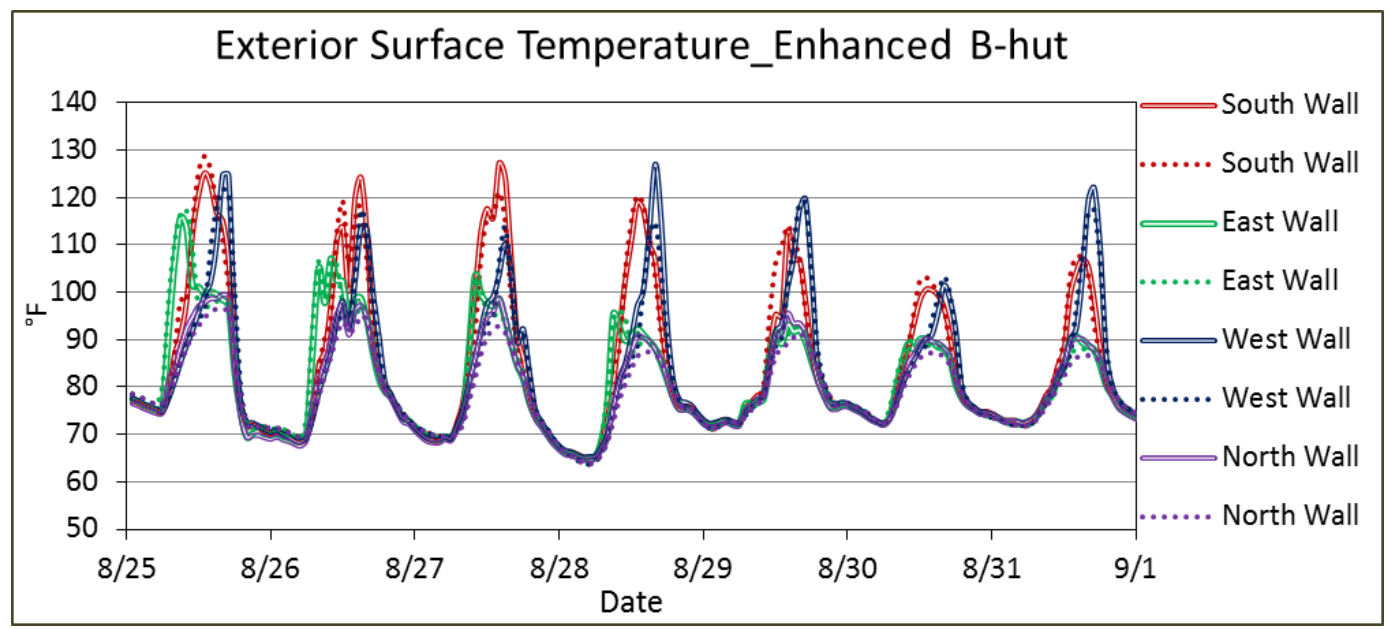


Figure 4-26. Measured (solid lines) and EnergyPlus predicted (dotted lines) interior surface temperature for the baseline B-hut

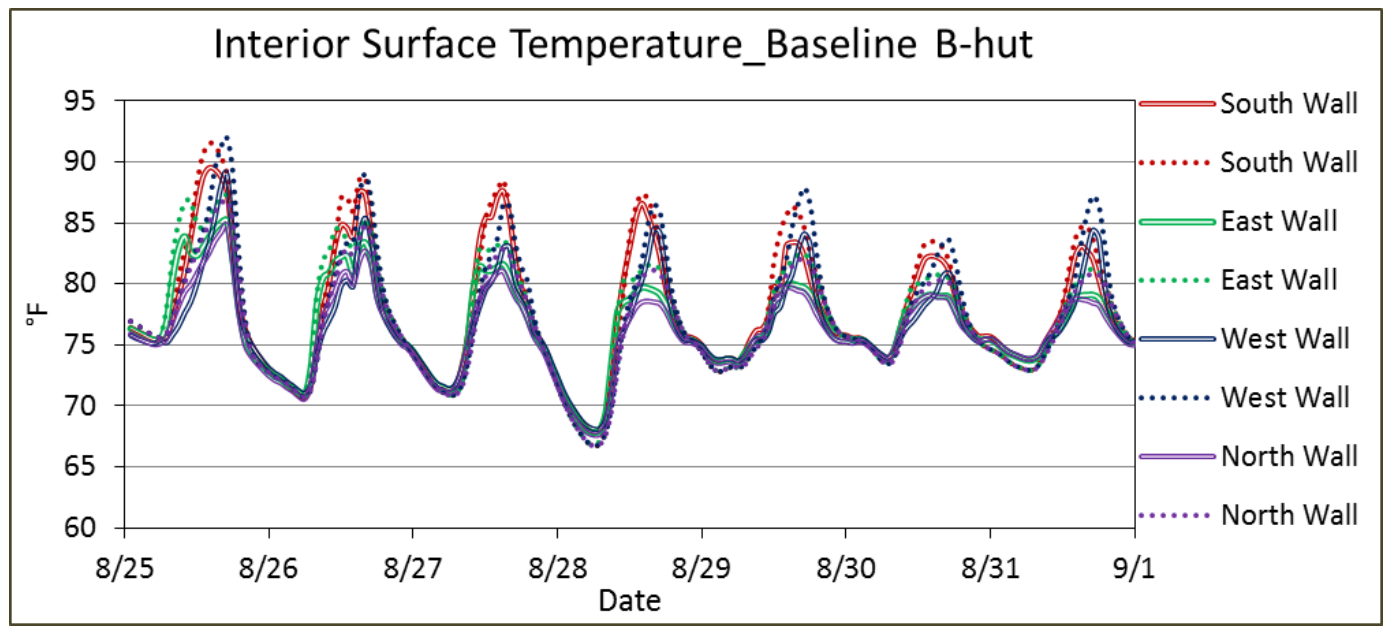

Figure 4-27. Comparison between the measured (solid lines) and EnergyPlus predicted (dotted lines) interior surface temperature for the enhanced B-hut.

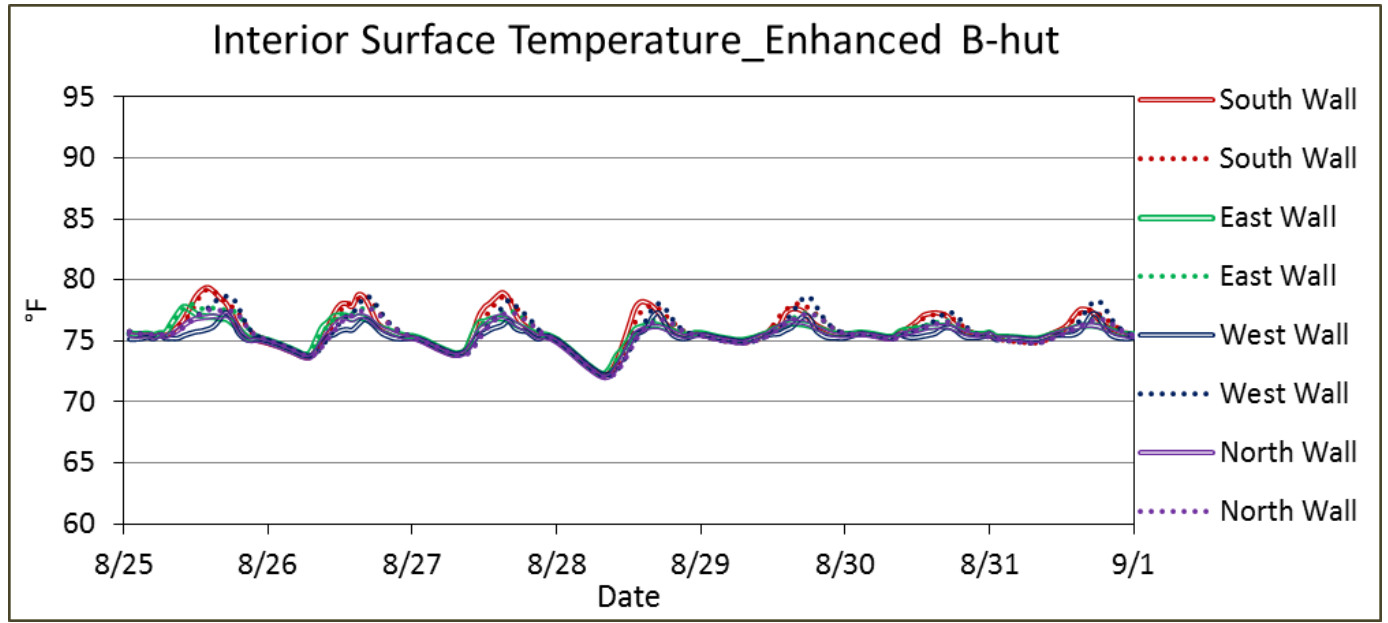

Results from the COMSOL simulation using field-measured surface temperature and materials properties were compared with EnergyPlus calculated heat flux at interior surfaces. Measured heat flux was then compared with COMSOL calculated heat flux at the plane where HFTs were located. Figures 4-28 and 4-29 show the results for the south wall of the baseline B-hut. Figures 4-30 and 4-31 show the results for the south wall of the improved B-hut. When compared to the measured values, the COMSOL calculated average heat loss at the HFT location was $12 \%$ lower for the baseline B-hut and 10\% lower for the enhanced B-hut. 
Figure 4-28. EnergyPlus and COMSOL predicted heat flux at interior surface of the south wall of the baseline B-hut.

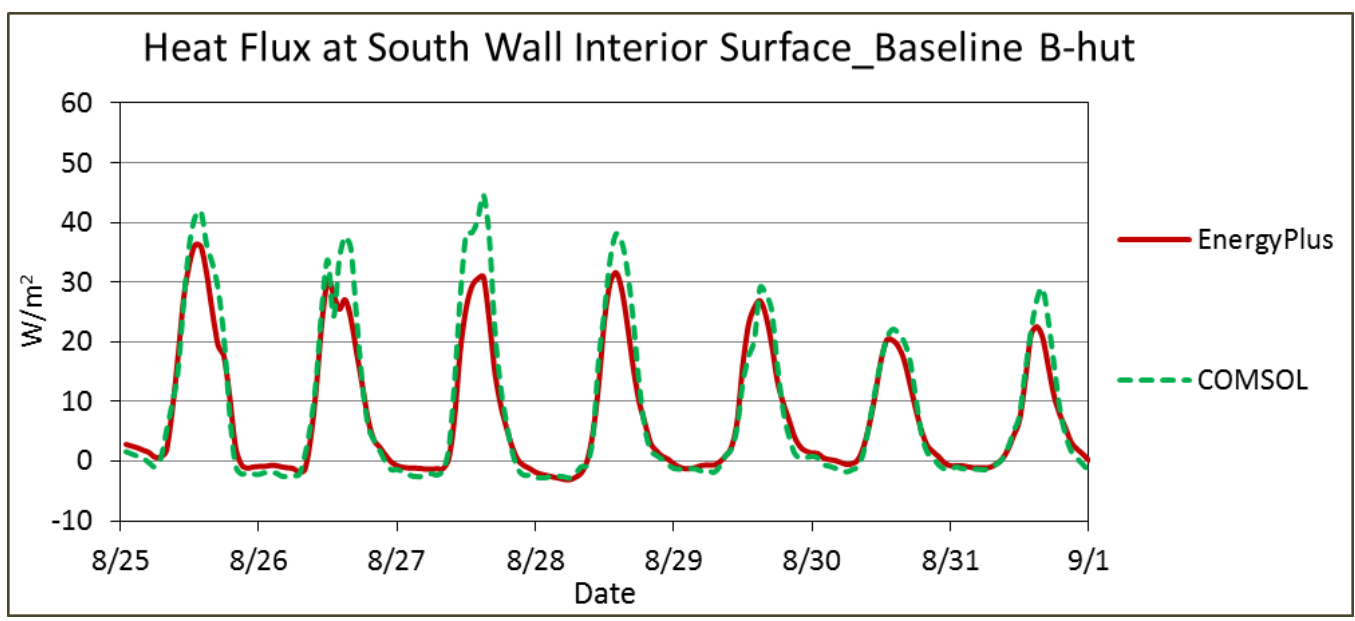

Figure 4-29. Measured and COMSOL predicted heat flux at the HFT location of the baseline B-hut.

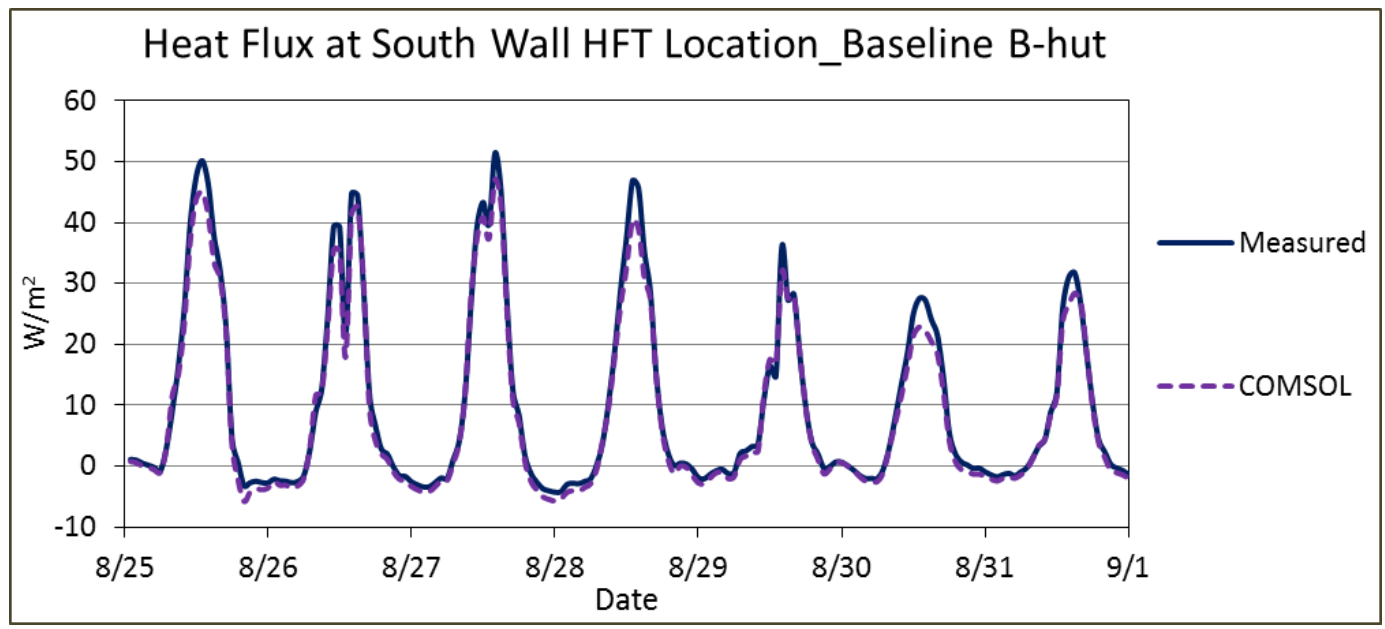

Figure 4-30. EnergyPlus and COMSOL predicted heat flux at interior surface of the south wall of the enhanced B-hut.

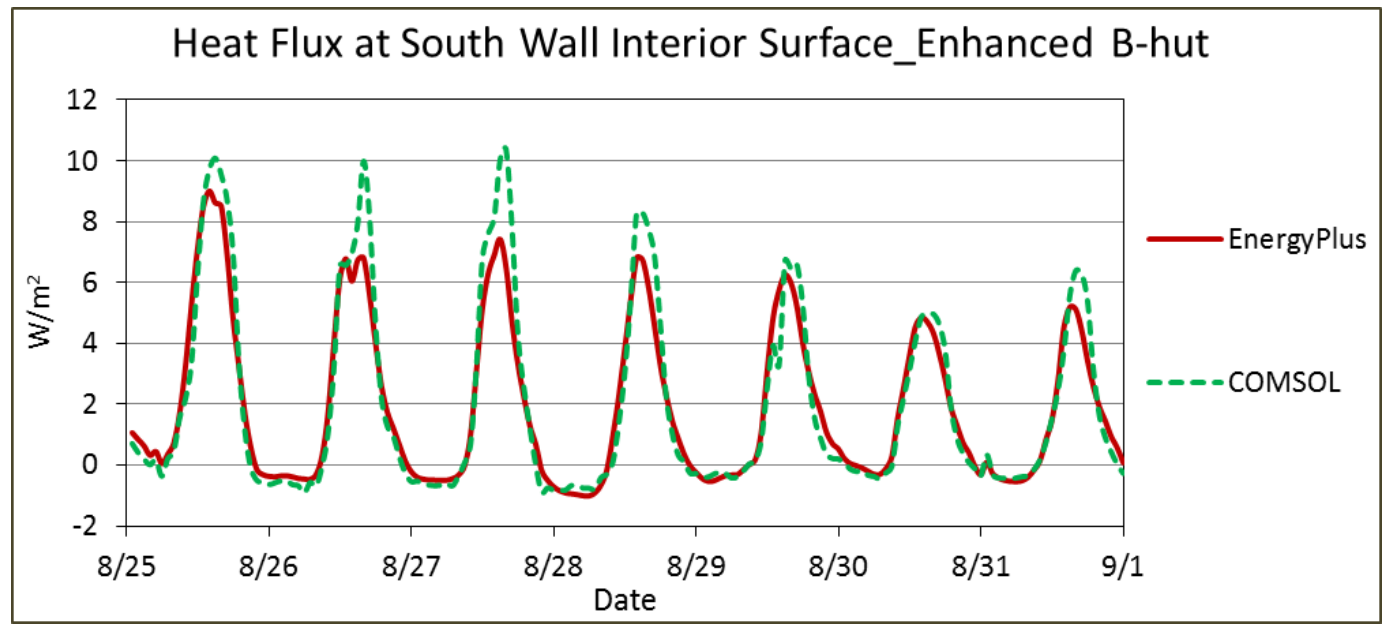


Figure 4-31. Measured and COMSOL predicted heat flux at the HFT location of the enhanced B-hut.

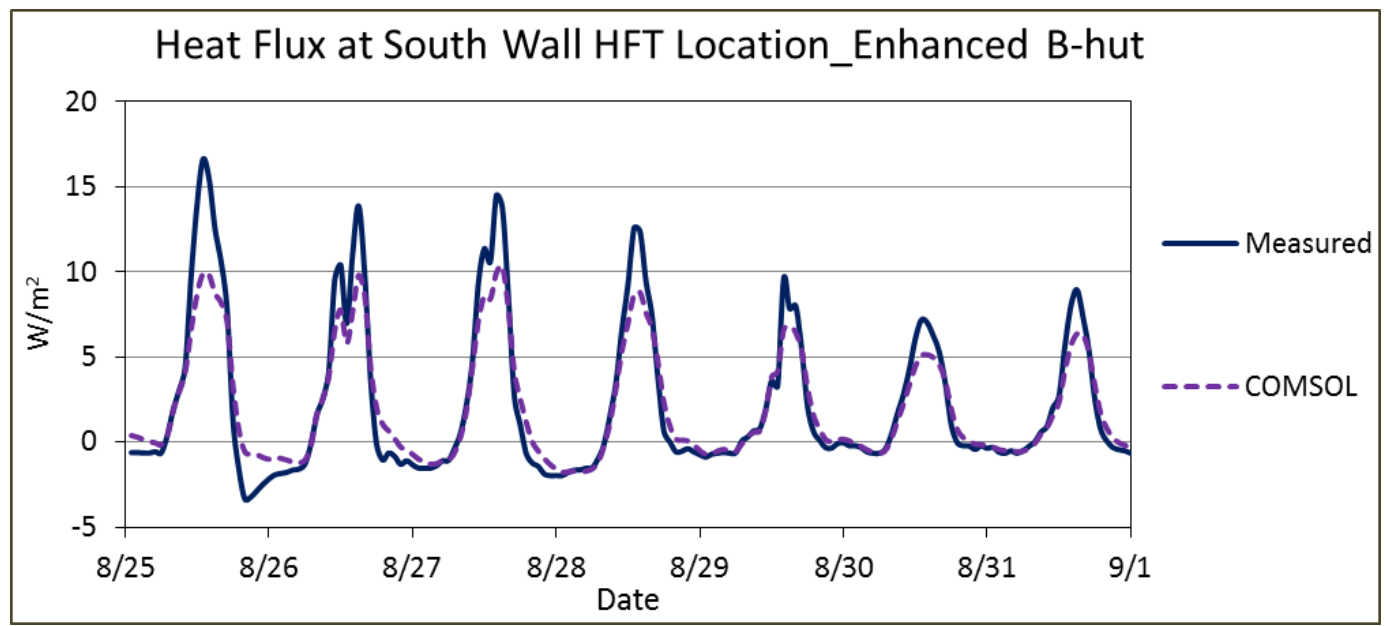

Infiltration was modeled using the blower door test result from J uly 2013, which yielded an average $\mathrm{ACH}$ of 0.67 for the baseline B-hut and 0.21 for the enhanced B-hut. The hourly average rate of energy use by the Chigo units for the period was 336 and 109W, and the EnergyPlus predicted cooling load was 908 and 191W for the baseline and enhanced B-huts, respectively. Therefore, the average coefficient of performance (COP) was 2.7 and 1.7 for the baseline and enhanced B-huts, respectively. For comparison, Figures 4-32 and 4-33 show the hourly EnergyPlus predicted cooling load and the Chigo energy use for the two huts. Coefficients of determination for linear fit are 0.96 and 0.88 for the baseline and enhanced B-huts, respectively.

Figure 4-32. EnergyPlus predicted cooling load and Chigo energy use for the baseline B-hut

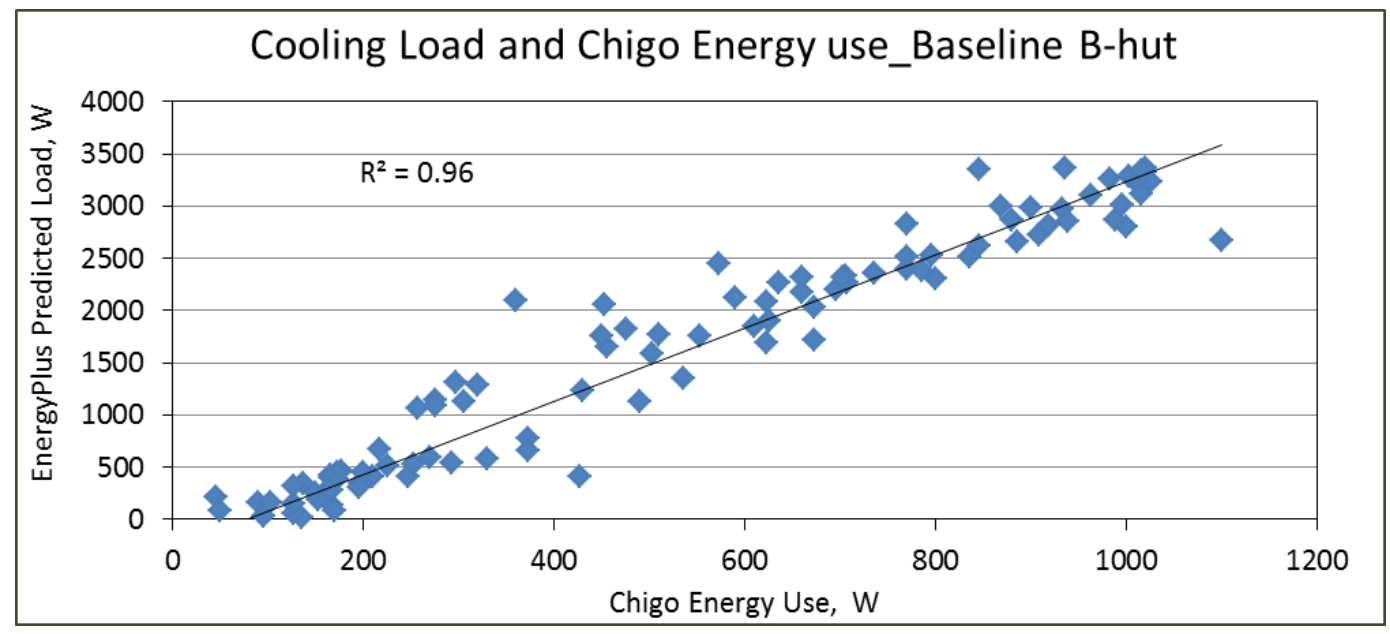


Figure 4-33. EnergyPlus predicted cooling load and Chigo energy use for the enhanced B-hut

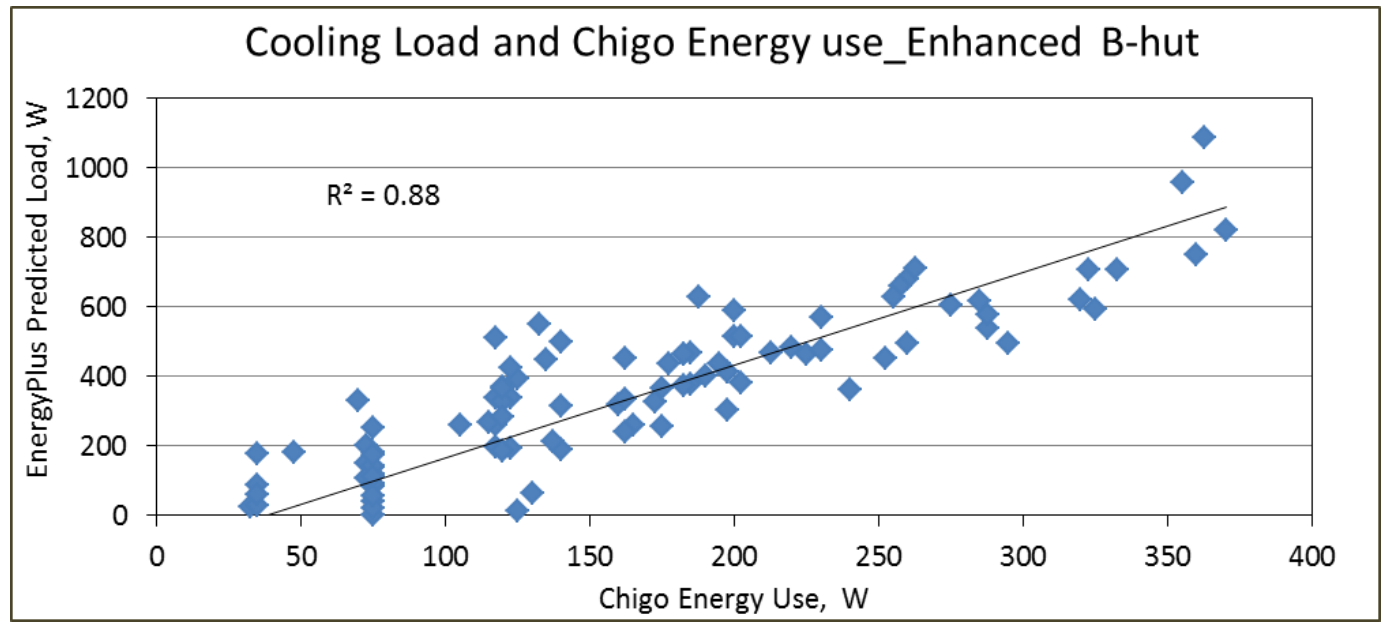

As mentioned earlier, the average conditioned space air temperature was 74.7 and $75.1^{\circ} \mathrm{F}$ for the baseline and enhanced B-huts, respectively. To calculate normalized energy use when both huts are maintained at $75^{\circ} \mathrm{F}$, an EnergyPlus simulation was run using the fixed indoor air temperature. This simulation showed the cooling load as 884 and 188W for the baseline and enhanced B-huts, respectively. Therefore, if the cooling units on both huts had the same efficiency, the enhanced B-hut would need only onefourth of the cooling energy used by the baseline hut to maintain a $75^{\circ} \mathrm{F}$ indoor temperature.

Of the $844 \mathrm{~W}$ cooling load for the baseline B-hut, $67 \%$ of the load was due to the heat loss through envelope and 33\% was due to the air leakage. Similarly, of the 188W cooling load for the enhanced B-hut, $61 \%$ of the load was due to the heat loss through envelope and 39\% was due to the air leakage.

\subsubsection{IECU}

\subsubsection{IECU in heating mode}

IECUs were installed at the B-huts in December 2014 to enable a side-byside comparison with the co-located SIP-hut performance. Heating capacity of the IECU was not adequate to maintain indoor air temperature even at $68^{\circ} \mathrm{F}$ at the baseline B-hut. Therefore, supplemental portable electrical resistance heaters were also used. All analysis in this section reference the data collected from 16 to 22 February 2015. 
Figure 4-34 shows the outdoor air temperature and relative humidity. Figure 4-35 shows the direct beam and diffuse solar radiation. The data in these figures indicate that all the days were cloudy days except for $19 \mathrm{Feb}-$ ruary 2015 . Outdoor air temperature varied between -4.1 and $29.8^{\circ} \mathrm{F}$, with an average value of $13.2^{\circ} \mathrm{F}$. For comparison, Figure 4-36 shows the conditioned space air temperatures at the two huts, which shows high fluctuation in indoor air temperature at the baseline B-hut while the temperature for the enhanced B-hut was mostly steady. The heating system, even with the supplemental portable electrical heaters, could not maintain the thermostat setpoint at the baseline B-hut. The average temperature in the baseline B-hut was $64.3^{\circ} \mathrm{F}$ and that in the enhanced B-hut was $67.3^{\circ} \mathrm{F}$, $3.0^{\circ} \mathrm{F}$ higher than the temperature at the baseline B-hut.

Figure 4-34. Outdoor air temperature and relative humidity.

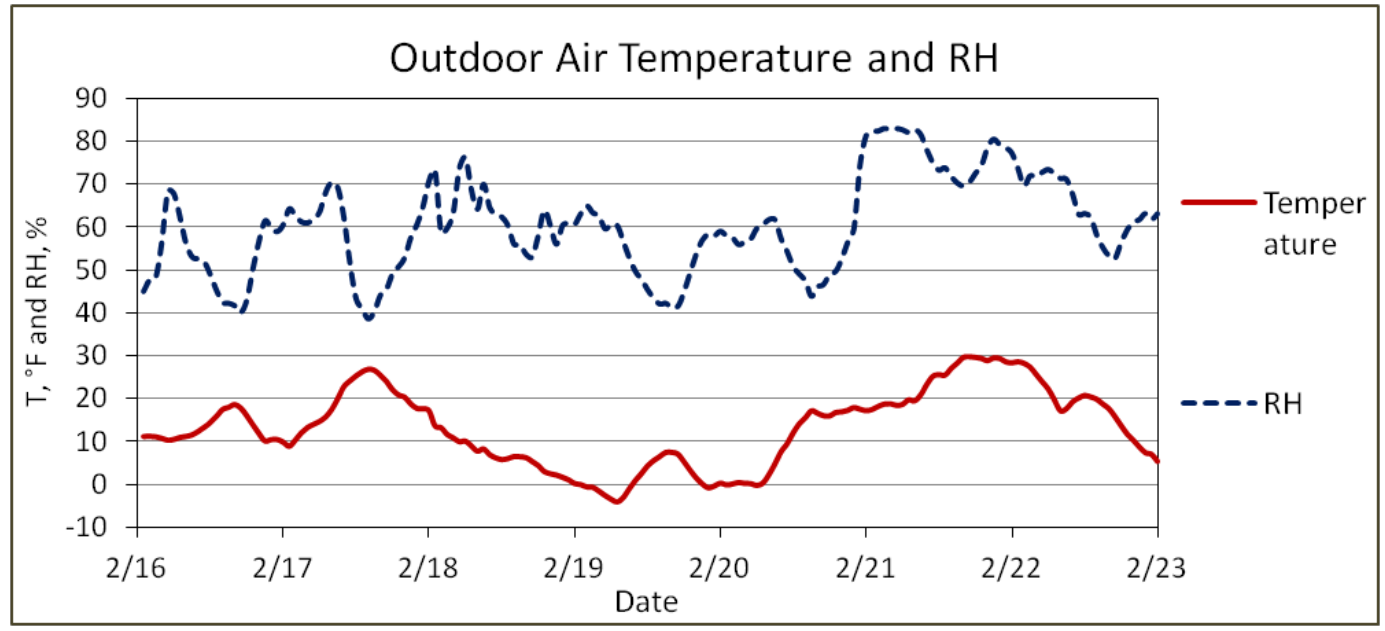

Figure 4-35. Solar radiation.

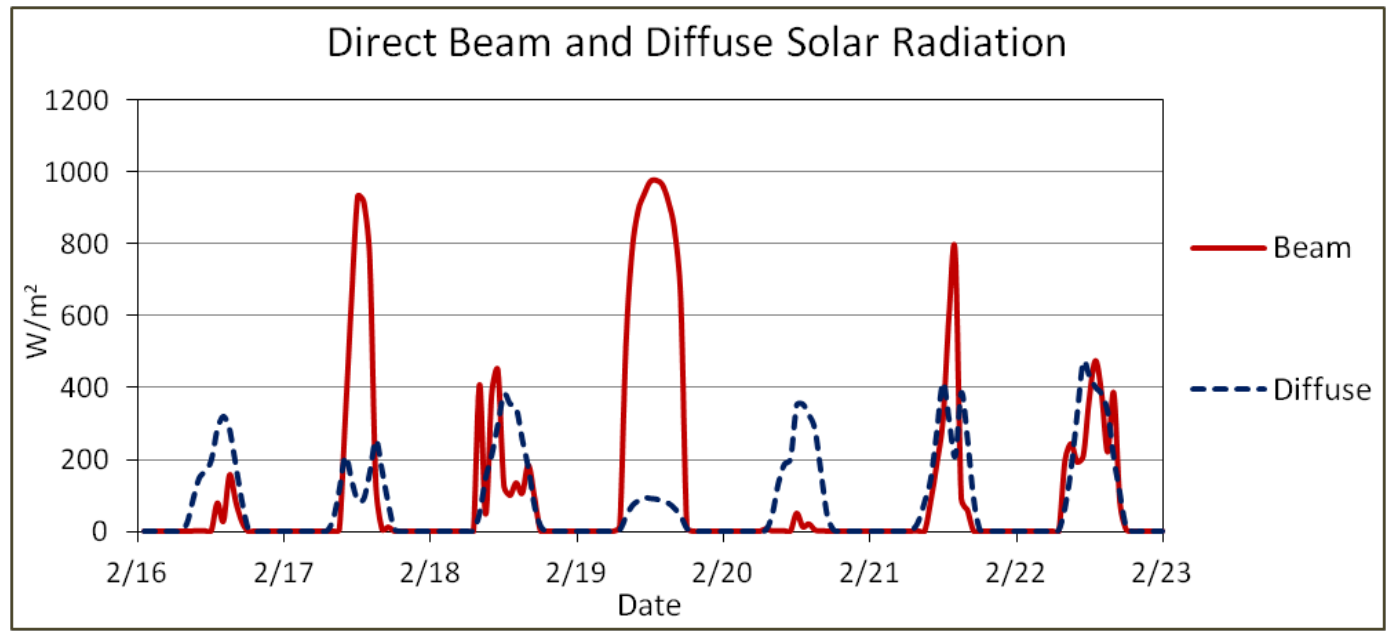


Figure 4-36. Conditioned space air temperature.

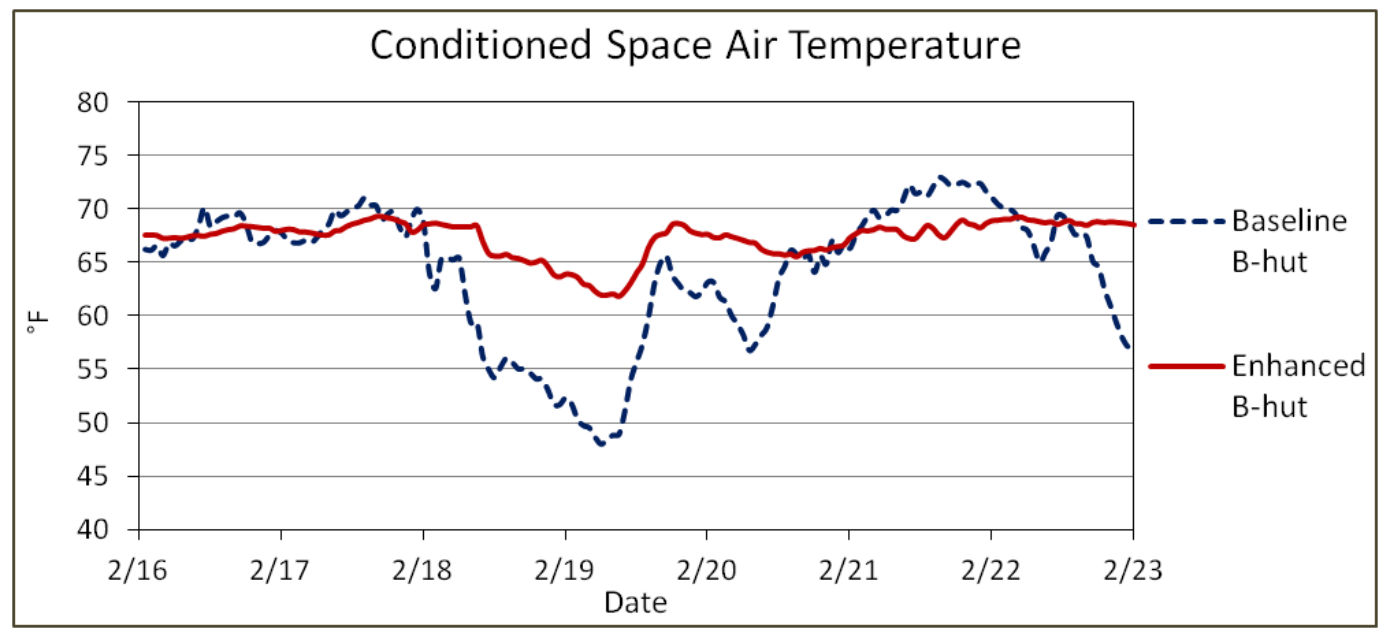

For comparison, Figures 4-37 and 4-38 show measured (solid lines) and EnergyPlus predicted (dotted lines) wall exterior surface temperature for the two huts. There was snow on the ground during this period, so the ground SR was changed from the EnergyPlus default value of 0.2 to 0.6 for the period of time when the ground was covered with snow. EnergyPlus predicted surface temperatures matched measured temperatures well except during sunny afternoon hours when EnergyPlus predicted surface temperatures up to $20^{\circ} \mathrm{F}$ lower at the enhanced wall south wall. For comparison, Figures 4-39 and 4-40 show measured (solid lines) and EnergyPlus predicted (dotted lines) interior surface temperatures.

Figure 4-37. Measured (solid lines) and EnergyPlus predicted (dotted lines) exterior surface temperature for the baseline B-hut.

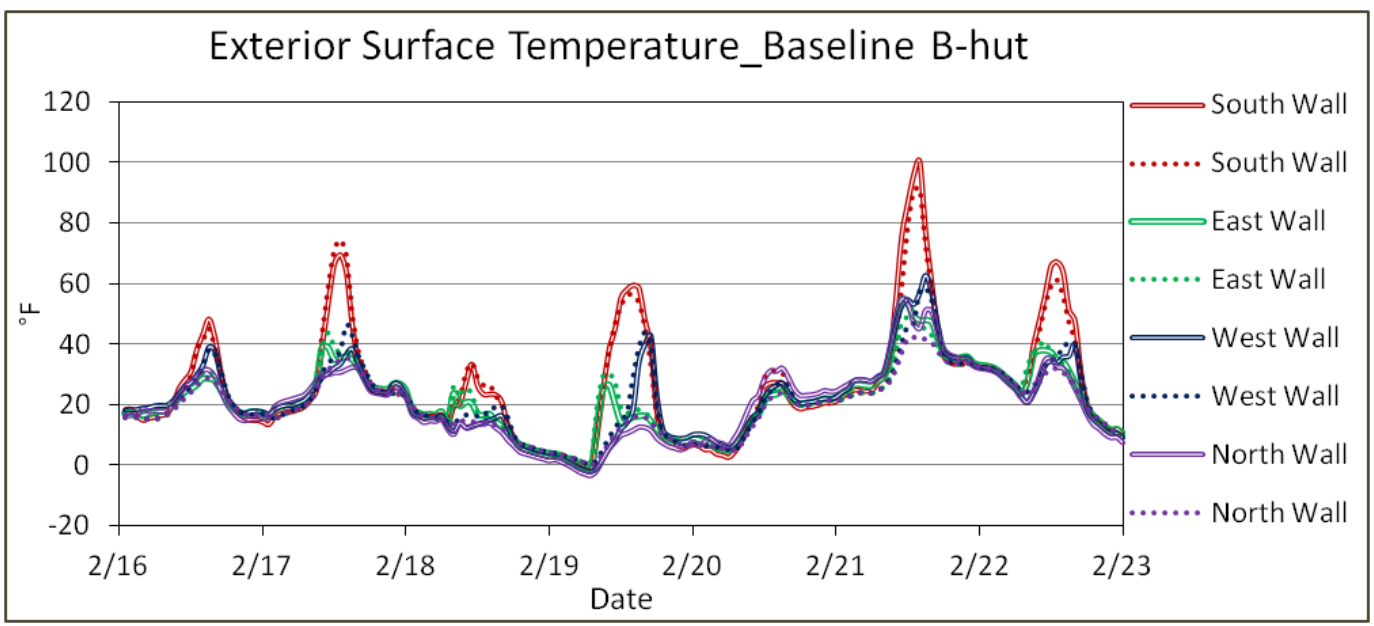


Figure 4-38. Measured (solid lines) and EnergyPlus predicted (dotted lines) exterior surface temperature for the enhanced B-hut

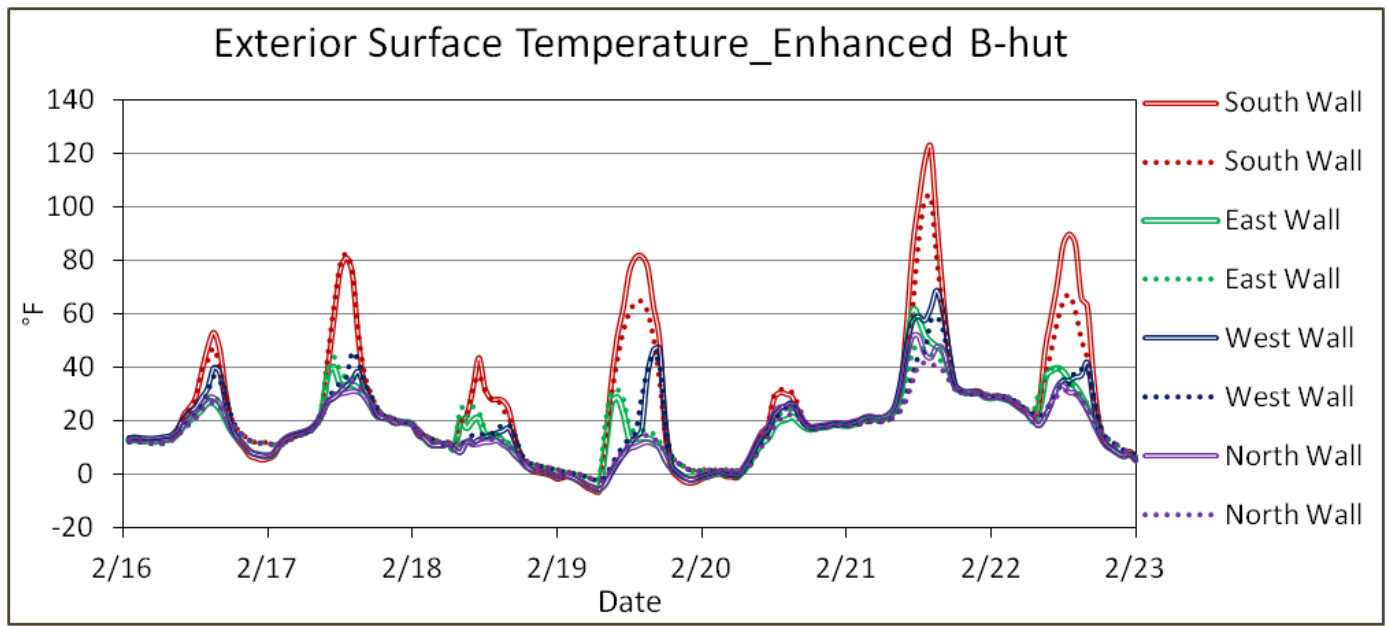

Figure 4-39. Measured (solid lines) and EnergyPlus predicted (dotted lines) interior surface temperature for the baseline B-hut.

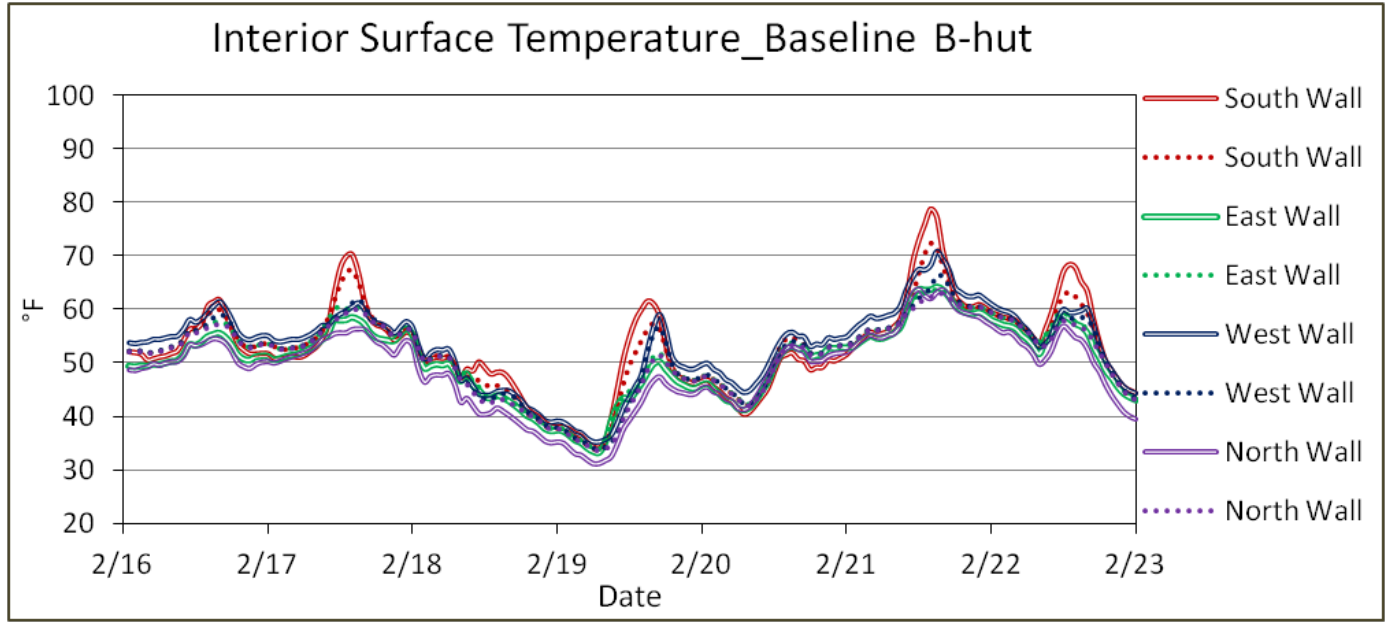

Figure 4-40. Measured (solid lines) and EnergyPlus predicted (dotted lines) interior surface temperature for the enhanced B-hut.

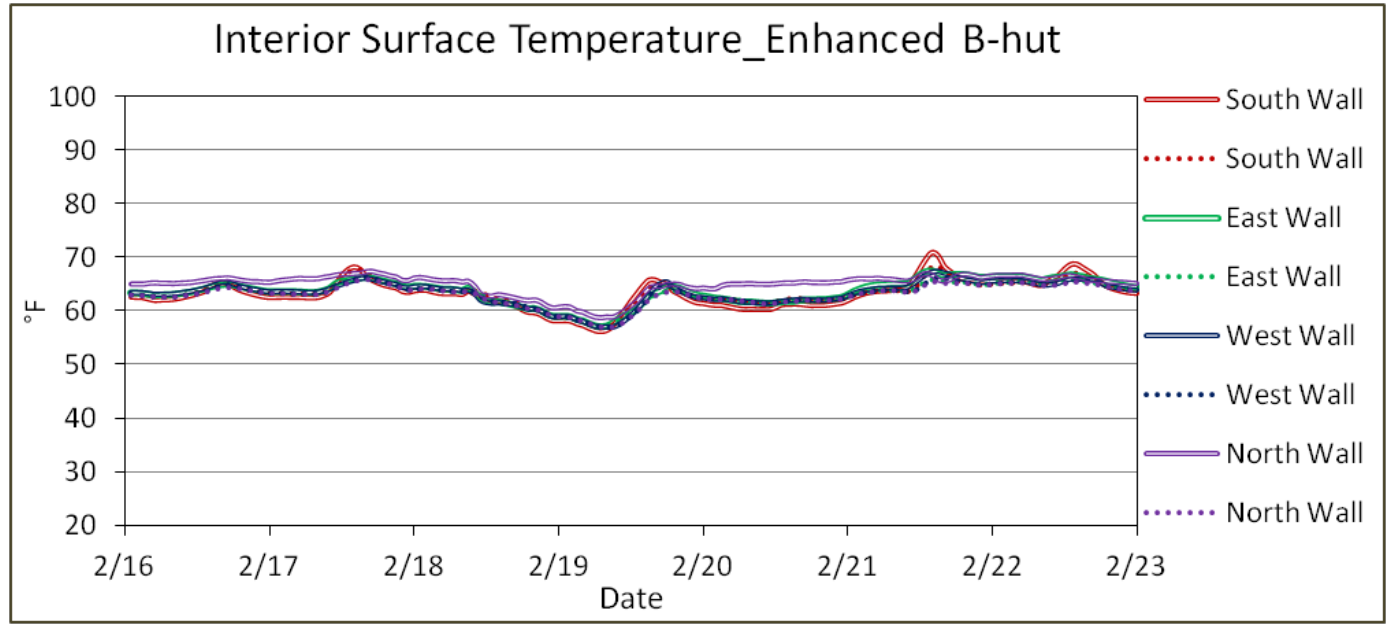


Results from the COMSOL simulation using field-measured surface temperature and materials properties were compared. Figures 4-41 and 4-42 show the results for the south wall of the baseline B-hut. Figures 4-43 and 4-44 show the results for the south wall of the improved B-hut, respectively. Compared to the measured data, the COMSOL calculated average heat loss at the HFT location was $4.2 \mathrm{~W} / \mathrm{m}^{2}$ higher for the baseline B-hut and $1.7 \mathrm{~W} / \mathrm{m}^{2}$ higher for the enhanced B-hut.

Figure 4-41. Comparison between the EnergyPlus and COMSOL predicted heat flux at interior surface of the south wall of the baseline B-hut.

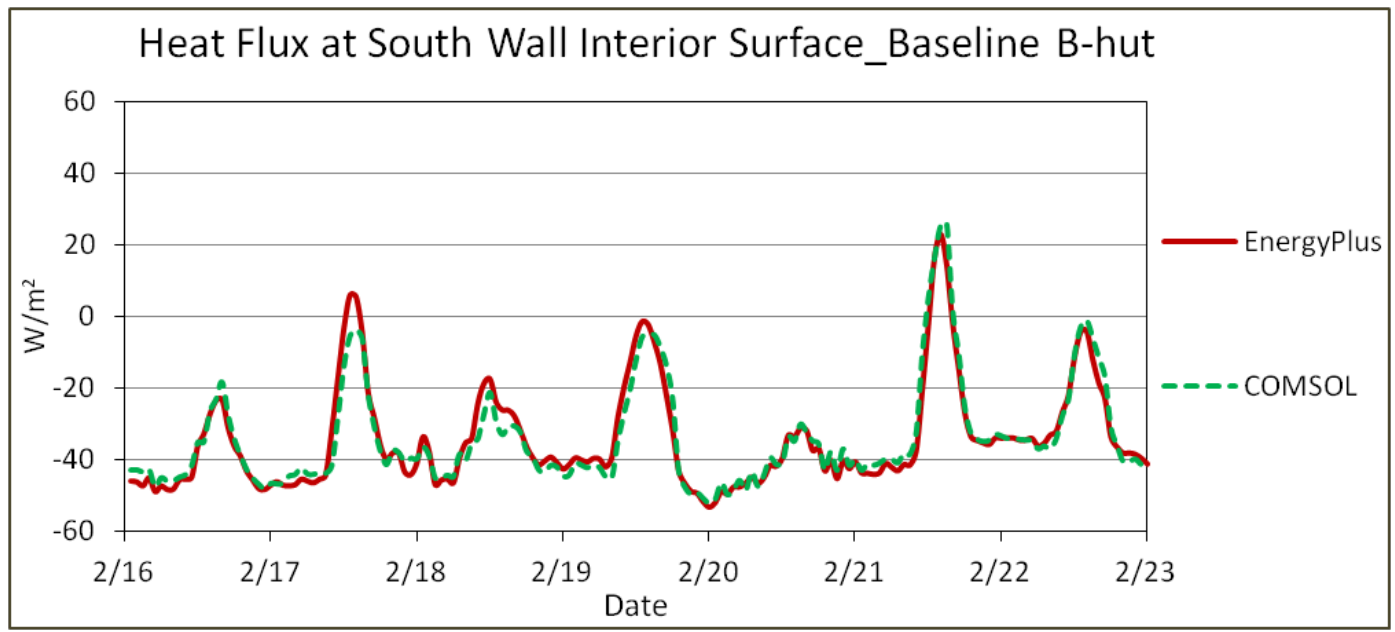

Figure 4-42. Comparison between the measured and COMSOL predicted heat flux at the HFT location of the baseline B-hut.

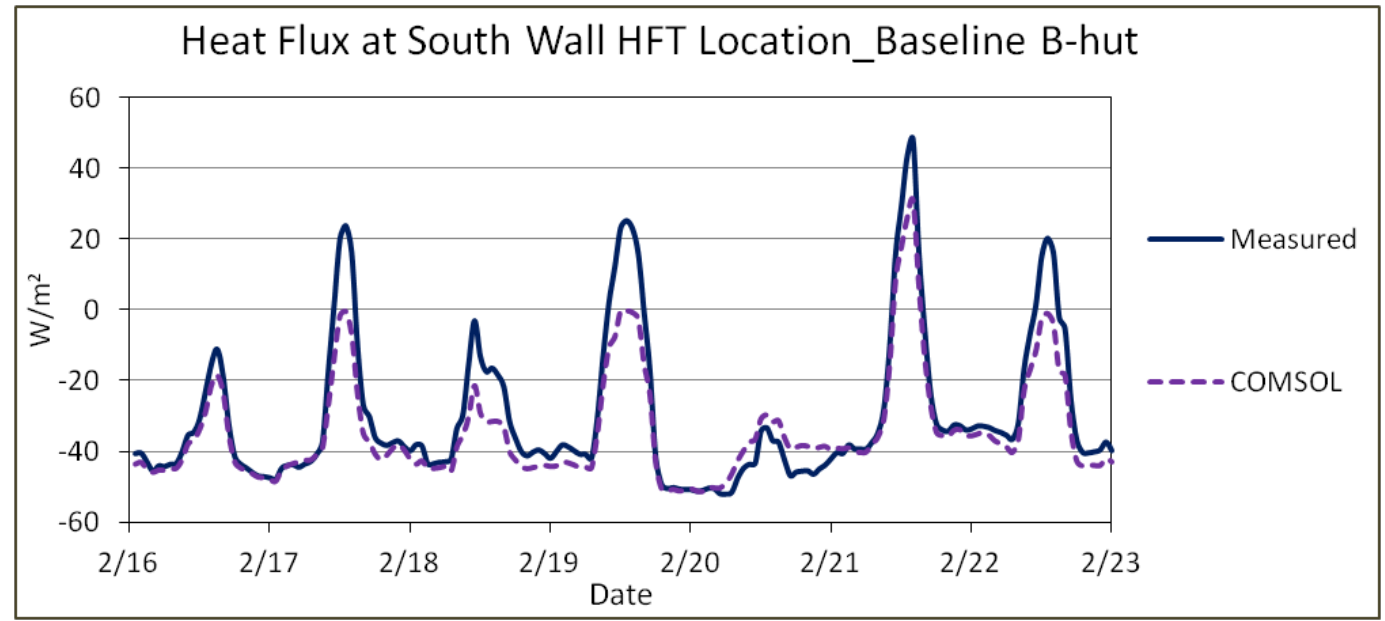


Figure 4-43. EnergyPlus and COMSOL predicted heat flux at interior surface of the south wall of the enhanced B-hut.

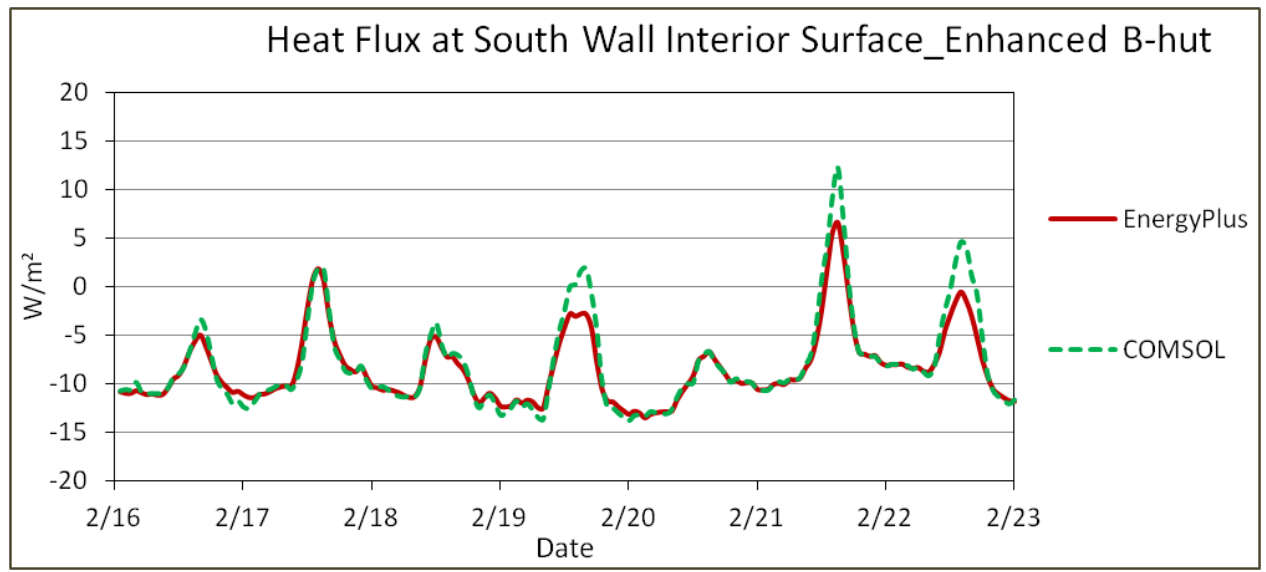

Figure 4-44. Measured and COMSOL predicted heat flux at the HFT location of the south wall of the enhanced B-hut.

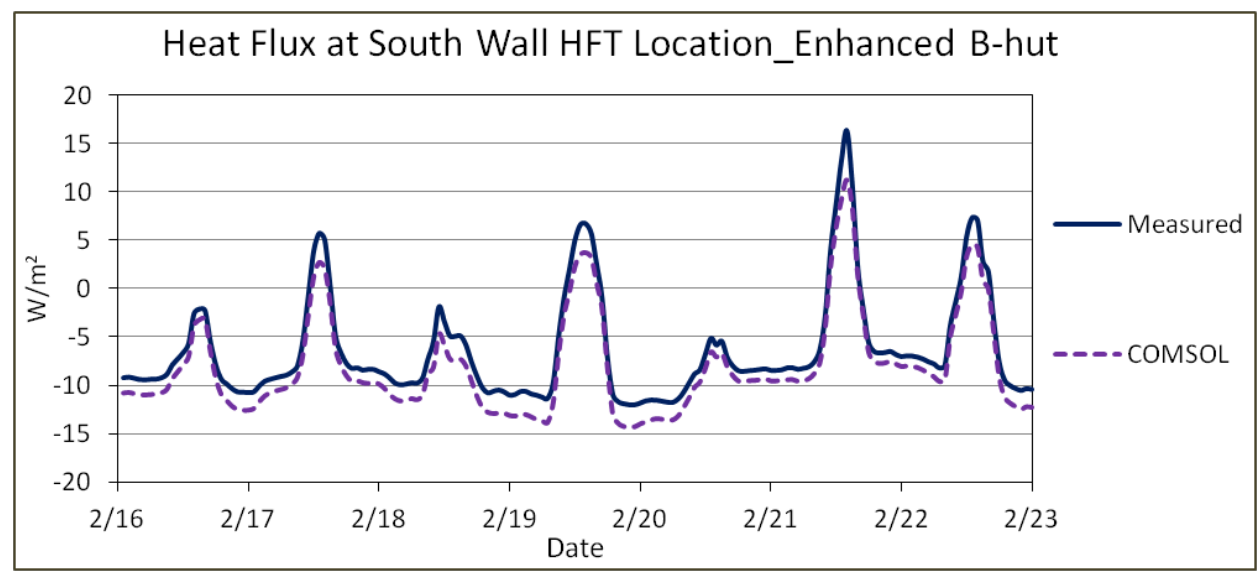

Supply and return air ducts between the huts and IECUs were connected using flexible ducts (Figure 4-45). The ducts were uninsulated and connections were not airtight. Blower fans on the IECUs run constantly, even when there is no heating load. Therefore, the infiltration rate and heating load increases when IECUs are used.

Blower tests do not capture the increased $\mathrm{ACH}$ for using IECUs as the blower door test is conducted with HVAC units turned off. In the case of Bhuts, the blower door test was conducted before installing IECUs. Therefore, the flow coefficient used to model infiltration was adjusted to match the EnergyPlus predicted $\mathrm{ACH}$ with tracer gas test data during the tracer gas test period (May 2015). Infiltration was modeled using the adjusted infiltration flow coefficients: 0.042 and 0.138 for the baseline and enhanced B-huts, respectively, which yielded an average $\mathrm{ACH}$ of 2.44 for the baseline B-hut and 0.81 for the enhanced B-hut. 
Figure 4-45. IECU serving the B-hut and the flexible ducts used as supply and return ducts.

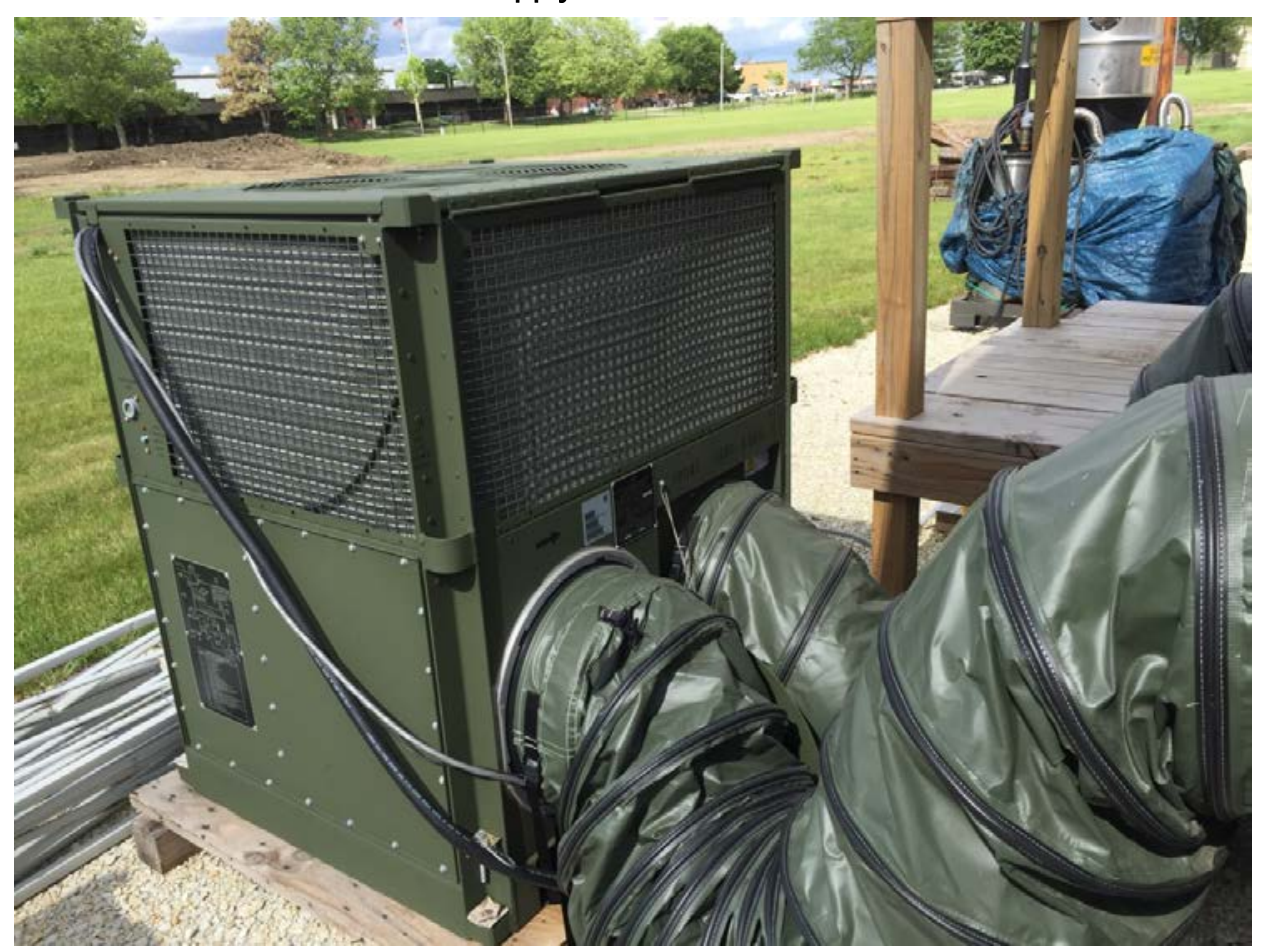

The hourly average rate of heating energy use for the period was 12705 and 4120W, and the EnergyPlus predicted heating load was 9527 and 2092W for the baseline B-hut and enhanced B-huts, respectively. Therefore, the difference between heating energy use and the simulation predicted heating load was 3178W for the baseline B-hut and 2028W for the enhanced Bhut. (EnergyPlus underpredicted in both cases.) The major contributors to this difference are the heat loss from the flexible supply and the return ducts between the IECU and the shelter, and the heat loss from the IECU housing. Note that the final report will include heat transfer through the ducts modeled using the AirflowNetwork subroutine in EnergyPlus.

The heating energy for the baseline B-hut is the sum of IECU energy use (8653W) and portable electric resistance heater energy use (4052W). IECU power is the sum of electric resistance heater power (in the IECU) and blower motor power. However, the blower motor is located in the air stream circulating to the hut, so all the electrical energy used by the blower motor is eventually dissipated as heat to the circulating air. For comparison, Figures 4-46 and 4-47 show hourly electric heater energy use and EnergyPlus predicted heating load for the two huts. 
Figure 4-46. Electric heater energy use and the EnergyPlus predicted heating load for the baseline B-hut.

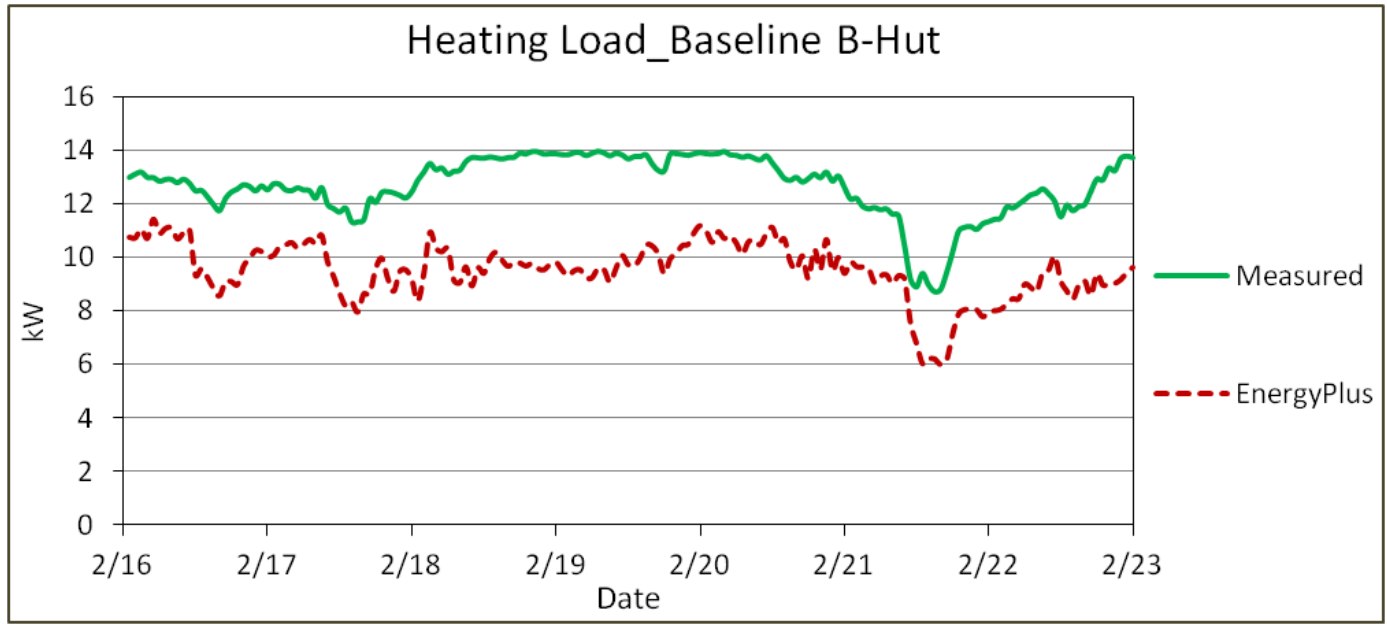

Figure 4-47. Electric heater energy use and the EnergyPlus predicted heating load for the enhanced B-hut.

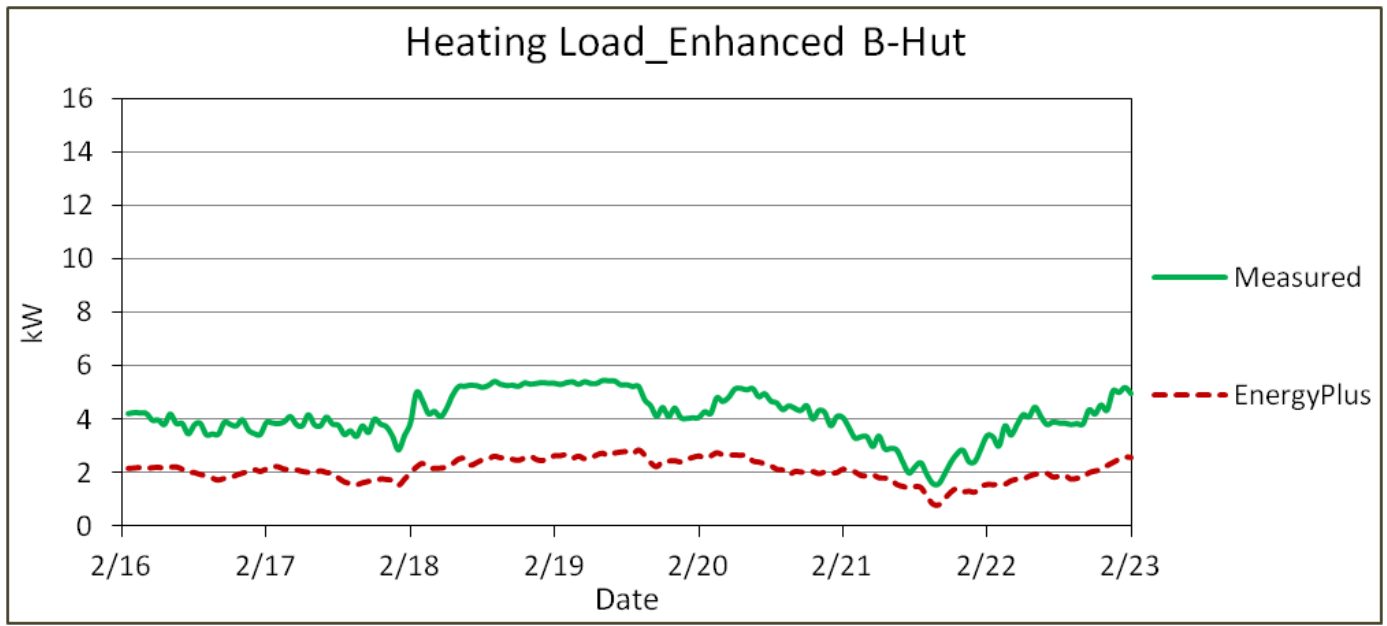

As mentioned earlier, the average conditioned space air temperature was 64.3 and $67.3^{\circ} \mathrm{F}$ for the baseline and enhanced B-huts, respectively. To calculate normalized energy use if both huts were maintained at $70^{\circ} \mathrm{F}$, an EnergyPlus simulation was run using the fixed indoor air temperature. This simulation showed the heating load as 11317 and 2237W for the baseline and enhanced B-huts, respectively. (Note that this does not account for the heating load due to the IECU duct heat loss.) Therefore, the enhanced B-hut needs only one-fifth of the heating energy to maintain a $70{ }^{\circ} \mathrm{F}$ indoor temperature, which is consistent with the test result with the Chigo on heating mode and an electric resistance heater. 
Of the 11317W heating load for the baseline B-hut, $72 \%$ of the load was due to the heat loss through envelope and $28 \%$ was due to the air leakage. Similarly, of the 2237W heating load for the enhanced B-hut, 55\% of theload was due to the heat loss through envelope and $45 \%$ was due to the air leakage.

\subsubsection{IECU in cooling mode}

IECUs were being used in cooling mode in summer of 2015. All analyses in this section reference the data collected from 1 to $7 \mathrm{~J}$ une 2015. Figure 4-48 shows the outdoor air temperature and relative humidity. Figure 4-49 shows the direct beam and diffuse solar radiation. Outdoor air temperature varied between 50.2 and $87.1^{\circ} \mathrm{F}$, with an average value of $66.9^{\circ} \mathrm{F}$. For comparison, Figure 4-50 shows conditioned space air temperature at two huts. The average temperature in the baseline B-hut was $71.5^{\circ} \mathrm{F}$ and the average temperature in the enhanced B-hut was $67.5^{\circ} \mathrm{F}, 3.9^{\circ} \mathrm{F}$ lower than the temperature at the baseline B-hut.

Figures 4-51 and 4-52 show measured (solid lines) and EnergyPlus predicted (dotted lines) exterior surface temperatures for the two huts. EnergyPlus predicted surface temperature matched measured temperatures well except during sunny afternoon hours when EnergyPlus predicted surface temperature up to $6^{\circ} \mathrm{F}$ higher.

Figures 4-53 and 4-54 show measured (solid lines) and EnergyPlus predicted (dotted lines) interior surface temperature for the two huts.

Figures 4-55 and 4-56 show the results for the south wall of the baseline Bhut. Figures 4-57 and 4-58 show the results for the south wall of the improved B-hut.

Infiltration was modeled using the method discussed in Section 4.4.2, IECU in Heating Mode, i.e., the flow coefficient used to model infiltration was adjusted to match the EnergyPlus predicted $\mathrm{ACH}$ with tracer gas test data during the tracer gas test period (May 2015), which yielded an average $\mathrm{ACH}$ of 0.91 for the baseline B-hut and 0.29 for the enhanced B-hut. 
Figure 4-48. Outdoor air temperature and relative humidity.

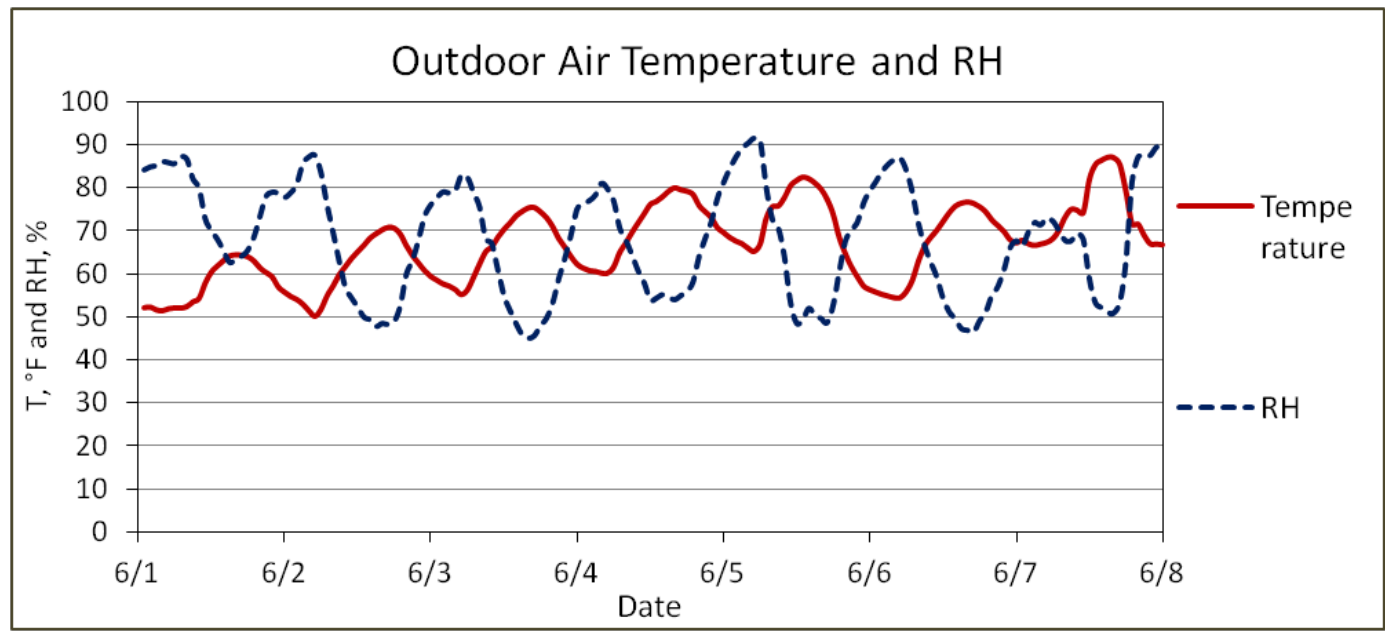

Figure 4-49. Solar radiation.

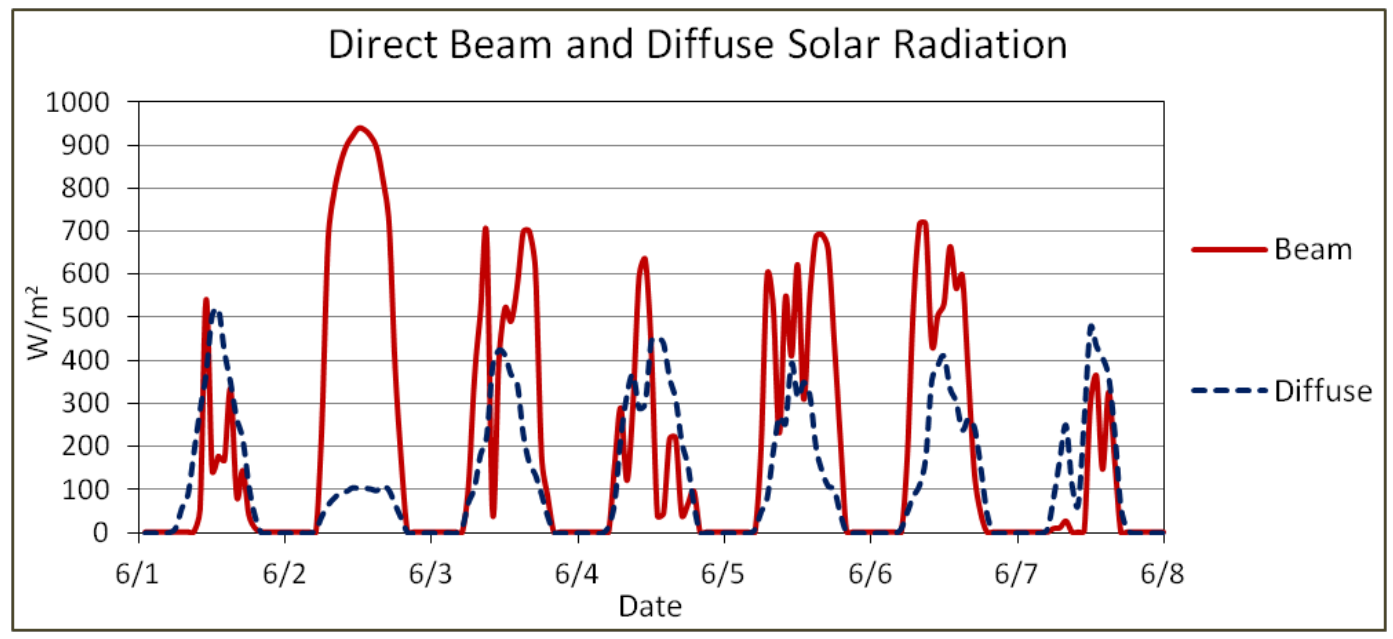

Figure 4-50. Conditioned space air temperature.

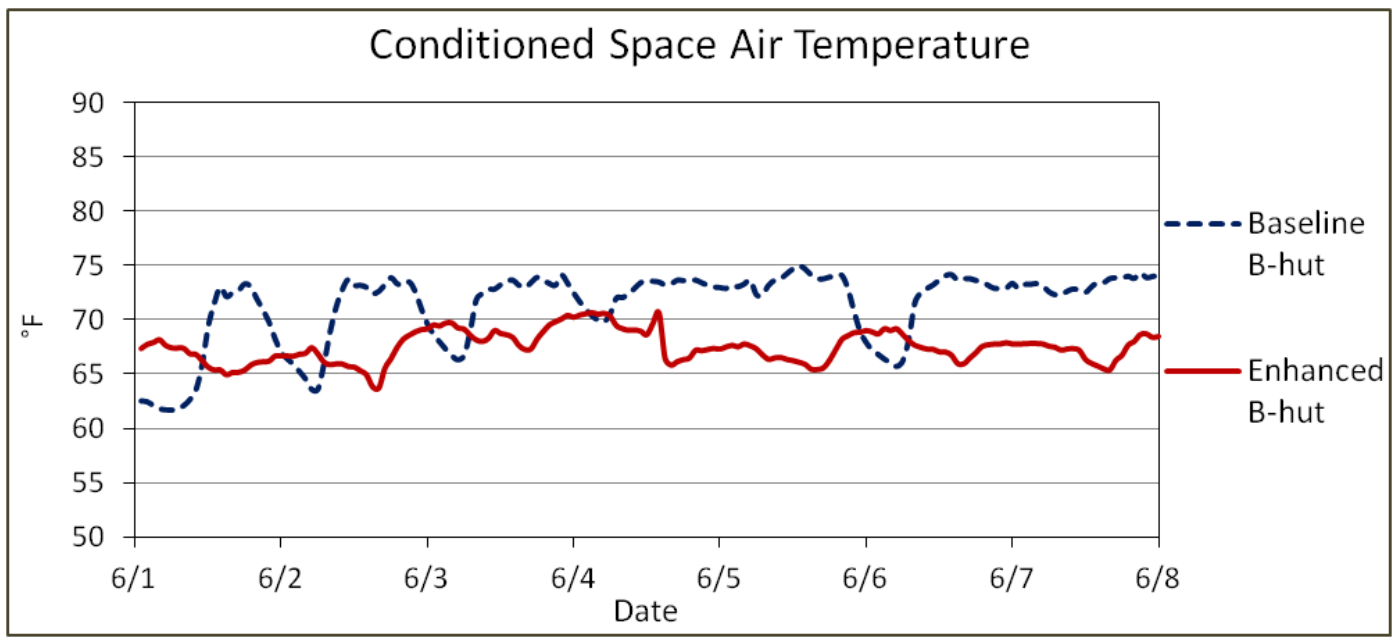


Figure 4-51. Measured (solid lines) and EnergyPlus predicted (dotted lines) exterior surface temperature for the baseline B-hut.

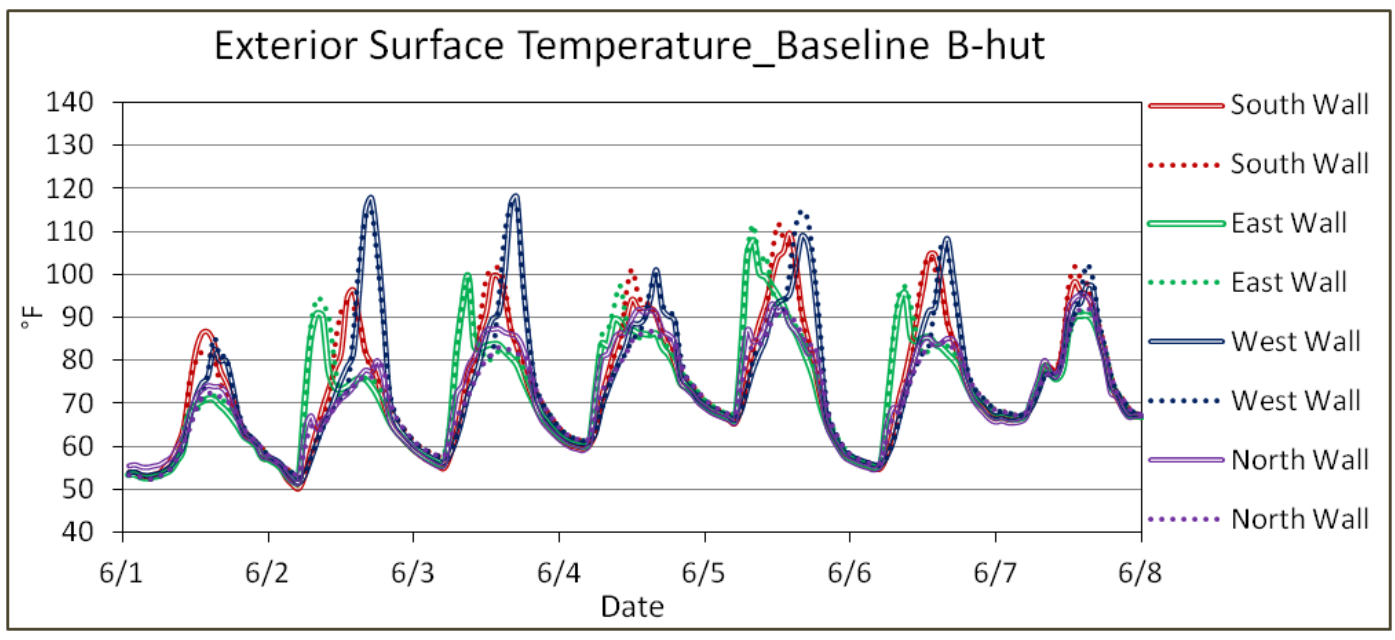

Figure 4-52. Measured (solid lines) and EnergyPlus predicted (dotted lines) exterior surface temperature for the enhanced B-hut.

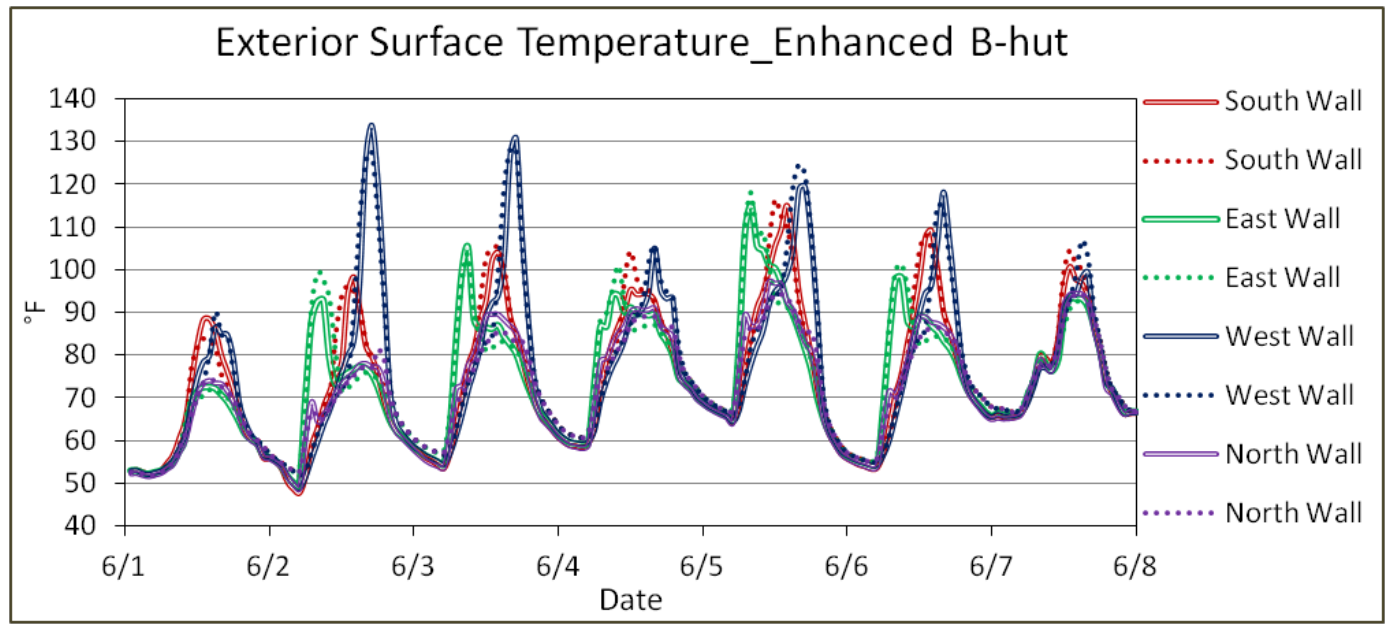

Figure 4-53. Measured (solid lines) and EnergyPlus predicted (dotted lines) interior surface temperature for the baseline B-hut.

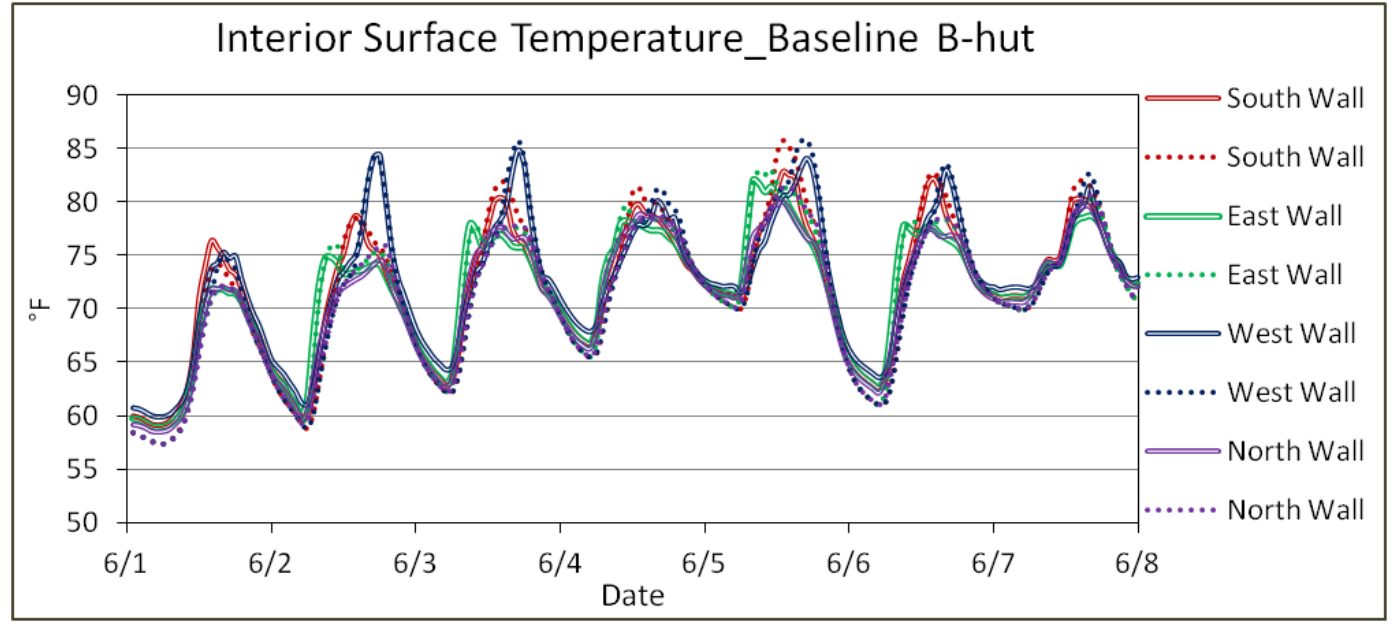


Figure 4-54. Measured (solid lines) and EnergyPlus predicted (dotted lines) interior surface temperature for the enhanced B-hut.

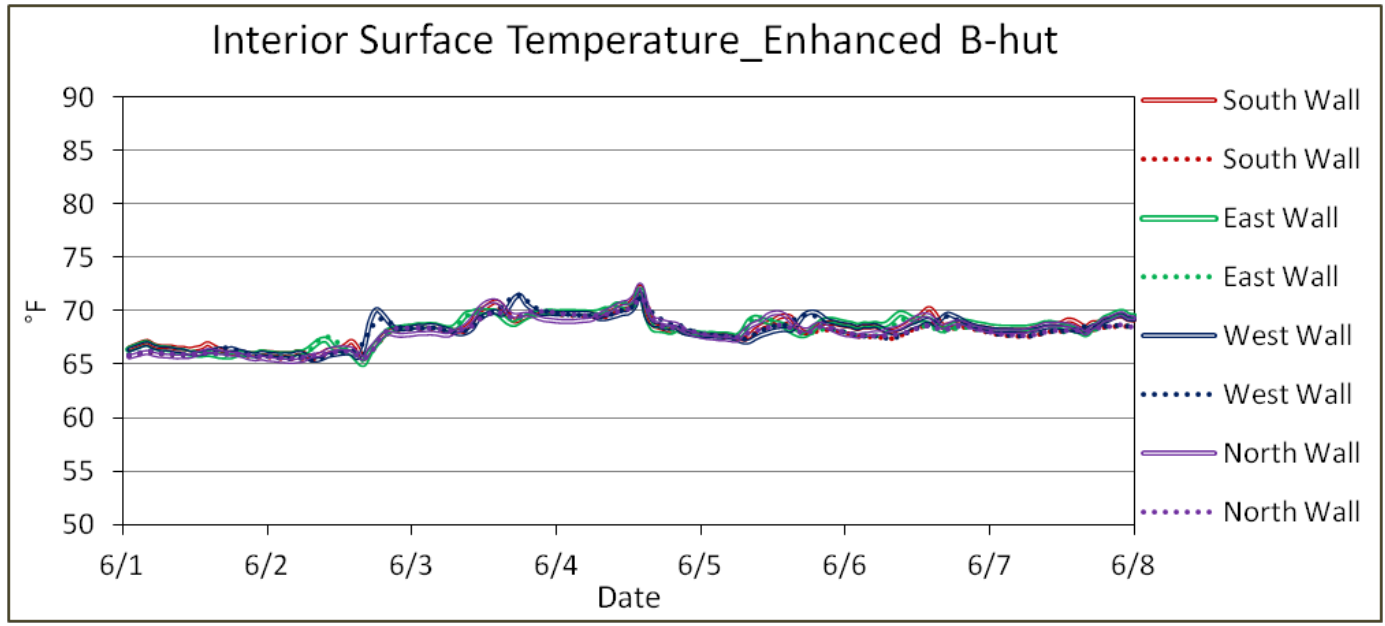

Figure 4-55. Comparison between the EnergyPlus and COMSOL predicted heat flux at interior surface of the south wall of the baseline B-hut

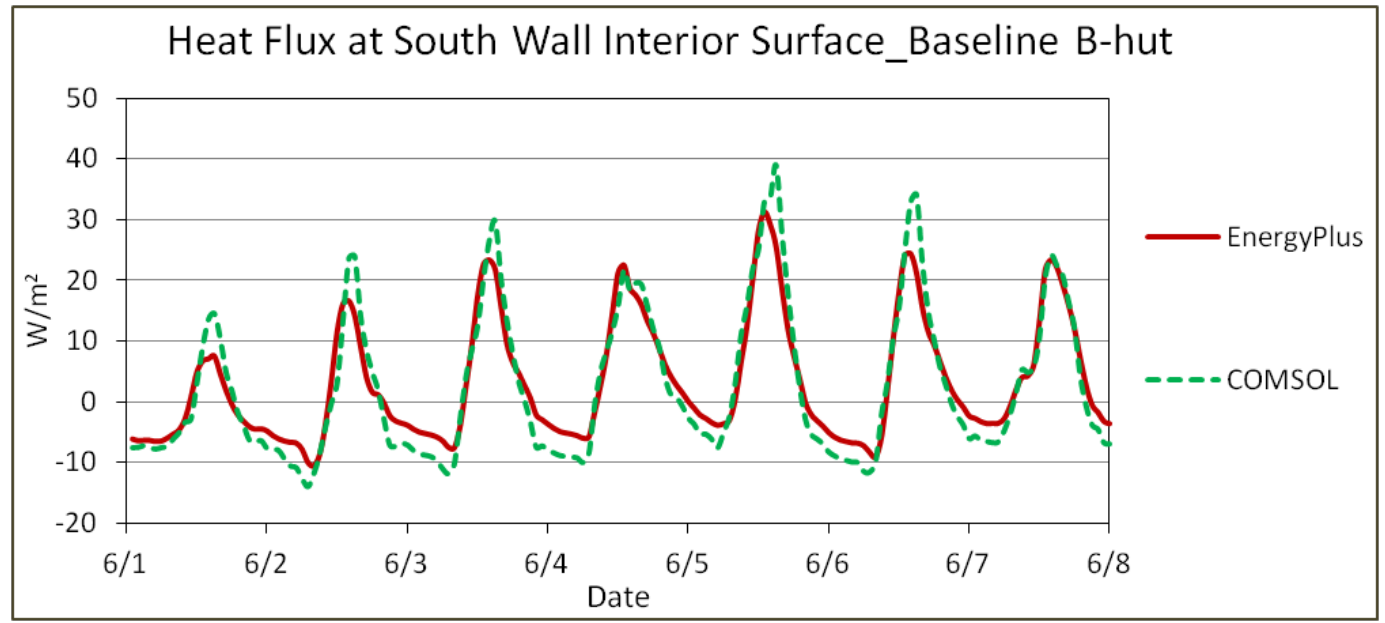

Figure 4-56. Comparison between the measured and COMSOL predicted heat flux at the HFT location of the baseline B-hut.

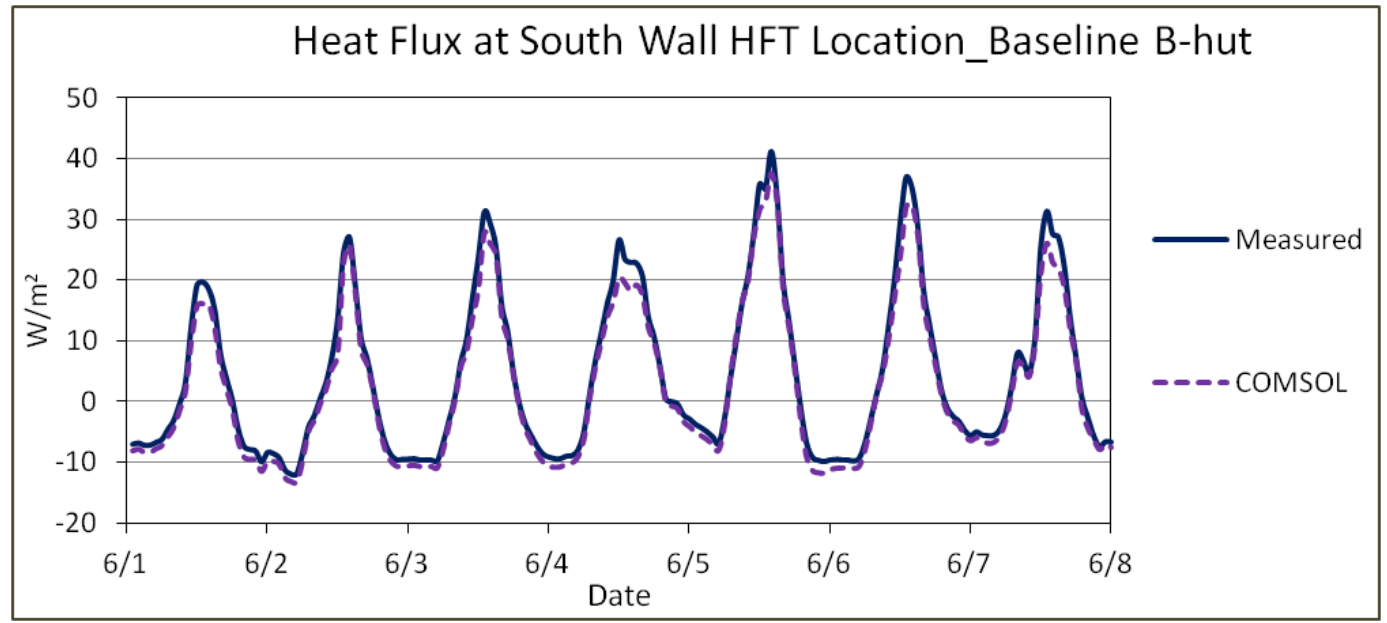


Figure 4-57. EnergyPlus and COMSOL predicted heat flux at interior surface of the south wall of the enhanced B-hut.

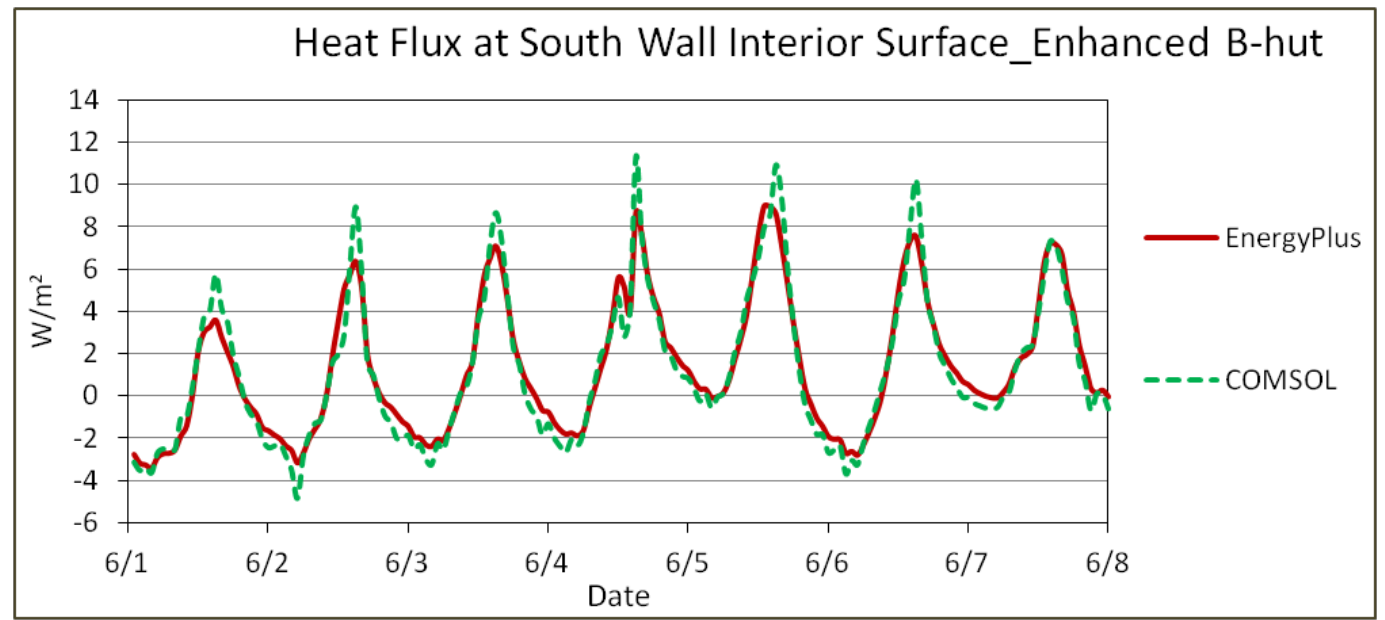

Figure 4-58. Measured and COMSOL predicted heat flux at the HFT location of the south wall of the enhanced B-hut.

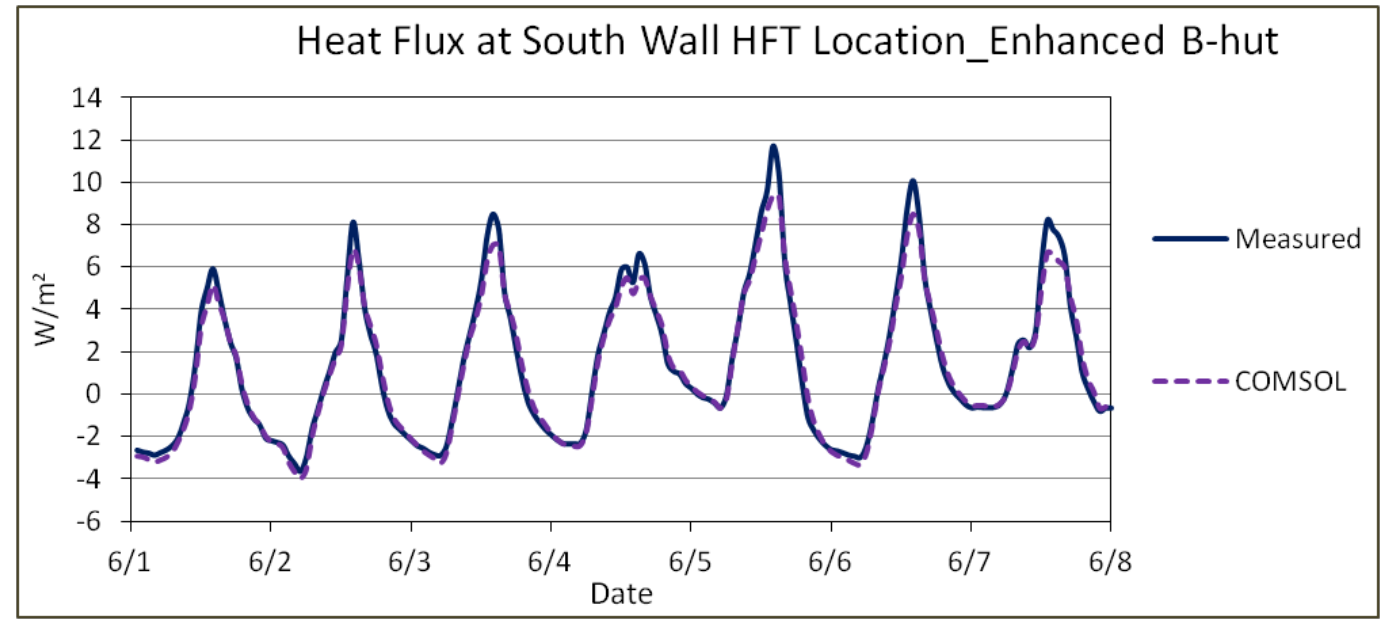

The hourly average rate of IECU energy use for the period was 2467 and 2381W for the baseline and improved B-huts, respectively. This includes the blower fan power that runs all the time, even when there was no cooling load. Blower fan power was 1630W (exceptionally high). To confirm that the data acquisition system (DAQ) was recording the blower power correctly, a separate measurement was taken in May 2015 using a handheld instrument. The fan power measured using the handheld instrument matched with the reading through the DAQ.

Because the blower motor is located in the air stream circulating to the hut, all the electrical energy used by the blower motor is eventually dissipated as heat to the circulating air. Therefore, the blower is essentially 
adding 1630W of cooling load at all the time. This load was modeled as internal load to the huts. For comparison, Figure 4-59 (also Figures 4-48 and 4-50) show that the outdoor air temperature was lower than the indoor air temperature during the first 3 days and on the $5^{\text {th }}$ day. Therefore, if the blower did not run when there was no cooling load, there would have been fewer cooling hours. As mentioned earlier, the average outdoor air temperature was $66.9^{\circ} \mathrm{F}$, which is lower than the average temperature in the baseline and enhanced B-huts.

The EnergyPlus predicted cooling load was 1894 and 1881W for the baseline and enhanced B-huts, respectively. If the cooling load induced due to the blower fan heat were separated from the actual cooling load from the envelope heat gain and infiltration, the net cooling load would be much lower. Since the average outdoor air temperature was lower than the indoor air temperature, the net impact of the heat transfer through the duct and infiltration was negative (losing heat).

Since the data from this analysis period do not represent the cooling period, no further analysis was performed. Note that the final ORNL report will include a more detailed analysis using the summer 2015 data. Heat transfer through the ducts will be modeled using the AirflowNetwork subroutine in EnergyPlus.

Figure 4-59. Conditioned space and outdoor air temperature

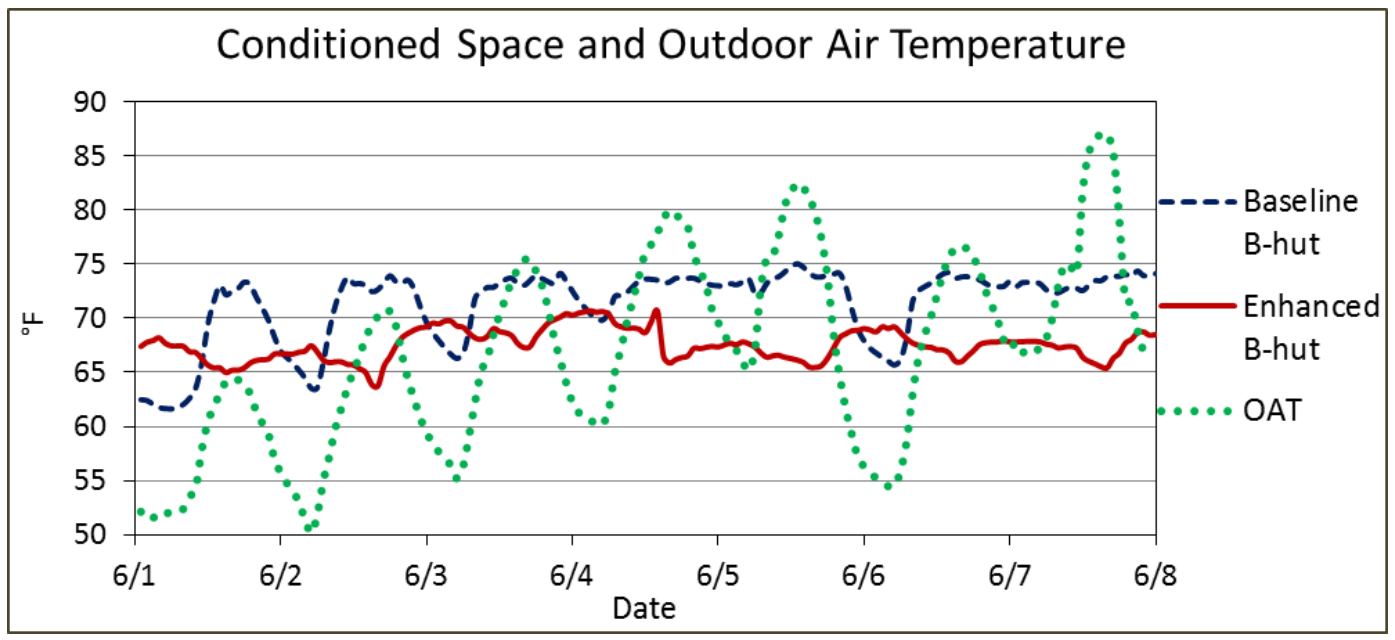




\subsubsection{Electrical resistance heaters}

The Chigo units could not maintain desired indoor temperature and tripped during the winter of 2013-2014. Therefore, six portable electric resistance heaters were installed in the baseline B-hut and two in the enhanced B-hut. A diesel generator powered the huts during this time. Data collected from 16 to 20 April 2014 were used for the analysis. Arguably, this is the best data for validation of EnergyPlus model as the electric resistance hearers have an efficiency of 1 and no performance curve is needed to convert from heating load to energy use.

The analyses in this and subsequent sections closely follow those in the previous sections. All discussion in this section reference the data collected from 16 to 20 April 2014. Figure 4-60 shows the outdoor air temperature and relative humidity. Figure 4-61 shows the direct beam and diffuse solar radiation. The data in these figures indicate that these were sunny days (high direct beam radiation and low diffuse radiation). Outdoor air temperature varied between 31.8 and $76.2^{\circ} \mathrm{F}$, with an average value of $53.2^{\circ} \mathrm{F}$. For comparison, Figure 4-62 shows conditioned space air temperature at the two huts, which indicates a high fluctuation in indoor air temperature at the baseline B-hut while the temperature at the enhanced B-hut was mostly steady.

The average temperature in the baseline B-hut was $72.2^{\circ} \mathrm{F}$ and that in the enhanced B-hut was $67.6^{\circ} \mathrm{F}, 4.5^{\circ} \mathrm{F}$ lower than the temperature at the baseline B-hut. For comparison, Figures 4-63 and 4-64 show measured (solid lines) and EnergyPlus predicted (dotted lines) wall exterior surface temperatures for the two huts. EnergyPlus predicted surface temperatures matched measured temperatures well except during sunny afternoon hours when EnergyPlus predicted surface temperatures of up to $5^{\circ} \mathrm{F}$ higher. For comparison, Figures 4-65 and 4-66 show measured (solid lines) and EnergyPlus predicted (dotted lines) interior surface temperatures.

Figures 4-67 and 4-68 show the results for the south wall of the baseline B-hut. Figures 4-69 and 4-70 show the results for the south wall of the improved B-hut, respectively. Compared to the measured data, the COMSOL calculated average heat loss at the HFT location was $0.31 \mathrm{~W} / \mathrm{m}^{2}$ higher for the baseline B-hut and $0.35 \mathrm{~W} / \mathrm{m}^{2}$ higher for the enhanced B-hut. 
Figure 4-60. Outdoor air temperature and relative humidity.

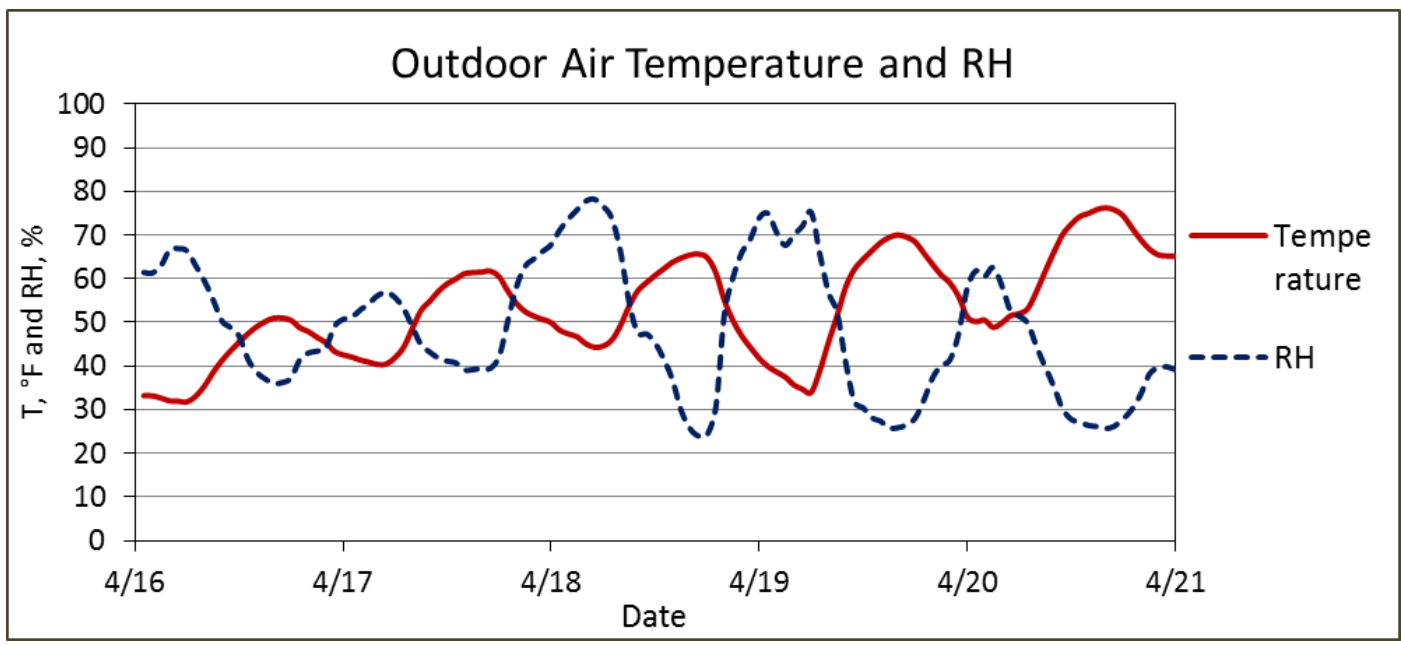

Figure 4-61. Solar radiation.

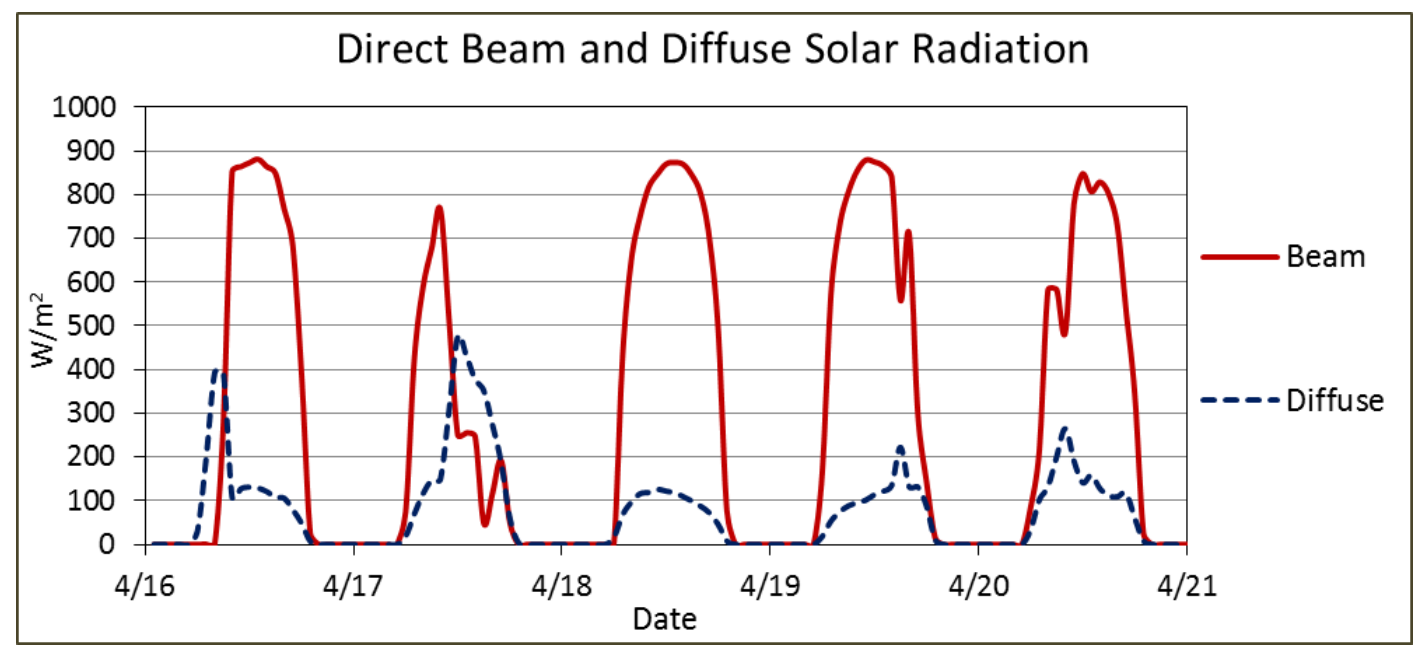

Figure 4-62. Conditioned space air temperature.

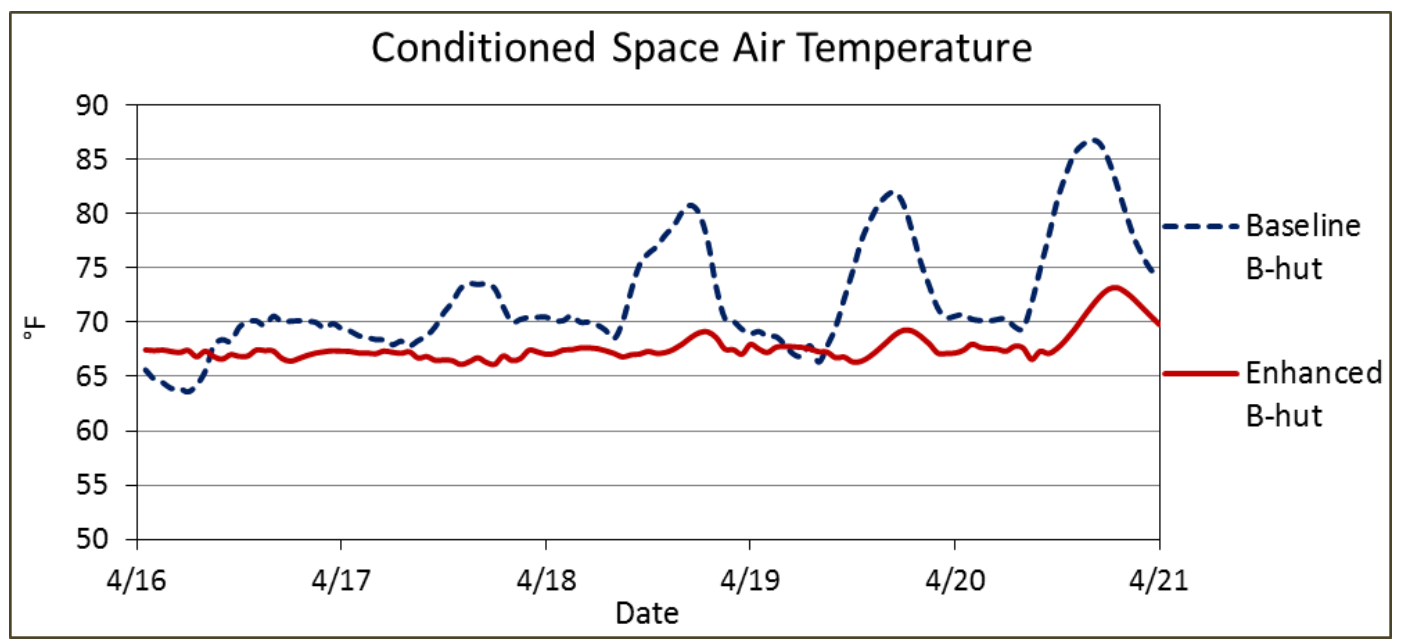


Figure 4-63. Measured (solid lines) and EnergyPlus predicted (dotted lines) exterior surface temperature for the baseline B-hut.

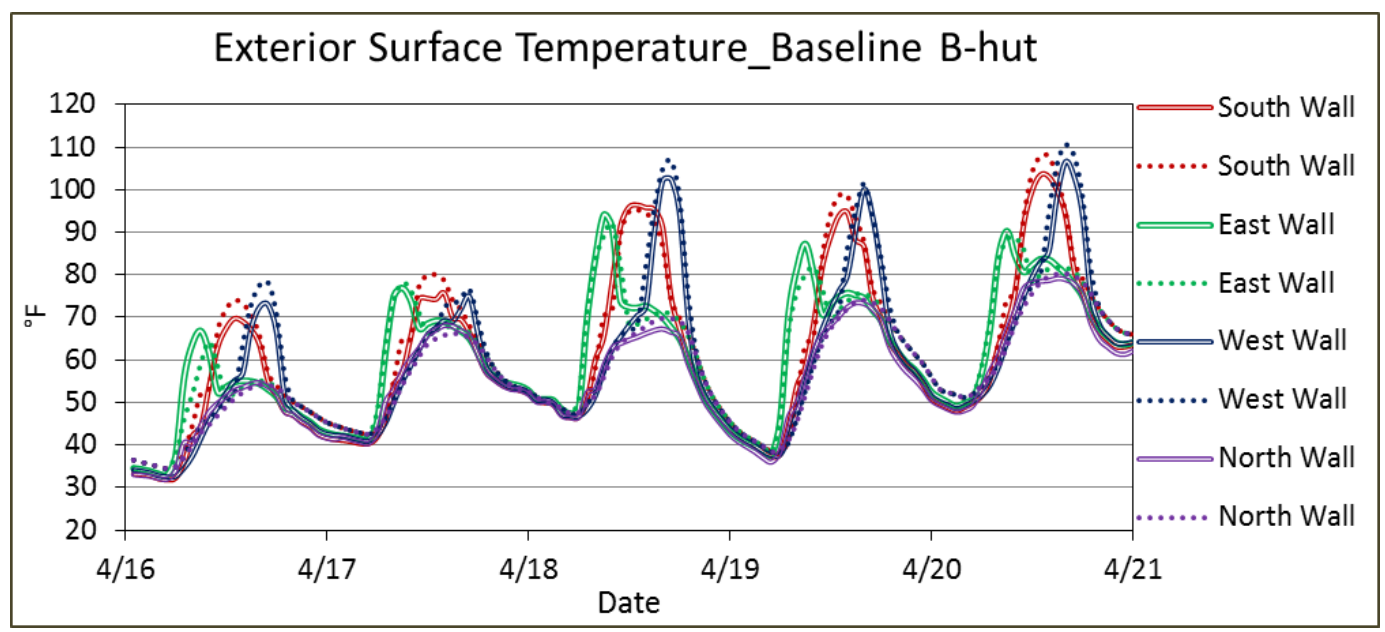

Figure 4-64. Measured (solid lines) and EnergyPlus predicted (dotted lines) exterior surface temperature for the enhanced B-hut.

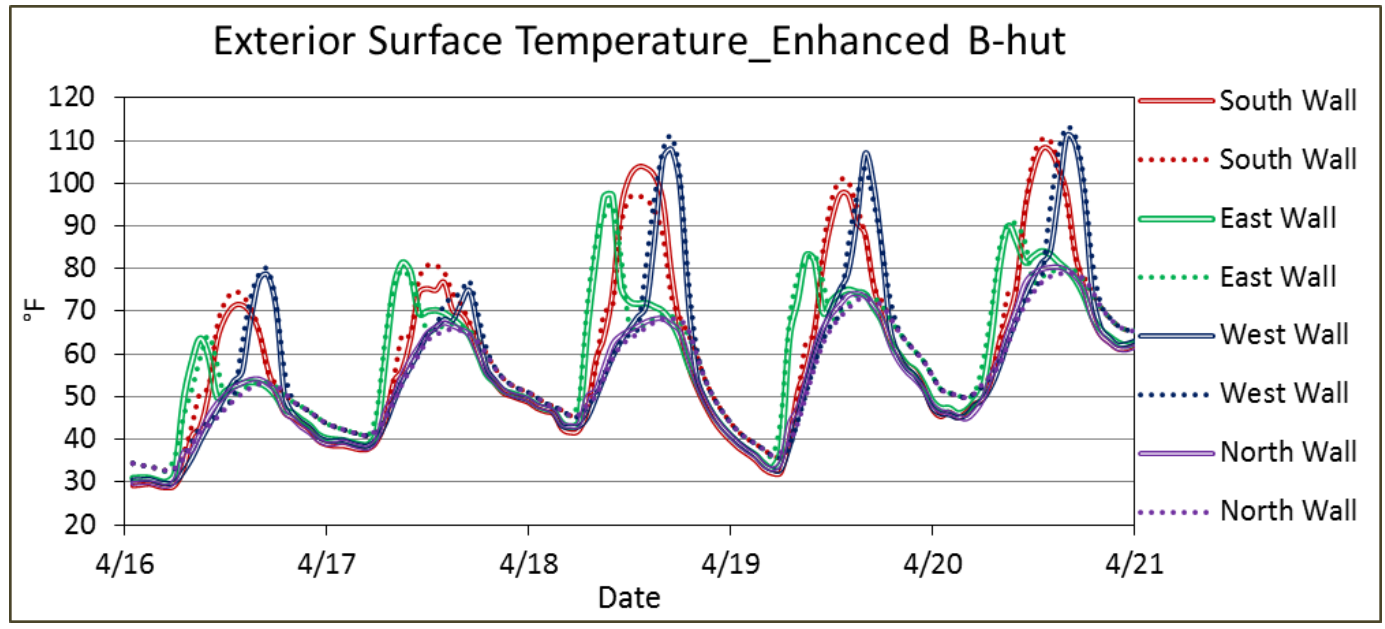

Figure 4-65. Measured (solid lines) and EnergyPlus predicted (dotted lines) interior surface temperature for the baseline B-hut.

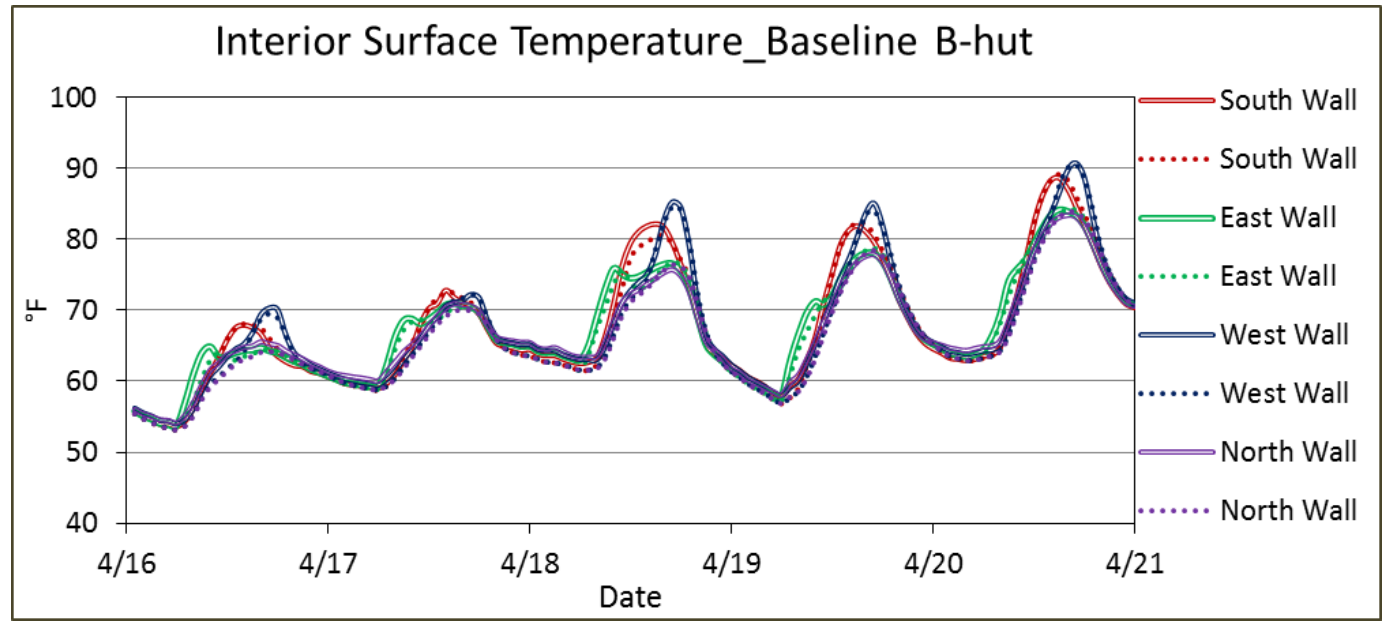


Figure 4-66. Measured (solid lines) and EnergyPlus predicted (dotted lines) interior surface temperature for the enhanced B-hut

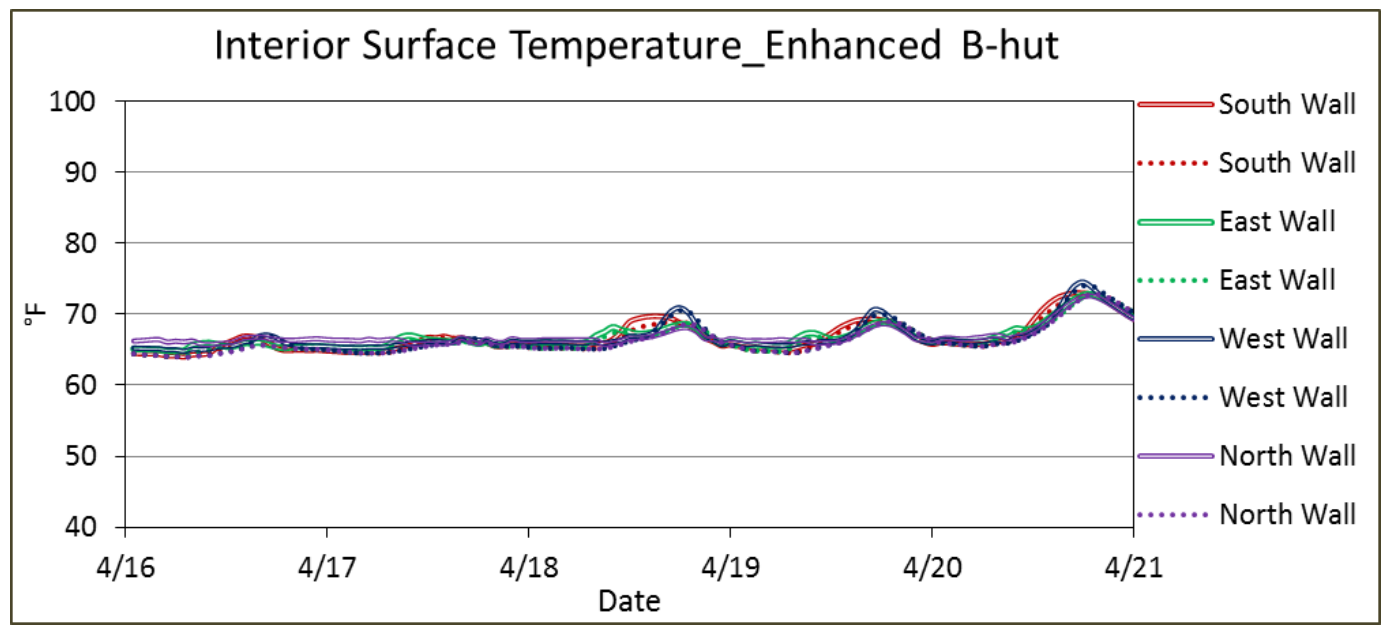

Figure 4-67. EnergyPlus and COMSOL predicted heat flux at interior surface of the south wall of the baseline B-hut.

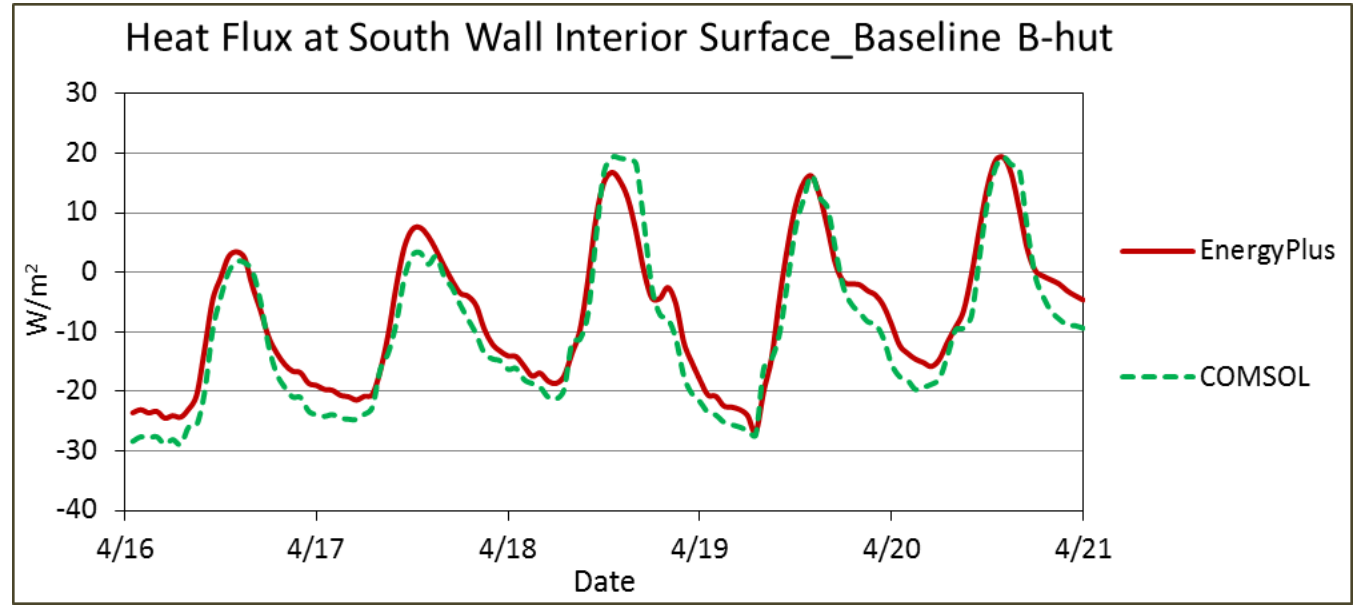

Figure 4-68. Measured and COMSOL predicted heat flux at the HFT location of the baseline B-hut.

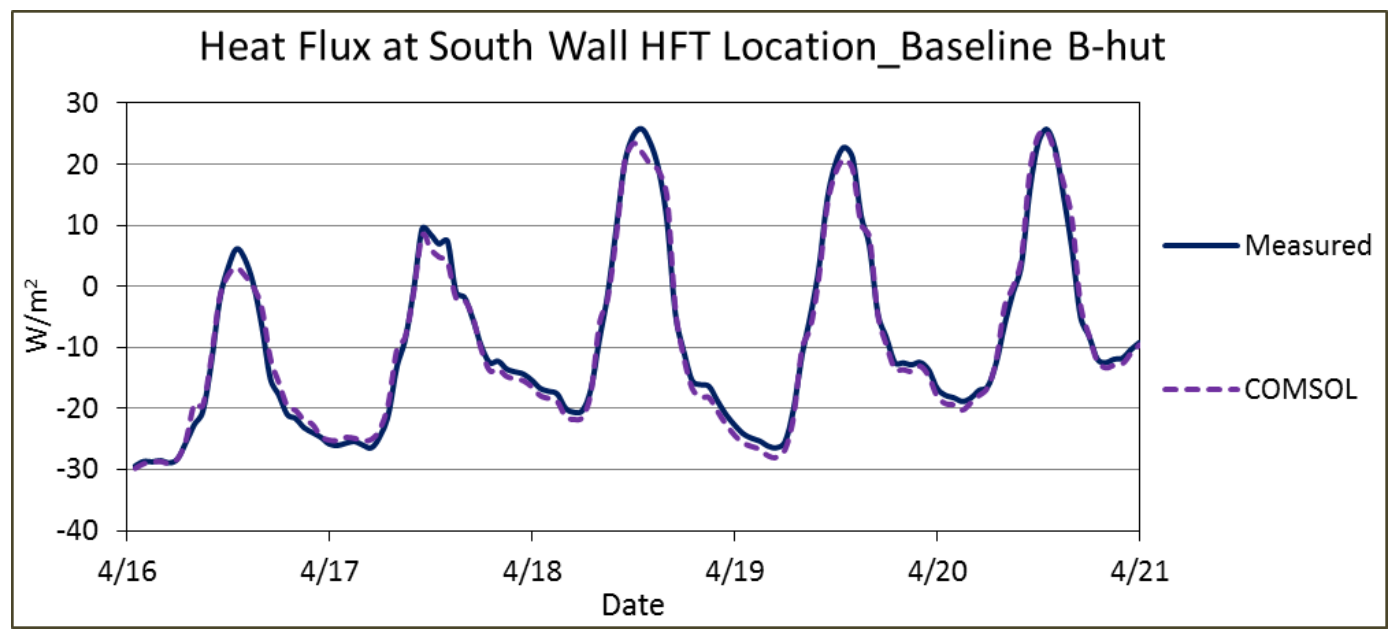


Figure 4-69. EnergyPlus and COMSOL predicted heat flux at interior surface of the south wall of the enhanced B-hut.

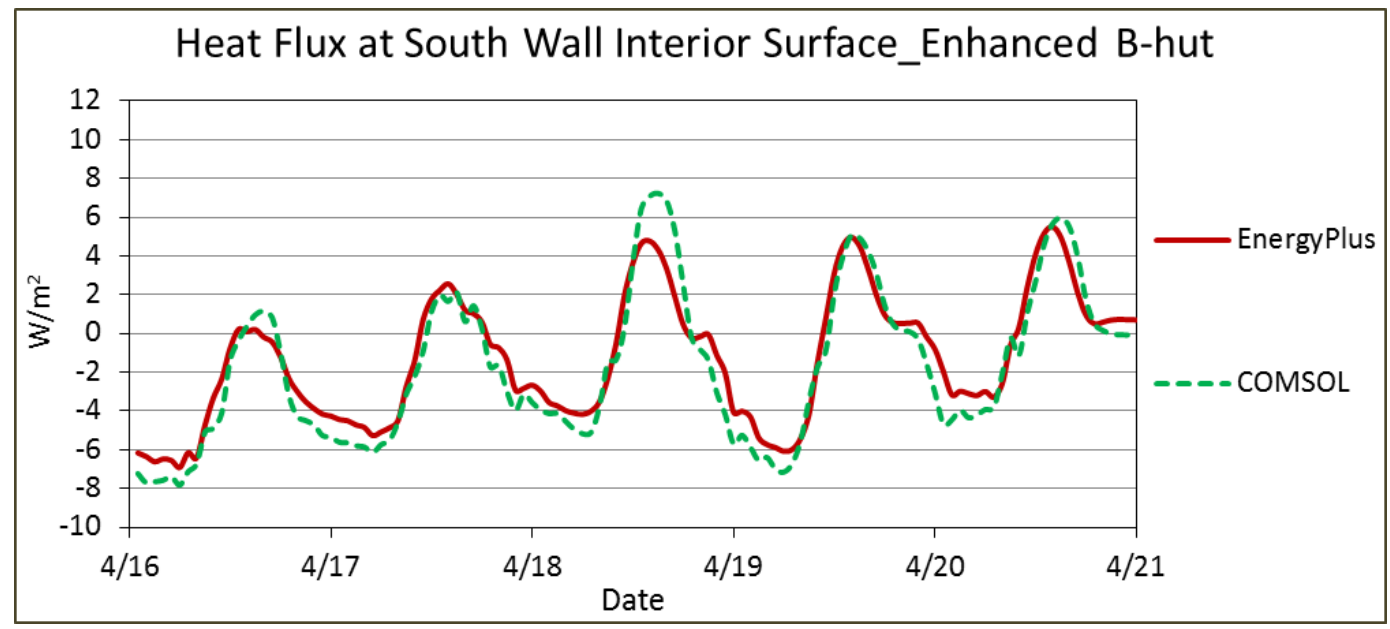

Figure 4-70. Measured and COMSOL predicted heat flux at the HFT location of the south wall of the enhanced B-hut.

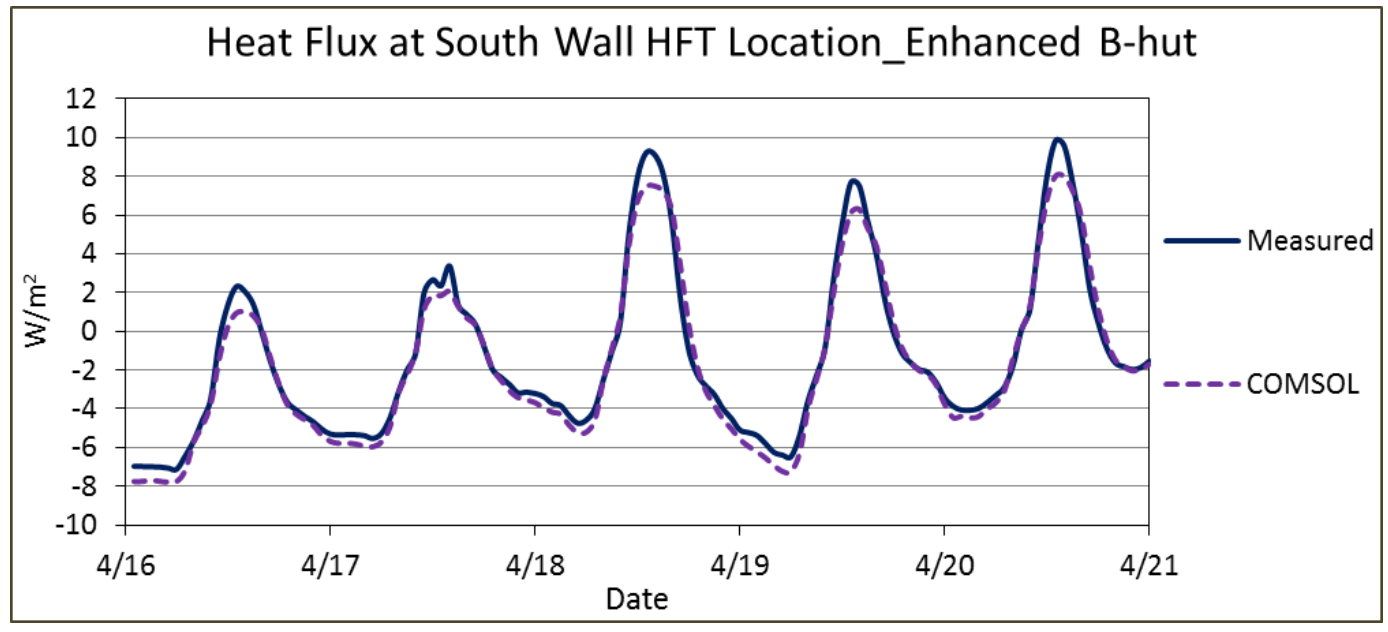

Infiltration was modeled using the blower door test result from J uly 2013, which yielded an average $\mathrm{ACH}$ of 1.24 for the baseline B-hut and an average $\mathrm{ACH}$ of 0.35 for the enhanced B-hut.

The hourly average rate of heating energy use for the period was 3149 and 489W and the EnergyPlus predicted heating load was 2886 and 455W for the baseline and enhanced B-huts, respectively. Therefore, the difference between heating energy use and the simulation predicted heating load was $8 \%$ for the baseline B-hut and 7\% for the enhanced B-hut. (EnergyPlus underpredicted in both cases.) For comparison, Figures 4-71 and 4-72 show hourly electric heater energy use and EnergyPlus predicted heating load for the two huts. 
Figure 4-71. Electric heater energy use and the EnergyPlus predicted heating load for the baseline B-hut.

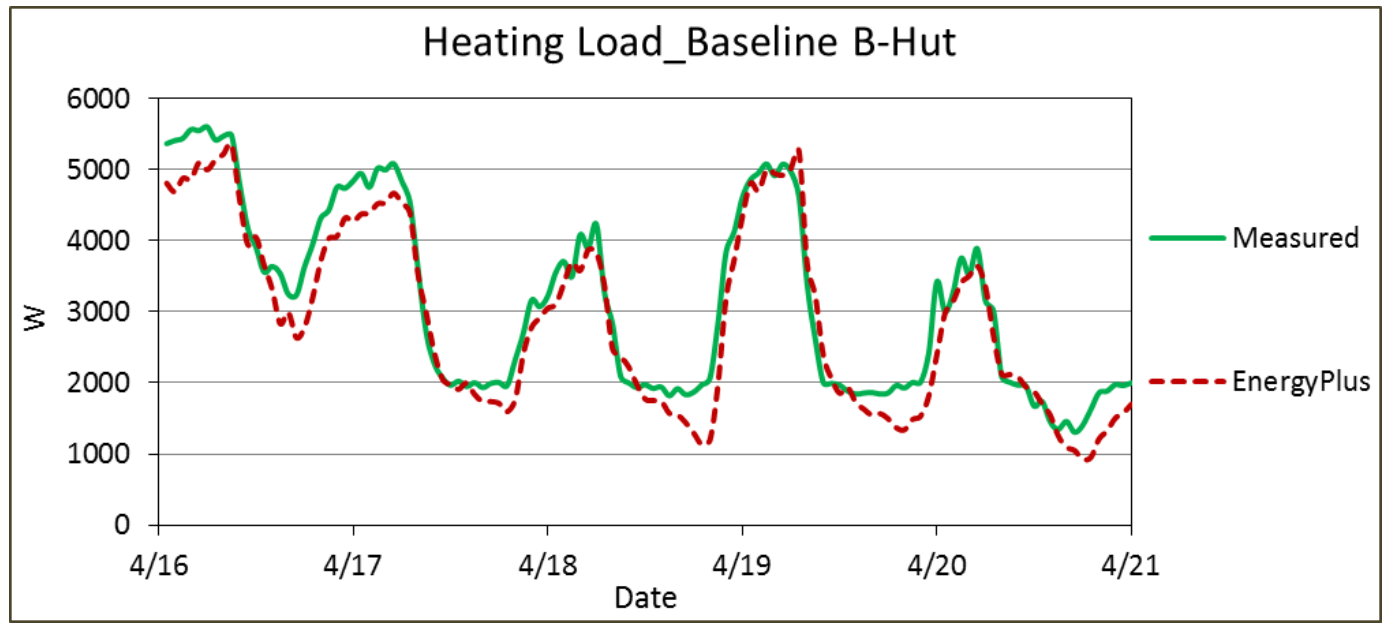

Figure 4-72. Electric heater energy use and the EnergyPlus predicted heating load for the enhanced B-hut.

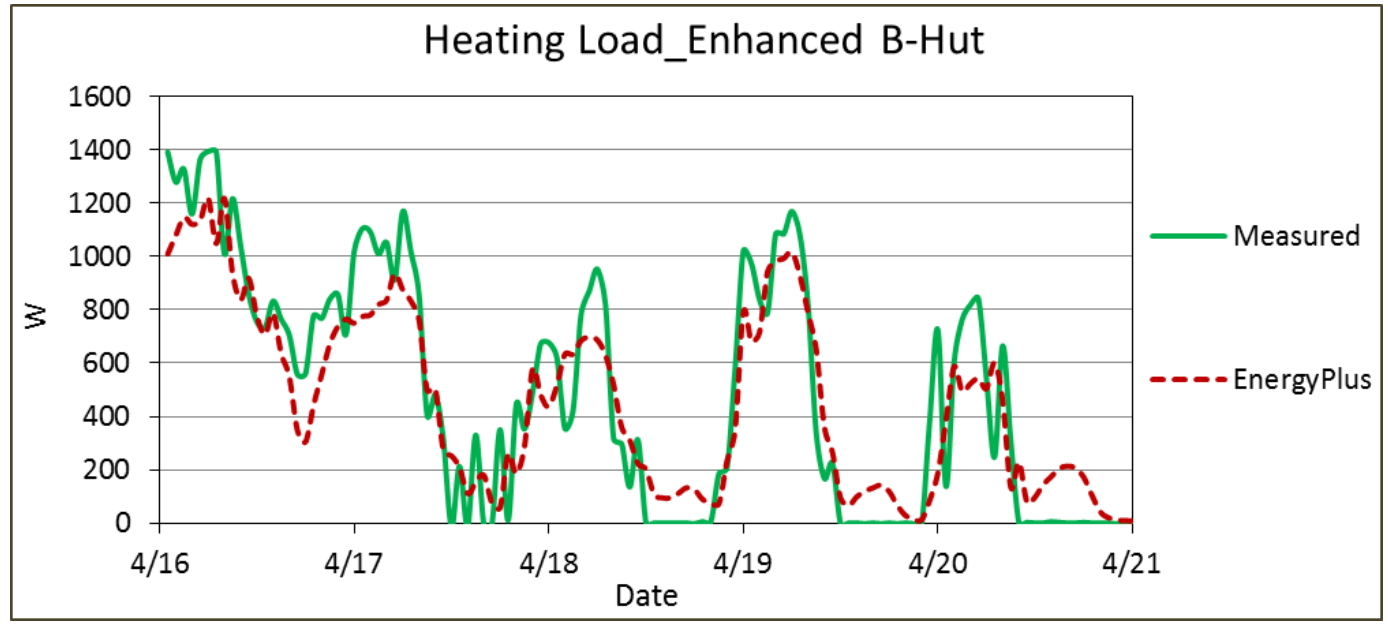

As mentioned earlier, the average conditioned space air temperature was 72.2 and $67.7^{\circ} \mathrm{F}$ for the baseline and enhanced B-huts, respectively. To calculate normalized energy use if both huts were maintained at $70^{\circ} \mathrm{F}$, an EnergyPlus simulation was run using the fixed indoor air temperature. This simulation showed the heating load was 2583 and 538W for the baseline and enhanced B-huts, respectively. Therefore, the enhanced B-hut needs only one-fifth of the heating energy to maintain $70^{\circ} \mathrm{F}$ indoor temperature, which is consistent with the test with the Chigo on heating mode.

Of the 2583W heating load for the baseline B-hut, $81 \%$ of the load was due to the heat loss through envelope and $19 \%$ was due to the air leakage. Similarly, of the 539W heating load for the enhanced B-hut, $71 \%$ of the load was due to the heat loss through envelope and $29 \%$ was due to the air leakage. 


\section{Conclusions, Findings, and Recommendations}

\subsection{Conclusions}

This work quantified the performance of commercially available technologies and common techniques (i.e., wall insulation, attic radiant barrier, and interior sealing to reduce air leakage) to evaluate their potential to improve the energy performance of Army Temporary Shelters, and to determine if the ROI for these enhancements is sufficient to modify the current standard configuration of shelters.

An analysis of preliminary data (Chapter 4), indicates that the Enhanced Shelter, which used the tested commercially available technologies, significantly outperformed the Control Shelter. Based on that data, this work concludes that the improvements made to the Enhanced Shelter did significantly and cost effectively reduce its energy consumption relative to that of the Control Shelter.

\subsection{Findings}

B-huts are commonly used at COBs due to their simple design, ease of construction by unskilled workers, and adaptability to a wide variety of uses. Because they are of all wood construction, locally sourced materials can often be used to build them. Unfortunately, the quality of B-huts can vary considerably due to the use of unskilled labor. Even the EFOB-L B-huts, which were built by a local contractor's skilled workers, were found to have gaps in the building envelope (Figure 5-1).

The lack of a tight building envelope, combined with little or no insulation, can result in extremely energy inefficient structures that are unable to provide comfortable working and living conditions for the occupants. This research effort studied the improvement in energy performance possible by adding insulation and improving the airtightness of B-huts through relatively simple enhancements to a basic "unimproved" B-hut. 
Figure 5-1. Gap in ceiling/wall connection as shown by light entering the space.

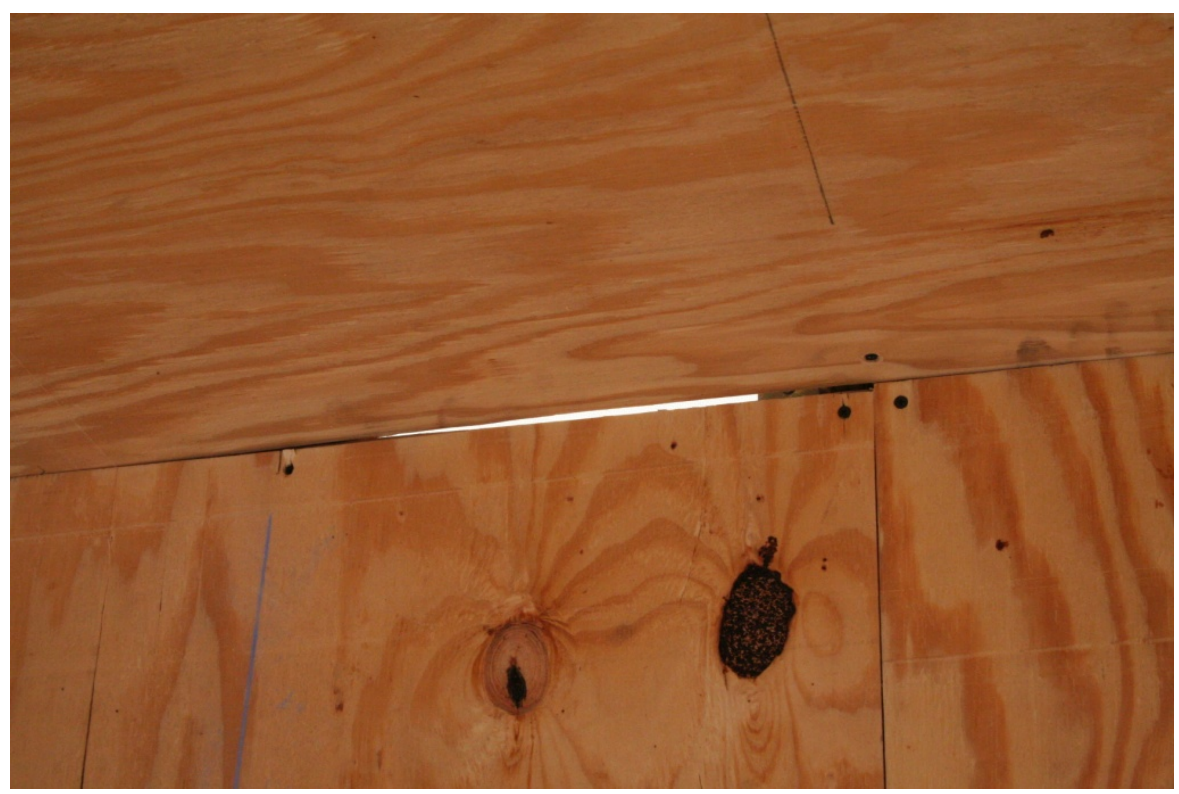

\subsection{Energy findings}

The performance of the baseline and enhanced B-huts were monitored under both cooling and heating conditions.

\subsubsection{Cooling performance}

An initial 1-month cooling energy study of the two B-huts was performed immediately after they were completed in J uly 2013. While maintaining an average $78^{\circ} \mathrm{F}$ indoor temperature in both huts, the electrical energy use of the Chigo mini-split unit in the baseline B-hut was found to be five times greater than that of the Chigo in the enhanced B-hut.

Subsequently, ORNL began a more detailed and longer period of monitoring the energy performance of both B-huts. Although ORNL was hampered by power supply issues at EFOB-L that limited their ability to collect and analyze uninterrupted periods of energy consumption, preliminary findings from summer 2014 results indicated that the Chigo unit in the enhanced B-hut would need only $25 \%$ of the energy used by the Chigo in the baseline B-hut to maintain an average $75^{\circ} \mathrm{F}$ indoor temperature. IECUs were used to provide cooling to both huts for the 2015 cooling season, and ORNL is currently monitoring the cooling performance of both B-huts for the 2015 summer, and will provide a follow-on report in September 2015. 


\subsubsection{Heating performance}

ORNL conducted a very limited analysis of the heating performance of the Chigo units in October 2013, which ended due to the weather becoming too cold for the units to function properly. The results indicated that the enhanced B-hut would need only one-fifth of the heating energy needed for the baseline B-hut if both huts were maintained at an average $70{ }^{\circ} \mathrm{F}$ interior temperature.

After the Chigo units were shut down in both B-huts, electric resistance heaters were placed in both huts to provide heating. To maintain an average $70^{\circ} \mathrm{F}$ indoor temperature, the baseline B-hut required six heaters while the enhanced B-hut needed only two. Both B-huts continued to suffer from power supply issues, and ORNL again was constrained in their ability to monitor and analyze uninterrupted periods of energy data. However, the results indicated the enhanced B-hut needs only one-fifth of the heating energy to maintain, which is consistent with the results using the Chigo units on heating mode.

During the winter of 2015, ORNL monitored the performance of IECU units that replaced the electric resistance heaters to provide heating. Consistent with the results of the tests using Chigo units and electric resistance heaters, ORNL found that the IECU for the enhanced B-hut needs only one-fifth of the heating energy required by the baseline B-hut to maintain an indoor temperature of $70^{\circ} \mathrm{F}$.

\subsection{Envelope findings}

Following the initial 1-month cooling energy study, ERDC-CERL researchers further improved the enhanced B-hut by sealing all interior seams and openings with air sealing tape. This was accomplished for a total tape cost of approximately $\$ 500$ and 14.5 hours of labor. The labor hours can be reduced further if the tape were applied during construction instead of post construction as was done at EFOB-L. ORNL's energy data analyses have shown that the addition of insulation in the walls, floor, and ceiling, and minimization of air leakage in a B-hut clearly and significantly improved the energy performance of the enhanced B-hut over the baseline B-hut.

Unfortunately, the reality is that B-huts at contingency bases are seldom, if ever, insulated. Fiberglass batt insulation is bulky and uneconomical to ship, and foam type insulation may be difficult and hazardous to dispose of 
at the end of the B-huts' service life. The proper installation or application of various other types of insulation also requires a certain amount of skill. A new gas-filled insulation panel (see Appendix B) has potential as an alternative to fiberglass batt insulation, but more testing and analyses is needed to determine its performance and practicality for use in B-huts.

Air sealing tape, on the other hand, has a proven effectiveness in significantly reducing air leakage in building envelopes. The tape takes up a very small amount of shipping volume, and can be easily applied after minimal instructions and training.

After the sealing of seams and openings in the enhanced B-hut, the only remaining major source of air leakage are the two exterior doors on either end of the structure. These doors are made on site and do not seal well (Figure 5-2). Besides allowing a high amount of air leakage, they also allow the entry of rainwater (Figure 5-3) and blown in snow (Figure 5-4) during inclement weather. This unwanted intrusion of water into a B-hut can increase interior space humidity, allow the growth of mold, and damage the plywood materials through delamination and rot.

Figure 5-2. Typical B-hut leaky door.

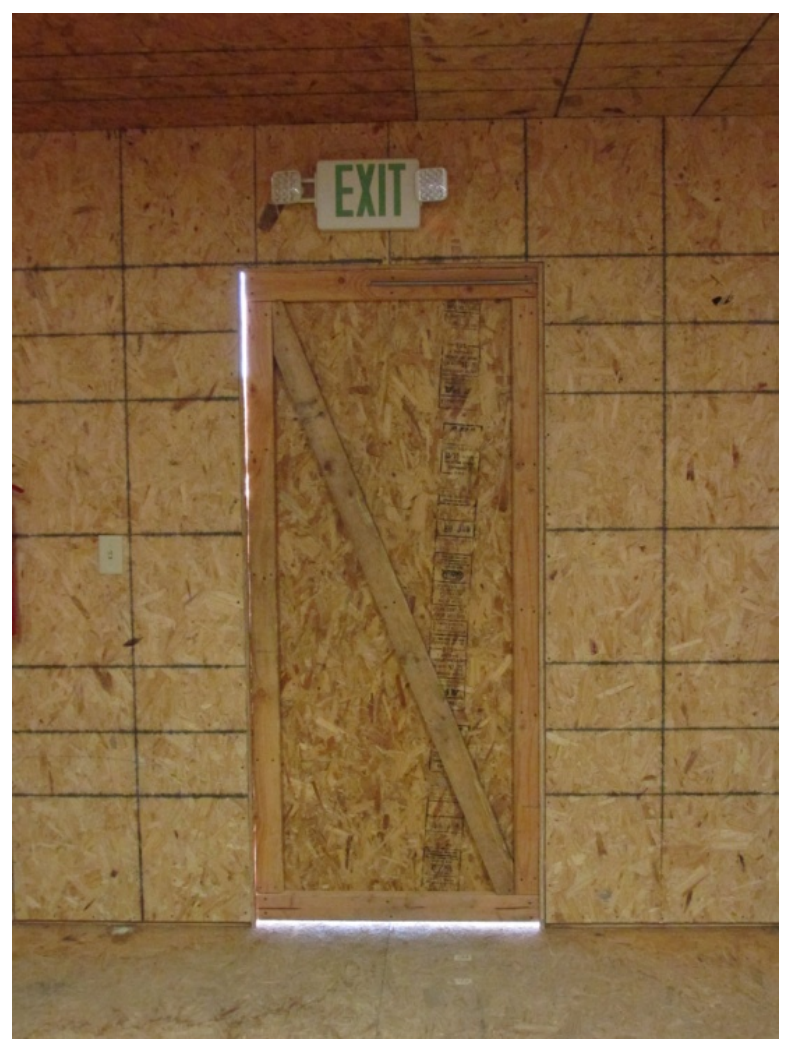


Figure 5-3. Entry of enhanced B-hut showing water stains and mold from entry of rainwater.

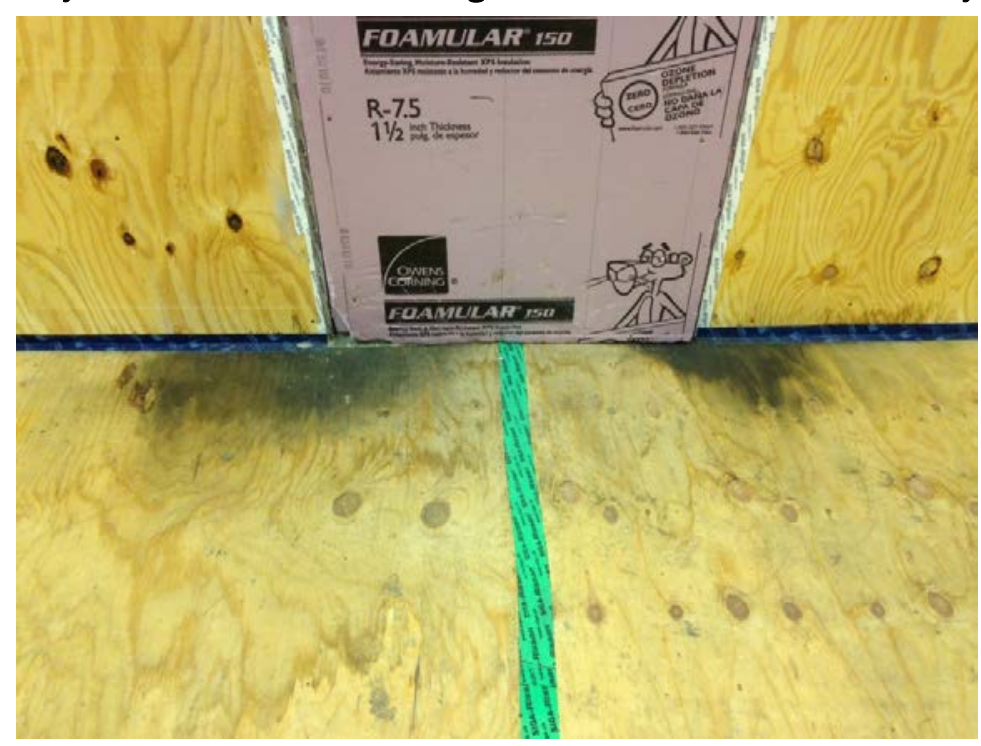

Figure 5-4. Snow blown in under sill of B-hut door.

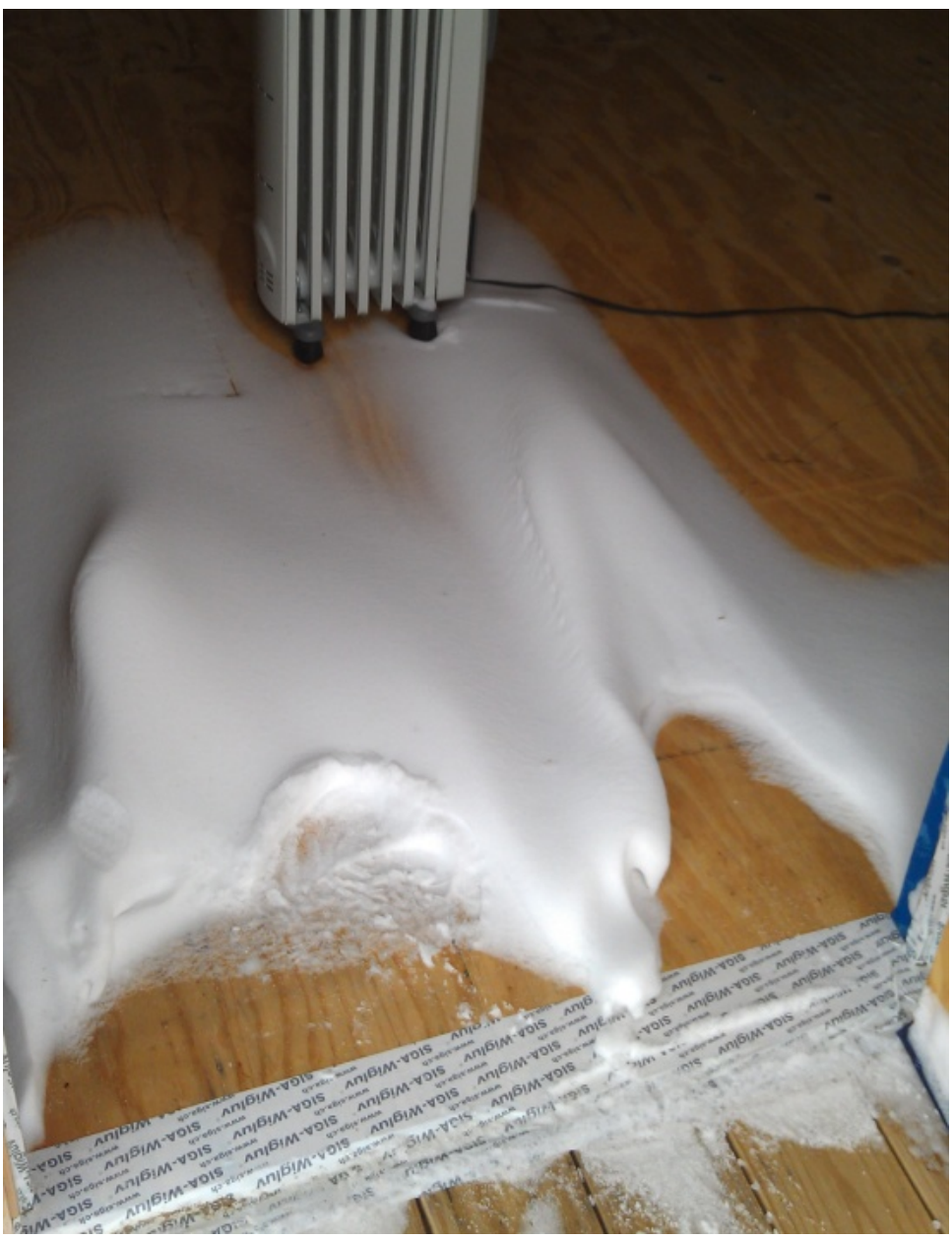




\subsection{Recommendations}

ORNL will complete monitoring and analysis of the B-huts' respective energy performance at the conclusion of the 2015 cooling season. Final recommendations for improving B-hut energy performance will be made upon the conclusion of their research. In the meantime, it is quite apparent that adding insulation and sealing against air leakage can yield substantial benefits to a B-hut. Although finding a suitable insulation material that is effective, yet not bulky to ship is still to be resolved, newer types of insulation (as described in Appendix B) may show promise. At the very least, serious consideration should be given to provide insulation to B-huts used as living quarters in climate locations where nighttime temperatures can be very cold.

Applying air sealing tape to all seams and openings in a B-hut is strongly recommended. The material cost is low, the tape can be applied quickly with no previous training or experience required, and the reduction in air leakage is immediate.

Pre-hung exterior entry doors should be installed on all B-huts in place of doors hand-built on site. Better quality doors, combined with air sealing, will significantly reduce air leakage, improve the overall energy performance, and prevent potentially damaging water penetration. 


\section{Acronyms and Abbreviations}

\begin{tabular}{|c|c|}
\hline $\begin{array}{l}\text { Term } \\
\text { AC }\end{array}$ & $\begin{array}{l}\text { Definition } \\
\text { Alternating Current }\end{array}$ \\
\hline $\mathrm{ACH}$ & Air Changes per Hour \\
\hline $\mathrm{AHU}$ & Air Handling Unit \\
\hline CEERD & U.S. Army Corps of Engineers, Engineer Research and Development Center \\
\hline CERL & Construction Engineering Research Laboratory \\
\hline $\mathrm{CMU}$ & Concrete Masonry Unit \\
\hline $\mathrm{COB}$ & Contingency Operating Base \\
\hline CRREL & Cold Regions Research and Engineering Laboratory \\
\hline DC & Direct Current \\
\hline DoD & U.S. Department of Defense \\
\hline DOE & U.S. Department of Energy \\
\hline ECU & Environmental Control Unit \\
\hline EISA & U.S. Energy Independence and Security Act of 2007 \\
\hline EO & Executive Order \\
\hline ERDC & Engineer Research and Development Center \\
\hline ERDC-CERL & Engineer Research and Development Center, Construction Engineering Research Laboratory \\
\hline FOB & Forward Operating Base \\
\hline HVAC & Heating, Ventilating, and Air-Conditioning \\
\hline NZE & Net Zero Energy \\
\hline ORNL & Oak Ridge National Laboratory \\
\hline NIST & National Institute of Standards and Technology (formerly National Bureau of Standards) \\
\hline OMB & Office of Management and Budget \\
\hline PID & Proportional-Integral-Derivative \\
\hline ROI & Return on Investment \\
\hline SEM & Scanning Electron Microscope \\
\hline SF & Standard Form \\
\hline TARP & Thermal Analysis Research Program \\
\hline TN & Technical Note \\
\hline TR & Technical Report \\
\hline URL & Universal Resource Locator \\
\hline WWW & World Wide Web \\
\hline XPS & Extruded Polystyrene \\
\hline
\end{tabular}




\section{References}

American Society of Heating, Refrigerating and Air-Conditioning Engineers (ASHRAE). 2013. 2013 ASHRAE Handbook: Fundamentals, Inch-Pound Edition. Atlanta, GA: ASHRAE.

American Society for Testing and Materials (ASTM). 2011. Standard Test Method for Thermal Performance of Building Materials and Envelope Assemblies by Means of a Hot-Box Apparatus. ASTM C 1363-05. West Conshohocken, PA: ASTM.

2012. Temperature-electromotive force (EMF) tables for standardized thermocouples. ASTM E 230. Volume 14.03, Temperature measurement. ASTM Standards. West Conshohocken, PA: ASTM,

Anis, W. 2014. Air Barrier Systems in Buildings, Web page. Washington, DC: National Institute of Building Sciences, http://www.wbdg.org/resources/airbarriers.php

Grimm, C. T. 2002. Air barriers for masonry walls. Masonry: Opportunities for the 21st Century. STP1432. West Conshohocken, PA: American Society for Testing and Materials (ASTM), pp. 241-256.

Harriman, L., and J . W. Lstiburek. 2009. The ASHRAE Guide for Buildings in Hot \& Humid Climates. Atlanta, GA: American Society of Heating, Refrigerating, and Air-Conditioning Engineers (ASHRAE).

Lstiburek, J . 2013. Stuck on you. Building Science Insights. BSI-067. Web page. Westford, MA: Building Science Corp., http://www.buildingscience.com/documents/insights/bsi-067-stuck-on-you/

Q-Lab. 2011. QUV ${ }^{\circledR}$ Accelerated Weathering Testers. Web page. Westlake, OH: Q-Lab, http://www.q-lab.com/documents/public/7783bc36-3484-4f92-941d-69df0121f862.pdf

Truly, Richard H., and Alvin L. Alm. May 2001. Report of the Defense Science Board on More Capable Warfighting through Reduced Fuel Burden. Final Report. Washington, DC: Defense Science Board.

U.S. Energy Information Administration (EIA). 2014. Electricity: State electricity profiles. Electricity. Web page. Accessed 27 August 2013. Washington, DC: EIA, http://www.eia.gov/electricity/state/

Yarbrough D. W., T. W. Petrie, D. Kinninger, and R. S. Graves. 2007. Thermal performance of gas-filled panels with reflective surfaces installed in an attic. Thermal Performance of the Exterior Envelopes of Whole Buildings X, Clearwater Beach, FL. ASHRAE THERMX, Conference, http://web.ornl.gov/sci/roofs+walls/staff/papers/49.pdf 


\section{Appendix A: Temporary Shelter Assembly Drawings}




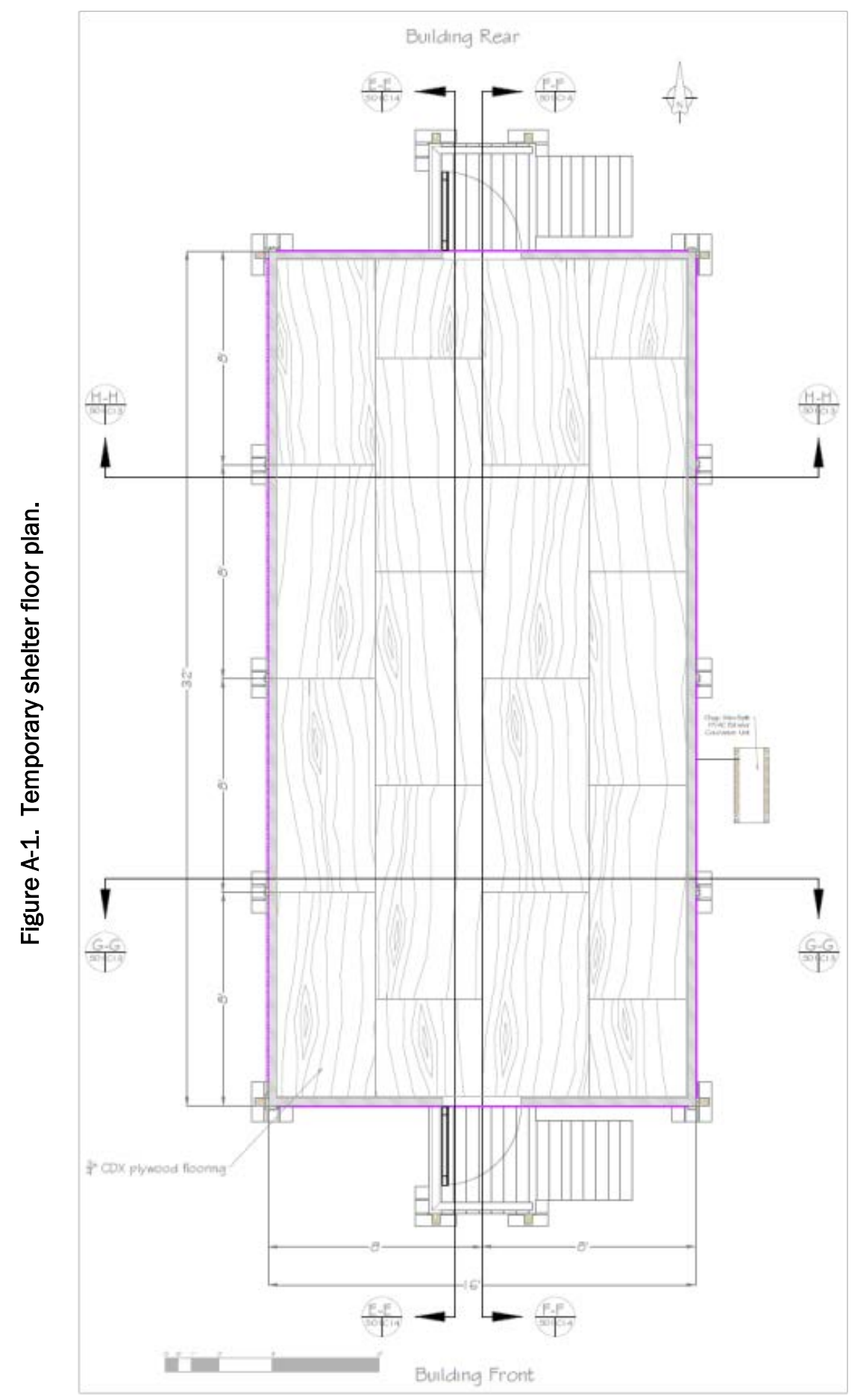




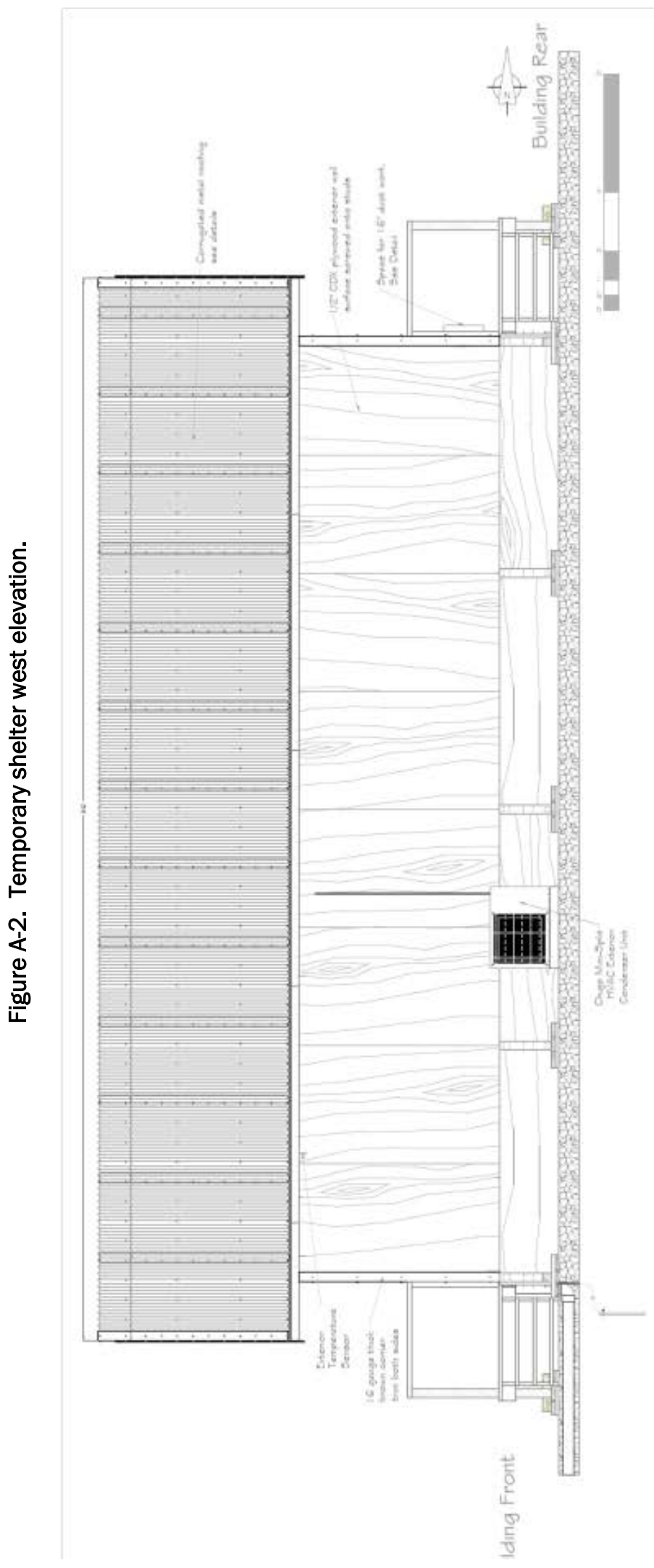




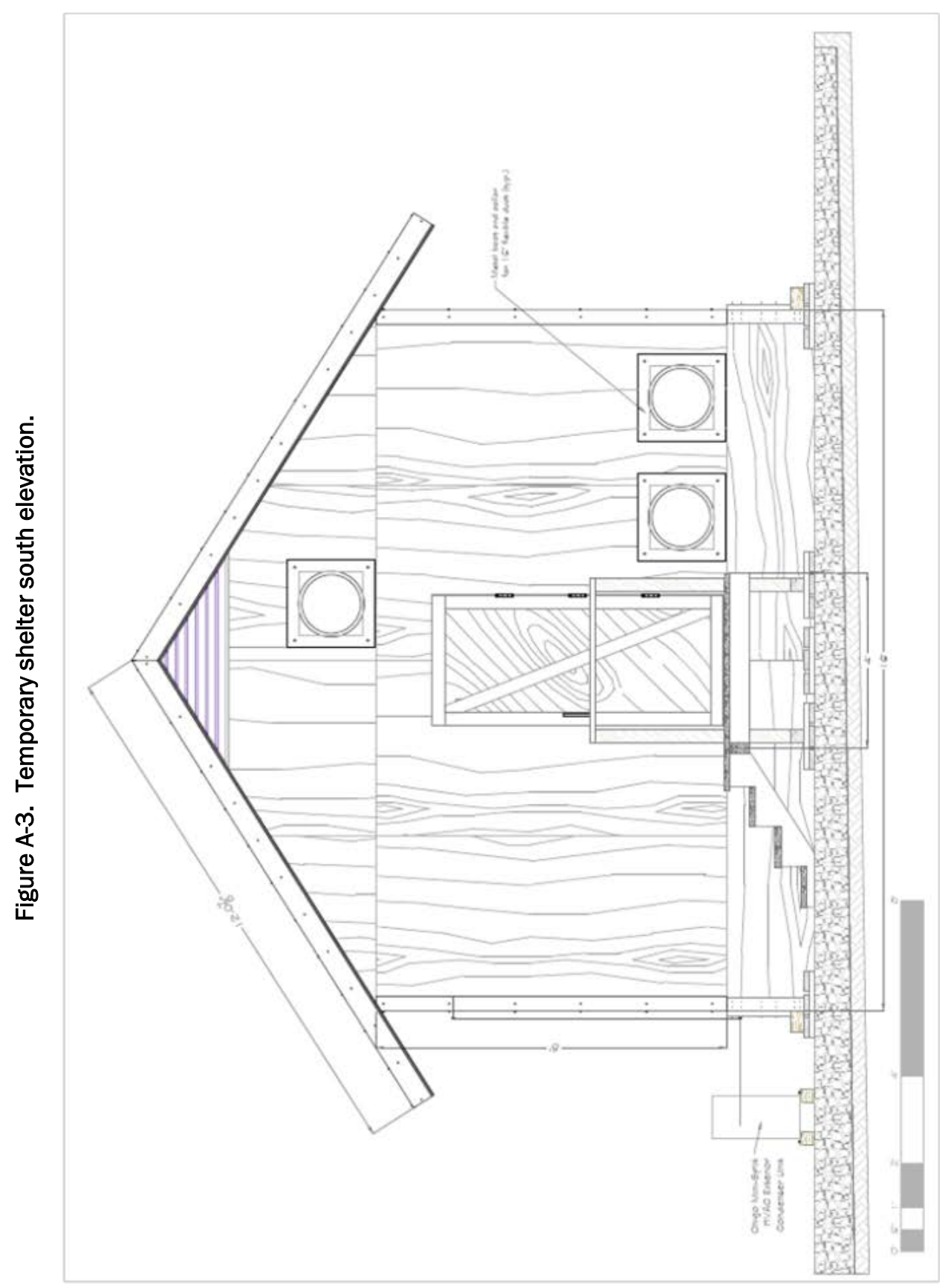




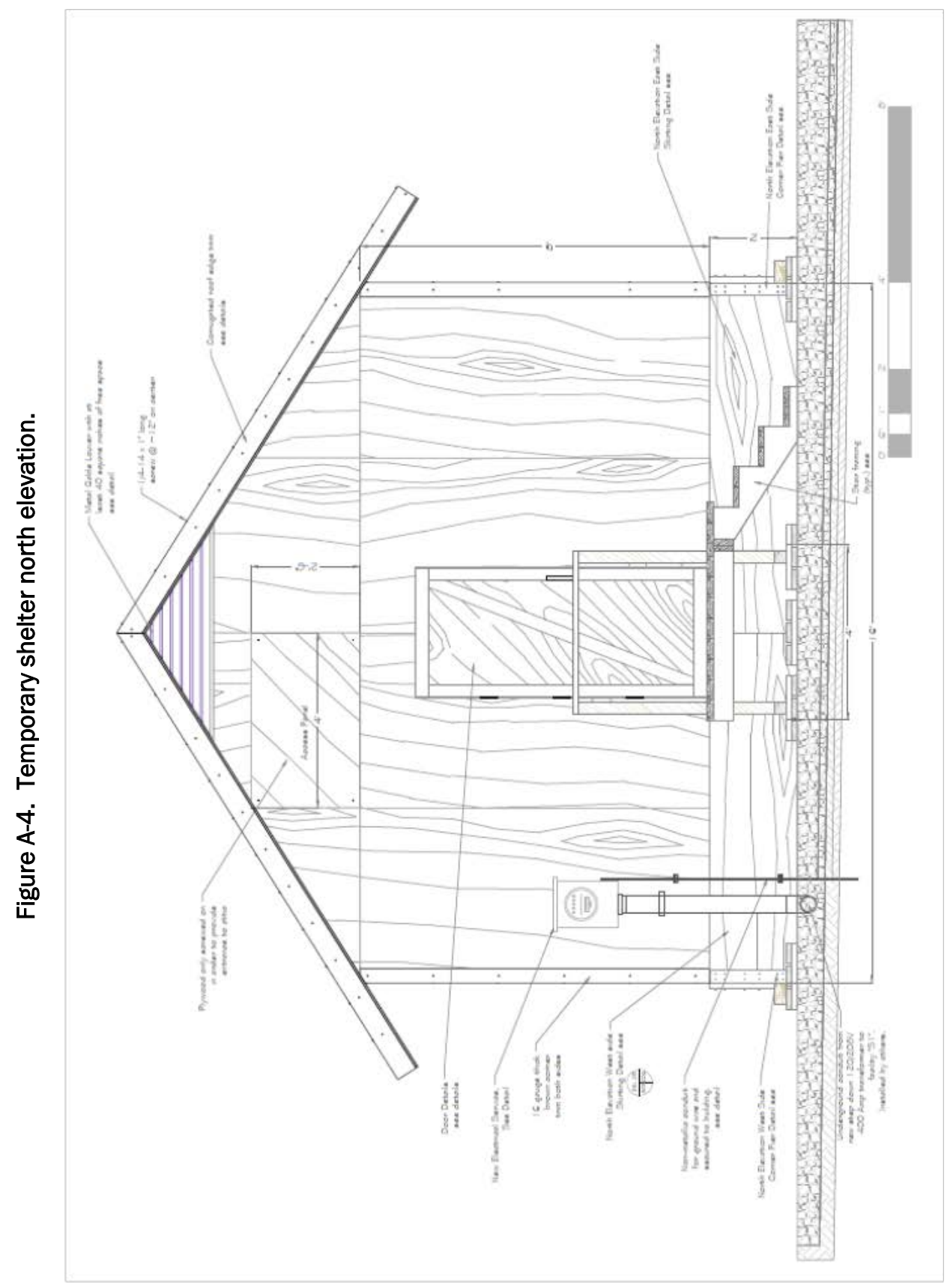




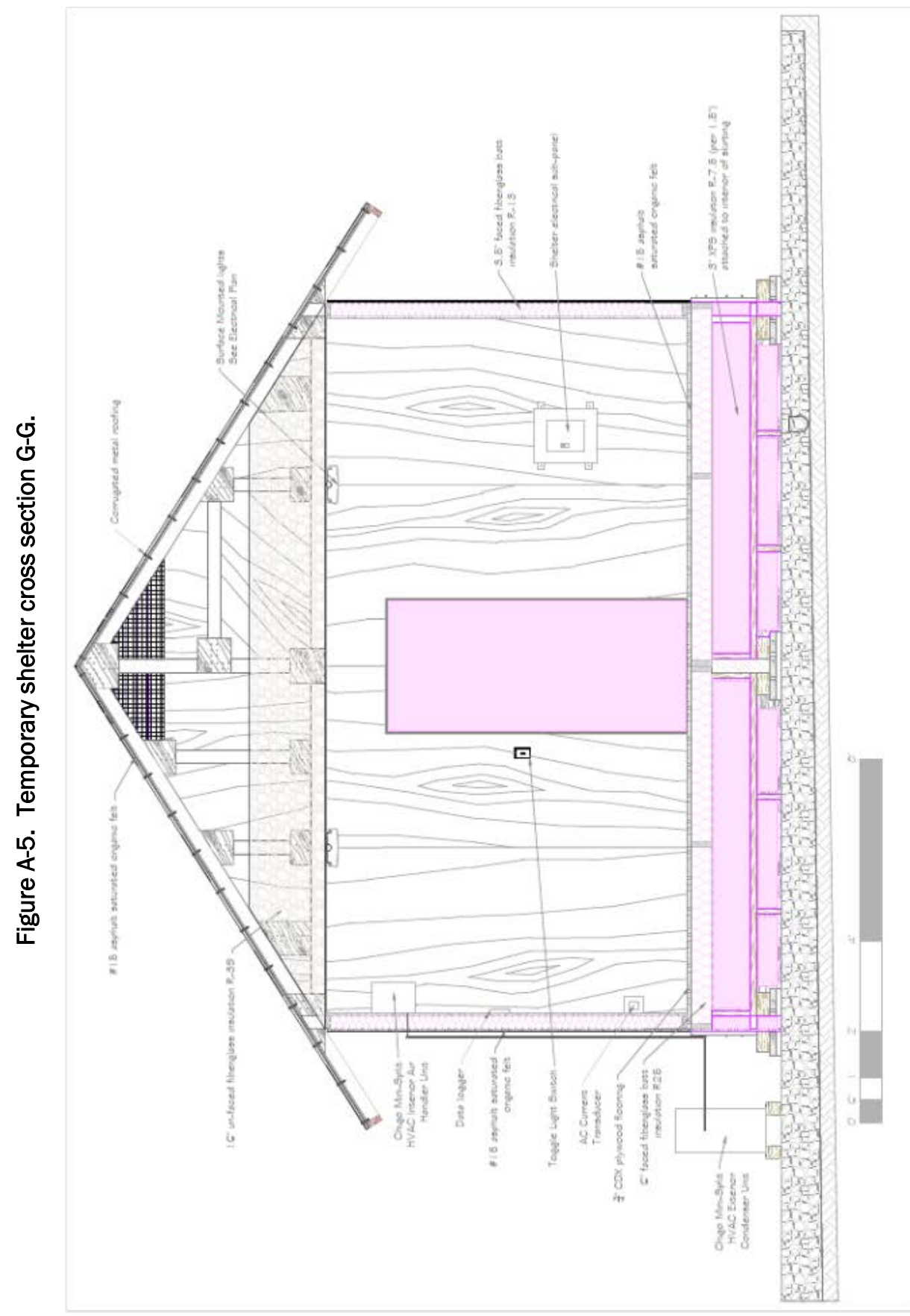




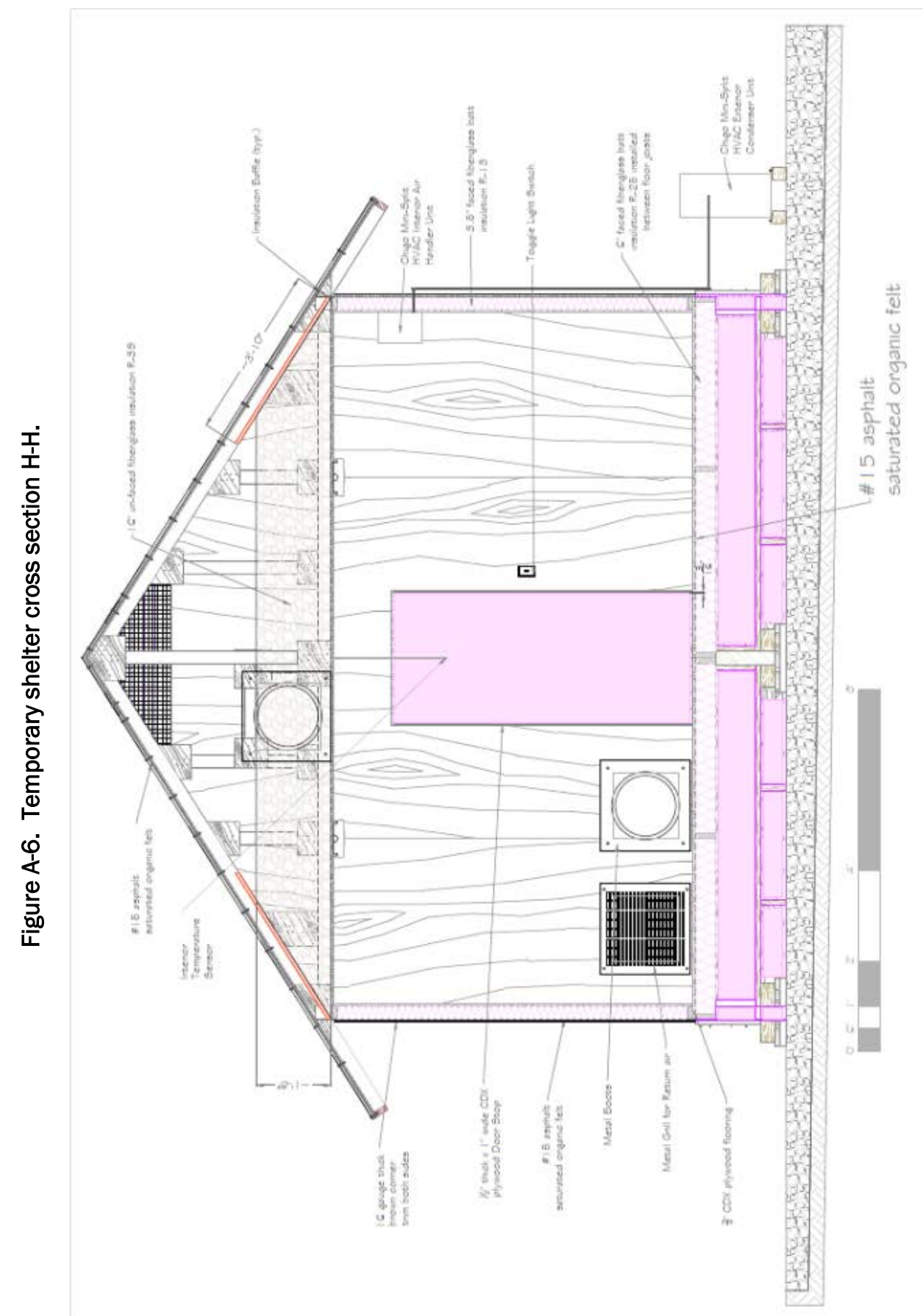




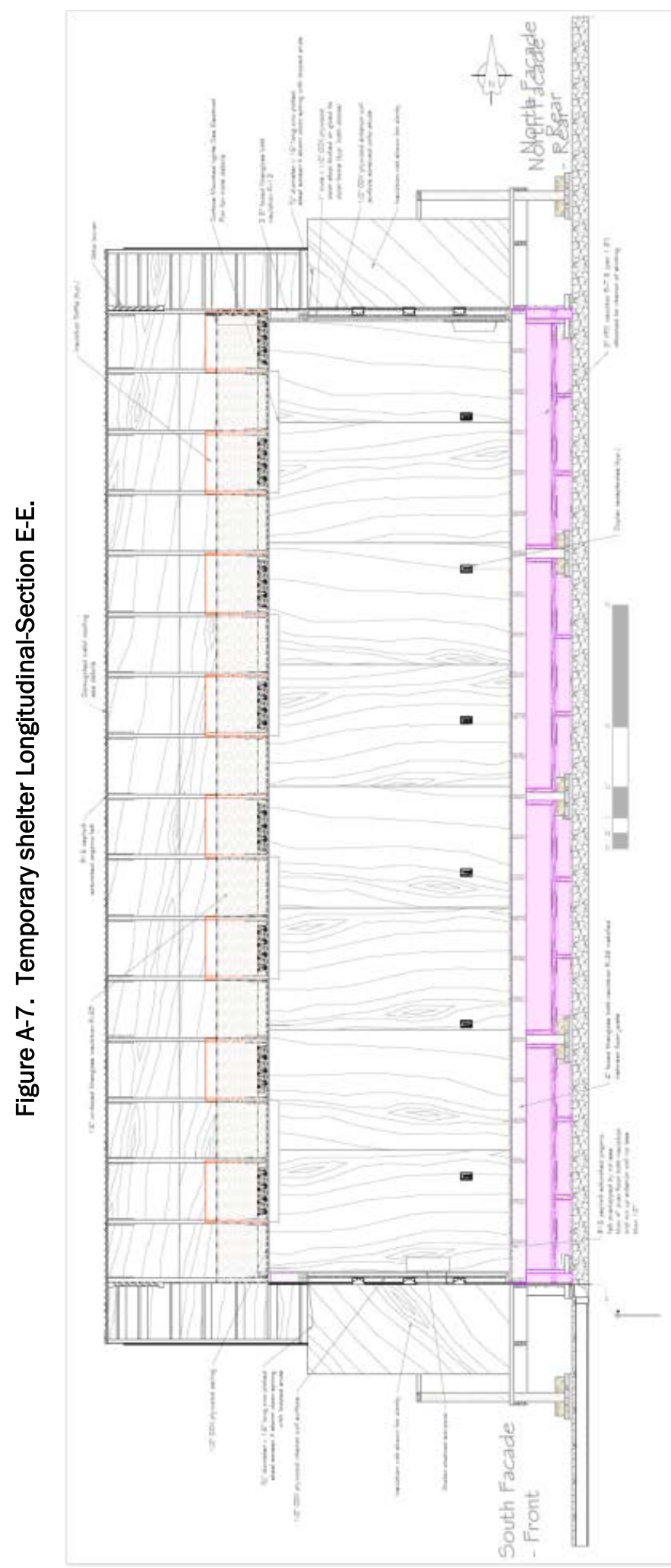




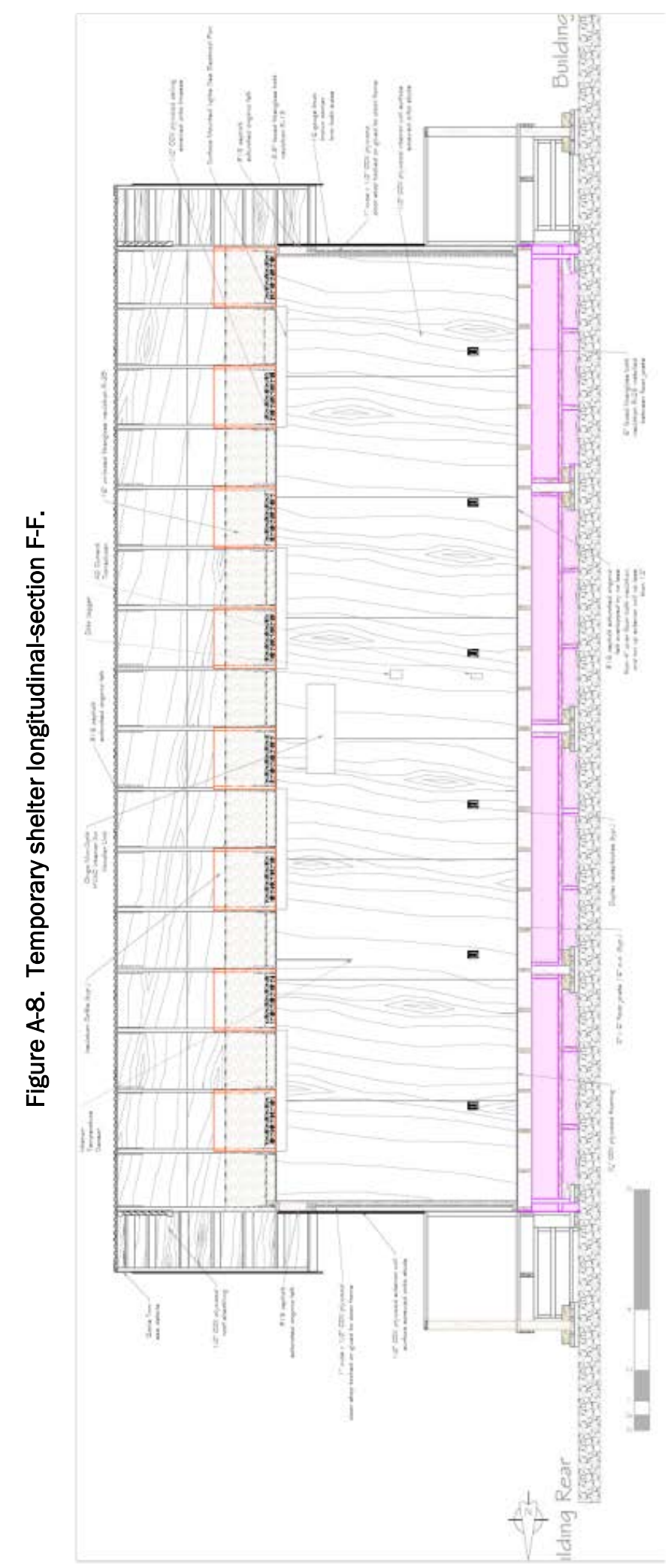




\section{Appendix B: Gas-Filled Panels}

Gas-filled insulation panels* (GFP), a product initially developed with a grant from the U.S. Department of Energy (DOE), are very lightweight, compact (when uninflated), advanced insulation products. GFPs consist of multiple layers of thin, low emittance (low-e) metalized aluminum. These baffled polymer chambers are enveloped by a sealed barrier and filled with either air or a low-conductivity gas. When expanded, the internal, low-e aluminum layers form a honeycomb structure. The sealed exterior aluminum foil barrier films provide thermal resistance, flammability protection, and properties to contain air or a low-conductivity inert gas.

The unexpanded product is nearly flat, which allows for easy storage and transport. Therefore, transportation volume and weight of the GFP to fill unit volume of wall cavity is much smaller than that of other conventional insulation products. This feature makes this product appealing for use at Army Contingency Basing, when transportation cost is significant compared to the cost of materials. The objective of this study was to evaluate thermal performance of walls, similar to those used at typical B-hut hard shelters, when GFPs are used in the wall cavities. Oak Ridge National Laboratory (ORNL) tested the performance of the wall in the rotatable guarded hot-box (RGHB) according to the American Society for Testing and Materials (ASTM) standard test method C 1363.

\section{B.1 Background and test wall details}

A team consisting of ORNL and ERDC-CERL researchers identified GFPs as potential insulation system to be used in B-huts. The ORNL objective of this project is to assist ERDC-CERL researchers to evaluate the thermal performance of a wall assembly consisting of GFP using RGHB. Yarbrough et al. (2007) evaluated thermal performance of gas-filled panels with reflective surfaces installed in an attic using ORNL large scale climate simulator (LSCS). The study found that the total contribution of the GFP layer installed above fiberglass batt insulation was 5 to $6 \mathrm{~h} \bullet \mathrm{ft}^{2} \bullet^{\circ} \mathrm{F} / \mathrm{Btu}$ for winter conditions and about $6 \mathrm{~h} \bullet \mathrm{ft}^{2} \bullet^{\circ} \mathrm{F} / \mathrm{Btu}$ for summer conditions. No other test result was available in published literature that shows performance of GFP insulated walls.

* http://www.fifoil.com/products/advanced-solutions-systems-reflective-insulation/gfp-insulation 
The construction of the test wall resembles that of a typical B-hut wall except that GFPs were used in the cavities of the test wall. (No insulation is used in typical B-hut wall cavities.) The test wall was constructed of nominal $2 \times 4$ lumber studs 16-in. on center, with 0.5-in. plywood on both sides of the wall. Figure B-1 shows the test wall being assembled for RGHB test.

The exposed side of the materials used on the exterior of the GFPs had low-e coating. TEs of the polymer with and without low-e metalized aluminum coating were measured using Devices \& Services emissometer model AE, which was operated in accordance with ASTM C 1371. Table B-1 lists the measured emittances.

The GFPs were inflated with compressed air with a pressure regulator set at $7 \mathrm{psig}$. Some of the GFPs bulged during inflation. Severely bulged GFPs were not used in this test. One GFP was punctured by a splinter while being installed on the test wall and was replaced. The honeycomb structure of the GFP was visually inspected (Figure B-2) by cutting one panel. Thickness of the inflated GFP was about 1.5-in., thus two layers of GFPs fills the cavities between $2 \times 4$ studs.

Figure B-1. Test wall with GFPs in the cavity.

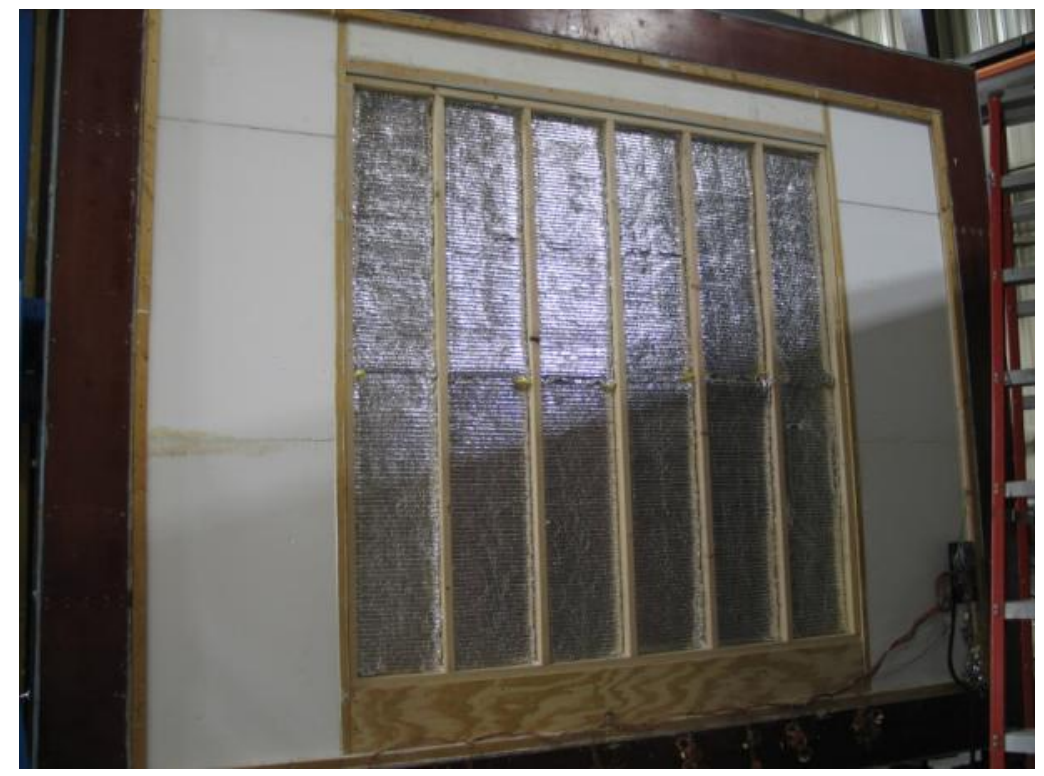


Table B-1. TE of the GFP material.

\begin{tabular}{|c|c|c|}
\hline Sample & Surface with low-e coating & Surface without low-e coating \\
\hline 1 & 0.08 & 0.65 \\
\hline 2 & 0.10 & 0.66 \\
\hline 3 & 0.08 & 0.68 \\
\hline 4 & 0.07 & 0.61 \\
\hline Average & 0.08 & 0.65 \\
\hline
\end{tabular}

Figure B-2. Honeycomb structure of the GFP.

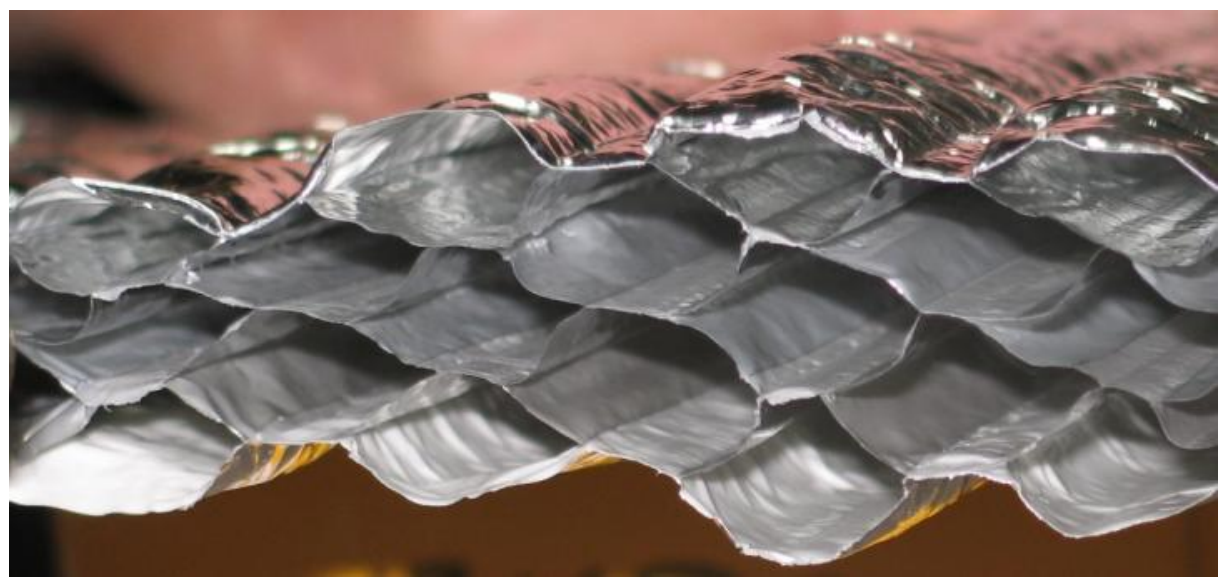

\section{B.2 Test apparatus and instrumentation}

ORNL operates and maintains a guarded hot-box that is used to measure the effective thermal resistance (R-Value) and thermal transmittance (UFactor) of full size wall and window assemblies. The hot-box operates under the requirements of ASTM C 1363. Figure B-3 shows the RGHB. Test assemblies are installed in a specimen frame mounted on a moveable dolly. The specimen frame has an aperture 13-ft long by 10 -ft high. The specimen frame/ test assembly is inserted between two "clam-shell" chambers of identical cross section. The placement of the test wall assembly between the chambers allows the chamber temperatures to be independently controlled, thus creating a temperature difference across the specimen. The chambers are designated as the climate (cold) and metering/ guard (hot) chambers. Figure B-4 shows a typical wall specimen installed in the test frame. The central 8x8-ft wall section, which aligns with the metering chamber boundary, is used for the actual test. 
Figure B-3. ORNL RGHB.

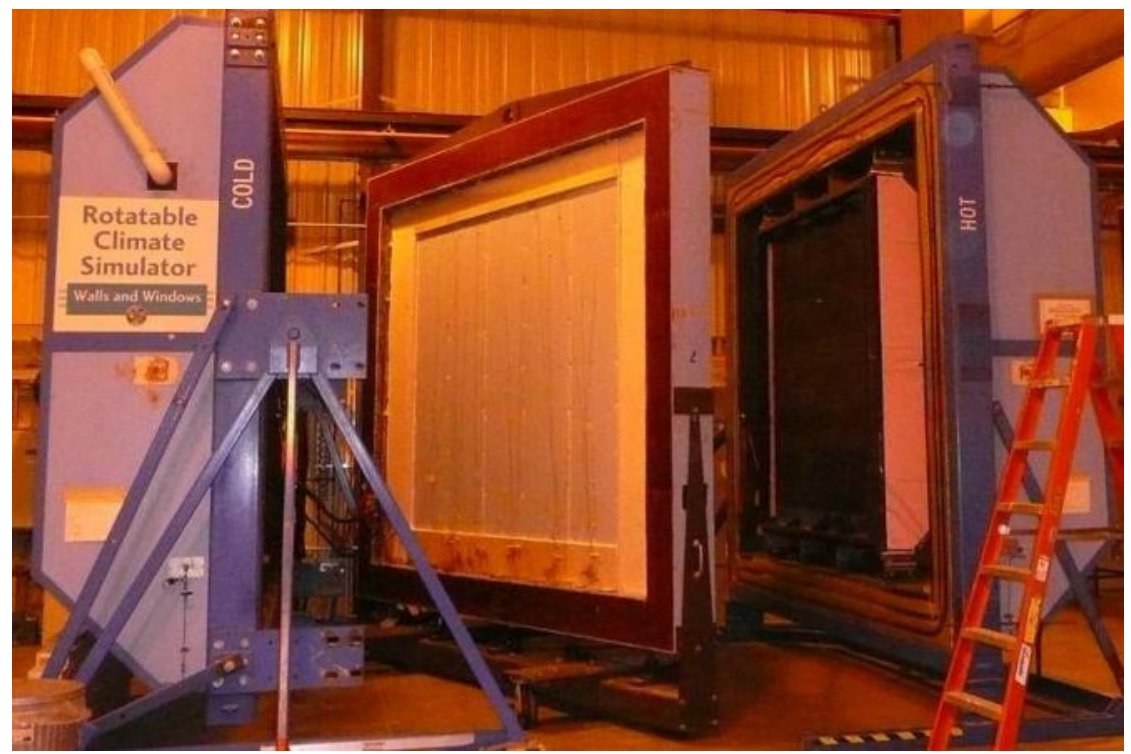

Figure B-4. Schematic of a typical test wall within the hot-box test frame.

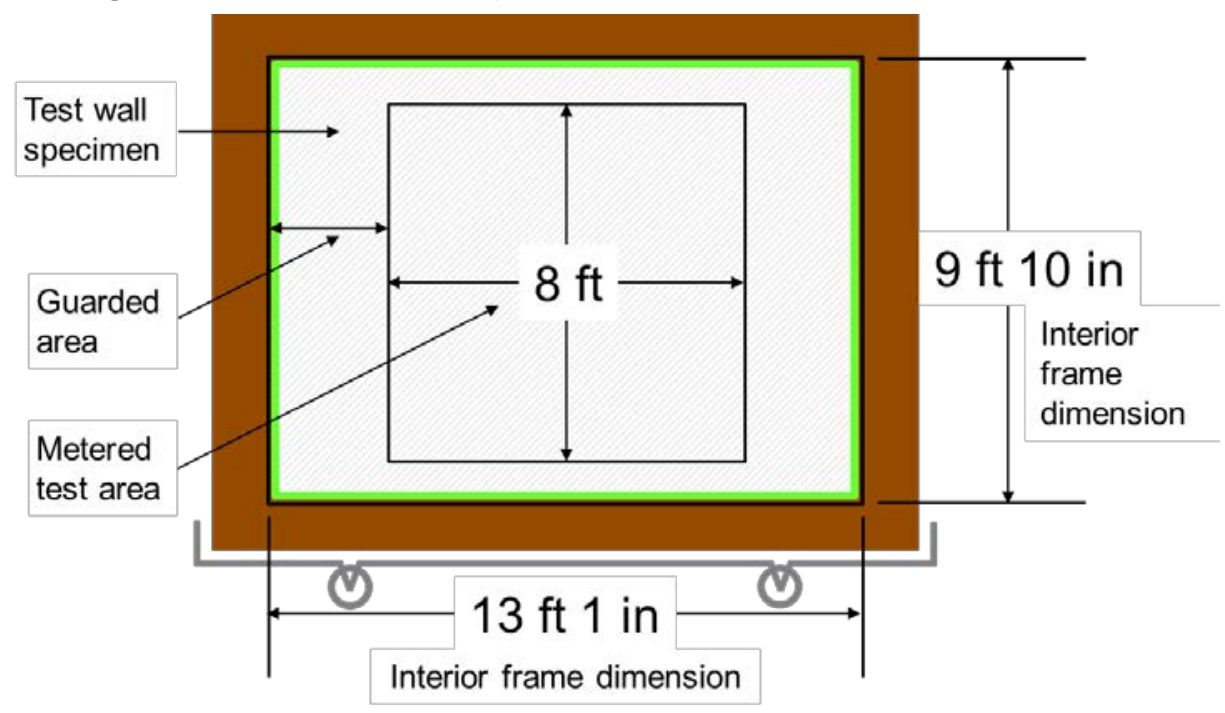

The climate chamber (cold side) is equipped with blowers and an air-conditioning system capable of producing stable environmental conditions to the extremes of $10^{\circ} \mathrm{F}$ and $15 \mathrm{mph}$ wind velocities. Five centrifugal squirrel cage air blowers, installed behind a baffle, are used to circulate the air through the airspace between the baffle and test specimen assembly. Five hot-wire anemometers, located in the center of the air stream produced by each of the five squirrel cage blowers, continuously measure the wind speed across the baffle surface. Temperature measurement of the baffle and air is accomplished by a series of thermocouples distributed evenly over the baffle surface. The thermocouples are distributed such that the 
average air and surface temperature of the center 8x8-ft area facing the test specimen, which is used for the actual test, can also be obtained. A relative humidity probe is located inside the climate chamber to monitor the relative humidity. The baffle surface facing the test specimen is covered with a black coating with an emittance of 0.9 .

The hot side consists of two similarly shaped chambers, a guard chamber surrounding the smaller metering chamber. The metering chamber has heaters and fans capable of producing stable environmental conditions to the extremes of $140{ }^{\circ} \mathrm{F}$ and $2.0 \mathrm{mph}$ wind velocities. The metering chamber is approximately 8-ft square by 1.3-ft deep and is suspended from the inside of the guard chamber by spring-loaded brackets that constantly push the open face of the metering chamber up against the warm side of the test specimen. The guard chamber and the climate chamber are then sealed against each side of the test frame with separate inflatable gaskets.

The walls of the metering chamber are constructed with 3-in. thick aged extruded polystyrene foam that has an approximate thermal resistance of $\mathrm{Rmb}, 15 \mathrm{~h} \bullet \mathrm{ft}^{2} \bullet^{\circ} \mathrm{F} / \mathrm{Btu}$ at $75^{\circ} \mathrm{F}$. A baffle is mounted inside the metering box, 6-in. from the exposed edge of the gasket. Behind the baffle, an array of eight fans and four electric resistance heaters force air upward between the baffle, through the resistance heaters, and then downward through the airspace between the baffle and test assembly. A relative humidity probe is mounted on the baffle surface inside the metering box. The average baffle air and surface temperature of the meter baffle is measured by equally spaced thermocouples attached to the surface and in the air space 3-in. away from the surface. Four warm side hot-wire anemometer velocity probes were located on the baffle surface, and an absolute pressure tap was located on the baffle surface near the geometric center of the baffle.

A 92 junction (46 pair) differential thermopile is applied on the interior and exterior walls of the metering chamber to sense the temperature imbalance across the metering chamber wall. Each thermopile junction is mounted in the center of one of the 48 equal areas into which the metering chamber is divided. The interior thermopile junction is mounted directly opposite the corresponding exterior junction. Additional arrays of temperature sensors are affixed to both the meter-side and climate-side surfaces of the foam panel surrounding the test specimen in the area covered by the guard chamber. 
The guard box has four heaters and six fans that heat and circulate the air in the guard space surrounding the metering box. The heaters are controlled by a proportional-integral-derivative (PID) controller that senses the surface temperature difference across the metering box walls measured by the metering box wall thermopile. The guard chamber also contains a relative humidity probe.

Three differential pressure transducers are installed in the RGHB. Two of the transducers, P1 and P2, measure the pressure difference across the test assembly. The third transducer, P3, monitors the pressure difference between the metering and guard chambers.

During operation, the temperatures of the climate and metering chambers are set at the desired level. Separate programmable DC power supplies in conjunction with a temperature controller are used to energize and control the metering chamber heaters and fans. The power to the fans is adjusted to set the desired wind speed in the airspace between the baffle and the test wall assembly. Anemometers are used to monitor this wind speed. The output of the differential thermopile controls the guard chamber heaters through a differential temperature controller. By this technique, the temperature difference across the metering box walls is minimized, thereby essentially eliminating the heat flow between the metering and guard chambers.

All temperature measurements are performed using Type T-type copper/ constantan thermocouples calibrated to the special limits of error specified in ASTM E 230, Temperature-Electromotive Force (EMF) Tables for Standardized Thermocouples (ASHRAE 2012). All sensors inside the RGHB are connected to a data acquisition system capable of measuring either thermocouple output or raw voltage signals. The modules used to measure thermocouples have an internal electronic reference junction to accurately calculate the temperature from the raw thermocouple output. Once started, the data acquisition modules automatically collect data at 30-second intervals for all sensors except those used for measuring energy input into the metering chamber, which are on 12-second intervals. All the instrumentation and control equipment used in the RGHB are annually calibrated against National Institute of Standards and Technology (formerly National Bureau of Standards) (NIST) traceable standards at ORNL or they are returned to the instrument manufacturer for calibration. 
The heat flow generated by the metering chamber heaters is calculated from the voltage and current measurements taken from a precision shunt resistor and from a watt-transducer. The energy dissipated by the metering chamber fans is metered with a precision resistor network. Once steady-state conditions have been achieved, the test period is continued until at least five successive data acquisition runs of periods equal to the time constant of the RGHB are obtained. The test is considered complete when each datum obtained for each measured variable differs from its mean by no more than the uncertainty of that variable. In addition, the data must not vary monotonically with time.

Over the years, ORNL has performed many characterization tests to ensure that the RGHB meets the specifications in the annex of ASTM C 1363. The standard requires the determination of a system time constant, as well as flanking losses and null offset. Although the results from these time constant and flanking loss tests are not presented here, it should be noted that test data have been compiled and analyzed to verify that the RGHB meets the requirements of ASTM C 1363.

\section{B.3 Calculation methodology}

The meter and climate-side average surface temperatures are calculated in an appropriate area-weighted manner. The surface area of the wall used for the test was $64-\mathrm{ft}^{2}$. The percentage of the total wall surface area that each individual wall component comprised was determined. The average temperatures were then computed by area-weighing the average cavity, stud, and track surface temperatures.

The energy exchange rate from the metering box to the guard chamber, Qmb is calculated as:

$$
Q_{m b}=\frac{A_{m b} \cdot \Delta T_{m b}}{R_{m b}}
$$

where:

$\mathrm{Q}_{\mathrm{mb}}=$ heat flow rate through metering box walls, Btu/ $\mathrm{hr}$

$A_{m b}=$ surface area of the metering box, $100.08 \mathrm{ft}^{2}$

$\Delta \mathrm{T}_{\mathrm{mb}}=$ temperature difference between the guard side and meter-side of the metering box walls, ${ }^{\circ} \mathrm{F}$

$\mathrm{Rmb}=$ thermal resistance of the metering box walls, $15 \mathrm{~h} \bullet \mathrm{ft}{ }^{2}{ }^{\circ} \mathrm{F} / \mathrm{Btu}$. 
The total energy flow through the wall assembly, $\mathrm{Q}_{\text {wall, }}$ is calculated as:

$$
Q_{\text {wall }}=Q_{h}+Q_{f a n}+Q_{m b}+Q_{v p}
$$

where:

$\mathrm{Q}_{\text {wall }}=$ total energy flow rate through the wall assembly, Btu/ $\mathrm{hr}$

$\mathrm{Q}_{\mathrm{h}}=$ energy input to the resistance heaters in the metering chamber, Btu/hr

$\mathrm{Qfan}_{\mathrm{fan}}$ energy input to the fans in the metering chamber, Btu/hr

$\mathrm{Q}_{\mathrm{vp}}=$ energy input to the velocity probes in the metering chamber, $\mathrm{Btu} / \mathrm{hr}$.

The surface-to-surface thermal resistance of the wall assembly, $\mathrm{R}_{\text {wall, }}$ is calculated as:

$$
R_{\text {wall }}=\frac{A_{\text {wall }} \cdot\left(T_{m s}-T_{c s}\right)}{Q_{\text {wall }}}
$$

where:

$\mathrm{R}_{\text {wall }}=$ surface-to-surface thermal resistance of the wall assembly, $\mathrm{h} \cdot \mathrm{ft}^{2} \bullet^{\circ} \mathrm{F} / \mathrm{Btu}$

Awall $=$ area of wall, $\mathrm{ft}^{2}$

$\mathrm{T}_{\mathrm{ms}}=$ area-weighted average metering-side surface temperature, ${ }^{\circ} \mathrm{F}$

$\mathrm{T}_{\mathrm{cs}}=$ area-weighted average climate-side surface temperature, ${ }^{\circ} \mathrm{F}$.

The meter-side and climate-side air film coefficients, $R_{m s}$ and $R_{c s}$, are calculated as:

$$
\begin{gathered}
R_{\text {msair }}=\frac{A_{\text {wall }} \cdot\left(T_{m a}-T_{m s}\right)}{Q_{\text {wall }}} \\
R_{\text {csair }}=\frac{A_{\text {wall }} \cdot\left(T_{c s}-T_{c a}\right)}{Q_{\text {wall }}}
\end{gathered}
$$

\section{B.4 Test conditions}

The tests were conducted with three configurations:

1. Two layers of GFPs on cavities between studs

2. One layer of GFP on climate-side

3. Without GFPs. 
The length of the GFPs is 4- $\mathrm{ft}$, so two GFPs were used to cover the 8-ft height of the test wall. The motivation for conducting the test with one layer of GFP was to evaluate if only one layer of GFP can be used without compromising the effective R-value significantly. Each configuration was tested at three temperature conditions to evaluate change in R-value as a function of temperature. The following test conditions were used:

1. Meter-side surface temperature $80^{\circ} \mathrm{F}$ and climate-side surface temperature $40{ }^{\circ} \mathrm{F}$

2. Meter-side surface temperature $100^{\circ} \mathrm{F}$ and climate-side surface temperature $60{ }^{\circ} \mathrm{F}$

3. Meter-side surface temperature $120^{\circ} \mathrm{F}$ and climate-side surface temperature $80^{\circ} \mathrm{F}$.

The meter-side and climate-side surface temperatures were determined by area-weighted averaging of the thermocouples attached to the individual components. On each side of the wall, 32 thermocouples were used to measure surface temperature.

The perimeter of the test wall and the joints were caulked and taped to prevent air leakage. The data from the final 15 hours after achieving stable temperature and heat flow conditions were used for the analysis.

\section{B.5 Test results}

Table B-2 lists the temperatures, heat flows, R-values, and calculated surface-to-surface R-values. For visual comparison, Figure B- 5 shows R-value as a function of temperature for walls with two layers of GFP and one layer of GFP. It is interesting to note that, while the R-value of the wall with two layers of GFP decreases sharply (change from $8.662 \mathrm{~h} \bullet \mathrm{ft}^{2} \bullet^{\circ} \mathrm{F} / \mathrm{Btu}$ at $80 / 40{ }^{\circ} \mathrm{F}$ to $7.762 \mathrm{~h} \cdot \mathrm{ft}^{2} \bullet^{\circ} \mathrm{F} / \mathrm{Btu}$ at $120 / 80^{\circ} \mathrm{F}$, resulting in a $10.4 \%$ decrease in R-value) as the temperature increases, the R-value of the wall with only one layer of GFP remains fairly steady (change from $7.241 \mathrm{~h} \bullet \mathrm{ft}^{2} \bullet^{\circ} \mathrm{F} / \mathrm{Btu}$ at $80 / 40{ }^{\circ} \mathrm{F}$ to $7.183 \mathrm{~h} \cdot \mathrm{ft}^{2} \bullet^{\circ} \mathrm{F} / \mathrm{Btu}$ at $120 / 80^{\circ} \mathrm{F}$, resulting in only a $0.8 \%$ decrease in R-value). At $120^{\circ} \mathrm{F}$ hot side surface temperature and $80^{\circ} \mathrm{F}$ cold side surface temperature, the R-value of the wall with one layer of GFP is only 7.5\% less than that of the wall with two layers of GFP. This phenomenon can be explained with the data available in the ASHRAE Handbook of Fundamentals (ASHRAE 2013). 
Table B-2. Summary test results.

\begin{tabular}{|c|c|c|c|c|c|c|c|c|c|}
\hline \multirow[b]{2}{*}{ Wall Configuration } & \multicolumn{3}{|c|}{ Two Layers GFP } & \multicolumn{3}{|c|}{ One Layer GFP on Climate-Side } & \multicolumn{3}{|c|}{ No GFP } \\
\hline & $80 / 40$ & $100 / 60$ & $120 / 80$ & $80 / 40$ & $100 / 60$ & $120 / 80$ & $80 / 40$ & $100 / 60$ & $120 / 80$ \\
\hline M-FAN-PWR* & 3.9 & 3.9 & 3.8 & 3.9 & 3.8 & 3.8 & 3.9 & 3.8 & 3.8 \\
\hline M-HTR-PWR & 271.4 & 287.5 & 305.3 & 329.8 & 331.9 & 332.7 & 1132.6 & 1013.2 & 1052.3 \\
\hline M-VEL-PWR & 20.2 & 20.0 & 19.7 & 20.0 & 19.6 & 19.3 & 19.7 & 9.9 & 9.9 \\
\hline$Q_{m b}$ & -0.1 & -0.1 & -0.1 & -0.1 & -0.1 & -0.1 & -0.1 & -0.1 & -0.1 \\
\hline TMP_DC & 295.4 & 311.3 & 328.7 & 353.6 & 355.3 & 355.8 & 1156.0 & 1026.9 & 1065.9 \\
\hline T-DIFF & 40.0 & 40.1 & 39.9 & 40.0 & 39.9 & 40.0 & 40.1 & 40.1 & 39.9 \\
\hline R-value & 8.662 & 8.232 & 7.762 & 7.241 & 7.192 & 7.183 & 2.218 & 2.500 & 2.396 \\
\hline \multicolumn{10}{|l|}{ *Nomenclature: } \\
\hline \multicolumn{10}{|c|}{ M-FAN-PWR = Meter fan power, Btu/hr } \\
\hline \multicolumn{10}{|c|}{ M-HTR-PWR = Meter heater power, Btu/hr } \\
\hline \multicolumn{10}{|c|}{ M-VEL-PWR = Meter velocity probe power, Btu/hr } \\
\hline$Q_{m b}$ & \multicolumn{9}{|c|}{$=$ heat flow rate through metering box walls, Btu/hr } \\
\hline TMP-DC & \multicolumn{9}{|c|}{$=$ Total heat flow rate into meter box, Btu/hr } \\
\hline T-DIFF & \multicolumn{9}{|c|}{$=$ Average temperature difference across wall surfaces, ${ }^{\circ} \mathrm{F}$} \\
\hline R-value & \multicolumn{9}{|c|}{$=$ Surface-to-surface R-value of the wall, $\mathrm{h} \bullet \mathrm{ft}^{2} \bullet{ }^{\circ} \mathrm{F} / \mathrm{Btu}$} \\
\hline
\end{tabular}

Figure B-5. R-value as a function of temperature.

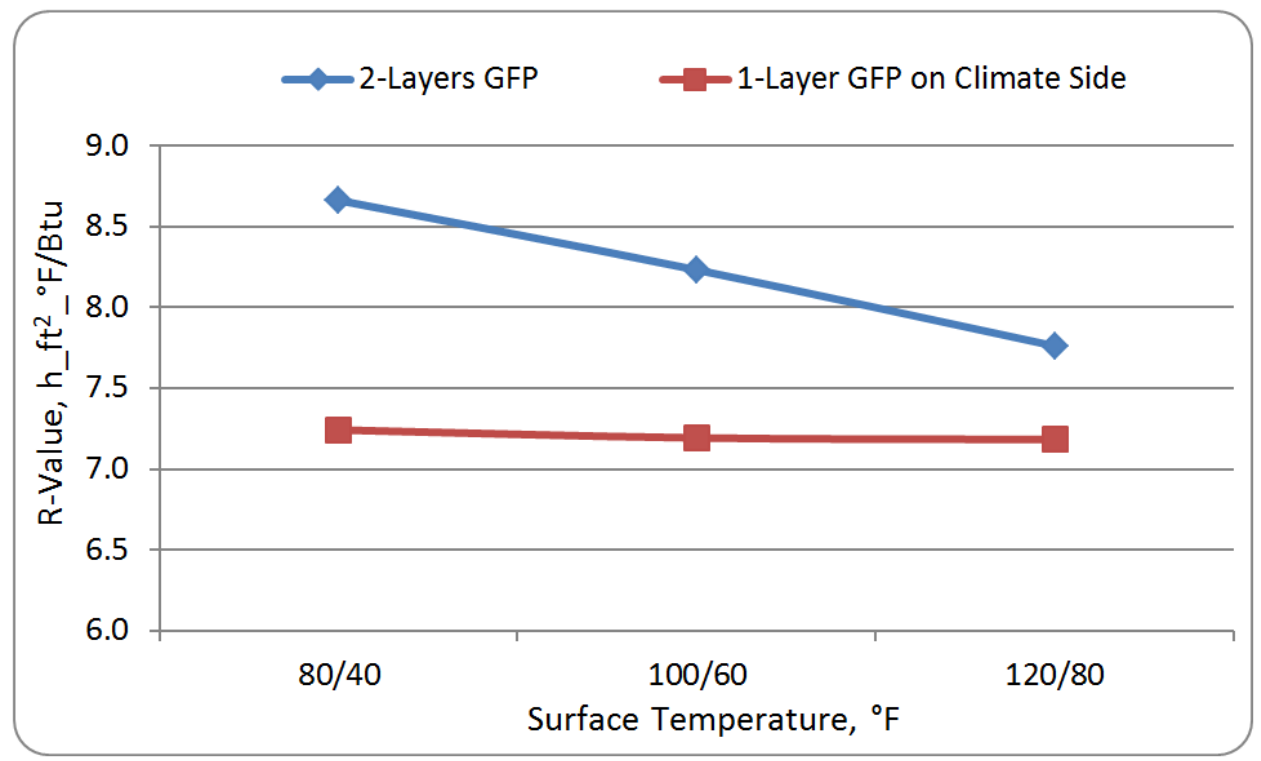

Figure B-6 shows the relevant data from Section 26 of ASHRAE 2013, in which the effective R-value of plain air spaces as a function of mean temperature for horizontal heat flow when the temperature difference is $10^{\circ} \mathrm{F}$ and the effective emittance is 0.05 . Note that, while R-value of 0.5-in. air space decreases as the mean temperature increases, it is just the opposite for a 1.5-in. air space. Even though the conditions in GFP test are not exactly the same as in ASHRAE 2013, an analogy can be made between the test data and the ASHRAE 2013 data. 
Figure B-6. Effective thermal resistance of plane air spaces.

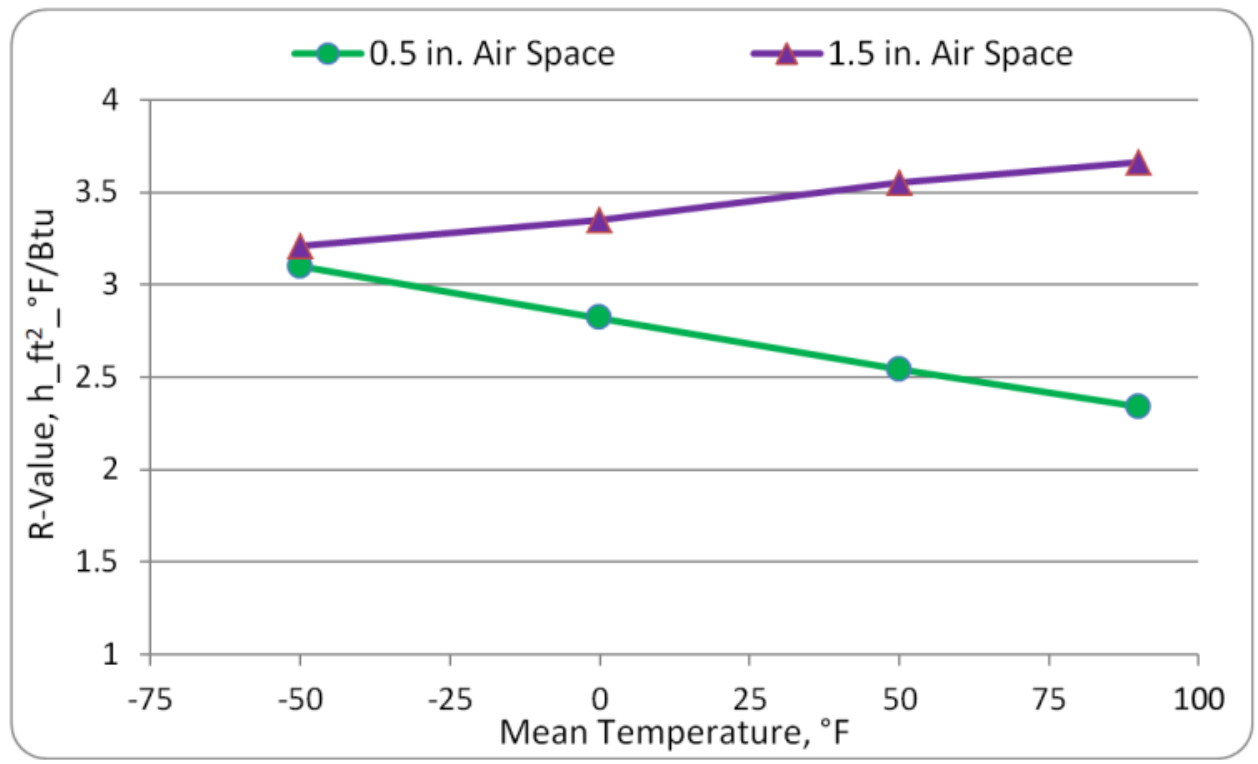

The test wall with two layers of GFP contains six layers of approximately 0.5-in. air spaces. Therefore, the R-value decreases as the mean temperature increases. For the test wall with one layer of GFP, the cavity between studs are filled with three layers of approximately 0.5 -in. air spaces and one layer of approximately 1.5-in. air space. The R-value of 0.5-in. air space decreases and that of 1.5-in. air space increases as the mean temperature increases. Thus, the resulting R-value for the test wall with one layer of GFP remains fairly steady over the range of temperature used in the tests.

Figure B-7 shows the increase in effective surface-to-surface R-value due to the use of GFPs. Several factors (such as cost of materials, transportation, energy, weather conditions, and application) would need to be considered to determine whether it is cost effective to use one or two layers of GFP in the B-Hut cavity.

\section{B.6 Summary}

In spring of 2014, thermal performance testing of wall assembly with two layers of GFP, one layer of GFP, and one layer without GFP was conducted at ORNL. The test wall was constructed of nominal $2 \times 4$ lumber studs 16in. on center, with 0.5-in. plywood on both sides of the wall. 
Figure B-7. Increase in R-value due to the use of GFPs.

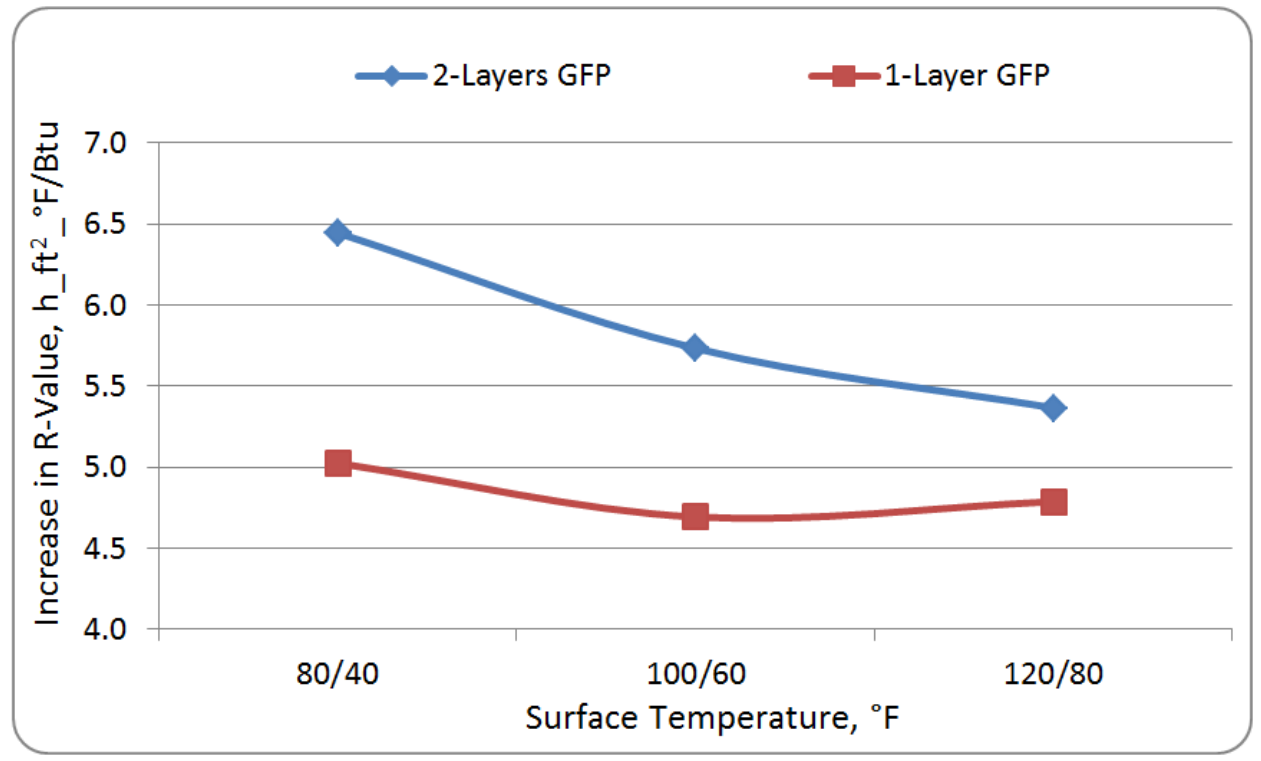

The walls were tested in the RGHB according to the ASTM C 1363 standard test method. Test results showed that, while the effective surface-to surface thermal resistance (R-value) of the wall with two layers of GFP decreases sharply as the temperature increases, the R-value of the wall with only one layer of GFP remains fairly steady.

For the range of test conditions $\left(80,100\right.$, and $120^{\circ} \mathrm{F}$ hot side surface temperature and $40,60,80^{\circ} \mathrm{F}$ cold side surface temperature), the R-value ranged from 8.662 to $7.762 \mathrm{~h} \cdot \mathrm{ft}^{2} \bullet^{\circ} \mathrm{F} / \mathrm{Btu}$ for the wall with two layers of GFP, 7.241 to $7.183 \mathrm{~h} \cdot \mathrm{ft}^{2} \bullet^{\circ} \mathrm{F} / \mathrm{Btu}$ for the wall with one layer of GFP, and 2.218 to $2.396 \mathrm{~h}^{\circ} \mathrm{ft}^{2} \bullet^{\circ} \mathrm{F} / \mathrm{Btu}$ for the wall without GFP. Thus, the increase in $\mathrm{R}$-value was 6.444 to $5.366 \mathrm{~h} \cdot \mathrm{ft}^{2} \bullet^{\circ} \mathrm{F} / \mathrm{Btu}$ for the wall with two layers of GFP and 5.024 to $4.787 \mathrm{~h} \cdot \mathrm{ft}^{2} \bullet^{\circ} \mathrm{F} / \mathrm{Btu}$ for the wall with one layer of GFP compared to the wall without GFP.

Several factors (such as cost of materials, transportation, energy, weather conditions, application) would need to be considered to determine whether it is cost effective to use one layer or two layers of GFP in the BHut cavity. A simulation study is recommended to quantify potential energy savings and associated cost savings potential of GFPs used in B-huts. 


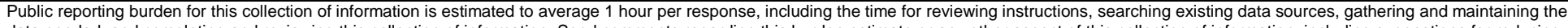

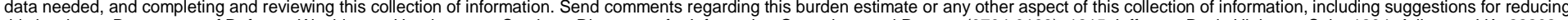

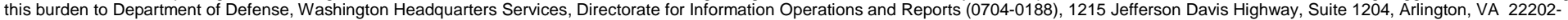

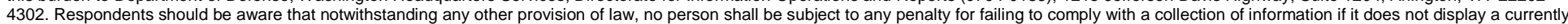
valid OMB control number. PLEASE DO NOT RETURN YOUR FORM TO THE ABOVE ADDRESS.

\begin{tabular}{l|l} 
valid OMB control number. PLEASE DO NOT RETURN YOUR FORM TO THE ABOVE ADDRESS. \\
\hline 1. REPORT DATE (DD-MM-YYYY) 2. REPOR
\end{tabular}

\begin{tabular}{|c|c|c|} 
30-09-2015 & Final \\
\hline
\end{tabular}

\section{TITLE AND SUBTITLE}

Comparison and Analysis of Energy Performance of Baseline and Enhanced Temporary Army Shelters

\section{AUTHOR(S)}

Axy Pagan-Vazquez, Dahtzen Chu, Megan Kreiger, Som Shrestha, Anthony Latino, Charles T. Decker,

Debbie J . Lawrence, and Ashok Kumar

3. DATES COVERED (From - To)

5a. CONTRACT NUMBER

\section{5b. GRANT NUMBER}

\section{5c. PROGRAM ELEMENT}

\section{5d. PROJECT NUMBER}

622784AT45

5e. TASK NUMBER

A1180

5f. WORK UNIT NUMBER

\section{PERFORMING ORGANIZATION NAME(S) AND ADDRESS(ES)}

U.S. Army Engineer Research and Development Center (ERDC)

Construction Engineering Research Laboratory (CERL)

PO Box 9005,

Champaign, IL 61826-9005

8. PERFORMING ORGANIZATION REPORT NUMBER

ERDC/CERL TR-15-26

\section{SPONSORING I MONITORING AGENCY NAME(S) AND ADDRESS(ES)}

Headquarters, U.S. Army Corps of Engineers

$441 \mathrm{G}$ St., NW

Washington, DC 2031401000

10. SPONSOR/MONITOR'S ACRONYM(S)

OASAALT

11. SPONSOR/MONITOR'S REPORT NUMBER(S)

\section{DISTRIBUTION I AVAILABILITY STATEMENT}

Approved for public release; distribution is unlimited.

\section{SUPPLEMENTARY NOTES}

\section{ABSTRACT}

The reduction and efficient use of resources are critically important issues for the U.S. Department of Defense. The Army builds and uses temporary shelters commonly known as "B-huts" at forward operating bases, where energy efficiency is mission critical. B-huts are typically not insulated, lack airtightness, and are inherently energy inefficient. Significant opportunities exist to improve the energy performance of these temporary shelters. This work tested the performance and feasibility of several common technologies and techniques to improve overall energy efficiency, constructability, and sustainability of the B-hut. The performance of one control (baseline) B-hut shelter was compared with the performance of one enhanced B-hut shelter, which used the tested commercially available technologies. The data indicate that improvements made to the Enhanced Shelter reduced its energy consumption to at least one-fourth that of the Control Shelter.

\section{SUBJECT TERMS}

energy efficient, building envelope, B-hut, temporary buildings, energy conservation

\section{SECURITY CLASSIFICATION OF:}

\section{a. REPORT}

Unclassified

\section{b. ABSTRACT}

Unclassified

\section{c. THIS PAGE}

Unclassified

\section{LIMITATION} OF ABSTRACT

SAR

\section{NUMBER} OF PAGES

120 19a. NAME OF RESPONSIBLE PERSON

19b. TELEPHONE NUMBER (include area code) 